\title{
The effects of patient charges on medical utilization, expenditure, and health : dutch investigations and international evidence
}

Citation for published version (APA):

Starmans, H. B. G. (1998). The effects of patient charges on medical utilization, expenditure, and health : dutch investigations and international evidence. [Doctoral Thesis, Maastricht University]. Universiteit Maastricht. https://doi.org/10.26481/dis.19980306hs

Document status and date:

Published: 01/01/1998

DOI:

10.26481/dis.19980306hs

Document Version:

Publisher's PDF, also known as Version of record

Please check the document version of this publication:

- A submitted manuscript is the version of the article upon submission and before peer-review. There can be important differences between the submitted version and the official published version of record.

People interested in the research are advised to contact the author for the final version of the publication, or visit the DOI to the publisher's website.

- The final author version and the galley proof are versions of the publication after peer review.

- The final published version features the final layout of the paper including the volume, issue and page numbers.

Link to publication

\footnotetext{
General rights rights.

- You may freely distribute the URL identifying the publication in the public portal. please follow below link for the End User Agreement:

www.umlib.nl/taverne-license

Take down policy

If you believe that this document breaches copyright please contact us at:

repository@maastrichtuniversity.nl

providing details and we will investigate your claim.
}

Copyright and moral rights for the publications made accessible in the public portal are retained by the authors and/or other copyright owners and it is a condition of accessing publications that users recognise and abide by the legal requirements associated with these

- Users may download and print one copy of any publication from the public portal for the purpose of private study or research.

- You may not further distribute the material or use it for any profit-making activity or commercial gain

If the publication is distributed under the terms of Article $25 \mathrm{fa}$ of the Dutch Copyright Act, indicated by the "Taverne" license above, 
Publication of this thesis was financially supported by the Dutch Ministry of Health, Welfare and Sport

ISBN 9090113657

(c) Bert Starmans, Maastricht 1998 


\title{
The effects of patient charges on medical utilization, expenditure, and health: \\ Dutch investigations and international evidence
}

\author{
PROEFSCHRIFT \\ ter verkrijging wan de graad van doctor \\ aan de Universiteit Maastricht, \\ op gezag van de Rector Magnificus, \\ Prof. Dr. A.C. Nieuwenhuijzen Kruseman, \\ volgens het besluit van het College van Decanen, \\ in thet openbaar te verdedigen \\ op vrijdag 6 maart 1998 om 14.00 uur \\ door
}

Hubertus Bernardus Gerardus Starmans Geboren te Margraten op 6 Oktober 1961 


\section{Promotor:}

Prof Dr. J.A.M. Maarse

Beoordelingscommissie:

Profi. Mr. F.C.B. van Wijmen (voorzitter)

Prof: Dr. R. T.J.M Janssen (Katholieke Universiteit Brabant)

Dr. J.G.A. van Mierlo

Prof. Dr. A.J P Schrijvers (Universiteit Utrecht)

Prof, Dr, C. Spreeuwenberg. 


\section{Contents}

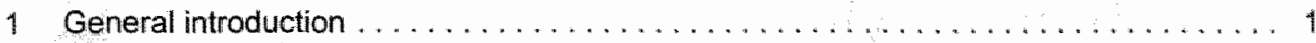

2 The effects of patient charges on medical utilization, expenditure, and health:

a synthesis of evidence from 1983 to 1995

3 Co-payment effects on the utilization of orthopaedic shoes:

evidence in Limburg. The Netherlands

4 Co-payment effects on the utilization of out-patient specialist physician care:

evidence in Limburg. The Netherlands

5 Benefit limit and co-payment effects on the utilization of antihypertension drugs:

evidence in Limburg. The Netherlands

6 Benefit limit and co-payment effects on expenditure for antihypertension drugs in Limburg. The Netherlands:

some implications for the effect of a reference price system

7 The effects of patient charges and other factors on the uttlization of cross-border care: evidence of a comparative study on cross-border hospital care in the Euregio Meuse - Rhine

8 Patient charges for prescription drugs in European public health insurance schemes:

a comparison and discussion

9 Patient charges in the Dutch sickness fund insurance scheme:

an overview and discussion

10 General discussion and health policy implications

11 Summary

12 Samenvatting

Acknowledgements (Dankwoord)

Curriculum Vitae 
$+3$

.

+

का a

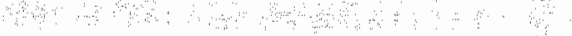
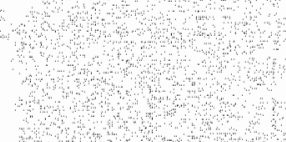

and

a

a

and

मान मे

$\therefore$ 
General introduction 


\section{General introduction}

In several countries the question whether or not patient charges for medical care are desirable, is frequently a topic health policy issue (1). A patient charge comprises a specific combination of different characteristics, which finally determines the money price which an insured person has to pay out-of-pocket for using a service that is included in a health insurance scheme. In The Netherlands, the discussion about the introduction or abolishing of patient charges in the public health insurance scheme has been relevant for many years. Since the sixties, several health policy advise councils (e.g. the Sickness Fund Council), expert committees (e.g. the Decker committee), political parties and interest groups (e.g. the organisation for chronically ill persons) have given their opinion on this issue. Table 1 gives an overview of advises in the field of cost sharing (read cost sharing) in The Netherlands in the period from December 1977 (the start of the first van Agtcabinet) up to the introduction of the current system of patient charges on 1 January 1997 (during the third year of the current Kok-cabinet).

The van Agt-cabinets, the Lubbers-cabinets as well as the current Kok-cabinet have continuously had the intention to increase the number and level of patient charges in the Dutch public health insurance scheme. Originally, the purpose of this increase was to shift costs from the collective means to the patient (financing health care). After some time, the reduction of the quantity and gross-price of using medical care (reducing medical consiumption) became a more important purpose. As part of the intention to increase the number and level of patient charges, the above mentioned cabinets have frequently asked several advisory boards and committees for advice. The essence of the advices provided is that there is a clear hesitation with respect to the introduction of (more) patient charges for medical care. In contrast with the intention of the third Lubberscabinet to reduce the regulations on the supply-side of the health care sector and to increase the regulations on the demand-side, most of the advices considered regulations on the supply-side as most appropriate in order to reduce medical consumption. Nevertheless, regulations on the demand-side, such as patient charges, were generally considered as an additional tool (table 1: Health Sickness Fund Council, National Council for Public Health, Social and Economical Council, Dekker-committee, Society for Public Health and Sciences, Biesheuvel-committee). Only the Dutch Health Council hesitated less with respect to the introduction of patient charges. This Council expected that charges could result in less medical consumption without adverse health effects. Reducing medical consumption without adverse health effects can be indicated as reducing moral hazard $(2,3)$.

Most of the Dutch advisory councils and committees formulated a number of restrictions with respect to the introduction of (new) patient charges. An important and frequently used restriction is that charges should not result in adverse health effects. Therefore, there should be a maximum to the total out-of-pocket expenditures per insurant or family per year, especially for those insurants having the lowest income or health levels. Except for the presence of a maximum expenditure, there has been little consensus with respect to the question which kind of a patient should be introduced (e.g. Which type and level of a patient charge and for which services).

So far, several Dutch empirical studies measured:

- the effect of being insured for the expenditure on one or more health care services $(4-7)$, or

- the combined effect of different patient charges and being insured for the expenditure on one or more health care services (8-16); in this group of studies the medical consumption of sickness fund insurants was compared with that of private insurants. 
Table 1 Overview of advices conceming patient charges in The Nethertands

(Dec 1977 - Dec 1996)

\begin{tabular}{|c|c|c|c|}
\hline Date & 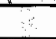 & Institution & Title of advice or nepoit \\
\hline Mar & 78 & $\mathrm{SFC}$ & Kuns"- en hulpmididelen bijzondere ziaktike osterverzekening \\
\hline Sep & 79 & SFC & Wogelijke onbuigingen in het verstrekkngenpakket ran 2 FW en AWD. \\
\hline Apr & 80 & SFC & Eigen bijuragen bi do verstrekking famaceutische hul $2 F$ verzekerng \\
\hline Jun & 80 & SFC & Maxmeng van egen bidragen zF w en hathedsclausule \\
\hline Jun & 80 & SFC & Wijzging verstrekking zekenvenroer zF -verzekering \\
\hline Nov & 82 & SFC & Het kraptemodel zektekostenverzekering \\
\hline Oct & 86 & $\mathrm{SFC}$ & Financieringswerschuswingen $1987-1990^{\circ}$ \\
\hline Now & 86 & $\mathrm{HC}$ & Granzen van de gezondheldszotg \\
\hline Jan & 87 & SFC & Financieringswerschulwingen wolksgezondhetd $1987-1990$ \\
\hline Mar & 87 & Dekker-Com & Bereidheid tol verandering \\
\hline Oct & 87 & SFC & Eigen bjidrage specialistische hulp \\
\hline Noy & 87 & $\mathrm{SFC}$ & Eigen bijdrage specielistische hulp \\
\hline Apot & 888 & NCPH & Kanttekeningen bil de nola Veranderning verzekerd \\
\hline Aug & 89 & SFC & Verdere stappen voof uitwoering van Verandering verzekerd \\
\hline Oet & 90 & NCPH & Adves nota Werken aan zorgvernieuwing \\
\hline JUn & 90 & SFC & Othodontische hulpwerlening \\
\hline Sep & 90 & SFC & Heriening regeting plastische esthetische chirurgie \\
\hline Od & 90 & SEC & Herziening van het stelsel van zielthekostenverzekeringen \\
\hline Now & 90 & $\mathrm{SFC}$ & Eigen bifdrage psychotherapie \\
\hline Apr & 91 & SFC & Wergrolen financies le weraniwoordelitheid verzekerden \\
\hline Augl & 91 & $\mathrm{SFC}$ & Invoering spectiek eigen risico \\
\hline Oct & 91 & SFC & Advies inzake Tussenbalans/Ombuighing hulpmiddelien AWBZ \\
\hline Jun & 92 & SPH & Standpunt eigen betalingen in de gezondheritszorg \\
\hline oet & 92 & SFC & Kostenbeheersende maairegelen 1993 \\
\hline Dec & 92 & NCPH & Eigen betalingen \\
\hline Dec & 92 & $\mathrm{SFC}$ & Eigen betalingen \\
\hline Mar & 93 & ICE & Voor eligen rekening \\
\hline Aug & 93 & $\mathrm{SFC}$ & Eigen buldragen hupmiddelen \\
\hline Allg & 93 & VB-group & Betalen woor zorg \\
\hline Dec & 93 & $\mathrm{SFC}$ & Modernisering zorgsecto: (onderdeel landheelkunde) \\
\hline Jan & 94 & Biesheuvel-Com & Gedeelde zorg: betere zorg \\
\hline Jun & 94 & SFC & Kastenbeheersing farmace utische hulp \\
\hline Od & 94 & SRH-Com & Gezondheidszarg in lel Deiel 2 \\
\hline Wov & 94 & NCCla a. & Breed Maatschappellik Standpunit Eigen bijdragen en cumulalle \\
\hline Jun & 94 & SFC & Kostenbeheersing famaceutlische hulp \\
\hline Dec & 94 & SFC & Beperking fysiotheraple, oefentherapie Cesar en oefentherapie Mensendieck \\
\hline Feb & 95 & CTWC & Zuinig met zorg \\
\hline Apr & 95 & SFC & Owerheveling aximspraken \\
\hline Hor & 95 & SFC & Verbandmitudelen \\
\hline Od & 95 & SFC & Aanpassing Regeling hulpmiddalen \\
\hline Jun & 6 & $\mathrm{SFC}$ & Itwoering elgen bidrage ZFW par 1 jan war 1997 . \\
\hline
\end{tabular}

HC: Heallth Council CCE: Anterim Council for Elderiy pollicy

NCCI a.o. National Committe for Chronical Ill and oher instlutions

NCPH: National Council for Public Health SEC: Social Economical Council

SFC: Sickness Fund Council

SRit: Strategic Reortentation of Health rate

SPH: Duth Sociely lor Public Heath

However, only few Dutch empirical studies measured the effects of a specific Kind of a patient charge (4, 17-19). Most of the latter studies intended to measure the effects of the introduction of a co-payment for out-patient prescription drugs in the Dutch sickness fund insurance scheme on the consumption of this provision. These studies, however, did not distinguish between the effects of the co-payment and other health policy measures (for details see chapters 5 and 6). More recently, some information has become avalable with respect to the effects of the introduction of a reference price system for prescription drugs in the Dutch public health insurance scheme (20-22). 
The purpose of this thesis is to deliver an evidence based contribution to the discussion about the desirability of patient charges for medical care in the Dutch and other public health insurance schemes. More specifically, on the basis of empirical evidence, the thesis intends to answer the question which kind of a patient charge may be desirable, if the purpose of such a charge is to reduce moral hazard (reducing medical consumption without adverse health effects). For this purpose, a number of cost sharing studies at the sickness funds in the province of Limburg (the southern part of The Netherlands) has been carried out (chapters 3 to 7 ). In addition, a synthesis of international empirical evidence of cost sharing is provided (chapter 2).

Chapter 2 gives a systematic overview of cost sharing evidence published in scientific peer reviewed, English language journals, indexed in Index Medicus, the Social Science Citation Index, or the Social Sciences Citation Index, in the period from 1983 to 1995 . Two of the publications included are Dutch studies $(23,24)$. These publications are described in more detail in chapters 5 and 6 . Chapters 3 and 4 describe 2 Dutch studies which meet all the inclusion criteria used for the synthesis of evidence in chapter 2, except that they have been published in non-English, nonindexed journals $(25,26)$. Chapter 7 describes a comparative study an cross-border in-patient hospital care in the Euregio Meuse - Rhine. This region covers almost the entire Dutch province of Limburg as well as provinces in Belgium and Germany. The study investigates several factors, such as cost sharing. which may influence the level of cross-border care and describes the current level of cross-border in-patient hospital in the Euregio Meuse - Rhine.

In the chapters 3 to 7 , the choices of the patient charges, health care provisions and sickness funds were based on the availability of appropriate data with respect to the consumption of health care services. In addition, charge effects have only been studied, if it was expected that these effects could be clistinguished from other possible influences or health policy measures. Frequently. the introduction of a patient charge is accompanied by one or more other policy measures (e.g. the intraduction of the reference price system for prescription drugs in The Netherlands in July 1991 was accompanied by a switch of this provision from the Dutch Sickness Fund Insurance Scheme and the private insurance schemes to the Dutch Exceptional Health Care Insurance Scheme).

In chapter 8 the patient charge which can - on the basis of the Dutch empirical evidence described in chapters 3 to 7 and with the synthesis of international cost sharing evidence described in chapter 2 - be considered as most desirable for reducing moral hazard ${ }_{n}$ is compared with the current patient charges for prescription drugs in the public health insurance schemes in the member states of the European Union. In chapter $\theta$ this patient charge is compared with the current patient charges in the Dutch sickness fund health insurance scheme.

Finally, chapter 10 comprises a general discussion of the outcomes in this thesis. It also indicates which information with respect to the effects of patient charges is still lacking and which difficulties and impacts can be expected if the patient charge considered to be most desirable for reducing moral hazard is implemented in the Dutch or a foreign public health insurance scheme.

\section{References}

1. Abel-Smith B, Mossialos. E. Cost containment and health care reform: a study of the European Union. Health Policy
$1994 ; 28: 89-132$.

2. Arrow KJ. Uncentainty and the welfare economics of medical care. Am Econ Rev $1963 * 53: 941-73$

3. Pauly MV. The economics of moral hazard: a comment. Am Econ Rev 1968;57:231-7.

4. van Gessel-Dabekaussen AAMW. Particulier verzekerden met en zonder eigen risico (Priwate insurants with and without deductible). Maandber Gezondheidsstatistiek 1993;12:4-4.4. 5. wan de Ven WPMM, van der Gaag J. Health as an unobservable: a MIMIC-model of the demand for health care.
$J$ Health Econ $1982,1: 157-83$. 


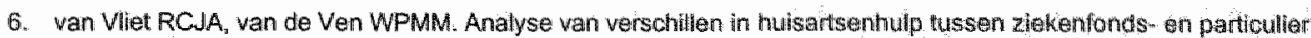
werzekerden (Analysis of differences in the use of GP-care bewesen sickmess funds insurants and phivate insurants. Econ Statist Bericht $1983,618.456 \cdots 61$.

7. Wan Vliet RCJA. Hospital utization, performance measures and health status: econometric analyses of Dutch micro data [Dissertation]. Erasmus University Rotterdam, 1988.

8. wanden Brekel EJG. Gezondheidsenquettes: ziekenhwisopnamen 1981-1983 Heath surveys: hospltal admissions 1981-1983). Maandber Gezondheidsstatistiek 1985:7:5-25.

9. Centraal Bureau voor de Statistiek. Statistische onderzoekingen. een onderzoek naar warschillen hn de verpleegduur van ziekenhulspatienten (Statistical investigations: a study of differences in the duration of stay af hospital patients). The Hague: Staatsuitgeverij/CBS-publikaties, 1985.

10. van der Gaag J, van de Wen WPMM. The demand for primary health care. Med Care 1975;16;299-312.

11. Mootz M. Gezondheid, medische consumptie en verzekering opnieuw bezien (Further analysis of health medical consumption, and insurance). Med Contact 1984; $39: 1201-5$.

12. Mootz M. The need for health care utilization and its relation to insurance coverage for medical expenses, Gezondh Samenl $1985 ; 6 * 232-7$.

13. van Rossum G. Tandartsbezoek en mondgezondheid (Dentist wisits and oral health: Nijmegen: lnstituut voor Toegepaste Socioiogie, 1985.

14. Rutten FFH, wan der Gaag J. Referrals and demand for specialist care in the Netherlands. Health Serv Res $1977 ;: 12: 233-49$.

15. Tijmstra T. Sociologie en tandheelkunde: resultaten van een gecombineerd sociaal-wetenschappelik en tandhee kundig onderzok (Sociology and dentistry: results of combined sociological and dental investigation) [Dissertation]. University of Groningen, 1980.

16. wan Vhet RCJA, van de Ven WPMM. Consumptieverschillen tussen ziekenifonds- en particulier verzekerden nader onderzocht: overzicht wan empirische bewindingen (Further analysis of differences in imedical consumption betwean sickness funds insurants and private insurants). Gezondh Samenl 1986;7:81-94.

17. wan den Berg J. De eigen bijdrage voor geneesmiddelen in 1983 (The co-payment for prescription drugs in 1983). Tijdschr Soc Gezondheidsz 1985;63:4-12.

18. de Klein JJM, Collaris JWM. Evaluatie wan de eigen bijdragematregel farmacie (Evaluation of the co-payment regulation fior prescription drugs). Zeist: Vereniging van Nederlandse Zlekenfondlsen, Afdeling Beleidsinformatie - Onderzoek, 1984.

19. Post D. Vijf jaar prescriptie: volume-en kostemveranderingen in een ziekenfondsreglo (Five years of prescription: changes in volume and expenditure in a Dutch sicknesis fund region). Med Contact 1986:41:1103-4.

20. Foundation for Pharmaceutical Statistics. Facts and figures: cost development of pharmaceutical care. The Hague: Foundation for Pharmaceutical Statistics, 1993.

21. KPMG Management Consulting. Effectiviteit van het GVS: evaluatie van de effecten van het Geneesmiddelen Vergoedings Systeem (Effectiveness of the GVS: evaluation of the effects of the Dutch reference price system). KPMG Management Consulting. 1995.

22. Ziekenfondsraad. Advies kostenbeheersing farmaceutische hulp (Advice on containing expenditure on prescriptlon drugs). No. 630. Amstelveen: Ziekenfondsiraad, 1994.

23. Starmans $B$, Janssen $R$, Schepers $M$, Verkooijen M. The effect of a patient charge and a prescription regulation on the use of antihypertension drugs in Limburg. The Netherliands. Health Pollcy 1994:26:191-206.

24. Starmans B, Janssen R, Schepers M, Verkooljen M. The effect of patient charge and a prescipiption regulation on expenditure for anthypertension drugs in Limburg. The Netherlands: some implications for the effoct of reference price system. Unt J Health Scl 1994:5:105:17.

25. Starmans HBG; Verkooijen JMHFM. Het effect van eigen betalingen in de Nederlandse gezondheidszorg: casus orthopedisch schoeisel (The effect of patient charges in Dutch health care: the case of orthopaedic shoes). Tijdisicht Soc Gezondheidsz 1990;68:383-8.

26. Stamans HBG, Verkooijen JMHFM, VanderBroeck M JAP. Het effect van eigen betalingen in de Nederlandse gezondheidszorg: casus poliklinische specialistenhulp (The effect of patient charges in Dutch health care: the case of outpatient specialist physician care). Tijdschr Soc Gezondheidsz 1993,74:223-30. 

The effects of patient charges on medical utilization, expenditure, and health: a synthes is of evidence from 1983 to 1995

(To be submitted) 


\section{Abstract}

This article presents a systematic method to synthesise empirical evidence of the effects of patient charges on medical utilization, expenditure, and health. The method may be an important step in further improving evidence based health care policy in the field of cost sharing More specifically, the article considers the question which kind of a patient charge may be desirable, if the purpose of a charge is to reduce noral hazard (reducing medical consumption without adverse health effects).

Firstly, to provide only quality-level evidence, the method sets a minimum standard for study and outcomes inclusion. Secondly, on the basis of economic literature, it distinguishes different effect variables (e.g. the probability of using care) on the one hand, and different charge, insurant, service and measurement characteristics (e.g. the patient charge type) on the other hand. Finally, the method is applied to empirical evidence published in the periad from 1983 to 1995.

The synthesis shows that at least the effect wariable, as well as the type and level of a charge, the level of a maximum expenditure, the service(s) to which a charge is applied, and the group of health care users considered, can be important determinants for the direction or magnitude of patient charge outcomes. As the total number of 35 publications included in this synthesis analyzed a limited range of different effect variables and patient charge regulations, however, the article is: not able to give a fully complete picture of the potential desirability of patient charges. Nevertheless, if the purpose of a charge is to reduce moral hazard, the evidence suggests that mandatory co-insurance of about $50 \%$ with an income dependent maximum expenditure. without the possibility of reinsurance, for non-elderly, applied to out-patient or even total health care, may be desirable.

\section{Introduction}

Although in most public health insurance plans over the world there are patient charges, the question whether or not such charges are desirable, is frequently a key issue in health policy discussions (e.g. 36-38). A patient charge comprises a specific combination of different characteristics, which finally determines the money price which an insured person has to pay outof-pocket for using service that is included in a health insurance scheme. Discussion does not only concern the issue whether patient charges should be maintained, enhanced or abolished in an insurance plan, but also which kind of a patient charge should be introduced: e.g. which type of a charge, for which health care service(s) and for which group(s) of insurants. Partly due to lack of agreement with respect to these issues, the presence and shape of patient charges show a wide variability in health insurance systems. Although charges may have been introduced for different purposes, disagreement about the previous issues also results from insufficient evidence. While a rather large number of studies of the effects of patient charges have been published, each study analyzed only a restricted and specific number of patient charge, health service or insurant characteristics. In addition, different methods have been used to measure the effects of charges. Due to different aspects analyzed on the one hand, and different methods used on the other hand, the outcomes of empirical studies are likely to show considerable variability. Nevertheless, articles which have presented an overview of the outcomes of patient charge studies, have usually concluded that, in general, a patient charge for a health care service for a group of insurants results in a decrease in medical utilization or expenditure concerning this service among these insurants
(e.g. $39-42)$.

The methods used to compare different study outcomes have not been sufficiently well developed so far. Frequently, review articles comprise a series of study abstracts, rather than a systematic 
synthesis of empirical evidence. Only few articles have presented an overview of outcomes in a more systematic way: Newhouse (43), for example, made a distinction belween different health care services to which a charge was applied. Further, previous reviewarticles usually have one or more of the following restrictions: (1) they consider one specific health care sentice, frequently prescription drugs, (2) they focus on the famous RAND-study (44), which is - as far as known - the only randomized controlled trial in this field, (3) they present only pirice-elasticities of medical consumption (price-elasticities generally represent the effects of changes in the level of an existing money price or patient charge, but do not represent the effects of introducing a patient charge). (4) they focus on outcomes published in the period before 1983 .

This article describes a more systematic and extensive method for comparing outcomes of published empirical studies of the effects of patient charges. The method intends to overcome most of the restrictions mentioned above. Nevertheless, it is also restricted in some respects. For example, it focuses on evidence published in the period from 1983 to 1995. Other restrictions are described in the next section. Accordingly, this article offers the opportunity for further extensions and refinements. The method developed, however, is expected to allow a better evidence based answer to the question which kind of a patient charge may be desirable in a public health insurance scheme.

\section{Methods and theoretical background}

\section{Selection of studies, journals, publications and outcomes}

In order to process only quality-level evidence, the overview is restricted to: (1) studies published in scientific, peer reviewed journals, indexed in Index Medicus, the Social Citation Index, or the Social Sciences Citation Index, (2) outcomes which have been statistically tested and which are non-preliminary. For pragmatic reasons anly English language journals have been considered. Scientific, peer reviewed journals, which have been introduced in the period from 1990, are not always indexed yet in the data bases mentioned above. The following journals, therefore, have been considered individually: The International Journal of Health Sciences (since 1990), The European Journal of Public Health (since 1991), Health Economics (since 1992) and PharmacoEconomics (since 1992). Publications of interest were selected on the basis of the following key words: cost sharing, co-payment, co-insurance, deductible, patient charge, user charge, or user fee. In addition, publications were selected on the basis of literature references of publications already incorporated. For publications in journals indexed in Index Medicus, MEDLINE (1983-1995) on CD-ROM was used.

As this overview serves to provide a contribution to the discussion which kind of a patient charge in a public health insurance scheme may be desirable, publications have been further selected on the basis of relevant information provided. At least the following aspects should have been made clear: (1) the effect variables analyzed, (2) the type and level of the charge, (3) the presence and level of a maximum out-of-pocket expenditure. (4) the group(s) of insurants to whom the charge was applied, (5) the health care service(s) to which the charge was applied, and (6) the direction and magnitude of the charge impacts measured (in terms of a percentage change or priceelasticity).

On the basis of economic literature it was expected that both the effect variable and a number of charge, insurant, service and measurement characteristics, would be important for the different study outcomes measured. The different effect variables distinguished on the one hand, and the different characteristics identified on the other hand, as well as their impacts expected, are briefly elaborated in the following paragraphs. 
In this article it is assumed that the different characteristics of a patient charge (e.g. the charge type), as well as the characteristics of the insurants and services to which a charge is applied (e.g. the income level of the insurants, and the reimbursement system of the services) include relevant health system information. This means that these characteristics are considered here as relevant healthisystem indicators $(45,46)$. Consequently, it is assumed that the method generally also enables comparisons of outcomes measured in different systems.

In order to make appropriate comparisons of different study outcomes, the overview does not include publications or outcomes which concerned the combined effects of different patient charge regulations (e.g. the combined effect of different charge levels). Neither does it include publications or outcomes which concerned the combined effect of a patient charge and a different health policy measure (e.g. the combined effect of a charge for hospital care and hospital budgeting). Due to the selection criteria used in this article, publications or outcomes which can - according to Newhouse (47) - be considered as inappropriate, are not included.

\section{Desired and adverse effects of patient charges}

Two aspects should be clear when dealing with the desirability of patient charges in health insurance plans: (1) for which purpose is a patient charge intended to be used (what are the desired effects), and (2) which sacrifices or adverse effects of a patient charge are thought to be acceptable while attaining the desired effects. The effect variables measured in a publication determine which of the desired or adverse effects of a patient charge have been investigated. Table 1 gives a brief overview of the most important possible desired and adverse effects of patient charges (e.g. 48-50).

Table 1 Overview of possible desired and adverse effects of patient charges

\begin{tabular}{|c|c|}
\hline Destred effects & Adverse effects \\
\hline - firuancing health care & - reduction in equity \\
\hline - reduction in medical consumption & - reduction in health \\
\hline - reduction in expenditure on administration & - increase in expenditure on administration \\
\hline - for insurert. reduction in risk & - for consumer: increase in risk \\
\hline - for insurer: craman skimmeng & - Ior high risth consumer: premium spiral \\
\hline - for onnumat sell solloction & Lor insurer adverse selection \\
\hline
\end{tabular}

All publications which met the inclusion criteria analyzed the impacts of a patient charge on effect variables representing medical utilization, expenditure, or health. The publications in question investigated to what extent a patient charge resulted in the desired effect "reduction in medical consumption" or to what extent it resulted in the adverse effect "reduction in health". Only these charge impacts and effect variables will be further elaborated, therefore. Reducing medical consumption (reducing medical utilization or expenditure) without adverse health effects can be indicated as "reducing moral hazard" $(51,52)$. 


\section{Identification of dependent variables: a four-part model}

Duan (53) has described and discussed several models of the demand for health (care) and has demonstrated that a four-part model is the most convenient for analyzing the effects of patient charges on medical consumption. However, as the effect varlables measured in the publications included in this synthesis are not always (exactly) equal to those used in the four-part model of Duan, a somewhat modified four-part model has been constructed:

1. The first part of the model is the chance (C) of using at least one unit of a service in question (Ci). The health care service in question (i) is the service or the group of services to which the charge is applied and whose consumption has been measured. One unit of ta service is defined as one prescription drug item, one medical supply, one ambulance travel, one health care provider visit, one health institute admission, or one episode of care. An episode of care is a particular combination of health care services which form the complete flow of services for a particular treatment (54). Most service units comprise one or more different kinds of subunits. Examples of a subunit are: one prescription drug tablet, one kilometre of ambulance travel, one health care provider procedure, one in-patient day, etc.

2. The second part of the model is the frequency $(F)$ of using a service unit, provided that at least one unit of a service in question is used (Fi). The product of the first two parts represents the total frequency of using a service unit in question (CiFi).

3. The third part is the quantity (Q) of subunits per service unit used (Qi). An example of this variable is the number of prescription drug tablets per prescription drug item. The product of the first three parts represents the total quantity of using a service subunit (CiFiQi). In case of prescription drugs, this is the total number of prescription drug tablets.

4. The fourth part of the model is the gross price $(\mathrm{Pg})$ of a service in question $(\mathrm{Pgi})$. In this article the gross price of a service is defined as the price requested by the health care provider for one subunit of care. The product of $Q$ i and Pgi represents expenditure per service unit in question (QiPgi). Finally, the product of all four parts represents total expenditure on a service in question (CiFiQiPgi).

Except for $\mathrm{Fi}$, Qi, Pgi and QiPgi, the effect variables mentioned above are commonly measured per insurant in question (j) and per unit of time (e.g. per month). The insurants in question are those insurants to whom the charge is applied and whose medical consumption or heaith has been measured. For services inside the insurance plan to which the charge is not applied, as well as for goods and services outside the insurance scheme, corresponding four-part models can be constructed. Consequently, total expenditure per insurant in question (Tj) on all (health care) goods and services both inside and outside the insurance scheme (Tioni), can be represented by the following equation:

$$
\begin{array}{ll}
\text { Tionj }=\text { CijFiQiPgi }+ \text { CojFoQoPgo }+ \text { CnjFnQnPgn } \\
\text { CijFiQiPgi: } & \text { expenditure on care in question* } \\
\text { CojFoQoPgo: } & \text { expenditure on other care covered by the insurance plan* } \\
\text { CnjFnQnPgn: } & \text { expenditure on goods and services not covered by the insiurance plan* }
\end{array}
$$

*: per insurant in question

Some publications which met the inclusion criteria did not (only) analyze the effect of a patient charge on medical consumption, but (also) its effect on the overall health status per insurant in question ( $\mathrm{Hj}$ ). If it is assumed that different gross prices for equal types of medical care (e.g. 
different gross prices for one killometre of ambulance travel) do not represent different quality levels of care, Hj can be represented by the following equation:

$$
\text { Hj (CijFiQi + CojFoQo + CnjFnQn) }
$$

CijFiOi: quantity of subunits of care in question

CojFoQo: quantity of subunits of other care covered by the insurance plan*

CnjFnOn: quantity of subumits of goods or services not covered by the insurance plan

* per insurant in question

The overall health status of an insurant in question is assumed to be determined by total medical utilization on the one hand, and the utilization of other goods and services (e.g. education and housing) on the other hand (55). Total medical utilization is, in turn, determined by the total use of health care services inside the insurance plan, as well as by that of health care services outside this plan.

If the purpose of a patient charge is to reduce moral hazard, the effect desired can be considered as a reduction in lotal expenditure per insurant in question on those health care services covered by the health insurance plan (CijFiQiPgi + CojFoQoPgo), without a (serious) reduction in the health status per insurant in question (Hj). More specifically, the effect desired is a reduction in total expenditure per insurant in question on those service(s) to which the charge is applied (CijFiQiPgi), without a reduction in $\mathrm{Hj}$.

\section{Impacts expected on effect variables}

The impact of a patient charge on medical consumption and health can be decomposed into two parts: (1) a substitution-effect and (2) an income-effect (56). Table 2 shows both the expected direction and magnitude of these impacts on the most important effect variables described above. More specifically, for an individual insurant in question, besides an income-effect, one of the following substitution-effects can be expected (on the aggregated level all of these substitutioneffects may appear simultaneously):

\section{External substitution}

Firstly, the service to which the charge is applied, may be substituted by a good or service outside the health insurance scheme (e.g. education or saving). This will be referred to as "external substitution". It is expected that consumers have less influence on the quantity of using a service, once the service is used, than on the initiall decision whether or not to use a service $(53,57)$. Therefore, it is expected that on the aggregated level a patient charge will decrease the probability of using a service per insurant in question (Cij) to a larger extent than the frequency of units, once this service is used $(F i)$. In addition, it is expected that a charge will decrease $F i$ to a larger extent, than the quantity of subunits, once a service unit is used (Qi). In table 2 the expected magnitude of charge impacts on the variables considered is indicated by different quantities of arrows. These arrows, however, are onlly an indication and not a pure quantification of these magnitudes. It is expected that a reduction in the product of $\mathrm{Cij}$. Fi and Qi will result in a decrease in the overall health status per insurant in question ( $\mathrm{Hj}$ ), unless the serwice in question is (partly) substituted by a (health care) provision which compensates this reduction in health or unless there is a situation of "flat-of-the-curve" medicine. The latter situation means that medical consumption does not longer result in significant additional health status gains. (58). The magnitude of the effect expected on $\mathrm{HJ}$, therefore, is represented by a number of arrows which is one half of those indicated for the product CijFiQi. External substitution can be considered as desired if it does not result in adverse health effects. 


\section{Intemal substitution}

Secondly, the service in question or one of its subprovisions may be substituted by an other senvice or subprowision to which the charge is applied (e.g. using generic drugs instead of trademark dnugs under a patient charge for out-patient prescription drugs). This is considered as "internal substitution". It is important to note here that several services comprise a number of different subprovisions. Prescription drugs, for example, comprise a number of drug categories, each with different properties and gross prices. If the entire service or the entire group of services to which a charge is applied, is considered as a black box, internal substitution represents a change in the gross price (Pgi). Internal substitution can be considered as desired, if Pgi decreases.

\section{Semi-external substitution}

Thirdly, the service in question may be substituted by a service inside the insurance plan, to which the charge is not applied (e.g. using out-patient primary physician care instead of out-patient prescription drugs under a charge for out-patient prescription drugs). This will be referred to as "semi-external substitution". Under semi-external substitution Cij decreases, while Coj increases. If both the entire service or the entire group of services to which a charge is applied, and the (group of) substitute(s) are considered as black boxes, semi-external substitution represents a change in the gross price of using health care within the insurance scheme. Semi-external substitution can be considered as desired, if the gross price of the substitute(s) (Pgo) is lower than that of the originall service(s) (Pgi).

The income-effect represents a reduction in the quantity of using the service(s) to which the charge is applied ( $\mathrm{Cij}, \mathrm{Fi}_{\mathrm{i}}$, and $\mathrm{Qi}$ ), as well as a reduction in the quantity of using other (health care) services. It is expected that the direction of an income-effect on the effect variables considered, corresponds with that of an external substitution-effect (except for the impact on Coj), but that the magnitude of an income-effect is generally much smaller (56).

Although some general expectations with respect to the direction and magnitude of the impacts of patient charges on the selected effect variables have been indicated above, a number of charge, insurant, health service and measurement characteristics, are expected to have an important influence on these effects. These characteristics and their expected impacts are also presented in table 2, and will be briefly elaborated in the following paragraphs. 


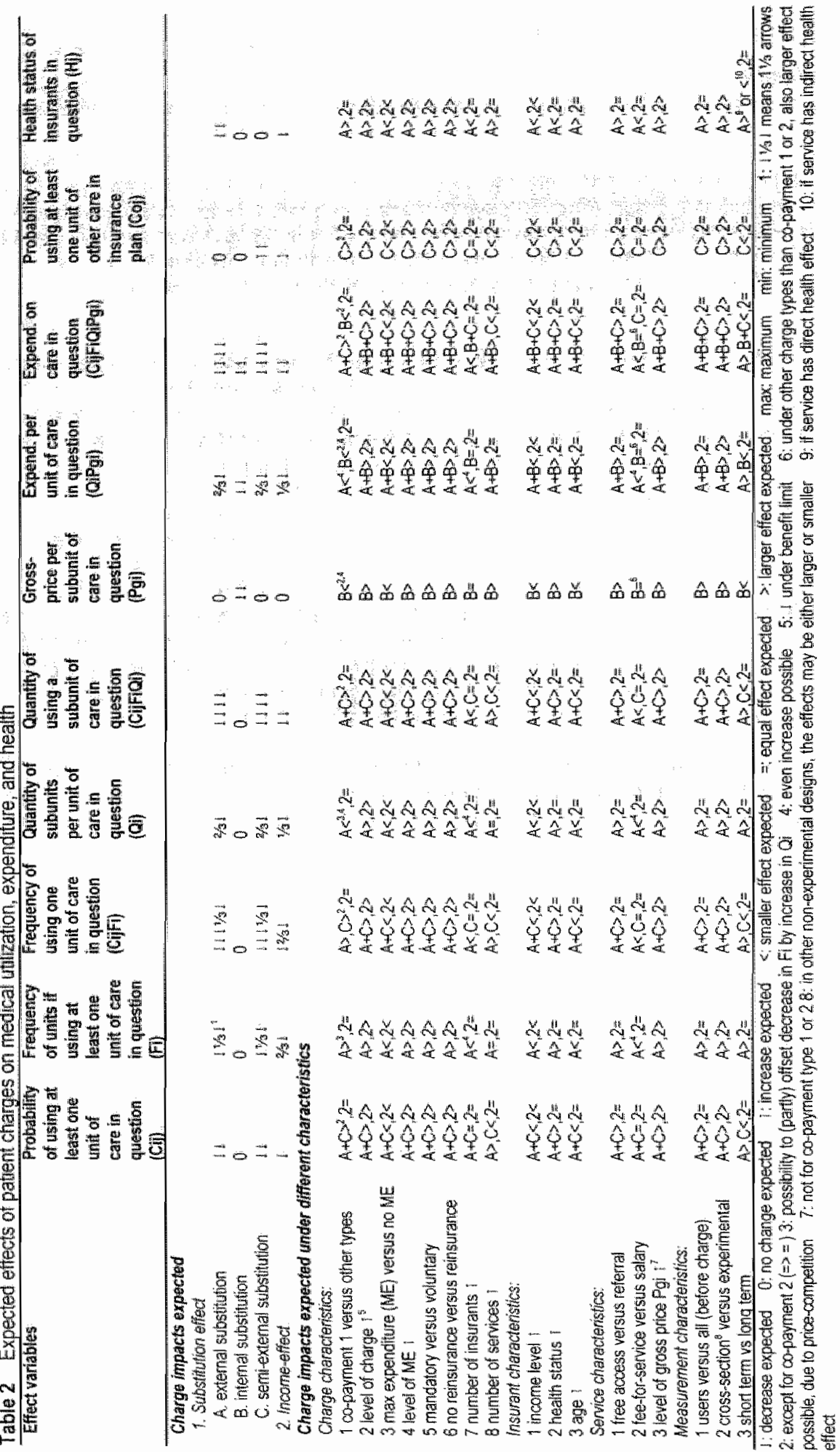




\section{Impacts expected under different charge characteristics}

The patient charge characteristics identified are not only considered to be important for the level of the money price which an insurant actually has to pay out-of-pocket for using a service, but also for the level of the effective price which can be considered as the value an insurant attributes to this money price (59). The relevance of the effective price for using care is indicated below. The money price or effective price is only one part of the total out-of-pocket price for using a service. Other parts are the time price and psychic price $(60,61)$.

\section{Type of patient charge}

The following charge types are distinguished: co-payment types 1 to 3, co-insurance, deductible types 1 to 3 , and benefit limit types 1 to 6 . In addition, combinations of these types or variations on these types are possible. The different charge types are defined and illustrated in table 3. Except for co-payment types 1 and 2, under all charge types the llevel of the money price usually depends on the gross price of the health care service in question (Pgi). As a consequence, the consumer is expected to have not only an incentive for external or semi-external substitution, but also an incentive for desired internall substitution: using that (sub)provision with the lowest gross price $(62,63)$. In case of co-payment types 1 or 2 , the level of the money price does not depend on Pgi, thus mainly setting incentives for external or semi-external substitution. Sometimes it is argued that, under co-payment types 1 or 2, the share in Pgi to be paid by the consumer diminishes with increasing $\mathrm{Pgi}$; thus setting adverse incentives to use that (sub)provision which has the highest gross price (64). In contrast to all other charge types under co-payment type 1 , the level of the money price does neither depend on the quantity of subunits per unit of care (Qi). As a consequence, a consumer is expected to have an adverse incentive to offset a decrease in $\mathrm{Fi}$ by an increase in Qi (65). In case of a deductible, the money price for using a service is zero after exceeding the deductible limit. As a consequence, insurants do not have an incentive to reduce medical utilization or expenditure any more after reaching the deductible limit. In addition, the larger the chance an insurant will exceed the deductible, the lower the value which this insurant attributes to the money price for using care. An important determinant for this chance is the total money price which an insurant thas already paid for using medical care. This means that, before reaching a deductible limit, the level of the value which an insurant attributes to the money price for using care (the effective price) is expected to be non-linear $(59,66)$. In case of a benefit limit, the money price for using a service is zero before reaching the limit. Consequently, insurants are expected to have an incentive to prevent exceeding this limit. This means that, although the money price for using care is zero, an insurant attributes a certain value to the money price. which is the effective price for using care. The larger the chance that the benefit limit will be exceeded, the higher the levell of the effective price before reaching this limit. An important determinant for this chance is the total reimbursement which an insurant has already received for using the service in question. As a consequence, before reaching a benefit limit, the level of the effective price is, once again, expected to be non-linear $(59,66)$. Thus, under a bemefit limit, it is expected that insurants have incentives to reduce medical consumption, both before and after reaching the limit. In general, however, these incentives are not the same. After exceeding a benefit limit (types 1 to 6 ) " insurants are expected to reduce $\mathrm{Ci}, \mathrm{Fi}$, Qi or Pgi. Before reaching the limit, insurants may - depending on the type of benefit limit - sometimes have an adverse incentive to offset a decrease in a specific effect variable. In case of a benefit limit type 4 , an insurant may have an incentive to offset a reduction in $\mathrm{Fi}$ by an increase in Qi. Further, under benefit limit types 1 and 5 , an insurant may have an incentive to offet a reduction in $\mathrm{Q}$ by an increase in $\mathrm{Fi}$. In table 2 the latter possible adverse impacts of patient charges are not shown. 
Table 3 Overview of different types of patient charges (ewamples between brackets)

\begin{tabular}{|c|c|c|c|c|}
\hline $\begin{array}{l}\text { Chargo } \\
\text { definod as: }\end{array}$ & $\begin{array}{l}\text { fixed amount of } \\
\text { mongy }\end{array}$ & $\begin{array}{l}\text { parcentage of } \\
\text { grosis price }\end{array}$ & $\begin{array}{l}\text { fixed number of } \\
\text { units }\end{array}$ & $\begin{array}{l}\text { fixed number of } \\
\text { subunits }\end{array}$ \\
\hline $\begin{array}{l}\text { per unit of } \\
\text { care }\end{array}$ & $\begin{array}{l}\text { Co payment fype } 1 \\
\text { (\$t per prescriptioni } \\
\text { drug } \\
\text { item) } \\
\text { Benefit limit type } 1 \\
\text { (\$50 per prescription } \\
\text { drug } \\
\text { tem) }\end{array}$ & $\begin{array}{l}\text { co-insurance type } 1 \\
(10 \% \text { of gross price } \\
\text { per prescription drug } \\
\text { item) }\end{array}$ & 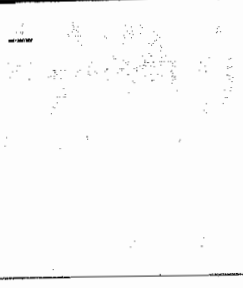 & $\begin{array}{l}\text { Co-payment lype } 3 \\
\text { (first } 10 \text { tablets per } \\
\text { prescription drug } \\
\text { tem) } \\
\text { Benefit limit type } 5 \\
\text { (40 tablets per } \\
\text { presciption drug } \\
\text { item) }\end{array}$ \\
\hline $\begin{array}{l}\text { per subutinit } \\
\text { of care }\end{array}$ & $\begin{array}{l}\text { Cowpayment type } 2 \\
(\$ 0.40 \text { per } \\
\text { prescription drug } \\
\text { talblet) } \\
\text { Benefit limit type } 2 \\
\text { (\$10 per prescription } \\
\text { drug } \\
\text { tablet) }\end{array}$ & $\begin{array}{l}\text { Co-insurance type } 2 \\
\text { (10\% of gross price } \\
\text { per prescription drug } \\
\text { tablet) }\end{array}$ & $\cdots$ & $=$ \\
\hline $\begin{array}{l}\text { per Insurant } \\
\text { or family } \\
\text { per unit of } \\
\text { time }\end{array}$ & $\begin{array}{l}\text { Deductible type } 1 \\
\text { (first } \$ 100 \text { for } \\
\text { prescription } \\
\text { drugs per insurant } \\
\text { per year) } \\
\text { Benefit limit type } 3 \\
\text { (\$1000 for } \\
\text { prescription } \\
\text { drugis per insurant } \\
\text { per year) }\end{array}$ & $\begin{array}{l}\text { Co-insurance type } 3 \\
\text { (10\% of gross price } \\
\text { of prescription drugs } \\
\text { per } \\
\text { insurant per year) }\end{array}$ & $\begin{array}{l}\text { Deductible type } 2 \\
\text { (first } 2 \text { prescription } \\
\text { drug } \\
\text { items per insurant } \\
\text { per month) } \\
\vdots \\
\text { Benefit limit type } 4 \\
\text { (4 prescription drug } \\
\text { thems per insurant } \\
\text { per month) }\end{array}$ & $\begin{array}{l}\text { Deductible type } 3 \\
\text { (first } 40 \text { prescription } \\
\text { drug tabllets per } \\
\text { insurant per month) } \\
\text { Beneftit limit type } 6 \\
\text { (80 prescription drug } \\
\text { tablets per insurant } \\
\text { per month) }\end{array}$ \\
\hline
\end{tabular}

1: As in this article it is assumed that the gross price of care is requested per subunit of care, there is actually no difference between co-insurance types 1 to 3 .

2. A benefit limit (also called "upper limit", "indemnity payment", or "balance billing") means that an insurant has to pay the full gross price of using care, after a fixed maximum reimbursement (see examples between brackets) has been received.

\section{Level of patient charge}

Table 3 also gives examples of different charge levels. In general, the higher (in case of a benefit limit: the lower) the level of a patient charge, the higher the money price or effective price which a consumer has to pay for using a service, and the larger the magnitude of the effects on medicall consurnption or health expected (56). According to Keeler (59) "however, an increase in the level of a deductible, which is around zero or which is in ranges high enough so that the deductible limit is unlikely to be exceeded, will cause little change in medical consumption or health. According to Ellis (67), also an increase in the level of a benefit limit, which is around zero or which is in ranges high enough so that the reimbursement limit is unlikely to be exceeded, will cause little change in medical consumption or health. In order to improve comparisons of charges investigated in different health systems or different periods of time, charge levels expressed as a fixed amount of money are presented in 1995 US dollars in this overview (68). If the period of investigation of one and the same nominall charge level was longer than 1 year, the calculation of 1995 US dollars is based on the charge level in the first year investigated.

Both under co-payment and co-insurance there may be a maximum to the total money price which an insurant has to pay per (sub)unit of care or which an insurant or family has to pay per unit of 
time. This will be referred to as a maximum expenditure". In general, the presence of such a maximum reduces the level of the money price or effective price which an insurant has to pay for using care, and , as a consequence, reduces the magnitude of the impacts on medical consumption or health "expected (56). In case of a maximum expenditure, the money price is zero after reaching the maximum. The larger the chance that the maximum will be exceeded; the lower the level of the effective price before reaching it. As a consequence, the level of the effective price is non-inear (69).

\section{Level of maximum expenditure}

In general "the higher the level of a maximum expenditure, the higher the levell of the money price or effective price the consumer has to pay for using a service, and, as a consequence, the larger the magnitude of the effects on medical consumption or health, expected (56). According to Buchanan (69), however, an increase in the level of a maximum expenditure, which is around zero or which is in ranges high enough so that the maximum is unlikely to be exceeded, will cause little change in medical consumption or health. Once again, to improve patient charge comparisons, maximum expenditure levels, which were expressed in terms of a fixed amount of money, are presented in 1995 US dallars in this overview.

\section{Mandatory versus voluntary patient charge}

If an insurant has the possibility to choose between a health insurance plan without patient charges and a health insurance plan with patient charges (in exchange of a higher or lower insurance premium), the charges involved are voluntary. If there is onlly an insurance plan with patlent charges, the charges involved are mandatory. It is expected that under a voluntary patient charge, especially consumers who expect high levels of use (high risk users) will choose for a health insurance plan without patient charge $(48,49)$. As a consequence, a voluntary charge is expected to generally result in smaller decreases in both medical consumption and health than a mandatory charge. When a publication did not indicate that a charge was voluntary, it is assumed that the charge was - as is most common in public health insurance schemes - mandatory.

\section{Possibility of reinsurance}

If a patient charge is mandatory, insurants may have the possibility to reinsure this charge by additional (usually private) health insurance. If there is such a possibility, especially high risk users are expected to choose for additional insurance (70): As a consequence, under such a charge, both medical consumption and health will decrease less than under a mandatory charge without this possibility. When a publication did not indicate that a mandatory charge could be reinsured, it is assumed that there was no such possibility.

\section{Number of insurants to whom the patient charge is applied}

In this article the number of insurants to whom a charge is applied, is considered as a charge characteristic. The features of these insurants (e.g. the average income level) are considered as insurant characteristics. The following possibilities with respect to the number of insurants are distinguished: (a) either or not internally restricted, and (b) either or not externally restricted. The number of insurants is internally restricted if certain insurants (e.g. low income persons) covered by the insurance scheme are exempted from paying the charge. The number of insurants is externally restricted if the insurance scheme (and, thus, the charge) covers only a certain percentage of all persons in a country. If a charge is applied to a large number of insurants, it is expected that $\mathrm{Cij}$ will be reduced, but it is also expected that the health care provider(s) in question will try to prevent a decrease in $\mathrm{Fi}$ or $\mathrm{Qi}$, as this decrease would result in a further reduction in their income-level (71). A decrease in Cij may even (partly) compensated for by an increase in $\mathrm{Fi}$ or $\mathrm{Qi}$. It is expected, therefore, that the larger the number of insurants to whom a patient charge is applied, the smaller the magnitude of the effect of this charge on utilization and expenditure per insurant, once the service in question is used. On the other hand, reducing the number of insurants to whom a charge is applied, is expected to enhance the possibility of health care providers trying 
to increase Fi or Qi among those insurants to whom the charge is not applied (72). The latter effect is sometimes referred to as a "spill-over-effect".

\section{Number of health care services to which the patient charge is applied}

The number of services to which a chargle is applied, is considered as a charge characteristic. The features of these services (e.g. the reimbursement system) are considered as service characteristics. A patient charge may be applied to one, several or even all health care services covered by a health insurance scheme. Most services comprise a number of different subprovisions. A patient charge may be applied to an entire service categiory, but may also be applied to one or more subprovisions. If a patient charge is applied to almost all services in a health insurance scheme, there will be few possibilities to substitute these services by a provision in the insurance scheme to which this charge is not applied. It is expected, therefore, that an increase in the number of services to which a patient charge is applied, will result in a smaller magnitude of semi-external substitution (73). The magnitude of internal substitution or external substitution, however, is expected to increase.

\section{Impacts expected under different insurant characteristics}

\section{Level of income}

The higher an insurant's income level, the lower a given money price or effective price as a percentage of income, and, as a consequence, the smaller the effect - especially the income effect - of a patient charge on medical consumption or health expected (74). Further, a higher income level is expected to increase the time price of using care. The higher the time price of care as a proportion of the total out-of-pocket price of using care, the smaller the effect of a patient charge is expected to be (61). Although, in general, no detailed information with respect to the income level of linsurants was provided in the different studies, frequently some general income information was available. The different income categories distinguished in this article (low, midlle, high, or various), therefore, are not defined in terms of a specific range of dollar amounts per insurant or family per year. They only give an impression of the income levels involved.

\section{Health status}

The additional health benefit of an additional unit of medical utilization or expenditure is expected to be smaller as total medical consumption is larger (58). Under a patient charge, therefore, it is expected that the reduction in medical consumption will be larger, but that the adverse effect on health will be smaller, if the health status of an insurant is higher $(55,75,76)$. Secondly, it is expected that an insurant with a higher health status has more influence on the decisions of using care, which will result in a larger magnitude of either internal, semi-external or external substitution. Once again, the different health level categories distinguished in this article (low, high, or various) only give an impression of the insurants' health levels involved. In general, insurants having a (specific) chronic disease are considered as persons with a low health status.

\section{Age}

Age can be considered as a rough estimation of the health status of insurants. According to Akin (75), there should be a U-shaped relationship between health and age. Children are usually more vulnerable to disease because of their immature immune systems and greater growth needs, while elderly are more vulnerable to degenerative diseases. In the present article, a higher age is considered to generally represent a lower health status. The following age categories are distinguished: children (lower than \pm 18 years), adults (between \pm 18 and \pm 65 years), non-elderly (lower than \pm 65 years), elderly (higher than \pm 65 years), or various (all age categories). It is assumed that employed insurants (and their dependents) represent mainly non-elderly. 
It is important to realize that the insurant characteristics mentioned above are generally not independent from each other. Income and health (age) are frequently associated: the health status of low-income persons is generally poorer than that of high-income persons (77). If no information with respect to the income level, health status, or age of the insurants in question was available at all, it is assumed that a study analyzed the effects of a charge among persons with various income, health, or age levels, respectively.

\section{Impacts expected under different service characteristics}

It is expected that many service characteristics determine the direction or magnitude of charge effects on medical consumption and health. The most important are:

- free access versus prior authorization (78);

- reimbursement system (79):

- level of grass price (56)

- number of substitution possibilities (73)

- service density (61)

- waiting list (61)

- direct versus indirect effect on health (80).

Except for the reimbursement system of a provision, however, information with respect to service characteristics is generally not provided in publications concerning the effects of patient charges. Therefore, the overview of study outcomes focusses on the impacts of patient charges per (sub)provision to which the charge was applied and of which the medical consumption has been measured. Table 4 gives an overview of health care services which are considered as one provision in this article. Unless otherwise indicated in a publication, it is assumed that all of the provisions mentioned in table 4 have, in principle, free access, except for out-patient prescription drugs (prescription needed), out-patient medical supplies (prescription needed), and in-patient care (referral needed). Below, some of the above mentioned service characteristics are briefly elaborated.

\section{Free access versus prior authorization}

If insurants have free access to a provision, they are assumed to have more influence on the initial decision whether or not to use this provision than if they need prior authorization (e.g. a prescription or referral). Consequently, the magnitude of internal, semi-external or external substitution is expected to be larger under free access (78).

\section{Reimbursement system}

It is expected that a health care provider under a fee-for-service reimbursement system will try to prevent a decrease in medical consumption due to patient charges, by increasing supplier-induced demand $(71,79,81)$. It is expected, therefore, that under a fee-for-service system, the magnitude of the effects of a charge on medical consumption, once a provision is used, will be smaller than under most other reimbursement systems (e.g. a salary system or a capitation system). A decrease in Cij may even be (partly) compensated for by an increase in Fi or Qi. A possible desired effect of a patient charge in case of a fee-for-service system, however, is a reduction in the level of the gross price (Pgi) of a provision, due to price competition between health care providers (43). If the level of the money price of using a provision depends on Pgi - this is under co-payment type 3,coinsurance, a deductible or a benefit limit - a decrease in Pgi will make the provider in question more attractive for consumers. 
Table 4 Oveniew of health care services considered as one provision

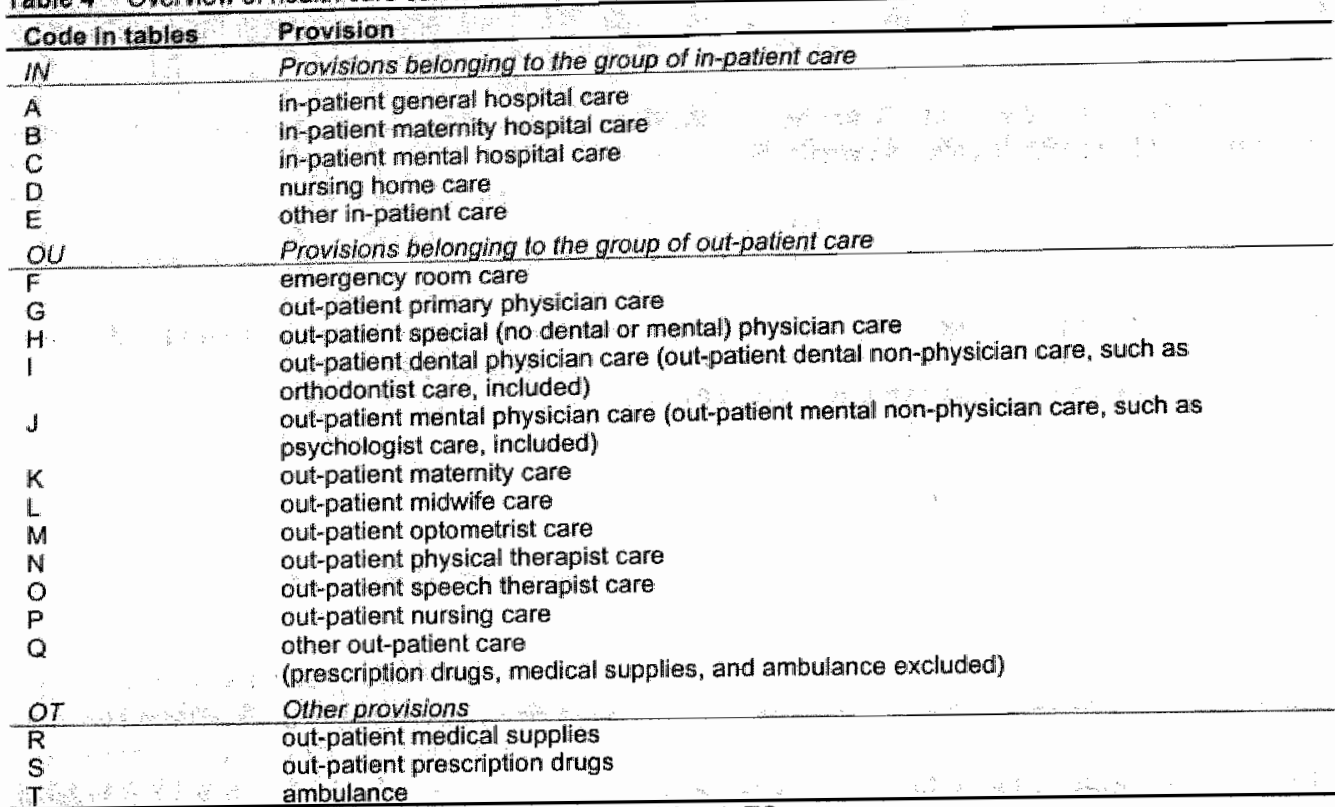

Code for total health care (total group of health care provisions): TO

Level of gross price

As has already been indicated, under co-payment type 3, co-insurance, a deductible or a benefit limit, the level of the gross price (Pgi) of a provision in question is an important determinant for the level of the price which an insurant has to pay out-of-pocket for using this provision. In general, the higher the level of Pgi, the higher the level of the money price or effective price. As a consequence, the magnitude of the effects on medical consumption or health will be larger (56).

\section{Impacts expected under different measurement characteristics}

As there are numerous measurement characteristics, it would be beyond the scope of this article to identify and describe them all. Only the following are considered.

Users versus all insurants in period before charge

The impact of a patient charge for a health care service may be measured among all insurants to whom this charge is applied, but may also be measured among users of a (different) service in the period before this charge. It is expected that the substitution-effects of a patient charge on medical consumption or health, measured among insurants who were users of care in the period before the charge, will be larger than if measured among all insurants in question, especially if the first group of insurants were high users of care (82).

\section{Study design}

The following categories of study designs are distinguished: randomized controlled trial, (interrupted) time-series analysis, before-after-comparison, cross-sectional study, and combinations of the previous study designs. It is expected that the outcomes of a randomized controlled trial are most valid. The most important disadvantage of both a (interrupted) time-series 
analysis and a before-after-comparison is that the charge impact may be biased by the effects of other changes in the period irvestigated. As it will not always be possible to correct for these changes perfectly, charge impacts measured in such studies can generally be expected to be either over or under-estimated. The most important disadvantage of a cross-sectional study is that the charge impact may be biased by differences between the groups of insurants under investigation. Especially, differences between the health status of the insurants may play a role. As it will, once again, not always be possible to correct for these differences perfectly, charge impacts measured in these studies can generally be expected to be overestimated.

\section{Short-term versus long-term effect}

Except for cross-sectional studies, and except for before-after comparisons in case of less than two observations after introducing or changing a patient charge, basically in all study designs it is possible to distinguish short-term (within one year) and long-term (after one year) patient charge impacts. If insurants know that a charge will be introduced (or increased) for a service, there may be an increase in medical consumption concerning this service, just before the introduction of the charge "anticipation-effect). As a result, an extraordinary decrease in medical consumption can be expected immediately after the introduction of the charge (83). A second possibility is that an insurant postpones using the service in question (postponement-effect) (65). As a result, once again, an extraordinary decrease in medical utilization concerning this service can be expected immediately after the introduction of the charge. In table 2 these effects are represented by a larger magnitude of external substitution in the short term. Whether or not adverse health effects will also be larger in the short time depends on whether or not the provision in question has a direct health effect. A third possibility is that an insurant will not immediately change medical consumption " because of being accustomed to it or because some period of time is needed to search for a (sub)provision with a lower out-of-pocket price and an equal health benefit $(83,84)$. In table 2 this possibility is represented by a smaller magnitude of both internal and semi-externall substitution in the short term.

\section{Description of the direction and magnitude of a patient charge impact}

With respect to the identification of the magnitude of a patient charge impact, publications could be divided into two groups: (1) those concerning the effects of the introduction of a patient charge, and (2) those concerning the effects of changes in the level of an existing patient charge. Some publications could be assigned to both of the previous groups.

Publications in the first group generally compared a situation with a patient charge to a situation with complete health insurance coverage. The direction and magnitude of the effects measured were usually expressed as a percentage change in the effect variable(s) investigated. If " $X$ " represents the value of an effect variable measured under a situation with a patient charge, and " $Y$ " represents the value of this variable measured under a situation with complete insurance coverage, the percentage change in the effect variable was commonly calculated by " $(X-Y) / Y X$ $100 \%$ ". Sometimes however, publications only provided " $X$ " and " $Y$ ". In this situation, the percentage change has been calculated on the basis of the former equation for this overview. Further, if a publiciation in the first group used a different effect measure, e.g. "( $Y-X) / X \times 100 \% "$ (e.g. 18), the outcomes were transformed to " $(X-Y) / Y \times 100 \%$ ". Only for few publications or outcomes such a transformation was not possible (e.g. 85). The latter publications, therefore, are not included in the present overview.

Publications in the second group usually calculated the price-elasticity of the effect variable(s) investigated. If such a publication measured medical consumption concerning a potential semiexternal substitute, the price-elasticity is called cross-price-elasticity. The elasticities calculated 
were actually patient-charge-level-elasticttes: they indicated the percentage change in medical utilization, expenditure, or health, due to a 1 percentage change in the level of a patient charge.

Sometimes, publications in either the first or secand group indicated that certain patient charge effects were not significant, without presenting the magnitude of the outcomes involved. Two situations could be distinguished: (1) the effect of a charge was not significantly different from zero and (2) the effect of a charge measured among a certain group of insurants separately (e.g. children) was not significantly different from that measured among all insurants together. In this article, in the first situation, the magnitude of the patient effect has been considered as equal to zero. To present outcomes of different studies in a similar way, all outcomes which were not significantly different from zero, have been considered as equal to zero. In the second situation, the magnitude of the effect has been considered as equal to that measured for all insurants together. In this article all outcomes of specific groups of insurants, which were not significantly different from the effects measured among all insurants together, have been considered as equal to these effects.

\section{Results}

\section{General overview of study publications and outcomes}

The total number of publications included in this thesis is 35. Almost all of these publications studied the effects of a patient charge among those insurants to whom the charge was applied. This means that, generally, no "spill-over-effects" have been analyzed. A majority of 28 publications (26 of the se publications are presented in table 5) belonged to group 1: publications which studied the effects of introducing a patient charge. A minority of 9 publications (all presented in table 6) belonged to group 2: publications which calculated the patient-charge-level-elasticity of medical consumption or health. Two publications belonged to both of the latter groups $(13,20)$. Some examples of publications or outcomes, which did not met the inclusion criteria, are given in the final paragraph of this results section.

Tables 5 and 6 give an overview of the patient charge impacts measured per effect variable on the one hand, and measured per effect category (indicating the direction and magnitude of a charge effect) on the ather hand. Except for the probability of using at least one unit of a service or group of services in the insurance scheme to which the charge is not applied per insurant in question (Coj), the tables do not show the impacts on other effect variables representing the consumption of services to which the charge is not applied. Only 2 publications $(17,27)$ have measured the impacts of a charge on the latter variables exclusively. As a consequence, these publications -which studied the effects of introducing a patient chargle - are not shown in table 5 .

Appendices 1,2 and 3 give an overview of the patient charge impacts measured per effect category on the one hand, and per charge characteristic on the other hand. The evidence pert insurant, service or measurement characteristic has been analyzed analogously. For pragmatic reasons the number of impact categories in the appendices is somewhat smaller than in tables 5 and 6. For publications in groups 1 and 2 , respectively, appendices 1 and 2 present the effects on medical consumption of the service(s) to which the charge was appllied (services in question). Impacts on medical consumption of other services investigated are not shown in these appendices. Effects on health are presented in appendix 3. 


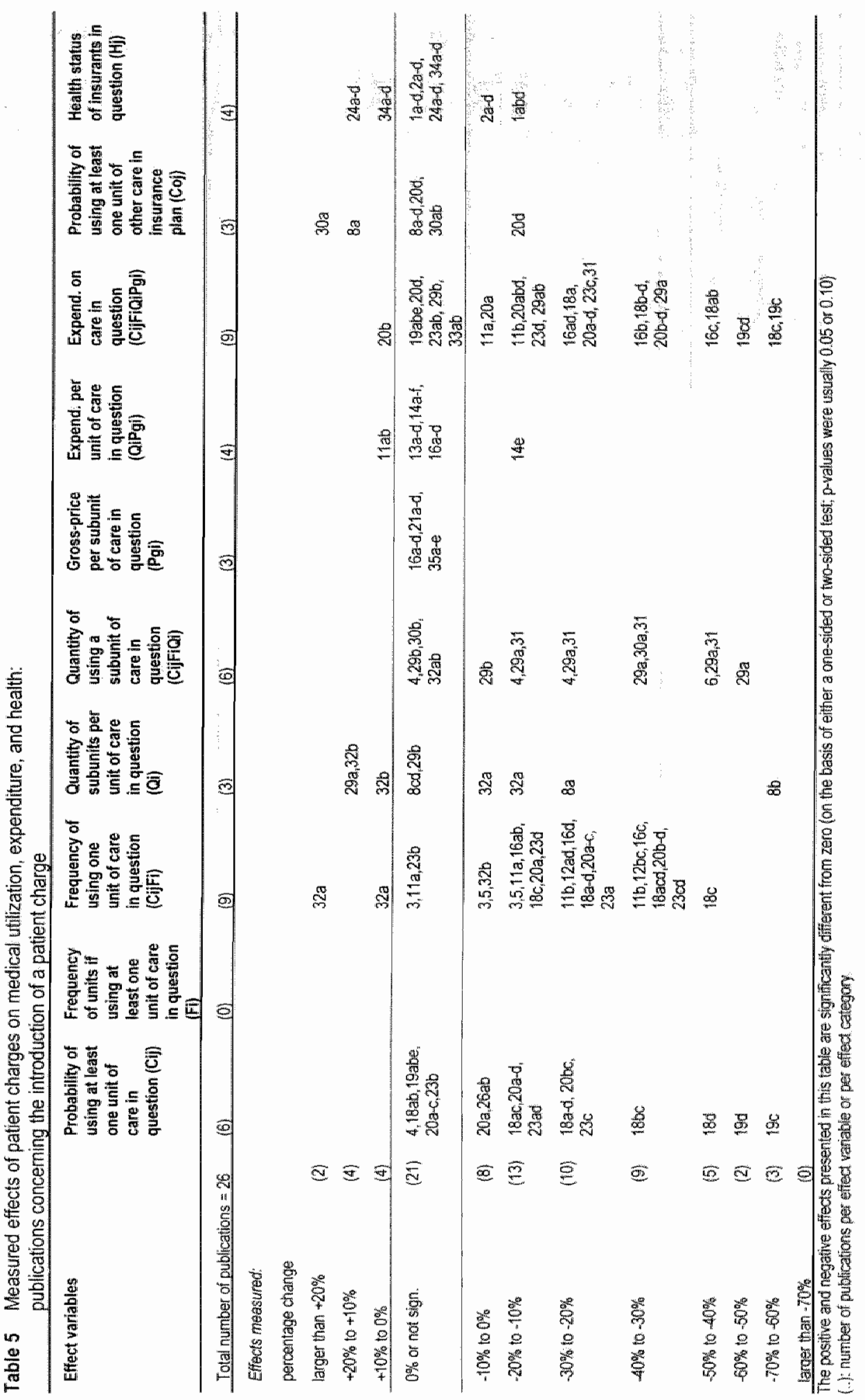




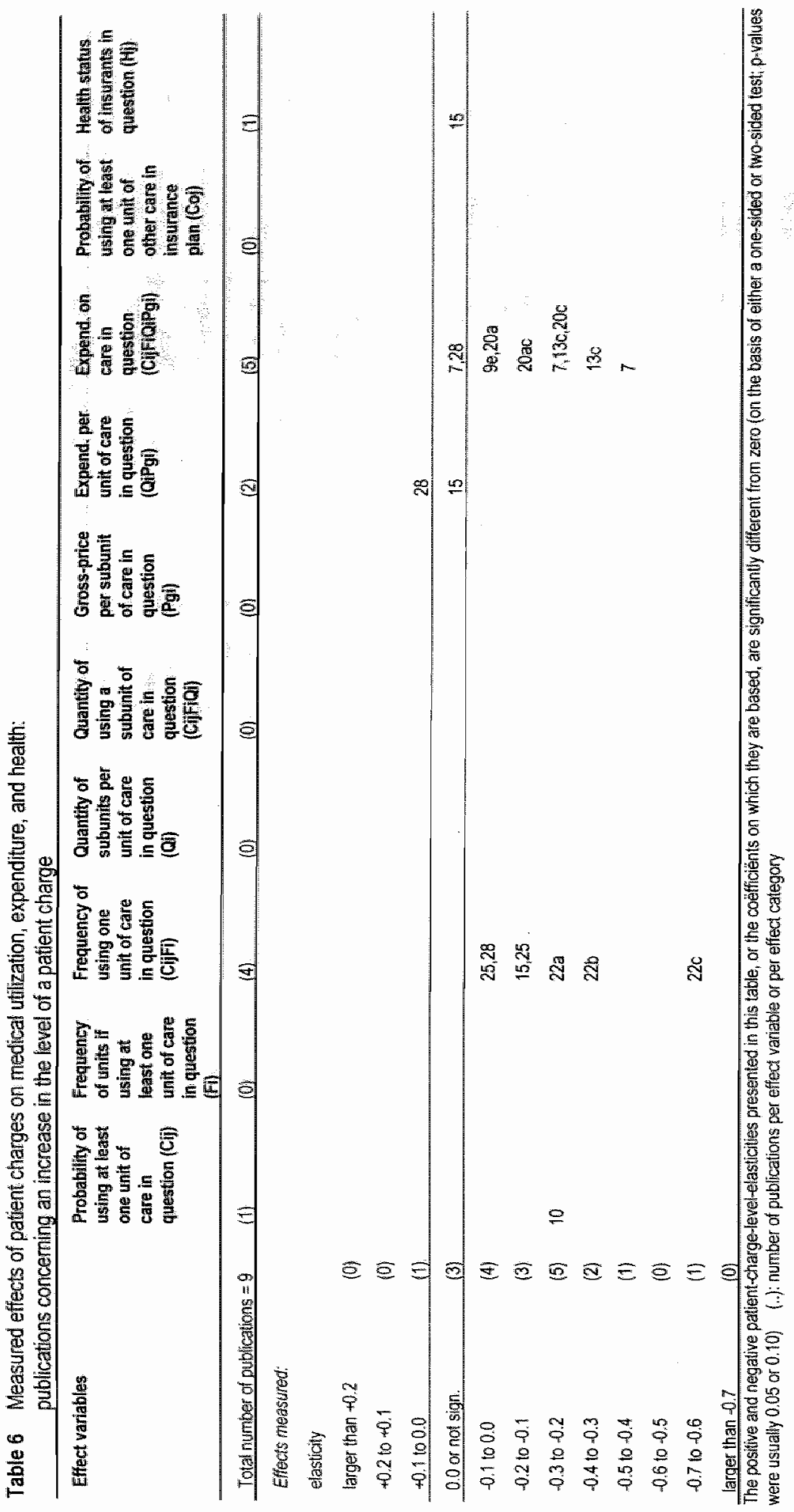


Several publications measured the impacts of a charge on more than one effect variable, or measured the impacts of more than one combination of patient charge, insurant, service and measurement characteristics. As a consequence, a number of publications are indicated more than once per effect variable or per characteristic. Within each "cell" (within each combination of effect variable and impact category, or within each combination of characteristic and impact category). however a publication is indicated only once. Publications which measured the effects of more than one patient charge separately (e.g. charges with different levels) are divided into two or more subpublications, each concerning only one specific combination of charge characteristics. Subpublications can be recognized in this overview on the basis of one or more characters added to the reference numbers (e.g. 29a, 29b). Below, the evidence presented in table 5, table 6 and the appendices is briefly described.

\section{Evidence per effect variablle}

The evidence in tables 5 and 6 suggests that - according to the charge impacts expected - the choice of the effect variable is (partly) important for both the direction and the magnitude of a patient charge impact.

Effect variables for which generally a decrease or no effect has been measured are: Cij, CijFl, CijFiQi and CijFiQiPgi. Variables for which - besides a decrease or no effect - more than once an increase has been measured are: $\mathrm{CijFi}, \mathrm{Qi}, \mathrm{QiPgil}$ and $\mathrm{Coj}$. In general, no effect has been measured on the variables Pgi and $\mathrm{Hj}$. Three publications (11ab, 28, 32b) showed that a charge resulted in a decrease in $\mathrm{CijFi}$, but that this decrease was partly or even totally compensated for by an increase in Qi or QiPgi. On the other hand, 1 publication (32a) showed that a decrease in Qi was totally compensated for by an increase in CijFi. As a result, in these publications a smaller or even no effect has been measured on CijFiQi or CijFiQiPgi. The increases in $\mathrm{CijFi}_{\mathrm{ij}} \mathrm{Qi}$ and QiPgi correspond with the impacts expected under specific charge types. This is further elaborated in the next paragraph. The increases in Coj correspond with the impacts expected under semi-external substitution. As will be indicated later (in table 7), the average gross prices of the semi-external substitutes were most probably higher than that of the original service to which the charge was applied (presence of adverse semi-external substitution).

The impact on Fi has not been directly measured in any publication. In general however, somewhat larger decreases have been measured in $\mathrm{CijFi}$ than in $\mathrm{C} i \mathrm{j}$. This suggests that a charge frequently also resulted in a decrease in FI, but that the magnitude of this decrease was simaller than that of the decrease in $\mathrm{Cij}$. These findings correspond with those expected under external substitution and an income effect (table 2).

In publications which analyzed charge impacts on $\mathrm{Hj}$, many different measurement units (e.g. shortness of breath or number of missing teeth) have been used to determine the health status of insurants. As it would be beyond the scope of this article to present the effects measured on all these units separately, tables 5 and 6 show the overall effects measured on three main categories of such units: (1) dental health status units, (2) mental health status units and (3) general health status units. Only important deviations of specific measurement units within these main categories are presented separately. In general, the publications did not measure significant charge effects on the former three categories of health status units. However, 1 publication (1abd) measured a decrease in periodontal health among children, while a second publication (2a-d) measured an increase in both diastolic blood pressure and corrected far vision among adults. Originally, the latter increase lied in the category from $+10 \%$ to $0 \%$. However, as an increase in the latter health status units represents a decrease in the (general) health status per insurant in question, the effects are presented in the effect category from $-10 \%$ to $0 \%$ (table 5 ). Further, 2 publications (24a-d, 34a-d) measured a decrease in the probability of having hay fever among children and a decrease in the 
to which the charge was not applied (not shown in appendices 1 and 2 ), especially the impacts on the effect variables Coj (table $5,8 \mathrm{a}-\mathrm{d}, 20 \mathrm{~d}$, 30ab) and CojFo $(3,27,20 \mathrm{~d}, 31$ ), suggest that semiexternal substitution is more likely to occur, f a charge is applied to one provision separately: For these variables an increase or no effect has been measured if a charge was applied to one provision separately (Ba-d, 30ab, 31); while a decrease or no effect was measured if a charge was applied to several provisions together $(3,20 \mathrm{~d}, 27)$. This means that the evidence suggests that the number of services to whicti a charge is applied, is important for the direction of a charge impact. This finding deviates somewhat from the charge effects expected. It was expected that a smaller number of services to which a charge is applied; would result in a larger magnitude of semiexternal substitution (table 2). It is important to note, however, that only 1 publication (20d) measured a decrease in Coj or CojFo. Finally, impacts on $\mathrm{Hj}$ (appendix 3) did not show a relationship between the number of services to which a charge was applied and the direction or magnitude of a charge effect.

\section{Evidence per insuirant characteristic}

\section{Income level}

The outcomes did not show a clear relationship between the income level of the insurants in question and the direction or magnitude of a charge impact. The lack of such a relationship is probably due to the lack of an important income effect of the charges investigated. This, in turn, seems to be due to two specific patient charge characteristics: the charge level and the presence of a maximum expenditure. In general, the publications in this overview analyzed the effects of a charge with either a rather low level (especially under co-payment) or with a (income dependent) maximum expenditure (especially under co-insurance). These charge characteristics may have resulted in a rather low level of a money price or effective price as a percentage of income.

Health status level

Most publications did not make a distinction between insurants with different health levels: Two publications (20a-d, 26ab), however, showed that the health status level of the insurants in question was not important for the direction or magnitude of the patient charge effects measured.

\section{Age level}

In general, the outcomes did not show a clear rellationshio between the ade level of the insutants.

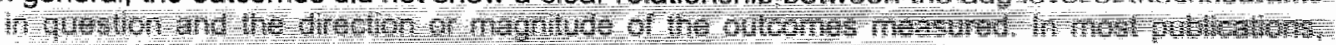

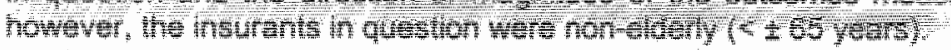

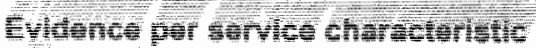

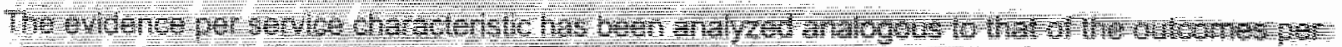

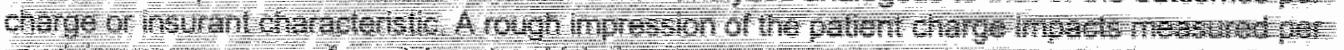

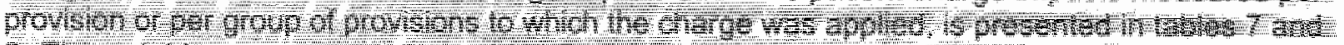

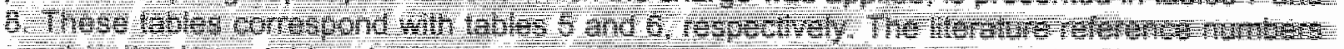

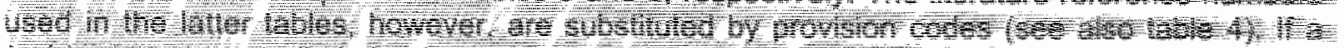

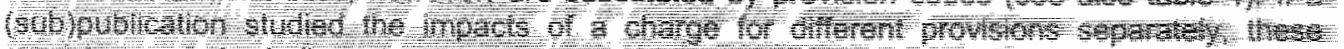

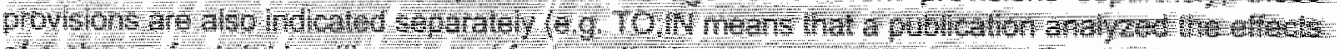

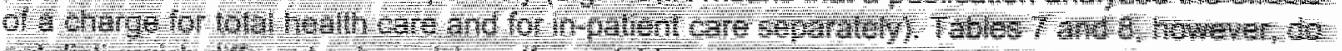

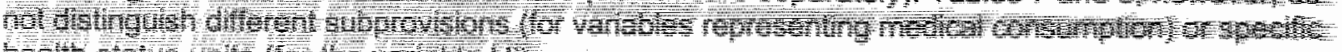

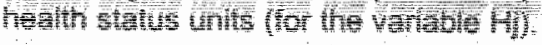




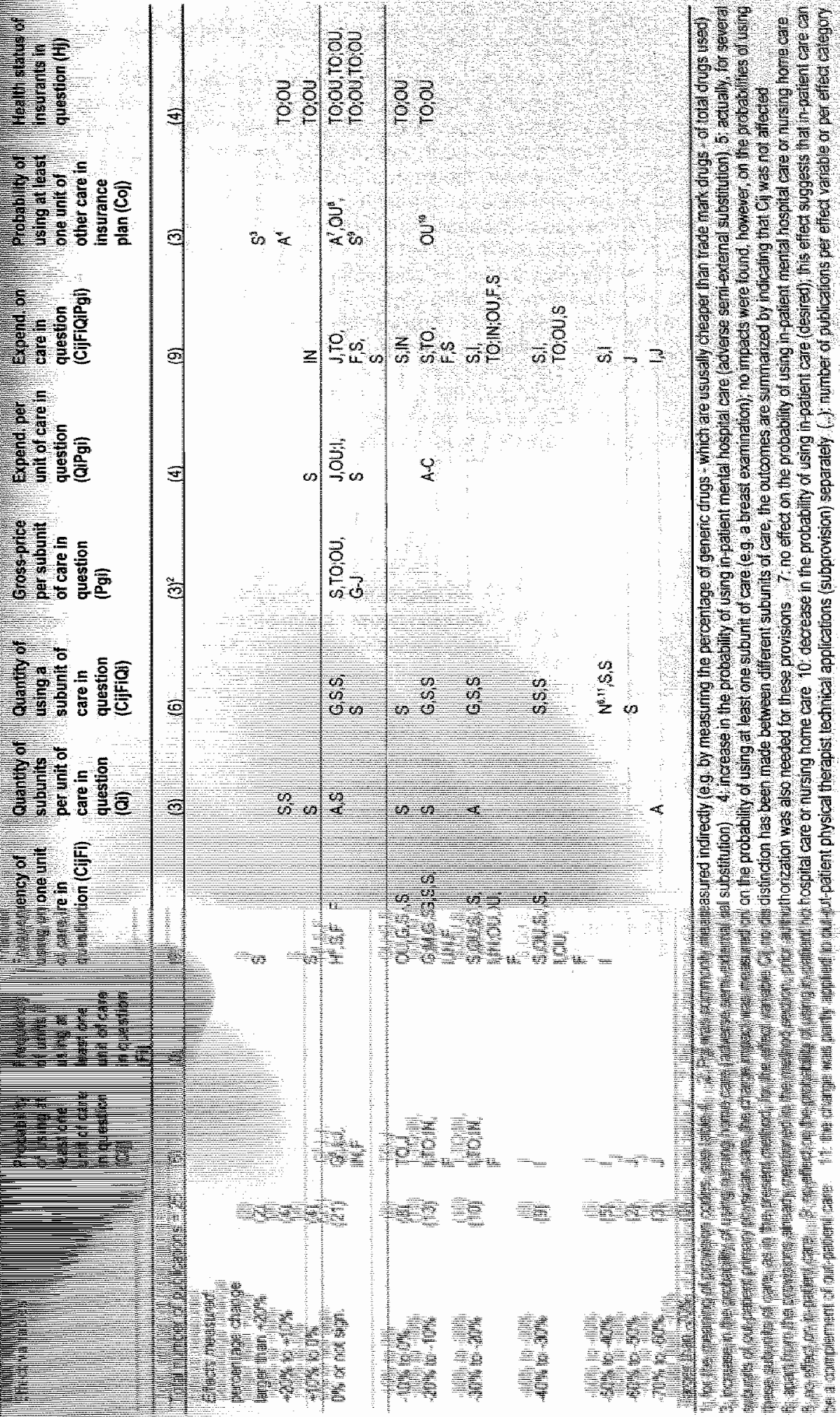




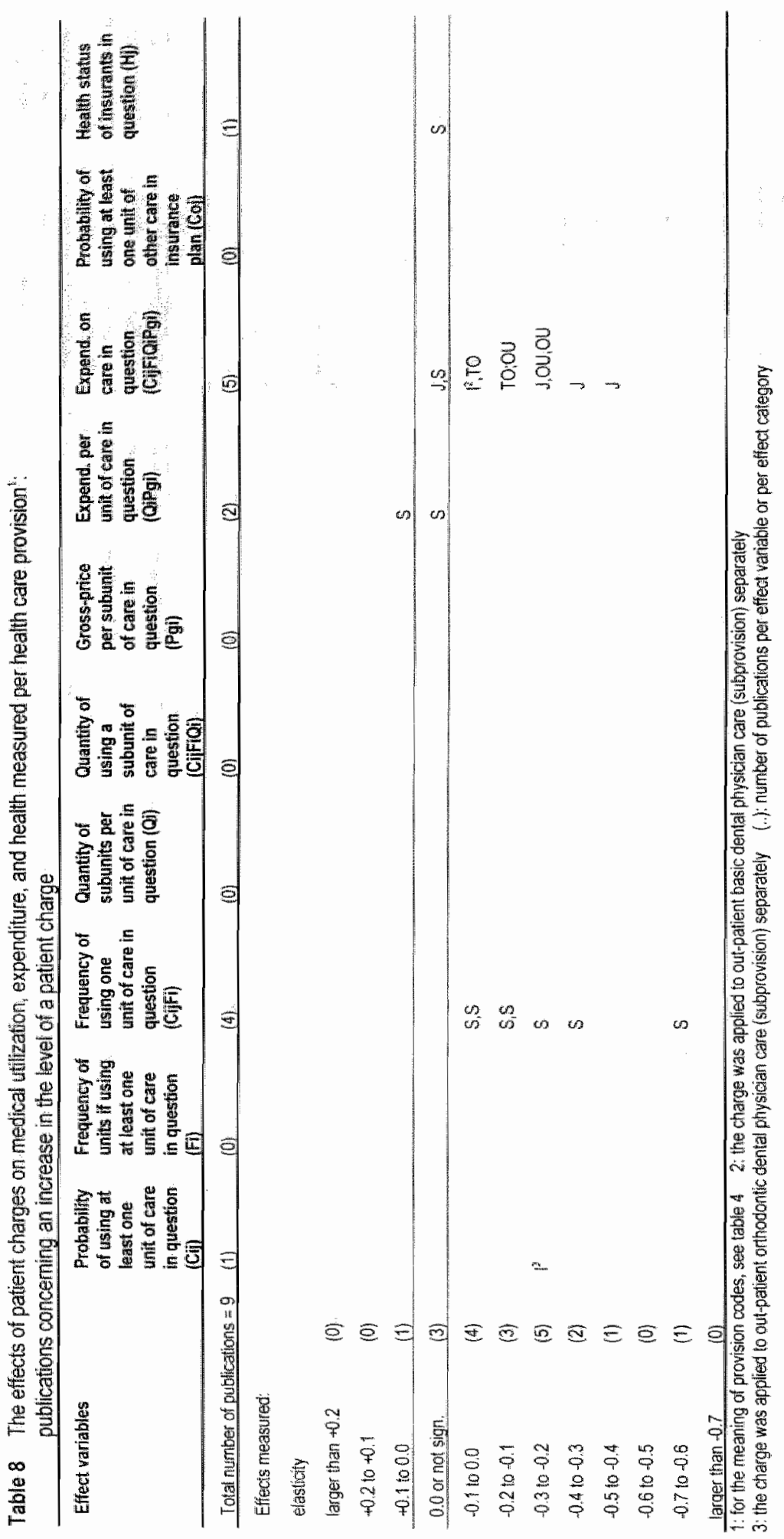


The health care (sub)provision to which a charge is applied, seems to be impartant for the magnitude of charge effects on medical consumption. in general, especially with respect to expenditure on care, it seems that out-patient care is more sensitive to introducing or increasing patient charges (larger decreases in CijFiQiPgi) than in-patient care or total health care. In particular, It seems that expenditure on both out-patient mental and out-patient dental physician care is rather sensitive to patient charges. Although detailed information about specific service characteristics was generally not provided in the publications, it seems that at least the presence or absence of free access to care is important for the magnitude of the effects on medical utilization and expenditure. For out-patient care - especially for primary physician, dental physician, and optometrist care - there is generally free access, while for in-patient care usually a referral is needed. Although also for out-patient prescription drugs prior authorization is needed, the consumption of this provision appears to be relatively sensitive to patient charges. It seems that non-essential and ineffective drugs are generally more sensitive to charges than essential drugs (subprovisions not shown in tables 7 and 8). Finally, with respect to the reimbursement system of a service, the evidence did not show a clear relationship with the direction or magnitude of a charge impact. Most publications, however, studied the effects of a charge under a fee-for-service system.

\section{Evidence per measurement characteristic}

\section{User group in period before charge}

Most publications measured charge effects among all insurants in question. One publication (table 5: 29ab), however, analyzed charge effects among insurants who were low or middle users of care in the period before the charge, while 2 publications (table 5: 29ab, 30ab) analyzed such effects among insurants who were high users of care in the period before the charge. It seems that the effect magnitude measured among high users of care is generally larger than that measured among low or middle users of care. Further, 1 publication (table 5: 31) measured charge effects among insurants who were users of care in the period before the charge on the one hand, and among all insurants in question on the other hand. This publication showed that the charge impact was larger if measured among the former group of insurants. These findings correspond with the expectations (table 2).

\section{Study design}

In general, the results did not show a clear relationship between the study design and the direction or magnitude of a charge effect on medical consumption or heaith. Although increases in medical consumption were most frequently found in non-experimental study designs, it seemed that this was mainly due to the type of effect variables investigated.

\section{Short-term versus long-term effect}

Although the term in which a charge impact was measured could be important, the results did generally not show a clear relationship with the effects on medical consumption or health. One publication (table 5: 20a-d) showed that there were no significant differences between short-term and long-term charge effects. Two publications (table 5: 18a-d; table 6:25), however, (glenerally) measured larger effects in the short term than in the long term (larger effect magnitudes), while a fourth publication (table 5: 32ab) most firequently measured larger effects in the long term than in the short term. 


\section{Examples of publications or outcomes which did not mett the inclusion criteria}

\section{Publications which did not provide sufficient relevant information}

Several publications have calculated the money price-elasticity of medical utilization or expenditure; but did not provide (sufficient) information with respect to the kind of a patient charge investigated (e.g.74,86, 87). This means that these publications were only able to indicate whether or not a patient charge may be desirable, but that they could not indicate which kind of a charge can be desirable. Further some publications measured the effects of patient charges on medical consumption, but did not provide a price-elasticity or a percentage change concerning the effect variable(s) investigated (e.g. $72,77,88$ ). Instead, they indicated only the direction of charge effects. Most frequently, the outcomes involved indicated a decrease in medical consumption.

\section{Outcomes not tested on a significance level}

Several publications have not been included in the present overview at all, as not any of its outcomes were tested on a significance level (e.g. 89-91). Also outcomes of publications included in the overview have been exempted, when not tested on a significance level. Examples of such outcomes are co-insurance-level-elasticities estimated under a hypothetical situation of coinsurance without maximum expenditure $(13,14)$.

\section{Publications or outcomes conceming the combined effects of different charges or policy measures Several publications or outcomes were not included in this overview, as these concerned the effects of a combination of different kinds of patient charges (e.g. 92, 93, several outcomes of 27) or concerned the effects of a combination of a patient charge and one or more other health policy measures (e.g. 94-96). It was not clear in these publications what the effect was of a patient charge separately.}

Publications or outcomes concerning the combined effects of charges and the absence of health insurance

Several publications measured the combined effects of both the presence of charges and the absence of health insurance (e.g. 97-99). Once again, it was not clear in these publications what the effect was of a patient charge separately.

\section{Discussion}

\section{To what extent is the method able to explain different patient charge outcomes?}

Firstly, the synthesis of evidence shows that both the effect variable investigated "the type of a patient charge, and the number of services to which a charge is applied can be important determinants for differences in the direction of patient charge effects. Secondly, it shows that both the effect variable investigated, the level of a charge, the level of a maximum expenditure, the health care (sub)provision in question, and the group of users considered, can be important determinants for differences in the magnitude of patient charge effects. Thirdly, the synthesis shows that also other characteristics (e.g. insurants' age and the measurement of a charge effect in the short term or in the long term) can be important determinants for differences in the magnitude of charge effects. However, the evidence does not show clear relationships between these characteristics and the charge effects measured.

Although the present method is able to isolate a number of factors which are important for differences in both the direction and magnitude of patient charge outcomes measured, it seems that a charge effect mainly depends on the specific combination of charge, insurant, service, and measurement characteristics under consideration. Analyzing a larger number of specific patient charge regulations will probably increase the possibility to determine more precisely the influence 
of each characteristic separately. This suggests that, although a rather large number of studies of the effects of patient charges has already been published, and, although the present method can be extended -e.g. by including outcomes published in non-indexed or non-English language journals - additional scientific research is needed.

\section{To what extent is the method able to indicate which kind of a charge may be desirable?}

The synthesis of evidence suggests that especially introducing mandatory co-insurance with a level of about $50 \%$, with an income dependent level of a maximum expenditure (between $5 \%$ and $15 \%$ of family income per year), without the possibility of reinsurance, for out-patient care or even total health care, for non-elderly, may be desirable for reducing moral hazard. In contrast to the expectations, however, this kind of a patient charge seems to have most frequently resulted among the insurants in question - in desired external substitution, rather than desired internal substitution: most frequently there was a decrease in the probability of using care in question ( $\mathrm{Cij}$ ), the frequency of using care in question ( $\mathrm{Cij} F \mathrm{i}$ ), and as a consequence, a reduction in the total quantity of using care in question (CijFiQi), rather than a decrease in the gross price of using care in question (Pgi). There was generally no decrease in the health status of the insurants in question $(\mathrm{Hij})$. If this charge was applied to out-patient care, there was neither an increase in the consumption of in-patient care (no adverse semi-external substitution).

The synthesis suggests that - corresponding to the expectations - co-payment type 1 and benefit limit types 4 and 5 may be less or even not desirable for reducing moral hazard due to adverse increases in $\mathrm{CijFi}, \mathrm{Qi}$ (the quantity of subunits per unit of care in question) or QiPgi (expenditure per unit of care in question). Further, corresponding to the expectations, adverse semi-external substitution (adverse increases in Coj) may occur if a charge is applied to one provision separately.

It is important to note that other charge types than co-insurance, co-payment type 1 or benefit limit types 4 to 6 have not been investigated in the publications considered. Further, most charges were mandatory without the possibility of reinsurance, and most charges have been applied to nonelderly and a number of insurants that was only externally restricted , and to health care services with a fee-for-service reimbursement system. In addition, certain charge characteristics were frequently associated. For example, co-insurance was frequently associated with a maximum expenditure, and co-payment type 1 was usually associated with a rather low charge level. This means that the synthesis is not able to give an evidence based answer to the question whether there are also other kinds of patient charges which may be (un)desirable for reducing moral hazard.

It is also important to realize that, although 2 publications (20a-d, 21a-c) have investigated the effects of a charge on total medical consumption among those insurants to whom this charge was applied, none of the publications analyzed the effects of a charge on total health care expenditure in a country. Further, although publications which have investigated the effects of a charge on the health status of insurants did generally find no adverse effects (1a-d, 2a-d, 15, 24a-d, 34a-d), there were some exceptions. The most important were a decrease in periodontal health among children ( $1 \mathrm{ab}$ ) and an increase in average blood pressure among adults (2a-d). High blood pressure is an important risk factor for cardiovascular disease, which in turn is the most important cause of total mortality in developed countries (100-102). This means that, although there were generally no adverse health effects measured, there may be significant effects on the longer term. 


\section{Conclusion}

The method developed in this article for comparing outcomes of published empirical studies of the effects of patient charges in health care (making a distinction between different effect variables. and between different charge insurant, service, and measurement characteristics), appears to be reasonable successful in explaining the different directions and magnitudes of the outcomes measured. It shows that at least the effect variable investigated, as well as the type and level of a charge, the level of a maxmum expenditure, the service(s) to which a charge is applied, and the group of health care users considered, are important factors in this respect. However, as the 35 publications included in this overview have analyzed only the effects of charges on medical utilization, expenditure, or health, and as these publications did not analyze all the possible combinations of charge, insurant, service, and measurement characteristics, the present overview is not able to give a complete answer to the question which kind of a charge in a public health insurance scheme may be most desirable. Nevertheless, if the purpose of a charge is to reduce moral hazard, it seems that this overview is able to indicate which kind of a charge may be desirable in mare detail than most of the previous review articles.

The evidence suggests that especially mandatory co-insurance with a level of about $50 \%$, with an income dependent level of a maximum expenditure (between $5 \%$ and $15 \%$ of family income per year), without the possibility of reinsurance, for non-elderly, applied to out-patient care or even all health care services, may be desirable for reducing the quantity of medical care among these insurants. It suggests that under such a charge: (1) the probability of using at least one unit of care, (2) the frequency of using one unit of care, and, as a consequence, (3) the total quantity of using care and (4) expenditure on care, are most likely to be reduced between $-40 \%$ and $-10 \%$, without a reduction in the overall health status of the insurants in question. The evidence also suggests that co-payment type 1, benefit limit types 4 and 5, charges applied to one (sub)provision separately, or charges applied to services for which a referral is needed, are less or even not desirable.

The article shows that evidence based policy making in the field of cost sharing requires an enormous amount of information. Additional scientific research (e.g. analyses of charge effects among elderly or charge effects on equity) seems to be important to further solve the issue of patient charges. The methad as described in this article may be an important tool to map new information and to support future health policy making.

\section{Note}

1. It is interesting to note that the level of co-insurance was frequently $95 \%$ and that this charge type was frequently accompanied by a maximum expenditure. This means that this charge was frequently nearly equal to a deductible which can be considered as co-insurance with a level of $100 \%$ and a maximum expenditure.

\section{References}

1. Bailit $H$, Newhouse J, Brook $R$, et al. Does more gernercus dental insurance coverage improve oral thealth? $J$ Am Dent Assoc 1985;110;701-7.

2. Brook $R_{H}$ Ware JE, Rogers WH, et al. Does free care improve adults' health?: results from a randomized contralled trial. New Engl J Med 1983;309:1426-34.

3. Cherkin $\mathrm{DC}$, Grothaus L, Wagner EH. The effect of office visit copayments on utilization in a health maintenance organization. Med Care 1989,27:669-79.

4. Cherkin DC, Grothaus L, Wagner EH. The effect of office visit copayments on preventive care senvices in ain $\mathrm{HMO}$. Inquiry $1990 ; 27: 24-38$. 
5. Cherkin DC, Grothaus L. Wagner EH. Is magnitude of co-payment effect related to income? using census data for health services research. Soc Sci Med 1902:34:33-41.

6. van Doorslaer $E$, Geurts J. Supplierinduced demand for physiotherapy in The Nothertands. Soe Sci Mud $1987: 24: 919-25$

7. Ellis RP, McGuire TG. Cost sharing and patterns of mental health care utllization, I Hum Resour 1986:24:359-79.

8. Frank RG, Lave JR. The impact of Medicaid benefit design on length of hospital stay and patient transfers. Hosp Commumity Psych 1985,36:749-53.

9. Grembowski D, Conrad D. Insurance effects on employer group dental expenditure. Med Care 1984,22,50,-10,

10. Grembowski D, Conrad DA, Milgrom P. Dental care demand among children with dental insurance. Healith Serv Res 1987:21:755-75.

11. Harris $B_{4}$ Stengachis $A$, Ried $L$. The effect of drug copayments on utilization and costt of pharmaceuticals in a heallh maintenance organization. Med Care 1990;28:907-17.

12. Keeler EB, Rolph JE. How cost sharing reduced medical spending of participants in the hoalth insurance experiment. \AMAA 1983;249:2220-2.

13. Keeler EB, Manning WG, Wells KB. The demand for episodes of mental health services. J Health Econ $1988 ; 7: 369-92$.

14. Keeler EB, Rolph JE. The demand for episodes of treatment in the health insurance experiment. J Health Econ $1988 ; 7: 337-67$.

15. Lavers Rul. Presctiption charges, the demand for prescriptions and morbidity. Appl Econ 1989,"21:1043-52.

16. Leibowitz A, Manning WG, Newhouse JP. The demand for prescription drugs as a function of cost-sharing. Soc Sci Med 198:21:1063-9.

17. Leibowitz A. Substitution between prescribed and over-the-counter medications. Med Care 1989:27:85-94.

18. Manning WG, Bailit HL, Benjamin $B$, Newhouse JP. The demand for dental care: ev idence from a randomized triall in health insurance. I Am Dent Assoc 1985;110:895-902.

19. Manning WG, Wells KB, Duan N, Newhouse JP. Ware JE. How cost sharing affects the use of ambulatory mental health services. JAMA 1986;256:1930-4

20. Manning WG, Newhouse JP. Duan $N$, et al. Health insurance and the demand for medical care: evidence from a randomized experiment. Am Econ Rev 1987;77:251-77.

21. Marquis MS. Cost-sharing and provider choice. J Health Econ 1985;4:137-57.

22. $O B$ Bien $B$. The effect of patient charges on the utilisation of presicription medicines, J Health Econ 1989;8:109-32.

23. O'Grady KF, Manning WG, Newhouse JP, Brook RH. The impact of cost sharing on emergency department use. New Engl J Med 1985;313:484-90.

24. Rogers WH, ORourke TW, Ware JE, et al. Effects of cost sharing in health insurance on disability days. Healith Policy $1991 ; 18: 131-9$.

25. Ryan M, Birch S. Charging for health care: evidence on the utilization of NHS prescribed drugs. Soc Sci Med $1991 ; 33: 681-7$

26. Simon GE. VonKonff M, Durham ML. Predictors of outpatient mental health utilization by primary care patients in a health maintenance organization. Am J Psychiat 1994;151:908-13.

27. Siu $A L$. Somnemberg FA. Manning WG, et all. Inapponopriate use of hospitals in a randomized trial of hoalth insurance plans. New Engl d Med 1986;315:1259m66.

28. Smith DG. The effects of copayments and generic substitution on the use and costs of prescription drugis. Inguiry $1993 ; 30: 189-98$.

29. Soumerai SB, Avorn \, Ross Degnan D, Gortmaker S. Payment restrictions for prescriptlon drugs under Modicaild: effects on therapy, cost. and equity. New Engl J Med 1987;317:550-6.

30. Soumerai SB, Ross-Degnan J, Avorn J, et al. Effects of Medicaid drug-payment limits on admission to hospitals and nursing homes. New Engl $J$ Med 1991;325:1072:7.

31. Soumerai SB, Mclaughlin TJ, Ross-Degnan D. Casteris CS. Bollini P. Effects of limiting medicaild drug-reimbursement benefits on the use of psychotropic agents and acute mental health services by patients with schizophrenia. New Engl J Med 1994;331:650-5.

32. Starmans $B_{*}$ Janssen $R$, Schepers $M$, Verkooijen $M$. The effect of a patient charge and a prescription regulation on the use of antihypertension drugs in Limburg. The Netherlands. Health Poltcy $1994: 26: 191-206$.

33. Starmans $B$, Janssen $R$, Schepers $M$, Verkooilen $M$. The effect of a patient charge and a prescription regulation on expenditure for antihypertension drugs in Limburg. The Netherlands: some implicetions for the effect of a reference price system. Int J Health Sci 1994;5:105-17.

34. Valdez RB, Brook RH, Rogers WH, et al. Consequences of cost-sharing for children's health. Fediatrics $1985 ; 75: 952-61$.

35. Wells KB, Mlanning WG, Duan N, et al. Cost-sharing and the use of general medical physicians for outpatient mental heath care. Health Serv Res 1987:22:1-17. 
36. Abel-smith B, Mossialos E Cost containment and heatth care reform: a study of the Eunopean Union. Health Policy $1994,28: 89-132$

37. Huber IH, Ensting access to health care with the introduction of user fees: a Kenyan example. Soc Sci Med $1993,36: 485,94$.

38. Fice T. Thorpe KE. Income-related aost shaming in thealth insurance Health Affair 1993;12-121-39.

39. Creese AL User charges for thealth care, a review of recent experience Health Pollcy Plann 1991,6:309-19.

40. Huth $C$. The use of preseription charges. Health Policy $1994,27,53-73$

41. Lewy RA Prescrption cost sharing economic and health impacts, anid implications for health pollicy. PharmacoEconomics 1992/219-37.

42. Fice T, Monison KR. Patient cost sharing for medical senvices: a review of the literature and implications for health care reform. Med Care Rev $1994 ; 51: 235-87$

43. Newhouse JP. Insurance beneifits, out-of-pocket payments, and the demand for medical care. Health Med Care Serv Rev 1978,1 1-15.

44. Newhouse JP. The insurance Experiment Group. Free for all?: lessons from the RAND Health llnsurance Experiment. Cambridge: Harvard University Press, 1993.

45. Leidl $R$, John J, Salzinger W. Perspectives on health reporting for the European Community. Eur $J$ Public Health $1992,2: 3844$

46. Rublee DA, Schneider M. International health spending: comparisons with the OECD. Health Affair 1991: 10:487-98.

47. Newhouse JP, Phelps CE, Marquis MS. On having your cake and eating fit too: econometric problems in estimating the demand for health servicesi d Economatrics 1980;13:365-90.

48. Feldman $R$, Dowd $B$. Must adverse selection cause premium spirals? J Hilealth Econ 1991;10:349-57.

49. Light DW. Escaping the traps of postwar Western medicine: how to maximize health and minimize expenses. Eur J Public Health 1993;3:281-9.

50. Rice T. Containing health care costs in the United States. Med Care Rev 1992;49:19-65.

51. Arrow KJ. Uncertainty and the welfare economics of medical care. Am Econ Rev 1963;53:941-73.

52. Pauly MV. The economics of imoral hazard: comment. Am Econ Rev 1968;57:231-7.

53. Duan $\mathrm{N}_{1}$ Manning WG, Morris $\mathrm{CN}$, Newhouse JP. A comparison of alternative models for the demand for medical care. Bus Econ Stat $1983 ; 1: 115-26$.

54. Stoddart GL, Barer ML. Analyses of demand and utilization through episodes of medical service. In: van der Gaag $J_{\text {. Perlman }} \mathrm{M}_{n}$ eds. Heatth economics, and health economics. Amsterdam: North-Holland Publishing Company. 1981:149-70.

55. Grossman M. Cn the concept of health capital and the demand for health. J Polit Econ 1972;80:223-55.

56. Samuilson PA, Nordhaus WD. Ecomomics. New York: McGraw-Hill, 1995.

57. Feldstein MS. Econometric studies of health economics. In: Intrilligator MD, Kendrick DA, eds. Frontiers af quantitative economics. W. 2. Amsterdam: North-Holland Publishing Company, 1974:377-434.

58. Newhoulse JP. Medical care costs: how much welfare loss? J Econ Perspect 1992;6:3-21.

59. Keeter EB, Newhouse JP. Phelps CE. Deductibles and the demand for medical care services: the theory of a consumer facing a wariable price schedule under uncertainty. Econometricai 1977:45:641-55.

60. Besley T. The demand for health care and health insurance. Oxford Rev Econ Pol 1989;5:21-33.

61. Phalps CE, Newhouse JP. Coinsurance, the price of time and the demand for medicall services. Rew Econ Stat $1974,56: 3344-42$.

62. Harris JS, Custer WS. Heallh care economic factors and the effects of benefits plan design changes. I Occup Med $1991,33: 270-87$.

63. Newhouse JP. The demand for medical care services: a retrospect and prospect. In: van der Gaag J, Perlman $M$, eds. Health, economics; and health economics. Amsterdam: North-Holland Publishing Company, 1981:85-102.

64. Borcherding TE, Silbeiberg E. Shipping the good apples out: the Alchian and Allen theorem reconsidered. $J$ Pollit Econ 1978:86:131-8.

65. Maynard A. Medical care and the price mechanism. In ل Judge K, ed. Pricing the social senvices. London: Macmillan, $1980: 86-106$.

66. Pialy MV. Taxation, health insurance, and market failure in the medical economy. J Econ Lit 1986;24:629-75.

67. Eillis RP. Rational behavior in the presence of coverage ceillings and deductibles. Rand J Econ 1986;17:158-75.

68. International Monetary Fund. International financial statistics yearbook. w. XLIX. Washington: 1 MF, 4996.

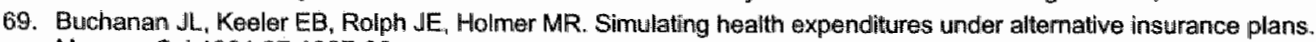
Manage Sci 1991;37:1067-90.

70. Marquis MS, Phelps CE. Price elasticity and adverse selection in the demand for supplementary health insurance. Econ lnq 1987;25:299-313. 
71. Rice TH. The impact of changing Medicare reimbursement rates on physician-induced demand, Med Care $1983 ; 21: 803-15$.

72. Fahs MC. Physician response to the United Workers' cost-sharing program: the other side of the coin. Heafth Sen Res 1992;27:25-45.

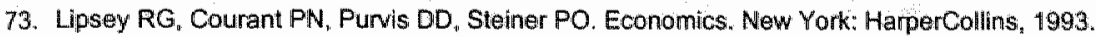

74. Gertler P, Locay L, Sanderson W. Are user fees regressive? The welfare implications of health care financing proposals in Peru. $J$ Econometrics 1987:36:67-88.

75. Akin JS, Guilkey DK, Griffin CC, Popkin BM. The demand for primary health services in the third world. Totowa, New Jersey: Rowman and Allanheld, 1985.

76. Wedig GJ. Health status and the demand for health: results on price elasticities. J Health Econ 1988:7:451-63.

77. Reeder CE, Nelson AA. The differential impact of copayment on drug use in a Medicaid population. Inquiry $1985 ; 22 ; 396-403$

78. Beck RG. The effects of co-payment on the poor. J Hum Resour 1974:9:129-42.

79. Farley PJ. Theories of the price and quantity of physician services. J Health Econ 1986:5:315-33.

80. Mooney G. Economics, medicine, and health care. Hertfordshire: Harvester Wheatsleaff, 1992.

81. Christensen S. Volume responses to exogenous changes in medicare's payment policies. Health Serv Res 1992;27:65-79.

82. Soumerai SE, Ross-Degnan D, Fortess EE, Abelson J. A critical analysis of studies of state drug reimbursement policies: research in need of disciplines. Milbank Q 1993;71:217-52.

83. Ginsburg PB, Manheim LM. Insurance, copayment, and health services utilization: a critical review. J Econ Bus $1973 ; 25: 142-53$.

84. Deaton $A$, Muellbauer J. Economics and consumer behavior. Cambridge: Cambridge University Press, 1980.

85. Smith DG, Rose LC. The effects of insurance palicy limits on product choice. J Risk Insur 1986;53:514-20.

86. Mirmirani S, Ott AF. Hospital care inflation in the United States: price adjustments in a disequilibrium. Appl Econ $1990 ; 22: 1567-75$.

87. Sauerborn R, Nougtara A, Latimer E. The elasticity of demand for health care in Burkina Faso: differences across age and income groups. Health Policy Plann 1994;9:185-92.

88. Wells KB, Manning WG, Valdez RB. The effects of insurance generosity on the psychological distrass and psychological well-being of a general population. Arch Gen Psychiat $4989 ; 46: 315-20$.

89. Roddy PC, Wallen J, Meyers SM. Cost sharing and use of health services: the United Mine Workers of America Health Plan. Med Care 1986;24:873-6.

90. Waddington C, Enyimayew KA. A price to pay, part 2: the impact of user charges in the Volta region of Ghana. Int J Health Plan Man 1990;5:287-312.

91. Watt $J$, Dixon $F$, Thompson $R$, Burgess $C_{r}$, Beasley $R$. The effect of the increased prescription charges on the collection of asthma drugs. New Zeal Med J 1992:105:153-4.

92. Foxman $B$, Valdez RB, Lohr KN, et al. The effect of cost sharing on the use of antibiotics in ambulatory care: results from a population-based randomized controlled trial. J Chron Dis 19:87:40:429-37.

93. Lohr KN, Brook RH, Kamberg CJ, et al. Use of medical care in the Rand Health Insurance Experiment: diagnosism and service-specific analyses in a randomized controlled triall. Med Care 1986:24:S1-S87.

94. Doerpinghaus HI. Effect of ambulatory surgery policy prowisions on medical expense insurance claims. J Risk Insur $1990 ; 57: 608-22$.

95. Litvack ul, Bodart $\mathrm{C}$. User fees plus quality equals improved access to health care: results of a field experiment in Cameroon. Soc Sici Med 1993;37:369-83

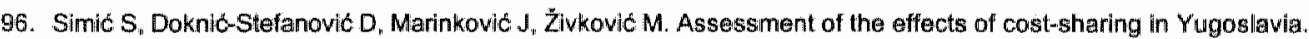
Med Care 1988;26:148-58.

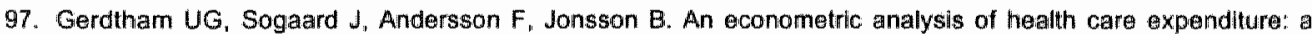
cross-section study of the OECD countries. J Health Econ 1992;11:63-84.

98. Pfaff M. Differences in health care spending across countries: statistical evidence. I Health Polit Polic $1990 ; 15: 1-67$.

99. Wagstaff $A_{n}$ van Doorslaer $E$. Equity in the finance of health care: some international comparisons. I Health Econ 1992:11:361-87.

100. Joint National Committee. The fifth report of the Joint National Committee on detection, evaluation, and treatment of high blood pressure. Arch Intern Med 1993;153:154-83.

101. Rutan GH, Kuller LH, Neaton JD, et al. Mortality associated with diastolic hypertension and isolated systolic hypertension among men screened for the Multiple Risk Factor Intervention Trial. Circulation 1988;77:505-14.

102. World Health Organisation. World health statistics annual. Geneva: WHO, 1990. 


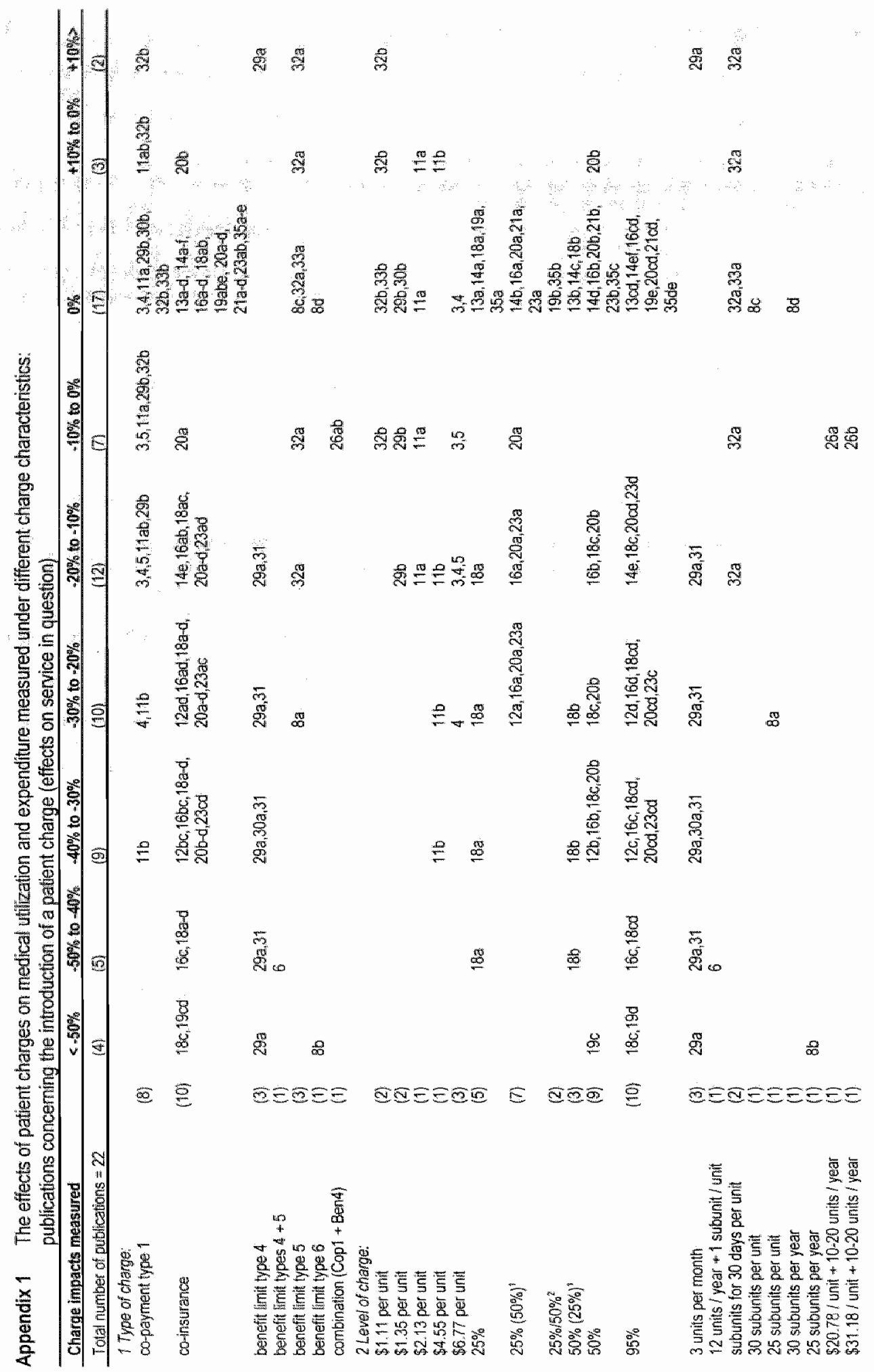




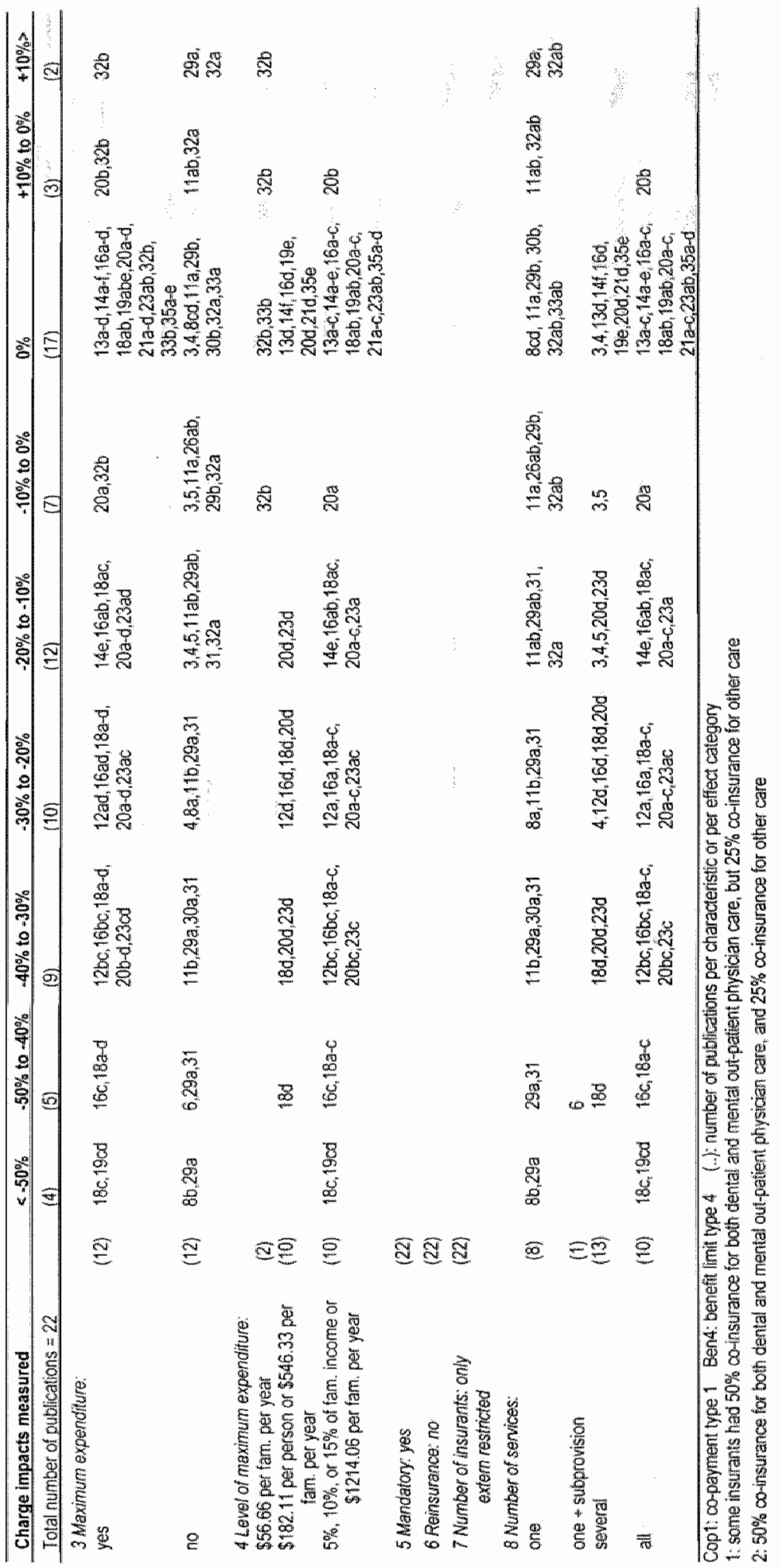




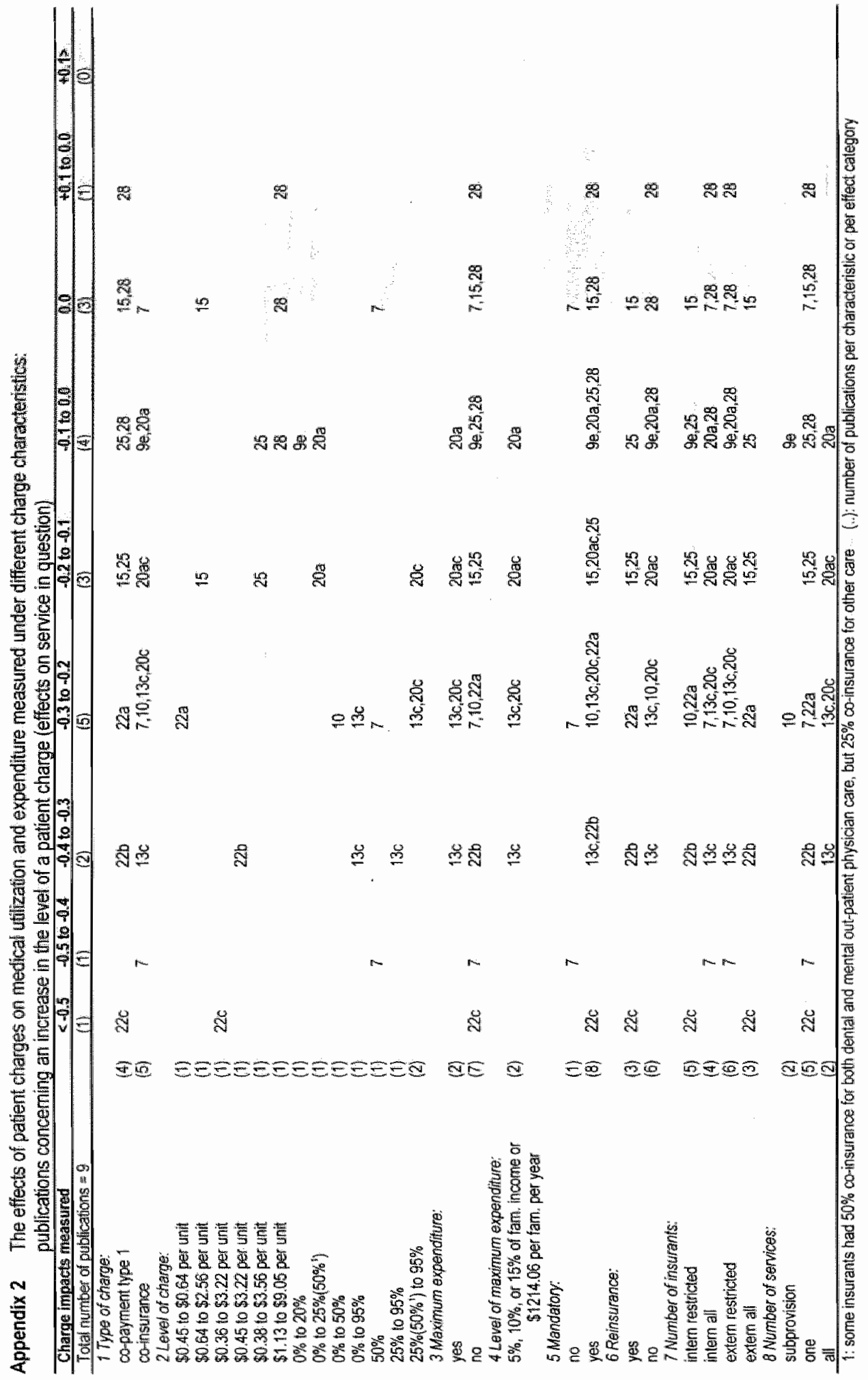




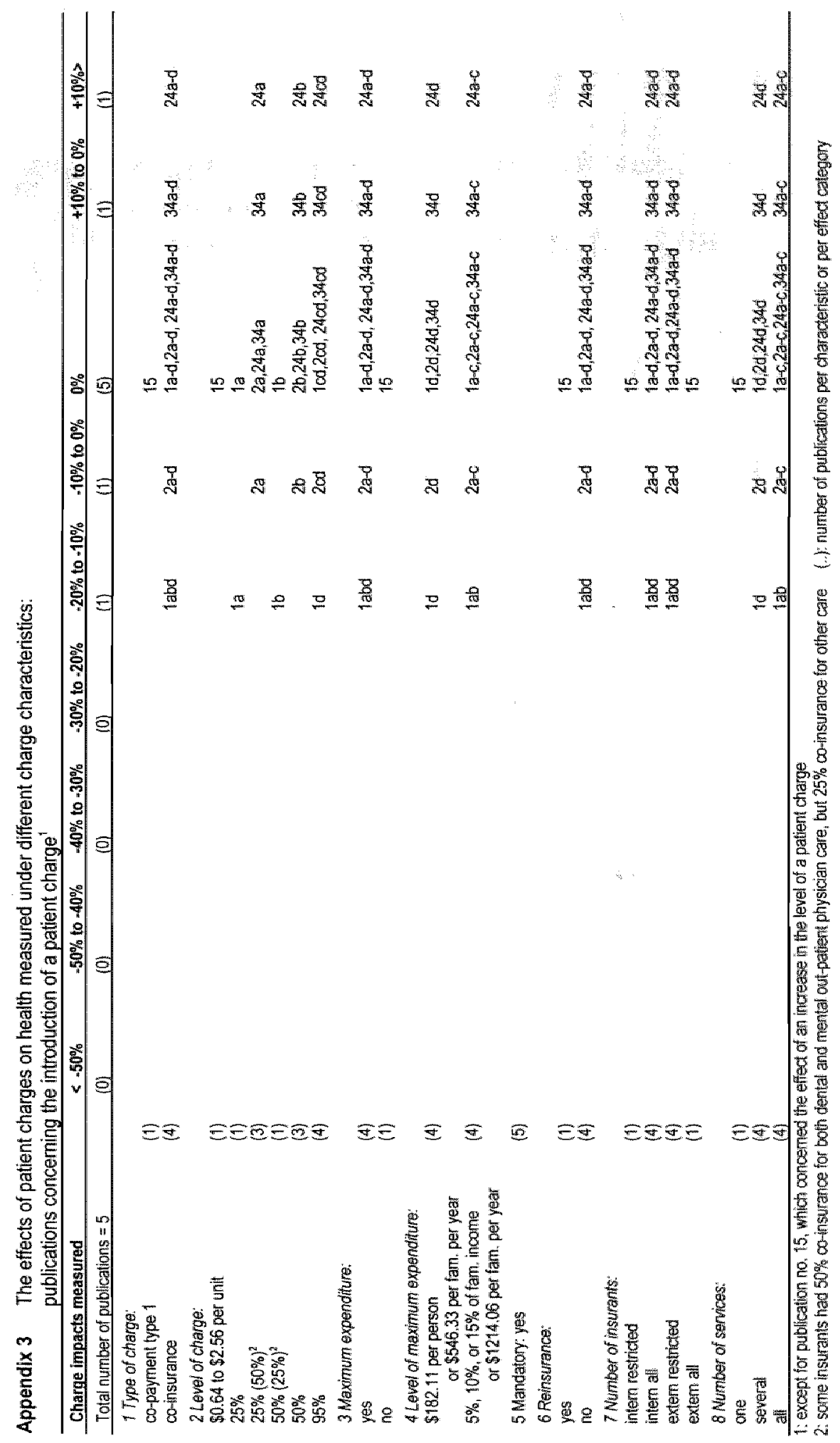



Co-payment effects on the utilization of orthopaedic shoes:

evidence in Limburg, The Netherlands

(Based on: Starmans HBG, Verkooijen JMHFM. Hel effect van eigen betalingen in de Nederlandse gezondheidszorg: casus orthopedisch schoeisel. Tijdschrift voor Sociale Gezondheidszorg 1990;68:383-8) 


\begin{abstract}
Up to 1997 patient charges for orthopaedic shoes (OS) in the Dutch sickness fund insurance scheme comprised of a combination of a co-payment and a benefit limit On the one hand, insurants had to pay a fixed amount of money for each pair of shoes. On the other hand, there was a maximum reimbursement of 1 pair of OS per insurant per year. On 1 January 1981 the nominal level of the co-payment was considerably increased, after it had remained constant for many years. For insurants aged 16 years and over, the level changed from NLG 35 to NLG 150 per pair (16 to 67 in 1995 US\$). The effects of this increase on the number of requests for OS were investigated in the province of Limburg by means of an interrupted time-series analysis.
\end{abstract}

It was demonstrated that the use of OS remained constant in the period before the increase in the co-payment level, although an obvious seasonal pattern could be recognised. Immediately thereafter, however, it showed a decreasing trend. After 3 years the total number of requests was $37 \%$ lower than in the previous period. The long term patient-charge-level-elasticity of this number was -0.10 . The largest reduction was measured among the elderly $(-43.5 \%)$.

\title{
Introduction
}

With the effort of the Dutch and other national governments to control public health care expenditure, the discussion on whether or not to introduce or increase patient charges regularly plays a role. An important question is whether patient charges only result in a shifting in the finance of care (from collective means to the patient) or that they can also result in a reduction in total expenditure on medicall care (by reducing medical utilization). Research in this field, especially done in the United States, suggests that patient charges may indleed lead to a decrease in medical consumption of the health care provisions involved (e.g. 1-6). So far, the effects of patient charges in the Dutch health care system have not been investigated extensively. The Dutch studies, for example, mainly focussed on the consumption of prescription drugs and out-patient primary physician care (e.g. 7-12).

The present study measured the effects of an increase in the level of a co-payment for orthopaedic shoes (OS) for Dutch sickness funds insurants on 1 January 1981. The effects on the number of requests for OS were investigated at the four sickness funds in Limburg (the southern part of The Netherlands). In the period from 1 January 1966 to 1 January 1981, for sickness fund insurants aged 16 years and over, a co-payment of NLG 35 for each pair of OS was in force. The copayment was combined with a maximum reimbursement (benefit limit) of 1 pair of OS per insurant per year. Below the age of 16 the co-payment level was NLG 15 to NLG 30, depending on the precise age of the insurant (13). On 1 January 1981 the co-payment level was increased from NLG 35 to NLG 150 (16 to 67 in 1995 US\$) for insurants aged 16 years and over, and was increased to NLG 75 (33 in 1995 US\$) for all insurants below the age of 16 years. In addition, the level was annually adapted for inflation from that date (14). During the study period the gross-price of 1 pair of OS amounted to approximately NLG 1000 (444 in 1995 US\$).

The study analyzed the effects of increasing the co-payment level from NLG 35 to NLG 150 per pair of OS. This means that the study population consisted of insurants with a medical indication for OS aged 16 years and over. Within the sickness funds of Limburg, the group of insurants with a medical indication for OS aged below 16 years, was too small to investigate the effect of the change in the co-payment level. During the period investigated, the sickness funds in Limburg counted approximately 600,000 insurants aged $\$ 6$ years and over, of whom approximately 5,500 with a medical indication for OS. 
In principle, only insurants who, because of a foot abnormality, can not wear (adapted) ready-made shoes, are eligible for a pair of OS. Whether or not an indication for OS is present, is determined by a physician on the basis of specific medical criteria. These criteria did not change during the study period. As insurants with a medical indication for OS can not wear (adapted) ready-made shoes, these shoes can principally not be a substitute for OS. If the level of co-payment for OS increases, however, this may result in a prolonged use of one pair of OS by the insurants. It is: expected that the introduction or the increase of a patient charge especially influences medical consumption when imedical care is mainly accomplished by the initiative of the patient $(15,16)$. Once an insurant owns a pair of $O S$, the initiative for the request for a new pair of OS is mainly one of the insurant. Therefore, the expectation was that the increase in the co-paymentlevel would lead to a less rapid request for a new pair of OS by insurants with a medical indication for OS. In addition, it was expected that this reduction would be larger, if the health status of the insurant is higher $(17,18)$. As age can be considered as a rough estimate of the health status of insurants (19), it was expected that the effect of the increase in the co-payment level would be the largest among non-ellerly.

\section{Method}

During the period under investigation a majority of the Dutch population (approximately $70 \%$ ) were covered by the sickness fund insurance scheme for various health care costs, such as costs of using primary physician care and orthopaedic shoes. Sickness fund insurants can be considered as low or middle income persons (e.g. in 1981 their income level was not higher than NLG 42,300 or 18,801 in 1995 US\$ - per family per year). Some groups of civil servants (approximately $5 \%$ of the population) had their own health insurance scheme. The remainder (approximately 25\%) of the population were privately insured. For exceptional health care costs, such as for hospital care lasting more than 1 year and nursing home care ${ }_{m}$ the entire Dutch population was compulsorily insured by an exceptional medical expenses insurance scheme. Both the sickness fund insurance plan and the exceptional medical expenses insurance plan were implemented by regional sickness funds.

Data are derived from the four sickness funds in Limburg. The use of OS was analyzed by means of an interrupted time-series analysis. More specifically, the use was analyzed in a three-year period before and a three-year period after the increase in the co-payment level. By means of a linear regression analysis the number of requests for OS in the second period was compared with the number that could have been expected on the basis of the first period. As the increase in the co-payment level was in force for all sickness funds in The Netherlands, it was not possible to create a control group.

Both the use of OS and the number of insurants with a medical indication for OS were measured quarterly for all insurants as well as for elderly and non-elderly separately. As the number of insurants with an indication changed during the study period, the usie of OS is expressed as the number of requests per 100 insuramts with an indication for OS. In addition, as the composition of the population of insurants with a medical indication also changed during the study period, because insurants joined and left, the use of OS among the steady group within the population was measured separately. The latter approach, however, did not lead to different results.

Apart from the increase in the co-payment, on 1 January 1981 other measures were introduced which could influence the use of $O S$. These measures are briefly described below. In addition, it is indicated which methods have been applied to correct for the possible influence of these measures. 
introduction of the necessify to motivate a request for orthopaedic shoes

In the period before "I January 1984 the maximum reimbursement of 1 pair of OS per insurant per year was applied very strictly. Requests for OS within one year were refused automatically, while requests after one year were automatically accepted. Since 1 January 1981 the benefit limit has been applied mainly as a directive. At most sickness funds in Limburg requests within one year were not refused automatically any more, but they had to be extra motivated, In addition, by a gradually more intensive review of the necessity of a provision, requests axfter one year were not always accepted any more. The more intensive review mainly contained that the sickness funds gradually asked more insurants to motivate their request (usually by demonstrating the old shoes). In order to correct for this need to motivate a request, not only requests which were accepted, but also requests which were refused, have been included for the use of OS. It could nat be checked, however, whether the insurants already requested less footwear in advance after some time.

\section{Introduction of a new regulation for spare pairs of onthopaedic shoes}

From 1976, at most sickness funds in Limburg all insurants with a medical indication for OS could request for one spare pair of OS via supplementary insurance (approximately $95 \%$ of the insurants was supplementarily insured). From 1 January 1981 this regulation was abolished. Only insurants receiving a pair of OS for the first time are allowed to request a spare pair. Once again, this spare pair is a provision given once. In order to correct for the possible influence of the new regulation for spare pairs on the use of OS, the number of requests for spare pairs was measured separately.

\section{Addition of orthopaedic working shoes to the sickness fund insurance plan}

Before 1 January 1981 the possibility existed to request for orthopaedlic working shoes on the basis of a disability insurance. Since 1 January 1981, however, orthopaedic working shoes have been covered by the sickness fund insurance plan. To keep comparable the study periods before and after 1 January 1981, requests for orthopaedic working shoes were not included.

\section{Results}

\section{The number of requests for orthopaedic shoes}

Figure 1 shows the total number of requests for OS per 100 insurants with a medical indication for this provision. Line A represents the number of requests excluding those for spare shoes ${ }_{\text {" while line }}$ $B$ represents the number of requests for spare shoes. The arrow at the first quarter of 1981 indicates the point in time where the co-payment level was increased. Figure 1 shows that the number of requests in the second and fourth quarter was generally higher than in the first and third quarter. Apparently, insurants requested for new footwear especially in the periods before the summer and before the winter. It seems that the number of requests for OS (excluding those for spare shoes) decreased gradually in the period after the increase in the patient charge.

As different regulations were in force for spare shoes before and after the change in the patient charge, it was not possible to determine the extent to which a change in the number of requests for these shoes was a result of the increase in co-payment level. Therefore, the regression analysis

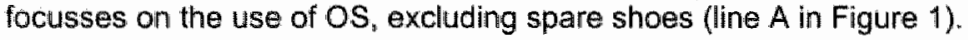

Figure 2 presents the total number of insurants with a medical indication for OS. It shows that this number increased considerably during the study period (from 4,612 in 1978 to 6,360 in 1983; an increase of $38 \%$ ). The increase appeared to be uniform during the entire study period. 


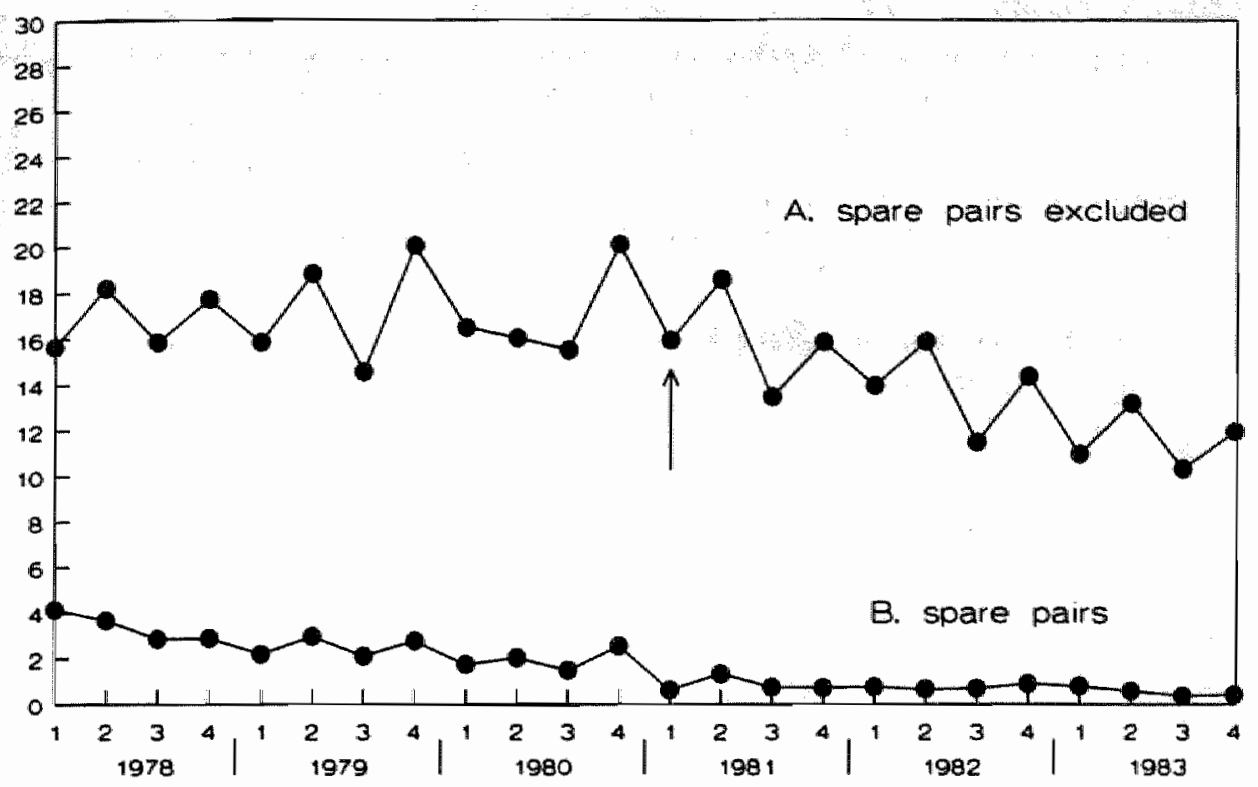

Figure 1 Number of requests for orthopaedic shoes per 100 insurants with a medical indication (note 1)

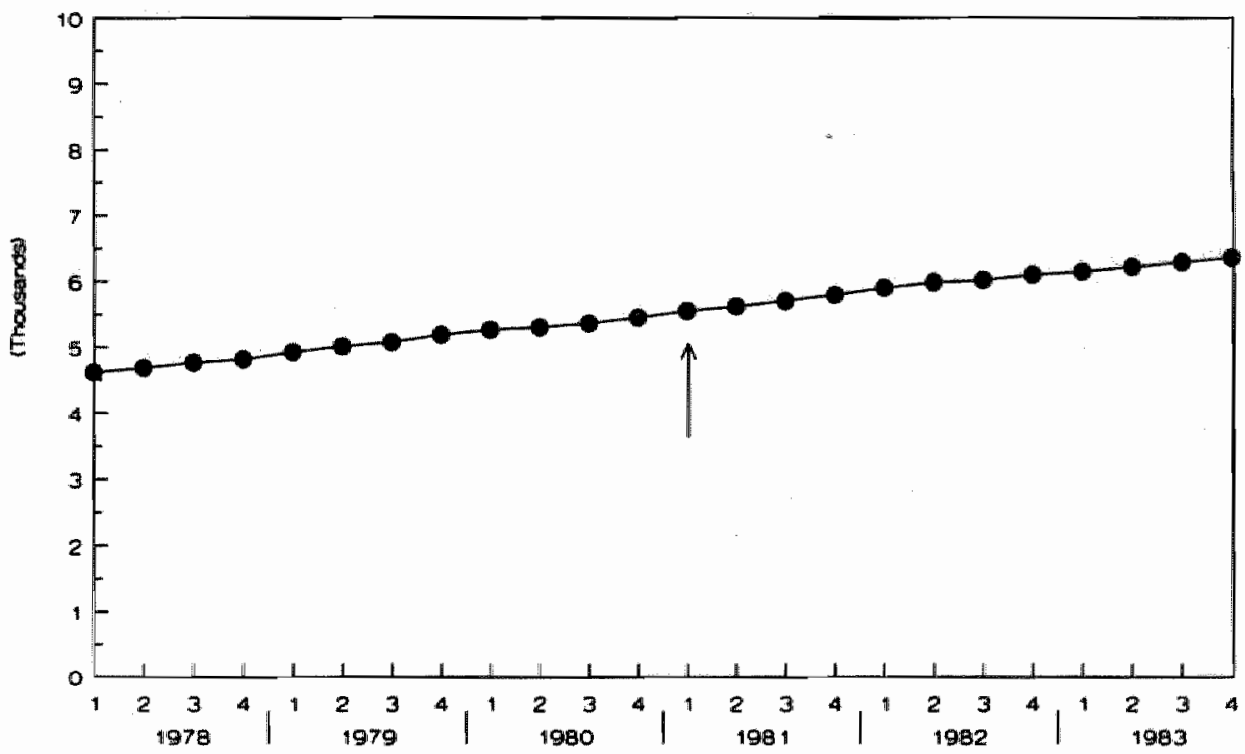

Figure 2 Number of insurants with a medical indication for orthopaedic shoes. 


\section{Results of regression analysis}

In order to determine whether the number of requests for OS (spare shoes excluded) in the period after the increase in the patient charge was significantly different from that in the previous period, finally a linear regression analysis was used in which the use of OS was log-transformed. Especlally for the different age categories separately, the use of OS was described best by using a combination of both a dummy variable for the level of the use of OS and a dummy variable for a trend in the use of OS in the period after the increase in the co-payment level. The results of the regression analysis are presented in table 1.

Tabie 1 Regression coefficients with respect to the natural logarithm of the use of orthopaedic shoes (t-values in parentheses)

\begin{tabular}{|c|c|c|c|}
\hline & $\begin{array}{l}\text { Total } \\
\text { (16-95 years) }\end{array}$ & $\begin{array}{l}\text { Adults } \\
\text { (116-65 years) }\end{array}$ & $\begin{array}{l}\text { Elderly } \\
\text { (66-95 years) }\end{array}$ \\
\hline intercept & 273410 & 2.79847 & 2.61235 \\
\hline Trend & $\begin{array}{l}0.000694512 \\
(0.14)\end{array}$ & $\begin{array}{l}0.00119570 \\
(0.21)\end{array}$ & $\begin{array}{l}0.00208947 \\
(0.35)\end{array}$ \\
\hline D second quarier & $\begin{array}{l}0.173600 \\
(5.98)^{* *}\end{array}$ & $\begin{array}{l}0.156984 \\
(4.61)^{* z}\end{array}$ & $\begin{array}{l}0.210802 \\
(5.98)^{* *}\end{array}$ \\
\hline D fouth quarter & $\begin{array}{l}0.199013 \\
(6.66)^{* k}\end{array}$ & $\begin{array}{l}0.218026 \\
(6: 22)^{* *}\end{array}$ & $\begin{array}{l}0.155366 \\
(4.28)^{* *}\end{array}$ \\
\hline D level & $\begin{array}{l}0.00614222 \\
(0.13)\end{array}$ & $\begin{array}{l}0.0754611 \\
(1.32)\end{array}$ & $\begin{array}{l}-0.147491 \\
(-2.49)^{* *}\end{array}$ \\
\hline D trend & $\begin{array}{l}-0.0426306 \\
(-6.21)^{* *}\end{array}$ & $\begin{array}{l}-0.0430030 \\
(-5.34)^{* *}\end{array}$ & $\begin{array}{l}-0.0385639 \\
(-4.63)^{* *}\end{array}$ \\
\hline $\mathrm{R}^{2}$ & 0.92 & 0.87 & 0.92 \\
\hline$F$ & $41.52^{* * *}$ & $23.29^{* 4}$ & $42,14^{* *}$ \\
\hline D.W." & 2.47 & 2.56 & 2.31 \\
\hline a & 24 & 24 & 24 \\
\hline
\end{tabular}

In table: 1 the intercept indicates the natural logarithm of the use of OS in the first quarter of 1978. The coefficient for the time variable $(T)$ indicates the average quarterly increase or decrease in the natural logarithm of the use in the period before the change in the patient charge. The value of $T$ varies from 0 (first quarter in 1978) to 23 (last quarter in 1983). The regression equation contained also dummies for the second and fourth quarter. The coefficients for these dummies show the extent to which the natural logarithm of the use of OS in these quarters was different from that in the remaining two quarters. The coefficient of the dummy for the level of the use indicates the extent to which the natural logarithm of the use in the first quarter of 1981 differs from that which could have been expected on the basis of the previous period. For that purpose the dummy for the trend in the use was multiplied with the time variable minus 12 . Finally, the coefficient of the dummy for the trend in the use of OS indicates the extent to which the trend in the natural logarithm of the use in the period following the increase in the patient charge differs from that in the previous period.

On the basis of the regression results, the number of requests for os per 100 insurants with a medical indication for this provision could be considered to be constant in the period before the increase in the patient charge. However, an obvious seasonal pattern was present: the use was significantly higher in the second and fourth quarter than in the other two quarters. Only among the elderly, the level of the use was significantly lower immediately after the increase in the patient 
charge. Nevertheless, among all insurants as well as among non-elderly and elderly separately, the trend in the use of OS significantly changed, namely from an almost constant use in the period before the increase in the patient charge to a declining use in the following period.

\section{Percentage change in the use of orthopaedic shoes}

On the basis of the regression equations, the use of OS in the period following the increase in the patient charge was compared with the use that would have been achieved when the pattern in the use, present before the increase in the patient charge, would have continued without change. Results are expressed as the percentage change in the use of OS and are presented in table 2.

Table 2 Percentage change in the use of orthopaedic shoes after the increase in co-payment

\begin{tabular}{|c|c|c|c|c|c|}
\hline & $\begin{array}{l}\text { 1st qut } \\
1981\end{array}$ & $\begin{array}{c}\text { 2nd qut } \\
1981\end{array}$ & $\begin{array}{l}\text { 4th qrit } \\
\text { t981 }\end{array}$ & $\begin{array}{l}\text { 4th qrt } \\
\text { t9882 }\end{array}$ & $\begin{array}{c}\text { 4th ant } \\
1983\end{array}$ \\
\hline & $\%$ & $\%$ & $\%$ & $\%$ & $\%$ \\
\hline $\begin{array}{l}\text { Total } \\
\text { (16-95 years) }\end{array}$ & 0.6 & -3.6 & -115 & -25.3 & -37.0 \\
\hline $\begin{array}{l}\text { Adults } \\
\text { (16-65 years) }\end{array}$ & 7.8 & 3.3 & -52 & -20.2 & -328 \\
\hline $\begin{array}{l}\text { Elderly } \\
\text { (66-95 years) }\end{array}$ & -13.7 & -17.0 & -23.1 & -34.1 & -43.5 \\
\hline
\end{tabular}

Table 2 shows that among the elderly, the level of the use of OS was $13.7 \%$ lower immediately following the increase in the patient charge (first quarter of 1981). On the long term, also the use among non-elderly decreased considerably. In the fourth quarter of 1983 the use of OS was $32.8 \%$ and $43.5 \%$ lower among non-elderly and elderly, respectively. Although the results in table 2 within the different age categories diverge on the short term, they more and more correspond with each other on the long term. At the end of the period investigated, total utilization of OS was $37 \%$ lower than could have been predicted from the period before the increase in the patient charge.

Usually, in case of relatively small changes in a patient charge level, patient-chargemlevelelasticities are calculated. These elasticities indicate the percentage change in medical consumption due to a 1 percentage change in the level of a patient charge. Although the increase in the co-payment level in the present study was considerably (even more than $300 \%$ ), table 3 shows the values of the arc-co-payment-level-elasticities. These elasticities are calculated on the basis of the outcomes in table 2 .

Table 3 Co-payment-lewel-elasticity of the use of orthopaedic shoes

\begin{tabular}{|c|c|c|c|c|c|}
\hline & $\begin{array}{c}\text { 1st qrt } \\
1981\end{array}$ & $\begin{array}{c}\text { 2nd qrith } \\
1981\end{array}$ & $\begin{array}{l}\text { 4th qurt } \\
1981\end{array}$ & $\begin{array}{l}\text { 4th qirt } \\
1982\end{array}$ & $\begin{array}{c}\text { 4th qirt } \\
1983\end{array}$ \\
\hline $\begin{array}{l}\text { Total } \\
\text { (16-95 years) }\end{array}$ & 0.00 & -0.01 & -0.03 & -0.07 & .0 .10 \\
\hline $\begin{array}{l}\text { Adults } \\
\text { (16-65 years) }\end{array}$ & 0.02 & 0.01 & .0 .02 & $-0,06$ & .000 \\
\hline $\begin{array}{l}\text { Elderly } \\
\text { (66.95 years) }\end{array}$ & -0.04 & -0.05 & -0.07 & -0.10 & -0.12 \\
\hline
\end{tabular}




\section{Conclusion}

Up to 1 January 1981, when the patient charge for orthopaedic shoes (OS) was increased, the number of requests for these shoes (spare shoes and working shoes excluded) at the four sickness funds in Limburg remained constant, although an obvious seasonal pattern could be recognised. After the considerable increase in the co-payment level (from NLG 35 to NLG 150 per pair), the utilization of OS was hardly lower during the first half year, but showed a significant decreasing trend. This finding corresponds with Deaton (20) who argued that a consumer may not immediately reduce (medical) consumption following a price change, because of being accustomed to it. After 3 years the utilization of OS was reduced by $37 \%$. The reduction in the number of requests and also the long term patient-charge-level-elasticity calculated $(-0.10)$ correspond with the findings of most of the prevlous studies: However, studies which distinguished short-term and long-term charge effects usually showed an immediate, permanent reduction in consumption instead of a gradually decreasing trend (e.g. $3,5,6)$.

Both among non-elderly and elderly, the use of OS showed a decreasing trend after the increase in the patient charge. In contrast to the expectations mentioned in the introduction section, however, the largest reduction was measured among the elderly. After 3 years the number of requests for OS was reduced by $32.8 \%$ and $43.5 \%$ among the non-elderly and the elderly, respectively. In addition, only among the elderly the use of OS was significant lower $(-13.7 \%)$ immediately after the increase in the patient charge. An explanation for the larger reduction among the elderly may be that - due to a lower average health status - they are less mobile than the nonelderly. As a consequence, the elderly generally wear out their shoes less quickly, which means that it is easier for them to reduce the number of requests for OS in case of an increase in copayment. Another explanation may be that the elderly generally had a lower income level than the non-elderly. According to Gertler (21) and Phelps (22), the effect of a patient charge can be expected to be largest among low income insurants. Income information for different age categories was not available, however, at the sickness funds.

Although the reduction in the use of OS following the increase in the patient charge corresponds with the findings in most of the previous studies, it is possible that also the introduction of the necessity to motivate a request for os plaid a role. There has been corrected for the possible influence of this measure by including the number of requests refused, but it may be that this measure had a preventive effect which was larger than the number of refusals registered.

\section{Note}

1. The number of requests is determined by summing up the number of accepted requests and the number of requests, refused after judgement. The time interval between date of request and date of acceptance or refusal by the sickness funds is approximately 14 working days. The figure shows the date of acceptance or refusal. With the change from 1980 to 1981 a few sickness funds stated that the date of request was determining the level of the patient charge. Therefore, a number of requests accepted in the first quarter of 1981 is related to the old patient charge regulation. 


\section{References}

1. Cherkin DC, Grothaus L, Wagner EH. The effect of office visit copayments on utitization in a health maintenance organization. Med Care 1989:27:669-79.

2. Lavers RJ. Prescription charges, the demand for prescriptions and morbidity. Appl Econ 1989,21:1043-52.

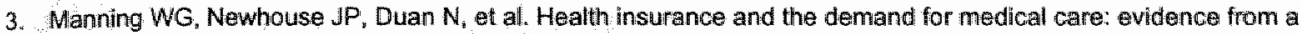
randomized experiment. Am Econ Rev 1987;77:25:-77.

4. O'Grady KF, Manning WG, Newhouse JP. Brook RH. The impact of cost sharing on emergency department use. Niew Engl J Med 1985;313:484-90.

5. Scitovsky AA, Snyder NM. Eftect of coinsurance on use of physician senvices. Soc Security Bull 1972;35.3-19.

6. Scitovsky AA, McCall N. Coinsurance and the demand for physician services four years lalter. Soc Securily Bull $1977 ; 40: 19-27$

7. van den Berg J. De eigen bijdrage voor geneesmiddelen in 1983 (The co-payment for prescription drugs in 1983 ). Tijdschr Soc Gezondheildsz 1985;63;4-12.

8. de Klein JJM, Collaris JWM. Evaluatie van de eigen bijdrage-maatregel farmacie (Evaluation of the coupayment regulation for prescription drugs). Zeist: Vereniging van Nederlandse Ziekentondsen, Afdeling Beleidsinformatie: - Onderzoek, 1984.

9. Mootz $\mathrm{M}$. The need for health care utilization and its relation to insurance coverage for medical expenses. Gezondh Samenl $1985 ; 6: 232-7$.

10. Post D. Vijf jaar prescriptie: valume- en kosterveranderingen in een ziekenfondsreglo (Five yaars of presctiption: changes in volume and expenditure in a Dutch sickness fund region). Med Contact 1986:4 1:4103-4.

11. van de Ven WPMM, van der Gaag J. Health as an unobservable: a MIMIC-model of the demand for health care. $J$ Health Econ 1982;1:157-83.

12. van Vliet RCJA, van de Ven WPMM. Consumptieverschillen tussen ziekenfonds- en particulier werzekerden nader onderzocht: overzicht van empirische bevindingen (Further analysis of differences in medical consumption between sickness funds insurants and privale insurants). Gezondh Samenl 1986;7:81-94.

13. Ministerie wan Sociale Zaken en Volksgezondheid. Beschikking Kunst- en Hulpmiddelen Ziekenfondswerzekering (Order on medical supplies in the Dutch Sickness Fund Insurance Act). Ned Staztscourant 1966(5)" $1=2$.

14. Ministerie van Volksgezondheid en Milieuhygiëne. Besluit Kunst- en Hulpmiddelen Ziekentondswerzekering 1981 (Decree on medical supplies in the Dutch Sickness Fund Insurance Act 1981). Ned Staatscourant 1980(249):10-2.

15. Duan N, Manning WG, Morris CN, Newhouse JP. A comparison of alternative models for the demand for medical care. \Bus Econ Stat 1983;1:115-26.

16. Feldstein MS. Econometric studies of thealth economics. In: Intrilligator MD, Kendrick DA, eds. Frontiers of quantitative economics. v. 2. Amsterdam; North-Holland Publishing Company "1974:377-434.

17. Grossman M. On the concept of health capital and the demand for health. J Polit Econ $1972 ; 80: 223-55$.

18. Wedig G.J. Health status and the demand for health: results on price elasticities. Health Econ $1988_{*}, 7: 151-63$.

19. Akin JS, Guilkey DK, Griffin CC, Popkin BM. The demand for primary health services in the thind world. Totowa, Now Jersey: Rowman and Alanheld: 1985.

20. Deaton A, Muellbauer J. Economics and consumer behavior. Cambridge: Cambridge University Prosis, 1980.

21. Gertler P, Locay L, Sanderson W. Are user fees regressive? The welfare implications of health care financing proposals in Peru. J Econometrics 1987"36:67-88.

22. Phelps CE, Newhouse JP. Coinsurance, the price of time and the demand for medical services. Rev Econ Stat $1974,56: 334-42$. 
.....

$\cdots+2$ 


\section{Co-payment effects on the utilization of out-patient specialist physician care: evidence in Limburg, The Netherlands}

(Based on: Starmans HBG, Verkooijen JMHFM, VanderBroeck MJAP. Het effect van eigen betalingen in de Nederlandse gezondheidszorg: casus poliklinische specialistenhulp. Tijdschrift voor Sociale Gezondheidszorg 1993;71:223-30) 


\section{Abstract}

On 1 February 1988 a patient charge was introduced for out-patient specialist physician care in the Dutch sickness fund insurance scheme. This patient charge was in force until 1 January 1990 and consisted of a co-payment of NLO 25 (10 in 1995 US\$) per referral to a specialist, to a maximum of NLG 75 (31 in 1995 US\$) per family per year. At 3 sickness funds in the south and middle of Limburg the effect of the introduction of the co-payment on the number of referrals to specialists was determined by means of interrupted time series analyses. Also a sickness fund in the province of Zuid-Holland was included in the study, because this fund covered the patient charge under an optional supplementary insurance plan (over $90 \%$ of the insurants were supplementarily insured).

In general, no effect of the co-payment on the utilization of out-patient speciallist physician care could be demonstrated. At 2 sickness funds in Limburg as well as at the sickness fund in ZuidHolland the level of the total number of referrals in 1988 was lower than in the previous period. This reduction could be explained, however, by an incomplete registration at the sickness funds due to a conflict between these funds on the one hand and medical specialists on the other hand. At the third sickness fund in Limburg, where no specialists conflict was in force, the use of out-patient specialist physician care in the period of the co-payment was not significantly different from that in the previous and following period. Only for ophthalmology there was a significant drop (approximately $9 \%$ ).

\section{Introduction}

With the effort of the Dutch and other national governments to control public health care expenditure, the option of introducing or increasing patient charges has been regularly discussed. An important question in the discussion on patient charges is whether a charge will only result in a shifting in the finance of care (from collective means to the patient) or that it will also result in a decrease in total health care expenditure (by a decrease in the utilization of medical goods and services). The results of foreign, mostly American, studies suggest that the introduction or the increase of patient charges may indeed lead to a reduction in the consumption of health care provisions (e.g. 1-6). So far, the effects of patient charges in the Dutch health care system have not been investigated extensively. The Dutch studies, for example, mainly focussed on out-patient primary physician care and prescription drugs (e.g. 7-12).

The present study investigated the effects of introducing a co-payment for out-patient specialist physician care (OSPhC) for Dutch sickness fund insurants. For this health care provision sickness fund insurants need a referral, usually from a primary care physician. The effects of the co-payment on the number of referrals to specialists were investigated at three sickness funds in the south and middle of Limburg (the southern part of The Netherlands) and one sickness fund in Zuid-Holland (the middle west part of The Netherlands). The charge was introdluced on 1 February 1988 and was in force until 1 January $1990(13,14)$. It consisted of NLG 25 (10 in 1995 US\$) per referral to a specialist, to a maximum of NLG 75 (31 in 1995 US\$) per family per year (note 1).

Several non-Dutch studies have demonstrated that a patient charge for out-patient physician care (frequently in combination with other types of out-patient care or in combination with in-patient physician care) may result in a reduction in the utilization of out-patient physician care (e.g. 1,5 , $6,15-17)$. When different types of out-patient physician care were distinguished, however, it appeared that the use of specialist physician care decreased much less than that of primary physician care $(15,17)$. Beck (15) showed that the introduction of a co-payment of $\$ 2.25$ to $\$ 3$ (in 1995 US $\$$ ) for out-patient physician care resulted in a decrease of $14 \%$ in the number of primary physician visits. The number of specialist physician visits, however, was not significantlly reduced. Cherkin (17) demonstrated that the introduction of a co-payment of $\$ 7$ (in 1995 US\$) for out-patient 
physician care (and other out-patient care) resulted in a decrease of $11 \%$ in the number of primary physician visits. Once again, however, the number of specialist physician visits was not significantly reduced.

The different outcomes for the two types of out-patient physician care may be explained by the larger influence which patients have on the decision for using primary physician care than on the decision for using specialist physician care. In the latter studies $(15,17)$ the insurants usually or even always needed a referral in order to use specialist physician care. According to Duan (18) and Feldstein (19), the introduction or the increase of a patient charge especially influences medical consumption when medical care is mainly accomplished by the initiative of the patient.

As Dutch sickness funds insurants also need a referral for using out-patient specialist physician care, it was expected that the use of this type of care would only be slightly reduced by the introduction of the patient charge. As the co-payment of NLG 25 was indebted as soon as the insurant visited the specialist and not at the moment of the referrall, the use of out-patient specialist physician care was measured in the number of referrals which were actually followed by a physician visit. This means that the use of out-patient specialist physician care was measured in the number of referrals reimbursed by the sickness funds (note 2).

\section{Method}

During the period under investigation a majority of the Dutch population (approximately $70 \%$ in the period before April 1986 and approximately $62 \%$ in the period thereafter) were covered by the sickness fund insurance scheme for various health care costs, such as costs of using primary physician care and specialist physician care. Sickness fund insurants can be considered as low or middle income persons (e.g. in 1988 their income level was not higher than NLG 49,650 - or 20,383 in 1995 US $\$$ - per family per year). Some groups of civil servants (approximately $5 \%$ of the population) had their own health insurance scheme. The remainder of the population were privately insured. For exceptional health care costs, such as for hospital care lasting more than 1 year and nursing home care, the entire Dutch population was compulsorily insured by an exceptional medical expenses insurance scheme. Both the sickness fund insurance plan and the exceptional medical expenses insurance plan were implemented by regional sickness funds.

The study was carried out at 'Algemeen Ziekenfonds voor de Mijnstreek' (AZM) in Heerlen (approximately 210,000 insurants), "Centraal Ziekenfonds' (CZF) in Sittard (approximately 260,000 insurants) and 'Ziekenfonds Zuid-Limburg" (ZZL) in Maastricht (approximately 100,000 insurants). In addition, 'Ziekenfonds Delftland, Schieland en Westland" (DSW) in Schiedam (approximately 210,000 insiurants) was included in the study, because this sickness fund covered the co-payment for out-patient specialist physician care (OSPhC) under supplementarily insured persons immediately from 1 February 1988 . From this date more than $90 \%$ of the insurants of DSW were supplementarily insured.

The effect of the introduction of the co-payment on the utilization of OSPhC was determined by means of interrupted time-series analyses. With regression analysis the level of the use in the period of the co-payment was compared with the level that could have been expected on the basis of the previous and/or following period. With the time-series analyses corrections could be made for the presence of an increasing or a decreasing trend in the use of out-patient specialist physician care during the study period. If the period before or after the introduction of the co-payment was too short at a sickness fund to detect a trend in the use, the level of the use in the period of the copayment was compared with the level in the previous or following period by means of a t-test. In the study 13 different types of specialist physician care were distinguished: (1) ophthalmology, (2) ear, nose and throat (ENT) treatment, (3) surgery, (4) orthopaedics, (5) urology, (6) gynaecology. 
(7) psychiatry (neurology included), (8) dermatology, (9) internal medicine, (10) paediatrics, (11) cardiology, (12) pulmonology and (13) oral/dental surgery (note 3).

Observational data from the sickness funds during the study period consisted of monthly, quarterly, semi-annual and annual figures. In order to compare the different types of data and to correct for the changes in the number of sickness fund insurants during the study period, at each sickness fund the average numbers of referrals to specialists per month per 10,000 insurants were calculated. An important change in the number of insurants occurred on 1 April 1986. On that date a part of the sickness fund insurants were obliged to switch to a private health insurance organisation. This switch was due to the introduction of a new law (the "Wet Toegang Ziektekostenverzekering") concerning the access to health insurance.

Apart from the introduction of the patient charge and modifications in the number of sickness fund insurants, the use of out-patient specialist physician care could possibly also have been influenced by changes in the density of specialists and primary care physicians in the sickness funds regions $(20,21)$. At three sickness funds (AZM, CZF and DSW) the number of specialists working in the associated sickness fund regions, however, could not be well determined from July 1987, because of the so-called specialists conflict (22). From that date many specialists working fee-for-service had cancelled their agreements with the sickness funds. These agreements regulated the direct payment of specialists' costs by the sickness funds. Nevertheless, at the fourth sickness fund (ZZL) the number of specialists could be easily determined because most of the insurants were referred to salaried specialists in the academic hospital in Maastricht. As there was no specialists conflict in academic hospitals, only data on the number of referrals to specialists working in the academic hospital in Maastricht were analyzed at ZZL.

As a consequence of the specialists conflict on July 11987 , several specialists working fee-forservice sent their bills to the insurant and not directly to the sickness fund any more. It is the question to what extent the insurants have subsequently declared these bills to the sickness funds. It is possible that at AZM, CZF and DSW not all the bills have been declared and, thus, not all referrals have been registered from July 1 1987. Especially as a consequence of the introduction of the co-payment on 1 February 1988, the amount of money the insurant could declare to the sickness funds had frequently become rather small (note 4). As stated before, in the academic hospital in Maastricht no specialists conflict was in force. Consequently, the above mentioned problem of registration did not occur at ZZL. For several specialists involved in the specialists conflict a so-called assignment regulation was established after some time. Such a regulation implied that the specialist was again authorized by the insurant to declare the costs of care (minus the co-payment of NLG 25) directly to the sickness fund. At DSW it was possible to distinguish between referrals to specialists with and without an assignment regulation. By analysing the referrals to both groups of specialists separately, it was possible to determine from the DSW-data to what extent the registration was complete.

At AZM and CZF the extent to which the level of using OSPhC in 1988 (the first year of the patient charge) was different from the level that could have been expected on the basis of the period from 1983 to 1987 was determined by means of a linear regression analysis. At DSW the level of the use in 1988 was compared with the level in the period from 1986 to the first half of 1987 by means of at-test. At ZZL the level of the use in the period of the co-payment (the second quarter of 1988 to 1989) was compared with the level that could have been expected on the basis of 1985 and the period from January to October 1990 by means of a linear regression analysis. In the regression equations for the ZZL data, both the number of specialists in the academic hospital in Maastricht and the number of primary care physicians having an agreement with $\mathrm{ZZL}$ for the reimbursement of care, were included as independent variables (table 1). At ZZL the referrals to specialists in the periad from 1986 to the first quarter of 1988 were not included because of a disturbed registration 
of the number of referrails at this sickness fund. The disturbance was a consequence of the hospital in Maastricht which became academic in 1986.

Table 1 The number of primary care physicians (PPh) having an agreement with $\mathrm{ZZL}$ and the number of special care physicians (SPh) in the academic hospital in Maastricht

\begin{tabular}{lcccc}
\hline Year & 1985 & 1988 & 1989 & 1990 \\
\hline Number of PPh & 71 & 75 & 71 & 75 \\
\hline Number of SPh & & & & \\
Ophthalmology & 4 & & 4 & 4 \\
ENT disease & 3 & 5 & 6 & 6 \\
Surgery & 12 & 4 & 23 & 18 \\
Orthopaedics & 5 & 18 & 7 & 7 \\
Urology & 2 & 6 & 4 & 5 \\
Gynaecollogy & 9 & 4 & 11 & 12 \\
Psychiatry & 9 & 10 & 17 & 44 \\
Dermatology & 4 & 12 & 4 & 27 \\
Internal medicine & 21 & 4 & 26 & 14 \\
Paedialrics & 9 & 21 & 14 & 17 \\
Cardiology & 11 & 13 & 4 & 4 \\
Pulmonology & 3 & 15 & 2 & 2 \\
Oraldental surgery & 3 & 5 & 139 & 134 \\
\hline Total & 95 & 3 & 120 & \\
\hline
\end{tabular}

\section{Results}

\section{The use of out-patient specialist physician care among the insurants of AZM and CZF}

For $A Z M$ and $C Z F$ the results of the regression analysis of the use of OSPhC with respect to all types of specialist care together are shown in table 2 (notes 5 and 6 ). The coefficient for the trend indicates the average monthly increase or decrease in the use of OSPhC. The coefficient for the effect-dummy indicates the extent to which the level of the use of OSPhC after the intraduction of the co-payment differed from the level that could have been expected on the basis of the previous period. For AZM also quarterly-dummies were included in the regression equations (only quarterlydummies of which the corresponding coefficient was significant). The coefficient for a quarterlydummy indicates the extent to which the use of OSPhC in the quarter involved differed from that in one or more of the other quarters.

Table 2 Regression coefficients with respect to the use of out-patient specialist physician care among the insurants of AZM and CZF ( $t$-values in parentheses)

\begin{tabular}{|c|c|c|c|c|c|c|c|c|}
\hline $\begin{array}{l}\text { Sickness } \\
\text { fund }\end{array}$ & Intercept & Trend & $\begin{array}{l}\text { D-fourth } \\
\text { quarter }\end{array}$ & D-effect & $\mathbf{R}^{2}$ & $F$ & D. W: & $\mathrm{n}$ \\
\hline$A Z M$ & 426,96 & $\begin{array}{l}-0.19 \\
(-1.01)\end{array}$ & $\begin{array}{c}19.09 \\
(2.72)^{*}\end{array}$ & $\begin{array}{c}-31.87 \\
(-3.11)^{\mathrm{k}}\end{array}$ & 0.71 & $12.48^{4 *}$ & 1.79 & 19 \\
\hline $\mathrm{CZF}$ & 411.48 & $-0.09^{b}$ & & $-59.98^{b}$ & $0.87^{\mathrm{b}}$ & & 2.80 & 6 \\
\hline
\end{tabular}


For AZM as well as for CZF the use of OSPhC in the period before the introduction of the patient charge could be considered constant. Nevertheless, at AZMI a seasonal pattern could be recognized: the use of OSPhC was significantly higher in the fourth quarter than in the remaining quarters. In addition; it appeared that at both sickiness funds the level of the total use of OSPhC after the introduction of the patient charge was (significantly) Jower than could have been expected on the basis of the previous period. The percentage change in the total level of OSPhC (the difference between the observed level and the predicted level in 1988) was $-7.60 \%$ for AZM and $-14.80 \%$ for $\mathrm{CZF}$.

Table 3 also shows the percentage changes in the use of OSPhC at AZM and CZF for the different types of specialist care separately. Except for psychiatry and oral/dental surgery at AZM, for all types of specialist care and at both sickness funds the level of the use of OSPhC was (significantly) lower than could have been expected on the basis of the period before the introduction of the patient charge.

Table 3 Percentage change in the use of out-patient specialist physician care per sickness fund and per type of specialist care in the period following the introduction of co-payment

\begin{tabular}{|c|c|c|c|c|c|}
\hline Slickness fund & $A Z M$ & $\mathrm{CZF}$ & $Z Z L$ & $\begin{array}{l}\text { DSWr } \\
\text { total }\end{array}$ & $\begin{array}{c}\text { DSW } \\
\text { assignment }\end{array}$ \\
\hline \multirow[t]{2}{*}{ Perlod } & 1988 & 1988 & $\begin{array}{c}\text { April } 1988 \\
\text { to } 1989\end{array}$ & 1988 & 1988 \\
\hline & $\%$ & $\%$ & $\%$ & $\%$ & $\%$ \\
\hline Ophthalmology & $-21.97 *$ & .17 .99 & $-8.55^{\circ}$ & $-24.37^{*}$ & .2 .19 \\
\hline ENT disease & $-8.97^{m i r}$ & -15.75 & 6.57 & $\times 7,08$ & -4.93 \\
\hline Surgery & $-6.51^{\text {twit }}$ & -10.29 & -274 & $.14 .52^{* * *}$ & $14.91^{* *}$ \\
\hline Orthopartics & -3.09 & -16.27 & -4.93 & $-15.59^{* *}$ & .7 .23 \\
\hline Urology & -2.97 & -14.07 & 9.16 & -3.51 & 190 \\
\hline Gynaecology & .8 .84 & -14.88 & -6.40 & $-20.27^{i \pi}$ & $-9.28^{\prime}$ \\
\hline Psychlatry & $11.19 *$ & -5.15 & .413 & -9.26 & 0.61 \\
\hline Dermatology & $\therefore-7.40$ & 14.36 & $-9.27^{m}$ & $-10.69^{* *}$ & $.7 .97^{4}$ \\
\hline Internal medicine & -2.96 & -4.71 & -5.67 & $-8.65^{*}$ & -4.32 \\
\hline Paediatrics & -0.67 & -8.50 & -296 & -8.79 & -.8 .27 \\
\hline Cardiology & $-11.96^{\mathrm{kt}}$ & .9 .18 & 9.46 & $-57.94^{* 2}$ & 6.88 \\
\hline Pulmonology & -0.65 & .7 .92 & 10.211 & -3.74 & $9.87^{\circ}$ \\
\hline Oralldental surgery & $11.02^{* *}$ & -11.79 & -2.48 & 9.10 & 11.52 \\
\hline Total & $-7.60^{* *}$ & -14.80 & 1,40 & $-14.91 \%$ & .0 .58 \\
\hline
\end{tabular}

\section{The use of out-patient specialist physicilan care among the insurants of $Z Z Z$}

The most important results of the regression analysis at ZZL are presented per type of specialist care in table 4 (note 7 ). The coefficient for the number of primary care physicians indicates the extent to which the level of the use of OSPhC increased or decreased when the number of primary

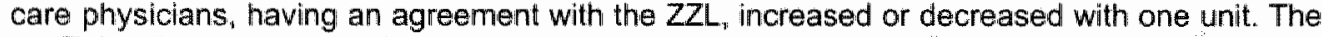
coefficient for the number of specialists has an analogous meaning. The coefficient for the effectdummy indicates the extent to which the level of the use of OSPhC in the period of the co-payment differed from that which could have been expected on the basis of the data in 1985 and in the period from January up to October 1990. The percentage change in the level of the use of OSPhC (the difference between the observed level and the predicted level in the period of the patient charge) is shown in table 3 . 
Table 4 Most relevant regression coefficients with respect to the use of out-patient specialist physician care among the insurants of ZZL ( $t$-values in parentheses)

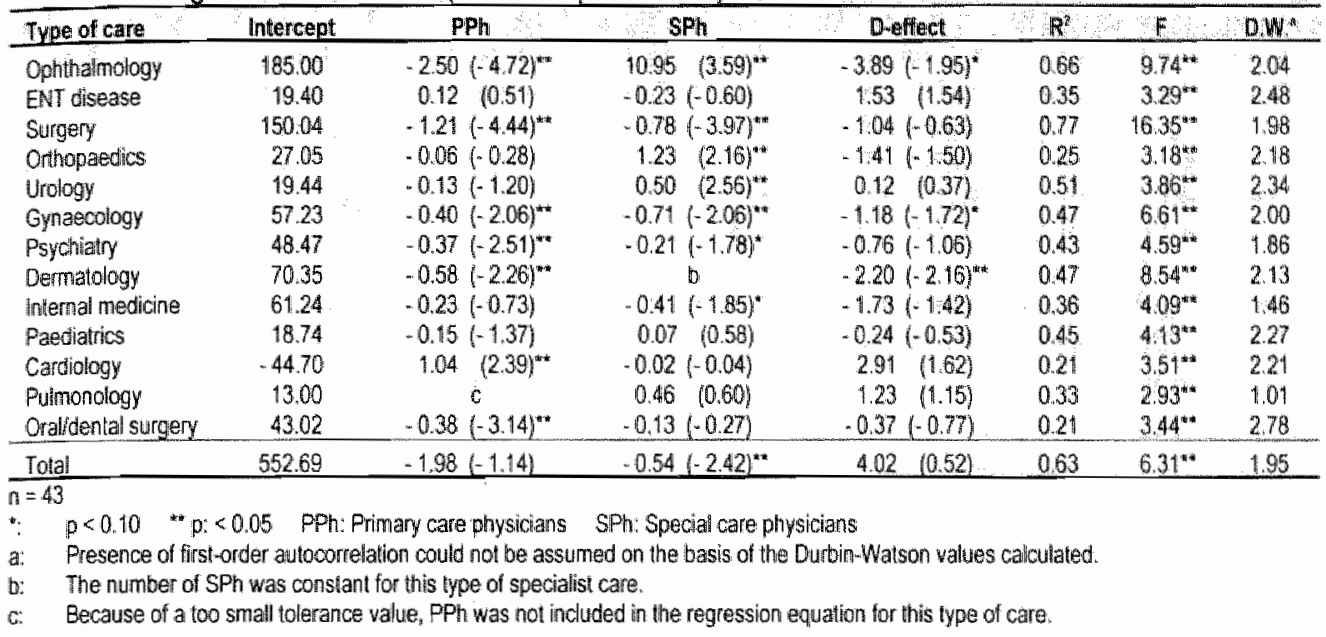

In the regression equations also monthlly-dummies were included lonly monthly-dummies of which the corresponding coefficient was significant). The coefficients involved, however, are not shown in table 4. In general, the use of OSPhC was significantly lower in the months February (carnival), April (Easter holiday), July to September (summer holiday) and December (Christmas holiday) in comparison with the remaining months.

For most types of specialist care a (significant) negative relationship was measured between the number of primary care physicians and the number of referrals to the specialist. This finding corresponds to the results in the study of Rutten (20). An obvious exception was cardiology "for which a significantly positive relationship between the number of primary care physicians and the number of referrals was measured. Partly due to this exception, for all types of specialist care together no significant relationship between the number of primary care physicians and the number of referrals to specialists was demonstrated.

With respect to the supply of specialists a significantly positive relationship between the number of specialists and the number of referrals was found for ophthalmology, orthopaedics and urology. For surgery, gynaecology, psychiatry and internal medicine, however, a significantly negative relationship was measured between the number of specialists and the number of referrals. For all types of specialist care together the above mentioned relationship was also significantly negative. This finding is in contrast with the results of other studies $(20,21)$. The negative relationship between the number of specialists and the number of referrals may possibly be a consequence of the hospital in Maastricht which became academic in 1986. Although from 1986 more specialists were working at this hospital (table 1), they possibly have on the average spent an increased part of their time on other activities, such as education and research, than in the period before.

At ZZL. there seemed to be an effect of the introduction of the NLG 25 co-payment, but only for three types of specialist care: ophthalmology. gynaecology and dermatology. For these types of care the level of the use of OSPhC in the period of the patient charge was significantly lower than could have been expected on the basis of the previous and following periods $(8.55 \%, 6.40 \%$ and $9.27 \%$ lower, respectively). For the remaining types of specialist care and for the total use of OSPhC no significant effect of the introduction of the co-payment was measured. 


\section{The use of out-patient specialist physician care among the insurants of DSW}

For the insurants of DSW the extent to which the Hevel of the use of OSPhC in 1988 differed from that in the previous period was determined by a t-test. This was done for specialists with and without an assignment regulation separately, as well as for the total of both groups of specialists. The results for all types of specialist care together are shown in table 5 (note 8 ). In addition, the percentage change in the level of the use of OSPhC per type of specialist care is shown in table 3. This table shows the percentage change in the level of OSPhC for those specialists with an assignment regulation as well as for all groups of specialists together.

Table 5 Results of test with respect to the use of outpatient specialist physician care among the insurants of DSW (t-values in parentheses)

\begin{tabular}{lccc}
\hline Group of specialists & $\begin{array}{c}\text { Level in } \\
1986 / 1987\end{array}$ & $\begin{array}{c}\text { Level in 1988: } \\
\text { difference }\end{array}$ & Percentage change \\
\hline Tolal & 457.45 & $-68.20(-4.47)^{* *}$ & -14.91 \\
With assignment regulation & 370.31 & $-2.16(-0.17)$ & -0.58 \\
Without assignment regulation & 87.14 & $-66.04(-12.83)^{* *}$ & -75.79 \\
\hline
\end{tabular}

$n=10$

it: $\quad p<0.05$

It appeared that the level of the total use of OSPhC among the insurants of DSW in 1988 had decreased with $14.91 \%$ in comparison with the level in the previous period, although DSW covered the co-payment for OSPhC in an additional insurance plan. The significantly smaller total number of referrals to specialists in 1988 appeared to be due to a significant decrease of $75.79 \%$ in the number of referrals to specialists without an assignment regulation. The level of the number of referrals to specialists with an assignment regulation remained almost constant in 1988 . The bills of the specialists without an assignment regulation were obviously not always declared or did not reach the usual data files. This finding indicates that the decrease in the level of the total number of referrals in 1988 among the insurants of AZM and CZF was probably also completely, or at least to an important extent, due to an incomplete registration and was not due to the introduction of the patient charge.

Table 3 shows that at $Z Z L$, for gynaecology and dermatology the level of the use of OSPhC was significantly lower in the period of the co-payment than in the previous and following periods. However, the table further shows that, at DSW, for these types of specialist care the level of the use of OSPhC (for specialists with an assignment regulation) was also significantly lower after the introduction of the co-payment. Because most of the insurants of DSW were not indebted to pay the patient charge for OSPhC, the decrease in the use of gynaecology and dermatology is probably a consequence of a different factor than the introduction of the patient charge. Eventually, only for ophthalmology a co-payment effect appeared to be present. At ZZL the level of the use of ophthalmology was significantly lower in the period of the patient charge $(-8.55 \%)$, while at DSW (for specialists with an assignment regulation) no significant change was measured for this type of specialist care. 


\section{Conclusion}

After the introduction of the co-payment of NLG 25 for out-patient specialist physician care (OSPhC) in the Dutch sickness fund insurance scheme on 1 February 1988 , at 2 of the 3 sickness funds in Limburg the level of the total use of OSPhC was significantly lower than could have been expected on the basis of the previous period. At AZM the level was approximately $8 \%$ lower and at CZF approximately $15 \%$ lower in 1988 . However, at DSW, where most insurants did not pay a patient charge for OSPhC, the level was also significantly lower (approximately 15\%) in 1988. At DSW it was demonstrated that the decrease in the total number of referrals to specialists was especially due to a large decrease $(76 \%)$ in the number of referrals to specialists, who, due to the so-called specialists conflict, from July 11987 sent their bills directly to the insurants instead of to the sickness fund. Apparently, the insurants did not declare these bills to the sickness fund or the bills did not reach the usual data files. The level of the number of referrals to the specialists, who continued to sent their bills directly to the sickness fund, remained constant in 1988 .

At the third sickness fund in Limburg $(Z Z L)$ the level of the total number of referrals to the specialists of the academic hospital in Maastricht was not significantly lower in the period of the patient charge than could have been expected on the basis of the previous and following periods. Only for ophthalmology, gynaecology and dermatology separately, the level of the number of referrals was significantly lower (approximately $9 \%, 6 \%$ and $9 \%$, respectively). As no specialists conflict was in force for this hospital, there was no registration problem at ZZL. At DSW, however, for gynaecology and dermatology the number of referrals to specialists who continued to sent their bills directly to the sickness fund (once again, no registration problem) was also significantly lower after the introduction of the patient charge (approximately $9 \%$ and $8 \%$, respectively). Therefore, the decrease in the use of gynaecology and dermatology is probably due to a different factor than the introduction of the co-payment. The only type of specialist care for which eventually an effect of the introduction of the co-payment could be demonstrated was ophthalmology (a decrease of approximately $9 \%$ ).

The results of the present study suggest that the introduction of the co-payment for OSPhC did generally not affect the utilization of this provision. This finding corresponds with the results of Beck (15) and Cherkin (17). These studies also demonstrated that a co-payment for OSPhC did not significantly affect the use of this health care service. The finding of the present study also supports the idea of Duan (18) and Feldstein (19) that the effect of the introduction or increase of a patient charge on medical consumption is smaller if medical care is less accomplished by the initiative of the patient. The fact that only for ophthalmology an effect of the introduction of the co-payment could be demonstrated may indicate that the visit to an ophthalmologist is, more than the visit to a different specialist, established on the initiative of the consumer. Another factor that could have played a role for ophthalmology is that the consumer had, to a certain extent, the possibility to substitute the visit to the ophthalmologist by a visit to the optician. According to Lipsey (23), the effect of a patient charge on medical consumption will be larger if there are more possibilities to substitute the use of the provision in question.

The present study suggests that the introduction of the co-payment for OSPhC mainly resulted in a shifting in the finance of health care instead of a reduction in medical consumption. Although the outcomes of the study are based on data of only a few sickness funds and more accurate analyses were difficult to perform with these data, there is no reason to assume that an extension of the study to other sickness funds would result in a different conclusion. In addition, it is the question whether it would be possible to measure the effect of the introduction of the NLG 25 co-payment on the national level and with more accuracy. Due to the specialists conflict, the registration of the number of referrals to specialists will be incomplete at most sickness funds. 


\section{Notes}

1. For a few types of specialist care the amount of NLG 25 was lowered to NLG 20 afterwards. For oral/dental surgery the co-payment level was NLG 20 from the beginning (24).

2. In order to use out-patient specialist physician care the sickness fund insurant needed a referral or a year-treatment licence from a primary care physician, dentist or other specialist in the period inwestigated. On the basis of a referral licence a specialist was allowed to supply out-pattent care during 1 month. If an insurant needed treatment during a longer period, generally recurrence licences were used after the first month. For a recurrence licence no patient charge was indebted. If a treatment tock more than 1 year, the insurant needed a new referrall licence after this year. For out-patient specialist physician care in an academic hospital the sickness fund insurant needed a year-treatment licence. On the basis of this licence the specialist was allowed to supply out-patient care for 1 year.

3. Types of specialist care with only few referrals were not considered.

4. In 1988 the gross-price (the so-called costs-out rate) of a referral licence varied from NLG 21.75 (oral/dental surgery) to NLG 66.14 (paediatrics). Subsequently, the insurant could declare, after deduction of the NLG 25 co-payment, an amount of NLG 1.75 and NLG 41.14, respectively to the sickness fund.

5. At AZM the average number of referrals per month per 10,000 insurants in the period from 1983 to the first half of 1987 was based on quarterly figures. In 1988 the average was based on an 11 -monthly figure. In the second half of 1987 and in the first month of 1988 , no figures were available at $A Z M$. At CZF the average number of referrals per month per 10,000 insurants was based on annual figures. Only in 1986 the average was based on a 9-monthly figure due to the absence of data in the first quarter of 1986.

6. As the average number of referrals per month per 10,000 insurants was not always calculated on the basis of an equally long period, a weight was attributed to each observation in the regression analysis. This weight corresponded with the rumber of months on the basis of which the average was callculated.

7. At $Z Z L$, both in 1985 and in the period from April 1988 to October 1990 , monthly figures were available.

8. At DSW the average number of referrals per month per 10,000 insurants was based on quarterly figures. As the assignment regulations were achieved only in the course of the third quarter of 1987 and as for a few specialists these regulations had already expired in the course of the fourth quarter of 1987, these quarters were not considered. 


\section{References}

1. Cherkin DC, Grothaus $L$, Wagner EH. Is magnitude of co-payment effect related to income ?: using census data for health services research. Soc Sci Med 1992;34:33-44.

2. Harris $B$, Stergachis $A$, Ried $L$. The effect of drug copayments on utilization and cost of pharmaceuticals in a heath maintenance organization. Med Care 1990;28:907-17.

3. Manning WG. Newhouse $\mathrm{JP}$, Duan $\mathrm{N}$, et al. Health insurance and the demand for medical care: evidence from a randomized experiment. Am Econ Rev 1987;77:251-77:

4. O'Grady KF, Manning WG, Newhouse JP, Brook RH. The impact of cost sharing on emergency department use. New Engl J Med 1985;313:484-90.

5. Scitovsky AA, Snyder NM. Effect of consurance on use of physician services. Soc Security Bull 1972;35:3-19.

6. Scitovsky AA, MCCall N. Coinsurance and the demand for physician services: four years later. Soc Security Bull 1977;40:19-27.

7. van den Berg J. De eigen bijdrage voor geneesmiddelen in 1983 (The co-payment for prescription drugs in 1983). Tijdschr Soc Gezondheidsz 1985;63:4-12.

8. de Klein $J J M$, Collaris JWM. Evaluatie van de eigen bijdrage-maatregel farmacie (Evaluation of the coupayment regulation for prescription drugs). Zeist: Vereniging van Nederlandse Ziekenfondsen, Afdeling Beleidsinformatie - Onderzoek, 1984.

9. Mootz M. The need for health care utilization and its relation to insurance coverage for medical expenses. Gezondh Sameni 1985;6:232-7.

10. Post D. Vijf jaar prescriptie: volume- en kostenweranderingen in een ziekenfondsregio (Five years af prescription: changes in volume and expenditure in a Dutch sickness fund region). Med Contact 1986;41:1103-4.

11. van de Ven WPMM, van der Gaag J. Health as an unobservable: a MIMIC-model of the demand for health care. 1 Health Econ 1982;1:157-83.

12. van Vliet RCJA, wan de Ven WPMM. Consumptieverschillem tussen zlekenfonds en particulier verzekerden mader onderzocht: averzicht van empirische bevindingen (Further analysis of differences in medical consumption between sickness funds insurants and private insurants). Gezondh Samenl 1986;7:81-94.

13. Ministerte van Welzijn Volksgezondheid an Cultuur. Regelling eigen bijdrage specialistische hulp ziekenfondsverzekering (Co-payment regulation for special care in the Dutch Sickness Fund insurance Act). Nedi Staatscourant 1987(233):9.

14. Ministerie van Welzijn Volksgezondheid en Cultuur. Wijziging Regeling eigen bijdrage specialistische hulp ziekenfondsverzekering (Change of the co-payment regulation for special care in the Dutch Sickness Fund Insurance Act). Ned Staatscourant 1987(244):30.

15. Beck RG. The effects of co-payment on the poor. J Hum Resour $1974 ; 9: 129-42$.

16. Beck RG, Horne JM. Utilization of publicly insured health services in Saskatchewan before, during and after copayment. Med Care 1980;18:787-806.

17. Cherkin $D C_{n}$ Grothaus $L_{\text {, Wagner }} \mathrm{EH}_{\text {. The }}$. The ffect of office visit copayments on utilization in a health maintenance organization. Med Care 1989;27:669-79.

18. Duan $\mathrm{N}_{8}$ Mlanning WG, Morris $\mathrm{CN}_{1}$ Newhouse JP. A comparison of alternative models for the demand for medical care. J Bus Econ Stat 1983:1:115-26.

19. Feldstein MS. Econometric studies of health economics. In: Intriligator MD, Kendrick DA, eds. Frontiers of quantitative economics. v. 2. Amsterdam: North-Holland Publishing Company, 1974:377-434

20. Rutten FFH, van der Gaag J. Referrals and demand for specialist care in the Netherlands. Heaith Serv Res $1977 ; 12: 233-49$.

21. Wijkel $D$, van der Zee J, de Bakker D. Ziekenfondsvenwijsclifers van samenwerkende huisartsen: een replicatieonderzaek (Dutch sickness funds referral figures of cooperating primary care physicians: a replication). Tijdschr Soc Gezondheidsz 1992;70:519-26.

22. Ziekenfondsraad. Jaarverslag Ziekenfondsraad 1987: algemeen deel (Annual report of the Dulch Sickness Fund Council 1987: general part). Amstelween: Ziekentondsraad, 1988.

23. Lipsey RG, Courant PN, Purvis DD, Steiner PO. Economics. New York: HarperCollins, 1993.

24. Ministerie wan Welzijn Volksgezondheid en Cultuur. Wijziging Regeling eigen bijdrage specialistische hulp ziekenfondswerzekering (Change of the co-payment regulation for special care in the Dutch Sickness Funid Insurance Act). Ned Staatscourant 1988(15):5. 



\section{Benefit limit and co-payment effects on the utilization of antihypertension drugs: evidence in Limburg, The Netherlands}

(Based on: Starmans B, Janssen R, Schepers $M$, Verkooijen $M$. The effect of a patient charge and $a$ prescription regulation on the use of antihypertension drugs in Limburg. The Netherlands. Health Policy 1994;26:191-206) 


\section{Abstract}

On 1 January 1981 a patient charge was introduced for out-patient prescription drugs in the Dutch sickness fund insurance scheme. From that date, for the majority of drugs, sickness funds refunded only a quantity of tablets for a maximum of 30 days per prescription item. This benefit limit ceased with the introduction of a new patient charge on 1 February 1983 . The new charge consisted of a co-payment of NLG 2.50 (1,10 in 1995 US\$) per prescription item up to a maximum of NLG 125 ( 55 in 1995 US\$) for each family per calendar year. The effects of both measures on the utilization of antihypertension drugs in Limburg were investigated in an interrupted time-series analysis.

The introduction of the benefit limit resulted in a decrease in the number of tablets per prescription item. However, this decrease was compensated for by an increase in the number of prescription items per insurant. The introduction of the co-payment resulted in a reduction in the number of prescription items per insurant. However, this reduction was compensated for by an increase in the number of tablets per prescription item. Consequently, neither measure significantly affected the number of tablets per insurant or the number of "defined daily doses" (DDDs) per insurant for antihypertension drugs. The findings suggest that for these drugs, both types of patient charges resulted in a shifting in the finance of care, rather than a reduction in the utilization of care.

\section{Introduction}

Hypertension (high blood pressure) is an important risk factor for cardiovascular disease (1, 2). In developed countries these diseases are the most important cause of total mortality (3). Antihypertensives are drugs that lower blood pressure. Several studies have demonstrated that the risk of certain cardiovascular diseases can be reduced by the use of antihypertensives $(4,5)$. in general, in developed countries antihypertensives are only available with a physician's. prescription. In these countries there is usually a health insurance system with patient charges for prescription drugs $(6,7)$. Patient charges may serve as an additional source of financing medical care, but may also serve to reduce medical consumption without adverse health effects $(8,9)$. What is the effect of a charge for prescription drugs on the utilization of antihypertensives? Does such a charge, compared to a system without charges, result in a decrease in the use of antihypertensives? If so, is the health status of the insurants negatively influenced?

Several studies have investigated whether or not charges for prescription drugs (among other health care supplies) result in a reduction in the utilization of these agents (e.9. 10-15). These studies generally showed that a patient charge for prescription drugs results in ai decrease in the total number of prescription items per insurant. However, the effect of a patient charge appears not to be the same for all kinds of drugs. Harris (10) and Soumerai (15) have demonstrated that, after the introduction of a patient charge for prescription drugs, the decline in the use of so-called essential drugs (e.g. antihypertensives) was smaller than that in the use of so-called non-essential drugs (e.g. analgesics) or ineffective drugs (note 1).

The RAND-experiment is almost the only study in which the effect of patient charges on the health status of the insurants has been investigated. Although the study did generally find no adverse health effects of patient charges for outpatient care (prescription drugs included) or even total health care, there were some exceptions (16-18). An important exception was an increase in the average blood pressure among adults. Whether or not a patient charge for prescription drugs, exclusively, results in a decrease in the utilization of antihypertensives or an inferior health status for insurants, was not investigated in the RAND-study. The researchers believed the increase in blood pressure resulted mostly from a reduction in physician visits. As a consequence, insurants with hypertension have probably been less frequently traced and treated (19). 
The present study analyzed the effects of introducing 2 different types of patient charges for outpatient prescription drugs in the Dutch sickness fund insurance scheme, separately, on the utilization of antihypertension drugs. The analysis covered the use of antihypertensives in Limburg (the southern part of The Netherlands). On 1 January 1981 a benefit limit was introduced. In Limburg, however, this charge was already in effect from the fourth quarter of 1980 . From that date, for the majority of drugs, sickness funds refunded only a quantity of tablets for a maximum of 30 days per prescription item (20). The benefit limit ceased on 1 January 1983, at almost the same time as the introduction of new patient charge. The second charge was in force from 1 February 1983 to 1 January 1990. It consisted of a co-payment of NLG 2.50 (1.10 in 1995 US\$) per prescription item up to a maximum of NLG 125 (55 in 1995 US\$) for each family per calendar year (21).

The effects of both charges on the use of antihypertension drugs was investigated in an interrupted time-series analysis. The use of drugs was measured in five ways: (1) the number of prescription items per insurant, (2) the number of deliveries per prescription item, (3) the number of deliveries per insurant, (4) the number of "defined daily doses" (DDDs) per delivery and (5) the number of DDDs per insurant. The number of prescription items per insurant is only a rude measure of the use of drugs. One prescription item may consist of 20,40 or 60 tablets. A more accurate measure is the number of tablets per insurant. In The Netherlands, this is expressed as the number of deliveries per insurant. In the case of antihypertensives 1 delivery usually consists of 28 tablets. The number of DDDs per insurant is an even more accurate measure of the use of drugs. One

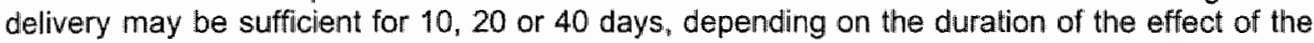
tablets. The number of DDDs per insurant indicates the number of days for which drugs have been prescribed. It is a measure that is recommended by the World Health Organization to quantify the use of drugs (22).

\section{Methods}

During the period investigated a majority of the Dutch population (approximately $70 \%$ ) were covered by the sickness fund insurance scheme for various health care costs, such as the costs of using primary physician care and prescription drugs. Sickness fund insurants can be considered as low or middle income persons (e.g. in 1983 annual family income was not higher than NLG 46,550 , or 20,599 in 1995 US\$). Some groups of civil servants (approximately $5 \%$ of the population) had their own health insurance scheme. The remainder (approximately 25\%) of the population were privately insured. On 1 April 1986 (the last year of the period investigated) several sickness fund insurants had to switch to private health insurance due to the introduction of the Health Care Tariffs Act. After the introduction of this act, approximately $62 \%$ of the population were covered by the sickness fund insurance scheme. For exceptional health care costs, such as for hospital care lasting more than 1 year and nursing home care, the entire Dutch population was compulsarily insured by an exceptional medical expenses insurance scheme. Both the sickness fund insurance plan and the exceptional medical expenses plan were implemented by regional sickness funds.

The data in the present study are derived from the four sickness funds in Limburg (approximately 760,000 insurants). The Anatomical, Therapeutical and Chemical codes (ATC-codes) of the study drugs and the names of the concomitant subgroups and active substances are given in appendix 1 (23). All these drugs had at least hypertension as an indication (24). A large number also had other disorders, such as heart rhythm disorders or oedema, as an indication. The data did not show whether a drug was used for hypertension or another indication. Therefore, the present study describes the effects of patient charges on the use of drugs that lower blood pressure (antihypertensives) but that might also be prescribed for disorders other than hypertension. 
In previous studies investigating the effect of the introduction of the NLG 2.50 co-payment for prescription drugs in the Dutch sickness funds insurance scheme, the use of drugs in the period of this co-payment was usually compared with that in the period of the benefit limit (25-27). It is therefore not clear which effect was measured in these studies: the effect of the introduction of the co-payment or of the expiration of the benefit limit, It was also impossible to distinguish the effect of the co-payment from the effect of the so-called October measure. This measure decreed that from 1 October 1982 the costs of a large number of drugs were not refunded by the sickness fund insurance any more, except with special authorization (28).

In the present study the use of antihypertension drugs was investigated in the following 3 periods:

1. a base period, without patient charges (1978 to the first half of 1980);

2. a period during which the benefit limit was in force (the second half of 1980 to 1982);

3. a period during which the co-payment was in force (1983 to 1986).

The use of drugs in the latter 2 periods was compared - by means of a linear regression analysis with the use that could have been expected if the regime without patient charges had been continuled. Among the drugs with hypertension as an indication, only 4 of the approximately 90 trademarks (see appendix 1) were covered by the October measure. For these drugs, with reserpine among the active ingredients, the number of DDDs per insurant had already been sharply reduced before the introduction of the October measure (note 2). This reduction could be explained by the serious side-effects of reserpine.

From 1978 to 1983 biannual data were available and from 1984 to 1986 there were annual data. The 2 kinds of data could be compared by converting each annual data into a biannual average (by dividing annual data by 2). In the regression equations, each biannual average was assigned a double weight. So, a weighted least-squares technique was used. The number of DDDs per insurant was not directly available from the data of the sickness funds, but could be calculated (see note 3$)$.

It was expected that the introduction of the benefit limit (reimbursement for a quantity of deliveries for a maximum of 30 days per prescription item) would result in a lower number of deliveries per prescription item or fewer DDDs per delivery. However, if it was desirable to use drugs for more than 30 days, without paying part of the costs out-of-pocket, the number of prescription items per insurant could be increased. Therefore, it was also expected that the benefit limit would result in a higher number of prescription items per insurant. As a result, the number of deliveries per insurant and the number of DDDs per insurant would hardly be lower in the period of the benefit limit than in the period without patient charges (see table 1).

Table 1 Expected change in the use of antihypertensiwes in the period of the benefit limit and in the period of the co-payment compared with the period without patient charges

\begin{tabular}{|c|c|c|}
\hline & Beneffit limit & Co-payment \\
\hline Proscriplions per 1,000 insurants & + & - \\
\hline Delivenies par proscription & - & + \\
\hline DDDs per dativery & - & + \\
\hline Dehtweries per 1,000 instirants & -10 & $\omega / 0$ \\
\hline DDDs per 1,000 insurants & 10 & 0 \\
\hline
\end{tabular}

It was expected that the introduction of the co-payment per prescription item would result in fewer prescription items per insurant. However, if desired, a reduction in the number of prescription items could be compensated for by an increase in the number of deliveries per prescription item or an 
increase in the number of DDDs per delivery. Therefore, it was also expected that the introduction of the co-payment would result in more deliveries per prescription item and more DDDs per delivery. As a result, the number of deliveries per insurant and the number of DDDs per insurant would, once again, hardly be lower in the period of the co-payment than in the period without patient charges (see table 1).

Initially, the following 3 independent variables were used in the regression equations: a time variable (T) to adjust for the presence of a trend in the use of antihypertensives during the period investigated, and 2 dummy variables (D1 and D2) for the level of the use of antihypertensives in the periods of the benefit limit and the co-payment. However, a better description of the use of antihypertensives could be achieved by replacing D1 and D2 with 2 dummy variables (S1 and $S 2$ ) for a trend in the periods of the benefit limit and the co-payment. It appeared that if the use of antihypertensives changed after the introduction of a patient charge, the use was not permanently lower or higher on a certain level, but it showed a decreasing or increasing trend. The values of the independent variables are shown in appendix 2 . Although the number of observations $(n=15)$ was relatively small (it was not possible to enlarge this number), linear regression analysis could be applied without gross violations of the regressions assumptions $(29,30)$.

\section{Results}

The changes in the number of prescription items per 1,000 insurants and the number of deliveries per prescription item over the period analyzed are shown in figure 1 . The number of DDDs per delivery, the number of deliveries per 1,000 insurants and the number of DDDs per 1,000 insurants over the period analyzed are shown in figure 2. Figures 1 and 2 give index data (the first half of $1978=100$ ). The biannual averages calculated in 1984,1985 and 1986 each are placed in the middle of the concomitant period (for example, the biannual average calculated in 1984 is placed at $T=13.5)$.

Table 2 shows the results of the regression analysis for each measure of the use of antihypertensives. The coefficient for the trend $(T)$ indicates the average half-year increase or decrease in the use of antihypertensives in the period without patient charges. The coefficient of the dummy for the trend in the period of the benefit limit (S1) indlicates the extent to which the trend in the use of antihypertensives in this period differed from the trend in the base period. The coefficient of the dummy for the trend in the period of the co-payment (S2) is analogous to $\$ 1$.

On the basis of the regression equations, the use of antihypertensives, measured in the periods of the benefit limit and the co-payment, was compared with the use that could have been expected if the regime without patient charges had been continued. Results are expressed as the percentage change in the use of antihypertensives and are shown in tables 3 and 4. 


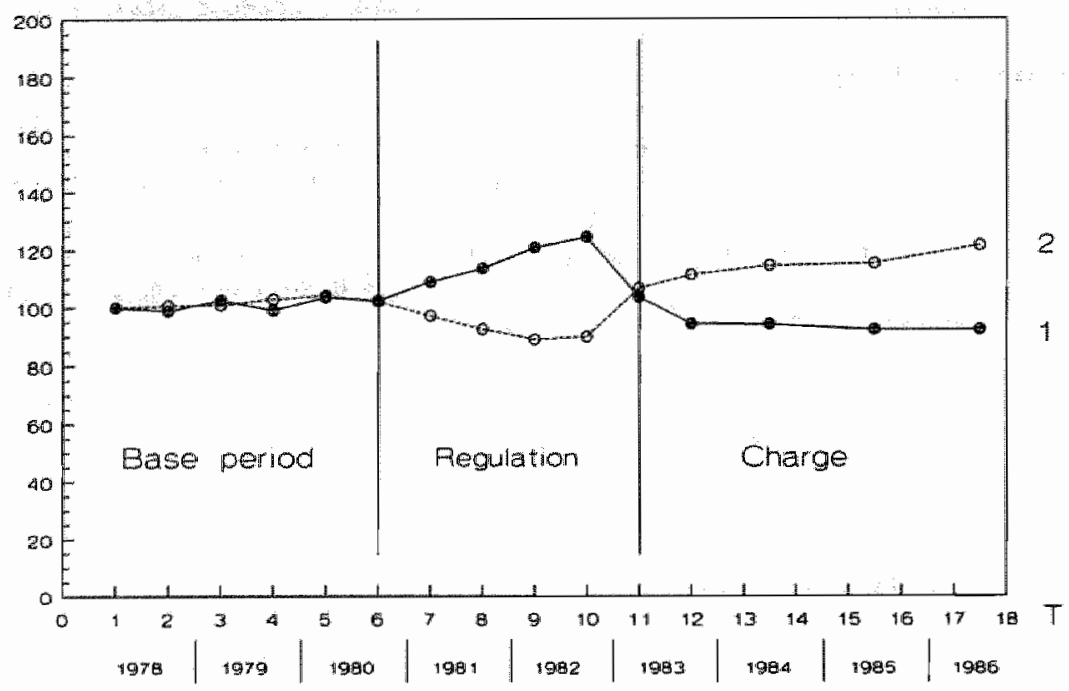

Figure 1 Index data of the use of antihypertensives among the sickness funds in Limburg ( 1 st half of $1978=100$ ): prescriptions per 1,000 insurants (line 1) and deliveries per prescription (line 2)

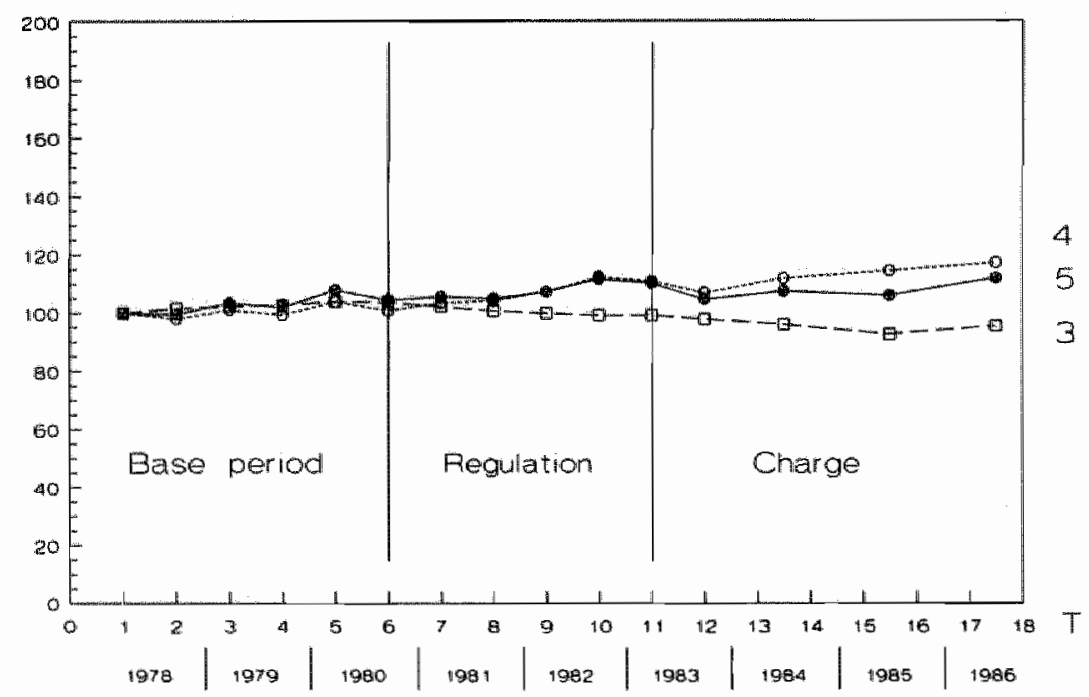

Figure 2 Index data of the use of antihypertensives among the sickness funds in Limburg (1st half of $1978=100$ ): DDDs per delivery (line 3 ), deliveries per 1,000 insurants (line 4) and DDDs per 1,000 insurants (line 5) 
Table 2 Regression coefficients with respect to the use of antihypertensives (t-walues in parentheses)

\begin{tabular}{|c|c|c|c|c|c|}
\hline & $\begin{array}{l}\text { Prescriptions per } \\
1,000 \text { insurants }\end{array}$ & $\begin{array}{c}\text { Deliverles per } \\
\text { prescription }\end{array}$ & DDDs per dellvery & $\begin{array}{l}\text { Deliveries per } \\
1,000 \text { insurants }\end{array}$ & $\begin{array}{c}\text { OoDs per } 10000 \\
\text { insurants }\end{array}$ \\
\hline Intercept & 298.05 & 2.71 & 21.77 & 806.54 & 175777 \\
\hline Trend (T) & $\begin{array}{l}-0.13 \\
(-0.14)\end{array}$ & $\begin{array}{c}0.03 \\
(3.96)^{4 * *}\end{array}$ & $\begin{array}{l}-0.06 \\
(-1.16)\end{array}$ & $\begin{array}{c}7.86 \\
(3.65)^{* *}\end{array}$ & $\begin{array}{l}115.49 \\
(2.01)^{*}\end{array}$ \\
\hline $\begin{array}{l}\text { D trend } \\
\text { regulation (S1) }\end{array}$ & $\begin{array}{l}9.4 .32 \\
(0.75)^{*+}\end{array}$ & $\begin{array}{c}-0.10 \\
(-8.65)^{+*}\end{array}$ & $\begin{array}{c}-0.01 \\
(-0.06)\end{array}$ & $\begin{array}{c}4.96 \\
(1.31)\end{array}$ & $\begin{array}{l}99.06 \\
(0.98)\end{array}$ \\
\hline $\begin{array}{l}\text { D trend } \\
\text { charge (S2) }\end{array}$ & $\begin{array}{c}-3.50 \\
(-1.80)^{* *}\end{array}$ & $\begin{array}{c}0.06 \\
(4.08)^{* *}\end{array}$ & $\begin{array}{l}-0.14 \\
(-1.24)\end{array}$ & $\begin{array}{l}4.15 \\
(0.92)\end{array}$ & $\begin{array}{r}.48 .71 \\
(-0.41)\end{array}$ \\
\hline$R^{2}$ & 0.95 & 0.99 & 0.79 & 0.93 & 0.65 \\
\hline$F$ & $75.49^{* *}$ & $245.40^{* *}$ & $13.57^{* *}$ & $46.80^{* *}$ & $6.83^{* * t}$ \\
\hline D.W. & 2.51 & 1.82 & 1.33 & 2.16 & 2.22 \\
\hline$n$ & 45 & 15 & 15 & 15 & -15 \\
\hline
\end{tabular}

$\frac{n}{2} \quad p<0.10$

*a: $\quad p<0.05$

a. Presence of first-order autocorrelation could not be assumed on the basis of the Durbin-Watson waltue calculated.

Table 3 Percentage change in the use of antihypertensives in the period of the benefit limit compared with the period without patient charges

\begin{tabular}{|c|c|c|c|c|c|}
\hline & $\begin{array}{c}\text { 2nd half } \\
1980\end{array}$ & $\begin{array}{c}\text { 1st half } \\
1981\end{array}$ & $\begin{array}{c}\text { 2nd half } \\
1981\end{array}$ & $\begin{array}{c}\text { Ist half } \\
1982\end{array}$ & $\begin{array}{c}\text { 2nd half } \\
1982 .\end{array}$ \\
\hline & $\%$ & $\%$ & $\%$ & $\%$ & $\%$ \\
\hline Prescriptions per 1,000 insuranis & 4.82 & 9.64 & 14.46 & 19.29 & 24,13 \\
\hline Deliveries per prescription & -3.46 & -6.85 & -10.17 & -13.42 & $.166 \pi$ \\
\hline DDDs per deliwery & -0.05 & -0.09 & -0.14 & .019 & -0.24 \\
\hline Deliweries per 9,000 insurants & 0.58 & 1.15 & 1.71 & 2.26 & 280 \\
\hline DDOs per 1,000 insurants & 0.54 & 1,08 & 1.81 & 2.13 & 2.64 \\
\hline
\end{tabular}

Table 4 Percentage change in the use of antihypertensives in the period of the co-payment compared with the period without patient charges

\begin{tabular}{lccccc}
\hline & $\begin{array}{c}\text { 1st half } \\
1983\end{array}$ & $\begin{array}{c}\text { 2nd half } \\
1983\end{array}$ & 1984 & 1985 & 1986 \\
\hline Prescriptions per 1,000 insurants & $\%$ & $\%$ & $\%$ & $\%$ & $\%$ \\
Deliveries per prescription & -1.18 & -2.36 & -4.13 & -6.50 & .8 .87 \\
Dodis per delivery & 1.97 & 3.91 & 6.74 & 10.39 & 13.91 \\
Deliveries per 1,000 insurants & -0.66 & -1.33 & -2.34 & -3.69 & .5 .07 \\
DoDs per 1,000 insurants & 0.46 & 0.92 & 1.59 & 2.46 & 3.30 \\
\hline
\end{tabular}


In the base period the number of prescription items per 1,000 insurants was almost constant, whereas the number of deliveries per prescription item showed a slightly increasing trend. In the period of the benefit limit the number of deliveries per prescription item showed a declining trend. Al the end of this period (the second half of 1982) the number of deliveries per prescription item was approximately $17 \%$ lower than could have been predicted from the base period. However, the number of prescription items per 1,000 insurants showed an increasing trend. At the end of the period of the benefit limit the number of prescription items per 1,000 insurants was approximately $24 \%$ higher than in the period without patient charges. In the period of the co-payment the opposite occurred: the number of prescription items per 1,000 insurants showed a declining trend, but the number of deliveries per prescription item showed an increasing trend. At the end of the period investigated (1986) the number of prescription items per 1,000 insurants was approximately $9 \%$ lower, but the number of deliveries per prescription item was approximately $14 \%$ higher than could have been predicted from the base period. Taken together, these changes correspond to the expectations mentioned in the methods section (table 1). The changes appeared to be larger in the long term (after 1 year) than in the short term.

During the entire period of investigation the number of deliveries per 1,000 insurants showed an increasing trend. During the periods in which the benefit limit or the co-payment was in force, the number of deliveries per 1,000 insurants was - after correction for the increasing trend - not significantly different from that in the base period. This was because the decrease in the number of deliveries per prescription item was compensated for by an increase in the number of prescription items per 1,000 insurants in the period of the benefit limit, while in the period of the copayment the decrease in the number of prescription items per 1,000 insurants was compensated for by an increase in the number of deliveries per prescription item. These findings are consistent with the expectations (table 1).

In the base period the number of DDDs per delivery remained almost constant. During the periods in which the benefit limit or the co-payment was in force, the number of DDDs per delivery was not significantly different from the number that could have been predicted from the base period. So, against expectations, neither measure appeared to have a significant effect on the number of DDDs per delivery.

During the period investigated the number of DDDs per 1,000 insurants showed an increasing trend. After correcting for this trend, the number of DDDs per 1,000 insurants in the periods of the benefit limit or the co-payment, was, as expected, not significantly different from that in the base period.

In the period of investigation several new antihypertensives have been introduced (appendix 3). A change in the number of prescription items per 1,000 insurants and the number of deliveries per prescription item was demonstrated precisely after the introduction of the benefit limit and precisely after the introduction of the co-payment. Because the introduction of new agents took place during more or less the entire period of investigation, the turnover of generations of antihypertensives is not a reasonable explanation for the above finding. However, the introduction of new generations of antihypertensives may (partly) be an explanation for the slightly increasing trend in the number of deliveries per 1,000 insurants and the number of DDDs per 1,000 insurants during the entire period investigated. 


\section{Conclusion}

After the introduction of the co-payment for prescription drugs on 1 February 1983 , the number of prescription items for antihypertension drugs per 1,000 insurants covered by the four sickness funds in Limburg showed a slight declining trend. At the end of the period investigated (1986) the number of prescription items was approximately $9 \%$ lower than could have been expected from a period without patient charges. The slight decrease in the number of prescription items per 1,000 insurants (approximately $2 \%$ ) in the first year after the introduction of the patient change roughly corresponds to the findings of Harris (10). In the latter study, however, the long-term effect on the inumber of prescription items per insurant was not investigated.

The present study has shown that after the introduction of the co-payment, the decrease in the number of prescription items per 1,000 insurants was compensated for by an increase in the number of deliveries per prescription item. Consequently, in the period of the co-payment the number of deliveries per 1,000 insurants was not significantly different from the number that could have been expected from the base period. The finding that, after the introduction of the copayment, the number of deliveries per prescription item increased (approximately $4 \%$ in the short term) is also consistent with the findings of Harris (10). The latter study showed that a co-payment for prescription drugs resulted in an increase in expenditure per prescription item.

In the period of the benefit limit an opposite reaction occurred compared with the period of the copayment. With the benefit limit the number of deliveries per prescription item showed a declining trend. At the end of this period (the second half of 1982) the number of deliveries per prescription item was approximately $17 \%$ lower than could have been predicted from the period without patient charges. However, the decrease in the number of deliveries per prescription item was compensated for by an increase in the number of prescription items per 1,000 insurants. As a result, the number of deliveries per 1,000 insurants was again not significantly different from the number that could have been predicted from the base period.

During the period of investigation the number of DDDs per 1,000 insurants showed an increasing trend. After correcting for this trend, in the periods of the benefit limit or the co-payment the number of DDDs per 1,000 insurants did not significantly differ from the numbers that could thave been predicted from the base period. In addition, neither of the 2 types of patient charges significantly influenced the number of DDDs per delivery.

Although both patient charges have influenced the utilization of antihypertensives among those covered by the four sickness funds in Limburg - expressed as the number of prescription items per 1,000 insurants and the number of deliveries per prescription item - neither measure resulted in a reduction in the number of deliveries per 1,000 insurants or the number of DDDs per 1,000 insurants. Although, as in other studies of the effect of patient charges on the use of prescription drugs, data on compliance were not available, the findings of the present study suggest that netther measure resulted in adverse health effects among the sickness fund insurants. Several studies of drug compliance have shown that the number of tablets to be taken daily, is an important factor $(31,32)$.

The results of the present study suggest that the use of antihypertensives, expressed as the number of deliveries per insurant or the number of DDDs per insurant, is not or is only slightly sensitive to the 2 types of patient charges investigated. The findings suggest that both types of patient charges resulted in a shifting in the finance of care, rather than a reduction in the utilization of medical care. 
Notes

1. Essentlal drugs influence morbidity and mortality. Non-essential drugs diminish symptoms but do not influence morbidity or mortality. Ineffective drugs have no effect or do not have the effect desired.

2. In the first half of 1978 the use of these agents - using the measure of the number of DDDs per insurant - was approximately $7 \%$ of the total use of antihypertensives. In the first half of 1982 this was reduced to approximately $3.5 \%$.

3. The data of the sickness funds in Limburg showed, for example the number of tablets of a drug prescribed. In addition, the milligrams of active substance per tablet was shown. The number of DDDs of a certain drug was calculated by multiplying the number of tablets by the quotient of the milligrams of active substance per tablet and the DDD value of the active substance involved. The DDD value of an active substance was calculated by the Nordic Council on Medicines (23). For combination drugs, which contain different active substances, the number of tablets was inultiplied by the sum of the quotients of the different numbers of milligrams of active substance and the corresponding DDD values.

\section{References}

1. Joint National Committee. The fifth report of the Joint National Committee on detection, evaluation, and treatment of high blood pressure. Arch intern Neid 1993;153:154-83,

2. Rutan $\mathrm{GH}$, Kuller $\mathrm{LH}$, Neaton $\mathrm{JD}$, al Mortality associated with diastolic hypertension and isolated systolic hypertension among men screened for the Multiple Risk Factor Interwention Trial. Circulation 19818;77:505-14.

3. World Health Organisation. World health statistics innual. Genewa: WHO, 1990.

4. Collins $R$, Peto $R_{4}$ MacMahon $S$, et al. Blood pressure, stroke and coronary heart disease. Part 2. Short term reductions in blood pressure. overview of randomized drug trials in their epidemiological context. Luancet $1990 ; 335: 827-38$

5. Sever PS. The year of the hypertension trials: interpreting the results. Trends Pharmacol Sci 1986:7:134-9.

B. Schnelder $M$, Biene-Dietrich $P$, Gabanyi $M$, et al. Gesundheidssysteme im intermationalen Vergleich (international comparison of health systems). Augsburg: BASYS 1993.

7. Schneider M, Dennerlein RKH, Köse A, Sicholtes L. Heallh care in the EC member states. Health Policy $1992 ; 20 \div 1-252$

8. Arrow Ku. Unicertainty and the welfare economics of medical care. Am Econ Rev 1963;53:941-73.

9. Brch $S$. Incrsasing patient charges in the National Health Service: a method of privatizing primary care. J Sioc Polloy $1986 ; 15: 16 ; 3-84$.

10. Haris $B$, Stergachis $A$, Ried $L$. The effect of drug copayments on utilization and cost of phamaceuticals in a health maintenance organization. Med Care 1990;28:907-17.

11. Lavers RJ. Prescription charges, the demand for prescriptions and morbidily. Appl Econ 1989;21:1043-52.

12. Leibowitz $A$, Manining WG, Newhouse JP. The demand for prescription drugs as a function of cost-sharing. Soc Scil Med 1985:24:1063-9.

13. Ryan M, Eirch S. Charging for heilth care: ewidence on the utilization of NHS prescribed drugs. Soc Sci Med $1991,33: 681-7$.

14. Smith DG. The effects of copayments and generic substitution on the use and costs of prescription drugs. Inquiry $1993 ; 30: 189-98$.

15. Soumeral SB, Avorn J. Ross-Degnan D, Gortmaker S. Payment restrictions for prescription drugs under Medicaid: effects on therapy "cost, and equity. New Engl J Med 1987;317:550-6.

16. Bailit $H_{3}$ Newhouse J, Brook $R_{n}$ at al. Does more generous dental insurance coverage improve oral health? $J$ Am Dent Assoc 1985; 110:701:7

17. Brook RH, Ware JE, Rogers WH, al. Does free care improve adults" health?: results from a randomized Controlled trial. New Engl J Med 1983:309:1420-34.

18. Valdez RB, Brook RH, Rogers WH. et al. Consequences of cost-sharing for children's health. Pediatrics $1985: 75: 952-61$. 
19. Keeler EB, Brook $\mathrm{RH}$, Goldberg $\mathrm{GA}$, el al. How tree cane reducediypentension in the Health lnsuramce Experment JAMA 1985:254:1926-31.

20. Ziekenfondsraad Beperking voor te schriven hoeveeheden geneesmiddelen (Restriction of preseniption drum dosages), Ziekenfondscirculaire $1981(34) 1-3$

21. Ministerie van Welzijn Volksgezondheid en Cultuur. Wijiging Besluit Famaceutische Hulp Ziekenfondsverzekerthe (Change of the decree on pharmaceutical care in the Dutch Sickness Fund Insurance Act). Ned Staatscourant $1983(3): 2$

22. World Health Organisation. Studies in drug utilization methods and applications. Copenhagen: WHO, 1979.

23. Nordic Council on Medicines. Nordic statistics on medicines 1981 - 1983. Part 11. Nordic drug index with classification and defined daily doses. Uppsala: Nordic Council on Medicimes, 1985.

24. Ziekenfondsraad. Farmacotherapeutisch Kompas (Gude for Phamacotherapy). Amstelveen, Zlekenfondsrand, 1986.

25. van den Berg J. De eigen bijdrage voor geneesmiddelen in 1983 (The co-paymamt for prescription drugs in 1983 ). Tijdschr Soc Gezandheidsz 1985;63:4-12.

26. de Klein JJM, Collaris JWM. Evaluate van de elgen bildrage maetregel farmacie (Evaluation of the co-payment regulation for prescription drugs). Zeist: Vereniging van Nederlandse Zlekenfondsen. Afdeting Beleidsinformatie - Onderzoek, 1984.

27. Post D. Vijf jaar prescriptie: volume- en kastenveranderingen in een ziekenfondsregio fFive years of prescription: changes in volume and expenditure in atch sickness fund region). Med Contact 1986,41:1103.4.

28. Ministerie van Volksgezondheid en Milieuhygiëne. Besluit Farmaceutische Hulp Ziekenfondsverzekering (Decree on pharmaceutical care in the Dutch Sickness Fund Hnsurance Act), Ned Staatscourant 1982(139);6-8.

29. Montgomery DC, Peck EA. Introduction to linear regression analysis, New York: Wiley, 1982.

30. Wonnacott TH, Wonnacott RJ. Regression: a second course in statistics. New York: Wiley, 1981.

31. Cramer JA, Mattson RH, Prevey ML, et al. How often is medication taken as prescribed? JAMA 1989;261:3273-7.

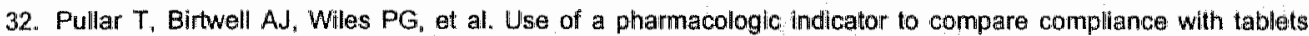
prescribed to be taken once, twice, or three times daily. Clin Pharmacol Ther 1988;44:540-5. 
Appendix 1 Overview of study drugs on the basis of ATC-codes

\begin{tabular}{|c|c|c|c|}
\hline ATC-Coder & Names of suburoups and active subastances & ATCucodies & Names of subgroups and active substances \\
\hline CO2AH & Rauwolia alkaloids & Cosch: & High-celing sulphonamide diuretics \\
\hline 002402 & Reserpine & COBCA01 & Furosemide \\
\hline COLAB & Methydopa & COOSCAO2 & - Bumetanide \\
\hline COLABOH & - Methylotopa-L & $\mathrm{Coscc}$ & Aryloxyaceticacid deminalives \\
\hline $\mathrm{CO} A \mathrm{AOOZ}$ & - Methyloopa DL & 0030001 & - Ethacrynic acid \\
\hline COLAC & Conidine and analogues & COSDA & Aldosterone antagonists \\
\hline COZACOA & Clonidine & CO3DAOA & -Spironolactone \\
\hline $\mathrm{COZACO2}$ & - Guantacina & CO3DB & Potassium-sparing diunetics \\
\hline CO2CA & a-blockers & CO3DBO1 & - Amilloride \\
\hline $\mathrm{CO2CA04}$ & - Prazosine & CO3DBO2 & Triamterene \\
\hline $\mathrm{CO2CB}$ & a and B-blockers & CD3EA & Combinations of low-eeiling diuretics \\
\hline CazCEOH & - Labelatol & & and potassium-sparing diuretics \\
\hline $\mathrm{CO} 2 \mathrm{CC}$ & Guanidine derivaliwes & COJEA01 & - Hydrochlorothiazidedriamterene \\
\hline $\mathrm{co20C02}$ & - Guanethidine & CD3EAD3 & - Epilizideftriamterene \\
\hline $\mathrm{CO2CCO3}$ & - Guanokan & CD3EA11 & - Hydrichilorothiazidelamiloride \\
\hline CO2DB & Hydralazine deriwatives & COTAA & Non-selective B-blockers \\
\hline CO2OBO1 & - Dhydralazine & COTAAD1 & - Alprenolo: \\
\hline Co20e02 & - Hyqdralazine & CO7AA02 & - Oxprenolol \\
\hline $\mathrm{CO} 20 \mathrm{C}$ & Pyrimidine deniwallives & COTAAOB & - Pindolal \\
\hline co20con & . Minoxidil & CO7AA05 & - Propranolol \\
\hline CO2DE & Calcium antagonists & C07AA06 & - Timolol \\
\hline C02DE01 & - Verapamili & COTAAO7 & - Sotallol \\
\hline CO20E02 & - Nifedipine & C07AA23 & - Penbutolol \\
\hline CO2DF & Sulphonarnides without thiazide stnucture & CO7AB & Selective B-blockers \\
\hline CO2DF01 & - Indapamide & C07ABO2 & - Metoprold \\
\hline CO2EA. & ACE inhibitors & C07ABO3 & - Atenolol \\
\hline CO2EA01 & - Caplopril & CO7ABDO4 & - Acebutolal \\
\hline $\mathrm{CO} 2 \mathrm{EA02}$ & - Enalapril & COTABO5 & - Betaxolol \\
\hline CO2LA & Combinations of rauwolfia alkaloids and diuretics. & COTBA & Combinations of non-selective s-blockers \\
\hline CO2LAO1 & - Reserpineldihydralazine/ hydrochlorothiazide & & and thiazides \\
\hline CO2LA11 & - Reserpineld dihydro-ergocristine/ clopamide & C07BA05 & - Propranololbendrollumethiazide \\
\hline CO2AA52 & × Reserpineldihydralazine & CO7BA06 & - Timalolibendroflumethiazide \\
\hline CO2LB & Conbinations of methyldopa and diuretics & COtBE & Combinations of selectiwe istblockers \\
\hline Co2L 301 & - Melhyldopalhydrochlorothiazide & & and thiazides \\
\hline CO2LC & Combinations ol clonidine and diuretics & $\mathrm{CO} \mathrm{BBO} 2$ & - Metoprololithydrochlorothiazide \\
\hline CORLOU1 & - Clonidneichlorthalidone & C078BO4 & Acebutolollhydrochiorothiazide \\
\hline COLLM & Combinattions of ACE inhibitiors and diuretics & COTCA & Combinations of non-selective B-blockers \\
\hline CO2LMO1 & - Captoprilhydrochiosolhiazide & & and other diuretics \\
\hline COSAA & Low-ceiling thiazide diuretics & COICAO3 & - Pindololdopamide \\
\hline COZAAO1 & - Bendroflumethazide & $\mathrm{Co} 7 \mathrm{CB}$ & Combinations of selective fs-blockers \\
\hline COMAMOZ & - Hydroilumethiazide & & and other diutratics \\
\hline $\operatorname{COSAA403}$ & - Hydrochtorailhiazide & Co7CBO3 & - Atenolol/chlorthalidone \\
\hline COBAAO4 & - Chilorothiazide & CO7DB & Combinations of selective fiblockers, \\
\hline comants & - Polythiazide & & thiazides and other diuretics \\
\hline COSAAMT & - Cyclopenthiazide & CO7OBO1 & - Atenolollhydrochlorothiazidelamiloride \\
\hline CO3BiA & Low coeiling sulphonamide diuretics & & \\
\hline CO3BA02: & - Quinethazone & & \\
\hline COSBADOS & - Clopamide & & \\
\hline CO3BAOA & - Chlorthalidone & & \\
\hline Co3BA05 & - Mafruside & & \\
\hline
\end{tabular}


Appendix 2 Values of the independent variables

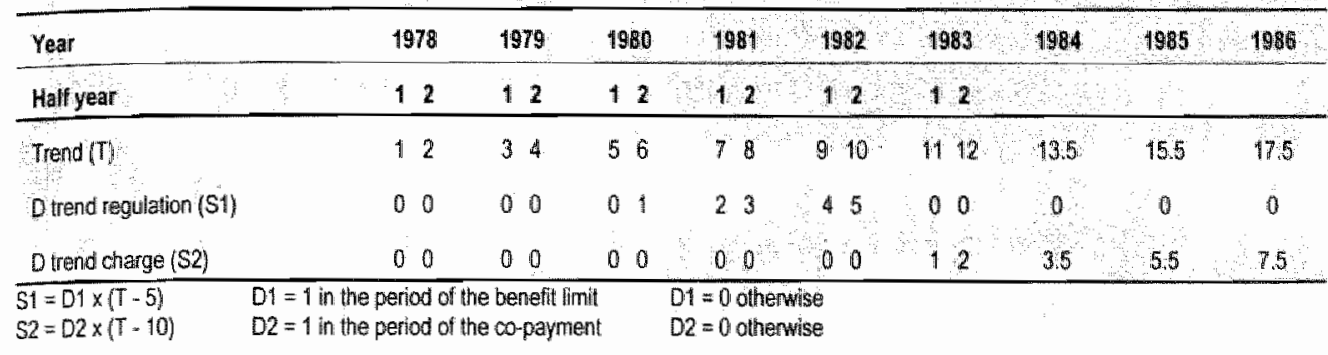

Appendix 3 Owerview of drugs introduced in the Dutch drug market during the study period

\begin{tabular}{|c|c|c|c|c|}
\hline Year & Half year & $\begin{array}{l}\text { New trade } \\
\text { mark. }\end{array}$ & $\begin{array}{l}\text { New (combination of) } \\
\text { active substances }\end{array}$ & ATC codes \\
\hline 1978 & $\begin{array}{l}1 \\
2\end{array}$ & $\begin{array}{l}1 \\
0\end{array}$ & $\begin{array}{l}1 \\
0\end{array}$ & $\mathrm{CO} 2 \mathrm{CBO}$ \\
\hline 1979 & $\begin{array}{l}1 \\
2\end{array}$ & $\begin{array}{l}2 \\
1\end{array}$ & $\begin{array}{l}1 \\
1\end{array}$ & $\begin{array}{l}\text { COTABO4 } \\
\text { CO7CAO3 }\end{array}$ \\
\hline 1980 & $\begin{array}{l}1 \\
2\end{array}$ & $\begin{array}{l}0 \\
1\end{array}$ & $\begin{array}{l}0 \\
1\end{array}$ & CO2DEO2 \\
\hline 1981 & $\begin{array}{l}1 \\
2\end{array}$ & $\begin{array}{l}1 \\
2\end{array}$ & $\begin{array}{l}1 \\
2\end{array}$ & $\begin{array}{l}\text { COICBO3 } \\
\text { CO2EA0 " } C O 7 A 423\end{array}$ \\
\hline 1982 & $\begin{array}{l}1 \\
2\end{array}$ & $\begin{array}{l}0 \\
4\end{array}$ & $\begin{array}{l}0 \\
3\end{array}$ & $\mathrm{CO} 2 \mathrm{DCO}, \mathrm{CO} \mathrm{BA} 055_{4} \mathrm{CO} \mathrm{BB} 02$ \\
\hline 1983 & $\begin{array}{l}1 \\
2\end{array}$ & $\begin{array}{l}1 \\
1\end{array}$ & $\begin{array}{l}1 \\
1\end{array}$ & $\begin{array}{l}\text { CO7BA06 } \\
\text { CO2ACO2 }\end{array}$ \\
\hline 1984 & & 1 & 0 & \\
\hline 9985 & & 10 & 4 & CO7ABOS, CD2EAO2, CO7BBOA, CO2LMO1 \\
\hline 1986 & & 4 & 1 & COTDBO1 \\
\hline
\end{tabular}





\section{Benefit limit and co-payment effects on}

expenditure for antihypertension drugs in Limburg, The Netherlands: some implications for the effect of a reference price system

(Based on: Starmans B, Janssen R, Schepers M, Verkooijen M. The effect of a patient charge and a prescription regulation on expenditure for antihypertension drugs in Limburg, The Netherlands: some implications for the effect of a reference price system. International Journal Health Sciences 1994;5:105-17) 


\section{Abstract}

Both the effect of introducing a benefit limit and the effect of introducing a co-payment for outpatient prescription drugs in the Dutch sickness funds insurance scheme, on expenditure for antihypertension drugs at the sickness funds in Limburg, were investigated by means of an interrupted time-series analysis. The benefit limit was in force from 1981 to 1983 . In this period, for the majority of drugs, sickness funds refunded only a quantity of tablets for a maximum of 30 days per prescription item. The co-payment was in force from 1983 to 1990 . It consisted of an amount of NLG 2.50 (1.10 in 1995 US\$) per prescription item up to a maximum of NLG 125 (55 in 1995 US\$) for each family per calendar year.

Total expenditure by the sickness funds and insurants on antihypertension drugs in Limburg showed a sharply increasing trend during the entire period investigated (1978-1986). Neither after the introduction of the benefit limit, nor after that of the co-payment, was this expenditure significantly reduced. The continuing increasing trend was mainly the result of a turnover between different subgroups of antihypertensive agents. Generally, less expensive agents were replaced by more expensive agents.

The findings of the present study imply that the current Dutch reference price system for prescription drugs, which consists of a combination of 2 types of benefit limits, will, once again , not be an effective measure in reducing total expenditure on antihypertension drugs.

\section{Introduction}

Health insurance systems in developed countries usually have patient charges for out-patient prescription drugs $(1,2)$. Such charges may serve as an additional source of financing, but may also serve to reduce medical consumption without adverse health effects $(3,4)$. Several studies have investigated the effect of patient charges for prescription drugs on the use of these agents (5-10). These studies generally showed that a patient charge for prescription drugs results in a decrease in the total number of prescription items per insurant. The number of prescription items, however, is only a rough measure of drug consumption. A reduction in total drug expenditure may be partly of even fully offset by an increase in total expenditure per prescription item, for example due to an increase in the number of tablets per prescription item $(5,9)$. The comprehensive RAND health insurance experiment, which studied the effects of patient charges for outpatient care (prescription drugs included) and even total health care, showed that both drug utilization and expenditure were reduced ( $\| 1$ ). This study, however, did not measure the effect of patient charges for prescription drugs exclusively. The researches believed the reduction in drug expenditure resulted mostly from a reduction in physician visits.

The primary aim of the present study was to analyze the effectiveness of a patient charge for outpatient prescription drugs in reducing expenditure on antihypertensives. High blood pressure (hypertension) is an important risk factor for cardiovascular disease $(12,13)$. In developed countries these diseases are the most important cause of total mortality (14). Several studies have demonstrated that the risk of certain cardiovascular diseases can be reduced by the use of antihypertensives (15-17). By means of an interrupted time-series analysis the present study investigated the effect of 2 different types of patient charges, a benefit limit and a co-payment, for prescription drugs in the Dutch sickness fund insurance scheme, on expenditure for antihypertension drugs. The analysis covered total drug ingredient expenditure on these agents by the four sickness funds in the province of Limburg (the southern part of The Netherlands) and their insurants. On 1 January 1981 a benefit limit was introduced. In Limburg, however, this charge was already in effect from the fourth quarter of 1980 . From that date, for the majority of drugs, sickness funds refunded only a quantity of tablets for a maximum of 30 days per prescription item (18). The benefit limit was withdrawn on 1 January 1983, at almost the same time as the 
introduction of a co-payment. The second charge was in force from 1 February 1983 to 1 January 1990. It consisted of an amount of NLG 2.50 (1.10 in 1995 US\$) per prescription item up to a maximum of NLG 125 (55 in 1995 US\$) for each family per calendar year (19).

The secondary aim was to predict, on the basis of the patient charge effects measured in this study. whether or not the current Dutch reference price system for prescription drugs is an effective measure in reducing total expenditure on antihypertensives. The current system, which was introduced in the Dutch sickness fund insurance scheme in 1991, consists of a combination of 2 different types of benefit limits (20). The first type directs that; for antihypertensives, the reimbursement for the expenditure on each prescription item is limited to a dosage of no more than 90 days (or 15 days if an insurant uses antihypertensives for the first time). Thus, this type corresponds with the benefit limit mentioned above, although the level is different. The second type of a benefit limil in the current system directs that a sickness fund is allowed to refund expenditure per drug tablet only to a certain maximum amount. In the present system drugs are divided into different groups, according to their active substance(s). Drugs with the same active substance(s), or active substances with more or less the same properties, are classed in a single group. For each group an average drug price (reference price) per Defined Daily Dosis (DDD) for tablets containing an equal amount of active substance (e.g. $10 \mathrm{mg}, 25 \mathrm{mg}$ or $100 \mathrm{mg}$ active substance) has been calculated. This price (which represents the drug ingredient costs per DDD) is the maximum amount a sickness funds is allowed to refund. Within each group the reference price system should stimulate the use of those agents with a lower than average drug price (drugs for which no out-ofpocket expenditure is indebted).

In a previous study the effects of the original benefit limit and co-payment on the volume of antihypertensives in Limburg were investigated (21). It appeared that after the introduction of the benefit limit, the number of tablets per prescription item showed a decreasing trend. However, this decrease was compensated for by an increase in the number of prescription items per insurant. After the introduction of the co-payment, the number of prescription items showed a declining trend. This decrease was compensated for, however, by an increase in the number of tablets per prescription item. As a result, neither the number of tablets per insurant, nor the number of DDDs per insurant was significantly affected by these patient charges. Other factors, such as an ageing population and the introduction of new antihypertensives, exerted their influence during the entire period of investigation. Therefore, these factors were not a reasonable explanation for the abovementioned findings. The outcomes suggested that neither measure significantly reduced total expenditure on antihypertensives in Limburg.

\section{Methods}

During the period under investigation a majority of the Dutch population (approximately $70 \%$ ) were covered by the sickness fund insurance scheme for various health care costs, such as the costs of using primary physician care and prescription drugs. Sickness fund insurants can be considered as low or middle income persons (e.g. in 1983 annual family income was not higher than NLG 46,550 , or 20,599 in 1995 US\$). Some groups of civil servants (approximately $5 \%$ of the population) had their own health insurance scheme. The remainder (approximately 25\%) of the population were privately insured. On 1 April 1986 (the last year of the period investigated) several sickness fund insurants had to switch to private health insurance due to the introduction of the Health Care Tariffs Act. After the introduction of this act, approximately $62 \%$ of the population were covered by the sickness fund insurance scheme. For exceptional health care costs, such as for hospital care lasting more than 1 year and nursing home care, the entire Dutch population was compulsorily insured by an exceptional medical expenses insurance scheme. Both the sickness fund insurance plan and the exceptional medical expenses plan were implemented by regional sickness funds. 
Datal are derived from the four Sickness Funds in Limburg (approximately 760,000 insurants). The Anatomical, Therapeutical and Chemical codes (ATC-codes) of the drugs investigated and the names of the concomitant subgroups and active substances are given in appendix 1 (22). These drugs were all indicated for hypertension, but a large number was also indicated for other disorders, such as heart rhythm disorders or oedema (23). The data did not show whether a drug was used for hypertension or another disorder. Therefore, the effects of patient charges are described with respect to drugs that lower blood pressure (antihypertensives), but could also have been prescribed for disorders other than hypertension. No other drug categories were included in the study due to unavailability of data. Data with respect to antihypertensives were available for analys is in the period from 1978 to 1986 . From 1978 to 1983 biannual data were available and from 1984 to 1986 annual data.

Expenditure on antihypertensives was measured in the following three sub-periods:

1. a base period; without patient charges (1978 to the first half of 1980);

2. a period during which the benefit limit was in force (the second half of 1980 to 1982);

3. a period during which the co-payment was in force (1983 to 1986).

Drug expenditure in the latter 2 periods was compared - by means of linear regression analysis with expenditure that could have been expected if the regime without patient charges had been continued. Biannual and annual data could be compared by converting each annual data into a biannual average (by dividing annulal data by 2 ). In the regression analysis each biannual average was assigned a double weight. So, a weighted least-squares technique was applied. Due to the relatively small number of observations $(n=15)$, it was not possible to use an ARIMA (autoregressive integrated moving average) procedure (24).

A previous study, concerning the effects of the benefit limit and the co-payment on the volume of antihypertensives in Limburg, showed that if the use of antihypertensives changed after the introduction of a patient charge, it did not reach a constant level, but showed a decreasing or increasing trend (21). On the basis of these findings, the following 3 independent variables were used in the regression equation: a time variable (T) to adjust for the presence of a trend in expenditure on antihypertensives during the period investigated, and 2 dummy variables (S1 and S2) for the trend in the periods of the benefit limit and the co-payment. The values of the independent variables are shown in appendix 2 . The value of T varies from 1 in the first half of 1978 to 17.5 in 1986 . This is because the biannual averages calculated in 1984,1985 and 1986 are each placed in the middle of the concomitant period. For example, the biannual average calculated in 1986 is placed in the middle of $T=17$ (the first half of 1986) and $T=18$ (the second half of 1986). The linear regression analysis sufficiently met the regression assumptions $(25,26)$. Finally, expenditure on antihypertensives was best described by a linear regression model in which this expenditure was log-transformed.

Among the drugs which were indicated for hypertension, onlly 4 of the 60 (combinations of) active substances were covered by the so-called October measure. This measure decreed that from 1 October 1982, expenditure on a large number of drugs was no longer refunded by the sickness fund insurance, except with special authorization (27). Among the 4 (combinations of) active substances involved, total drug expenditure had already been stharply reduced before the introduction of the October measure (in the first half of 1978 total expenditure on these agents was $5 \%$ of total expenditure on antihypertensives in Limburg, while this percentage was $2 \%$ in the first half of 1982). The reduction could be explained by the serious side-effects of reserpine, (one of) the active ingredient(s). 


\section{Results}

Figure 1 shows total expenditure on antihypertensives per 1,000 insurants among the sickness funds in Limburg during the period from 1978 to 1986 . The results of the regression analysis are shown in table 1 . The coefficient for the trend $(T)$ indicates the average half-year increase in the logarithm of total expenditure on antihypertensives in the period without patient charges. The coefficient of the dummy for the trend in the period of the benefit limit (S1) indicates to what extent the trend in expenditure on antihypertensives in this period differed from the trend in the base period. The coefficient of the dummy for the trend in period of the co-payment (S2) is analogous to $\mathrm{S} 1$.

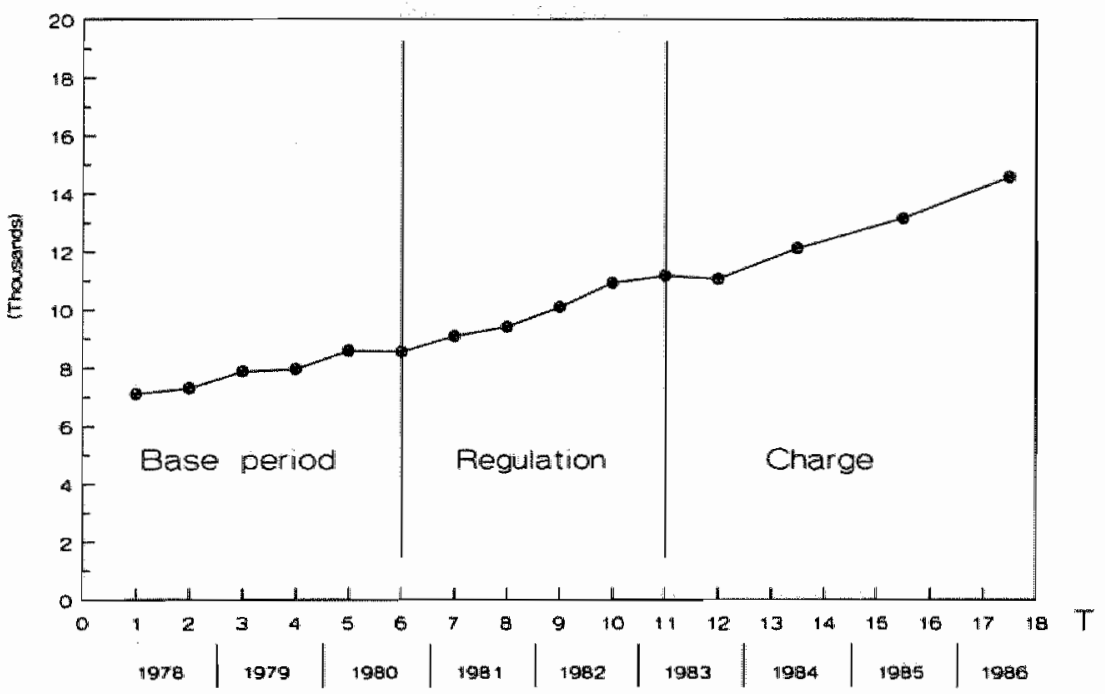

Figure 1 Total expenditure on antihypertensives per 1,000 insurants among the sickness funds in Limburg (in NLG)

Table 1 Regression coefficients with respect to the logarithm of expenditure on antihypertensives (t-values in parentheses)

\begin{tabular}{ll}
\hline Variable & Regression coefficient \\
\hline Intercept & 8.82095 \\
Trend (T) & $0.0425030(15.88)^{* * *}$ \\
D trend fegulation (S1) & $0.00492550(1.05)$ \\
D trend charge (S2) & $0.00229224(0.41)$ \\
$R^{2}$ & 0.99 \\
$F$ & $610.80^{* *}$ \\
$D . W^{*}$ & 2.21 \\
n & 15 \\
\hline
\end{tabular}

a: Presence of first-arder autocorrelation could not be assumed on the basis of the Durbin-Waison value calcullatad. 
On the basis of the regression equation, expenditure on antihypertensives, in the periods of the benefit limit $(S 2=0)$ and the co-payment $(S 1=0)$, was compared with the expenditure that could have been expected in these periods if the regime without patient charges had been continued (S1 $=0$ and $52=0$ ). Results are expressed as the percentage change in expenditure on antihypertensives and are shown in table 2 .

Table 2.1 Perceritage change in total expenditure on antifypertensives in the period of the benefit limit compared with the period without patient charges

\begin{tabular}{lccccc}
\hline & $\begin{array}{c}\text { 2nd half } \\
1980\end{array}$ & $\begin{array}{c}\text { 1st half } \\
1981\end{array}$ & $\begin{array}{c}\text { 2nd half } \\
1981\end{array}$ & $\begin{array}{c}\text { 1st half } \\
1982\end{array}$ & $\begin{array}{c}\text { 2nd half } \\
1982\end{array}$ \\
\hline Expenditure per 1,000 insuranis & $0.49 \%$ & $0.99 \%$ & $1.49 \%$ & $1.99 \%$ & $2.49 \%$ \\
\hline
\end{tabular}

Table 2.2 Percentage change in total expenditure on antihypertensives in the period of the co-payment compared with the period without patient charges

\begin{tabular}{lccccc}
\hline & $\begin{array}{c}\text { 1st half } \\
1983\end{array}$ & $\begin{array}{c}\text { 2nd half } \\
\mathbf{1 9 8 3}\end{array}$ & $\mathbf{1 9 8 4}$ & $\mathbf{1 9 8 5}$ & 1986 \\
\hline Expenditure per 1,000 insurants & $0.23 \%$ & $0.46 \%$ & $0.81 \%$ & $1.27 \%$ & $1.73 \%$ \\
\hline
\end{tabular}

During the entire period af investigation total expenditure per 1,000 insurants showed a sharply increasing trend. During the periods in which the benefit limit or the co-payment was in force, this expenditure was not significantly different from expenditure that could have been expected if the regime without patient charges had been continued. So, neither after the introduction of the benefit limit nor after that of the co-payment, a significant reduction in total expenditure on anthypertensives could be demonstrated.

The sharp increase in total expenditure on antihypertensives, from NLG 7,108 per 1,000 insurants in the first half of 1978 to NLG 14.587 per 1,000 insurants in 1986 (an increase of 105\%), was mainly the result of a turnover in drug use between different subgroups of antihypertensive agents. This could be demonstrated by using and adapting a method developed by the Dutch Sickness Fund Council to explain increases or decreases in expenditure on prescription drugs (28). On the basis of this method it is possible to distinguish 3 components of a change in drugs expenditure: 1. a change in the total number of defined daily doses (DDDs) per 1,000 insurants (use component);

2. a turnover in the use between different (sub)groups of prescription drugs (turnover component);

3. a change in the overall price level (price component).

It was calculated that these components explained $14 \%, 68 \%$ and $18 \%$, respectively, of the total increase in expenditure on antihypertensives in Limburg (see appendix 3 for the calculation method). This means that $14 \%$ of the increase could be explained by an increase in the total number of DDDs per 1,000 insurants, $68 \%$ could be explained by a turnover in antihypertension drug use and $18 \%$ by an increase in the overall price level of antihypertensives. For the calculation method, the antihypertensives investigated were divided into subgroups according to their ATCcodes (as described in appendix 1). Appendix 3 shows that the turnover component was mainly the result of a decrease in the number of DDDs per 1,000 insurants among the subgroups with ATC-codes C02AB, C02LA, C03BA and C07AA, and an increase in the number of DDDs per 1,000 insurants among the subgroups with ATC-codes C02DE, C02EA, C03EA and C07AB. Antihypertensives in the former 4 subgroups were generally less expensive than those in the latter subgroups. In 1986 expenditure per DDD was NLG 1.00, 0.38, 0.16 and 1.27, respectively, for the former subgroups. In this year, expenditure per DDD was NLG 1.41, 2.57, 0.40 and 1.38, 
respectively, for the latter subgroups. The contribution of the furnover component of each of these subgroups separately was at least $10 \%$ of the total tumover component.

In the current reference price system in The Netherlands, drugs are also divided into subgroups. For each subgroup a reference price per DDD for tablets containing an equal number of ming active substance has been calculated. The subgroups of antihypertensives and the concomitant reference prices are shown in appendix 4 . The reference prices presented are the lowest in each subgroup and are those for tablets containing the most usual amount of $\mathrm{mg}$ active substance per tablet: Tablets with deviating numbers of $\mathrm{mg}$ active substance have higher reference prices. The division of antihypertensive agents in the current system mainly follows the division of drugs according to ATC-codes (as described in appendix 1). These are also presented in appendix 4. Not all the antihypertensives investigated are included in the system. Some are no longer refunded by sickness funds or no longer used (e.g. antihypertensives with ATC-Codes C02AA and C02LA), while others are provisionally fully refunded, because they have not yet been classed in one of the subgroups. Appendix 4 describes the situation in the year that the system was introduced (1991). In addition, it shows the antihypertensives which were introduced or deleted in the period from 1991 to 1994. Finally, it also shows the changes in the division of subgroups of antihypertensives in this period.

In 1991 some reference prices were lower, but most reference prices were higher (see appendix 4) than the prices (costs per DDD) for the corresponding subgroups in 1986 (see appendix 3). There are several explanations for the differences between the reference prices in 1991 and the costs per DDD in 1986:

- the price level may have increased or decreased;

- the introduction of new antihypertensives in the period from 1987 to 1991 may have changed the average price level of a subgroup (in appendix 4, antihypertensives introduced in this period are marked);

- the reference prices per DDD presented in appendix 4 are those for tablets which contain the most usual amount of $\mathrm{mg}$ active substance per tablet (these are the lowest reference prices for each subgroup); in reality, tablets with larger or smaller numbers of $\mathrm{mg}$ active substances (which are more expensive) are also used;

- the division of antihypertensives into subgroups is not always the same;

- it is possible that in 1986 antihypertensives were used with a higher or lower than average drug price (reference price) per DDD.

The reference price system is intended to achieve a change in drug use within the different subgroups (from agents with a higher than average drug price per DDD to agents with a lower than average drug price per DDD). However, the most important cause of the sharply increasing trend in expenditure on antihypertensives in the study period, was a change in drug use between the different subgroups (from agents in a subgroup with a relatively low average drug price per DDD to agents in a subgroup with a relatively high average drug price per DDD). In 1991, the reference prices of the subgroups which contributed at least $10 \%$ to the turnover component in the period from 1978 to 1986 were NLG 1.06 (ATC-code C02AB), 0.40 (ATC-code C03BA) and 1.29 (ATCcode COPAA), respectively, for the 4 subgroups which showed a declining trend in the number of DDDs per 1,000 insurants (ATC-code CO2LA is not included in the current system), and NLG 1,88 (ATC-code C02DE), 2.24 (ATC-code C02DE), 1.99 (ATC-code C02EA), 0.57 (ATC-code C03EA) and 1.28 (ATC-code CO7AB), respectively, for the 4 subgroups which showed an increasing trend in the number of DDDs per 1,000 insurants (there are 2 subgroups with ATC-Code C02DE in the current system). The reference price system does not contain incentives to stop a turnover in drug use as described above. It is interesting to see that most antihypertensives introduced in the period after 1986 can be found in (new) subgroups with relatively high reference prices (NLG 1.28 per DDD or more; see appendix 4). This seems to indicate that the turnover trend in antihypertension drug use from subgroups with a relatively low average drug price per DDD to subgroups with a relatively high average drug price per DDD, has continued. 


\section{Conclusion}

Nether the introduction of a benefit limit nor that of a co-payment for prescription drugs in the Dutch sickness fund insurance scheme resulted in a significant reduction in total expenditure on antihypertension drugs in Limburg. During the entire period investigated (1978 - 1986) this expenditure showed a sharply increasing trend. This increase was mainily the result of a turnover between different subgroups of antihypertensive agents. In general, less expensive agents were replaced by more expensive agents. Other, less important factors which contributed to the increase in expenditure, were an increase in the total number of DDDs per insurant and an increase in the overall price level of antihypertensive agents. If the objective of patient charges for out-patient prescription drugs in a health insurance scheme is to reduce total expenditure on this provision, then, at least for antihypertensives, both types of charges investigated in this study seem to be ineffective.

The findlings of the present study correspond with the predictions on the basis of the results of a previous study with respect to the effects of the benefit limit and the co-payment on the volume of antihypertensives in Limburg (21). The latter study showed that both types of patient charges had an effect on the number of prescription items per insurant and the number of tablets per prescription item. However, neither measure resulted in a reduction in the number of tablets per insurant or the number of DDDs per insurant. In addition, the findings of the present study are consistent with those presented by the Dutch Sickness Fund Insurance Council (28) and by Zijlstra (29). These studies showed that a turnover in antihypertension drug use was the most important cause of an increasing trend in expenditure on antihypertensives in the Dutch sickness fund insurance scheme in the period from 1979 to 1987.

The present study implies that the current reference price system in The Netherlands, which consists of a combination of 2 types of benefit limits, will, once again, not be an effective measure in reducing total expenditure on antihypertension drugs. It is to be expected that, at least for antihypertensives, the system will result in a decrease in the number of tablets per prescription item, but also that a decrease in total expenditure per insurant will be offset by an increase in the number of prescription items per insurant. In addition , the system does not contain incentives to stop a turnover in antihypertension drugs use between different subgroups of antihypertensives. While the reference price system is intended to achieve a shift in drug use within different subgroups (from agents with a higher than average drug price per DDD to agents with a lower than average drug price per DDD), by far the most important cause of the increase in expenditure on antihypertiensives in the period investigated, was a change in drug use between different subgroups (from agents in a subgroup with a relatively low average drug price per DDD to agents in a subgroup with a relatively hight average drug price per DDD).

The effect of a patient charge may not be the same for all kinds of drugs $(5,10)$. Therefore "the study outcomes and its implications are not necessarily true for all drug categories. The implications my be true, however, for the effect of other reference price systems for prescription drugs on expenditure for antihypertensives. In Germany, a reference price system for prescription drugs was introduced in 1989, while in both Denmark and Sweden such a system was introduced in 1993.

To achieve a reduction in total antihypertension drug expenditure, it seems especially important to prevent a change in drug use between different subgroups of antihypertensive agents. Firstly, however, it should be determined whether or not such a change in drug use is desirable from a medical perspective. More research is needed, therefore, with respect to the cost-effectiveness of different subgroups of antihypertensives. Examples of such studies are Edelson (30), Johannesson (31) and Laaser (32). 


\section{References}

1. Schneider $M_{n}$ Dennerlen RKH, Köse $A$, Scholtes. $L$. Health care in the EC member states. Health Policy 1992;20:1-252.

2. Schneider $M$, Blene-Dietrich $P, G a b a n y i M$, et al. Gesundheidssysteme im internationalen Vergleich (International comparison of health systems). Augsbung: BASYS, 1993.

3. Arrow KJ. Uncertainty and the welfare economics of medical care. Am Econ Rev 1963;53:941-73.

4. Birch S. Increasing patient charges in the National Health Service: a method of privalizing primary care. I Soc Policy 1986;15:163-84.

5. Harris $B$. Stergachis $A$, Ried $L$. The effect of drug copayments on utilization and cost of pharmaceuticals in a health maintenance organization. Med Care 1990;28:907-17.

6. Lavers RJ. Prescription charges, the demand for prescriptions and morbidity. Appl Econ 1989:21:1043-52.

7. O'Brien B. The effect of patient charges on the utilisation of prescription medicines. J Health Econ 1989;8:109-32,

8. Ryan M, Birch S. Charging for health care: evidence on the utilization of NHS prescribed drugs. Soc Scil Med $1991 ; 33: 6811-7$.

9. Smith DG. The effects of copayments and generic substitution on the use and costs of prescription drugs. Inquiry 1993;30:189-98.

10. Soumerail SB, Avorn $\mathrm{J}_{\mathrm{n}}$ Ross-Degnian D, Gortmaker $\mathrm{S}$. Payment restrictions for prescription drugs under Medicaid: effects on therapy, cost, and equity. New Engl J Med 1987;317:550-6.

11. Leibowitz A, Manning WG. Newhouse JP. The demand for prescription drugs as a function of cost-sharing. Soc Sci Med 1985;21:1063-9.

12. Joint National Committee. The fifth report of the Joint National Committee on detertion, evaluation, and treatment of high blood pressure. Arch Intern Med 1993:153:154-83.

13. Rutan $\mathrm{GH}_{3}$ Kuller LH, Neaton JD, el al. Mortality associated with diastollic hypertension and isolated systolic hypertension among men screened for the Multiple Risk Factor Intervention Trial. Circulation 1988;77:505-14.

14. World Health Organisation. World health statistics annual. Geneva: WHO, 1990.

15. Collins R, Peto R, MacMahon S, et al. Blood pressure, stroke and coronary heart disease. Part 2. Short term reductions in blood pressure: overview of randomized drug trials in their epidemiological context. Lancet 1990;335:827-38.

16. Sever PS. The year of the hypertension trials: interpreting the results. Trends Pharmacol Sci 1986;7:134-9.

17. Medical Research Council Working Party. Medical research council trial of treatment of hypertension in older adults: principal results. Brit Med J 1992;304:405-12.

18. Ziekenfondsraad. Bieperking voor te schrijven hoeveelheden geneesmiddelen (Restriction of prescription drug dosages). Ziekentondscirculaire 1981(34):1-3.

19. Ministerie van Welzijn Volksgezondheid en Cultuur. Wijziging Besluit Farmaceutische Hulp Ziekenfondswerzekering (Change of the decree on pharmaceutical care in the Dutch Sickness Fund Insurance Act). Ned Staatscourant 1983(3):2.

20. Ministerie van Welzijn Volksgezondheid en Cultuur. Regeling Farmaceutische Hulp Ziekanfondswerzekering (Regulation of pharmaceutical care in the Dutch Sickness Fund linsurance Act). Ned Staatscourant 1991(73):6-23.

21. Starmans $B$, Janssen $R$, Schepers $M_{*}$ Verkooijen $M$. The effect of a patient charge and prescription regulation on the use of antihypertension drugs in Limburg. The Netherlands. Health Policy 1994;26:191-206.

22. Nordic Council on Medicines. Nordic statistics an medicines 1981 - 1983. Part 11. Nordic drug indlex with classification and defined dally doses. Uppsala: Nordic Council on Medicines, 1985.

23. Ziekenfondsraad. Farmacotherapeutisch Kompas (Guide for Pharnacotherapy) Amstelveen: Ziekenfondsrald, 1986.

24. McDowall D, McCleary R, Meidinger E, Hay R. Imterrupted time series analysis. Beverly Hills: Sage, 1980.

25. Montgomery DC, Peck EA. Introduction to linear regression analysis. New York: Wiley, 1982.

26. Wonnacott TH. Wonnacott RJ. Regression: a second course in statistics. New York: Wiley, 1981.

27. Ministerie van Wolksgezondheid en Milieuhygiène. Besluit Farmaceutische Hulp Ziekenfondswerzekering (Decper on pharmaceutical care in the Dutch Sickness Fund Insurance Act). Ned Staatscourant 1982(139):6-8.

28. Ziekenfondsraad. Verschuivingen op recept: analiyse kostenstijging farmaceutische hulp ziekenfondswerzekering (Shifts in prescriptions: analysis of the increase in expenditure on pharmaceutical care in the Dutch sickness fund insurance scheme). Amstelveen: Ziekenfondsraad, 1989.

29. Zijlstra IF. De regionaal klinisch farmacoloog: fanmacotherapie overteg met huisarts en apotheker (The regional clinical pharmacologist: consultations with the general practitioner and the chemist on pharmacotherapy) [Dissertation]. Groningen, 1991.

30. Edelson JT, Weinstein MC, Tosteson AM, et al. Long-term cost-effectiveness of various initial monotherapies for mild to moderate hypertension. JAMA 1990;263:408-13. 
31. Johanriesson $M$, Wikstrand $ل$, Jorisson $B$, el al. Cost-effectueness of anthypertensive treatment metoprolol versus thizide duretics. PharmacoEconomics 1993,3:36-44.

32. Laaser U. Wenzel H. Anthypentensive treatment in Giermany, subjected to a cost-effectiveness analysis. J Hum Hypertens $1990 ; 4: 436-40$. 
Appendix 1 Overview of study drugs on the basis of ATC-codes

\begin{tabular}{|c|c|c|c|}
\hline ATC-codes & Names of subgroups and active stubstances & ATC-codes & Names of subgroups and active substalices \\
\hline CORAA & Reviwolfia alkaloids & COSCA & High-ceiling sulphonamide diunetics \\
\hline $\mathrm{COZAAO2}$ & - Reserpine & COSCAOH & - Furosemide \\
\hline$C O 2 A B$ & Methyldopa & CO3CAO2 & - Bumetanide \\
\hline CO2ABOA & - Methyldopar & $\mathrm{cos} \mathrm{CC}$ & Ajyloxyaceticacid derivalives \\
\hline CO2ABO2 & - Methyldopa-DL & $\mathrm{coscc01}$ & - Ethacrynic acid \\
\hline COZAC & Cionidine and analogues & COSDA & Aldostercone antagonists \\
\hline CO2ACO1 & - Clonidine & CO3DAOH & Spironolaclone \\
\hline $\mathrm{CO2ACO2}$ & - Guanfacine & CO3DB & Potassium-sparing diuretics \\
\hline $\mathrm{CO2CA}$ & a-blockers & CO3DB0 & Amilonide \\
\hline CO2CAOT & - Prazosine & CO3DBO2 & - Triamterene \\
\hline $\mathrm{CO2CB}$ & $a$ and B-blockers & CO3EA & Combinations of low-ceiling diluretics \\
\hline $\mathrm{CO} C \mathrm{CBO}$ & - Labetatol & & and potassium-sparng diuretics \\
\hline $\mathrm{CO2CO}$ & Glanidine derivatives & CD3EA01 & - Hytrochlorothiazided Iriamterene \\
\hline $\mathrm{CO2CCO2}$ & - Guanethidine & CO3EA03 & - Epitizideifriamterene \\
\hline $\mathrm{CO2C003}$ & - Guamoxan & C03EA11 & - Hydrochlorothiazidlefamiloride \\
\hline $\mathrm{CO2DB}$ & Hydralazine derivatives & COTAA & Non-selective B-blockers \\
\hline CO2OBOA & - Dihydralazine & COTAAO4 & - Alprenolol \\
\hline $\mathrm{CO} 20 \mathrm{BO} 02$ & - Hydralazine & $\mathrm{COTAAO2}$ & - Oxprendol \\
\hline $\mathrm{C} 02 \mathrm{OC}$ & Pyrimidine derivatives & COTAAOS & Pindolol \\
\hline $\mathrm{C} 020 \mathrm{CO} 1$ & - Minoxidil & COTAA05 & - Propranolol \\
\hline CO2DE & Calcium antagonists. & CORAA06 & - Timolol \\
\hline CO2DEO 1 & - Verapamil & COTAAD7 & - Sotalol \\
\hline CO2DE 02 & - Nifedipine & COTAA23 & - Penbutalol \\
\hline $\mathrm{CO2DF}$ & Sulphonamides without thiazide structure & $\mathrm{COTAB}$ & Selective B-blockers \\
\hline C02DF01 & - Indapamide & $\mathrm{COTABD2}$ & - Metoprolol \\
\hline CO2EA & ACE inthibitors & COTABD3 & - Atenolol \\
\hline C02EA01 & - Captopril & C07ABD4 & - Acebutolol \\
\hline CO2EA02 & - Enalapril & CO7ABD5 & - Betaxobl \\
\hline CO2LA & Combinations of rauwolfia aikaloids and diuretics & COTBA & Conabinations of mon-selective \\
\hline CO2LA01 & - Reserpine/ dihydralazine/hydrochlorothiazide & & is-blockers and thiazides \\
\hline CO2LA11 & - Reserpine/dilitydro-ergocristine/clopamide & CO7BA05 & - Propranolol bendrollumethiazide \\
\hline CO2AA52 & - Reserpine/dihydralazine & COTBADG & - Timololl bendroflumethiazide \\
\hline CORLB & Combinalions of methyldopá and diurelics & $0078 B$ & Conibinations of sellocive \\
\hline C02LBO1 & - Methyldopahydrochlorothiazide & & Bablockers and thataides \\
\hline CO2LC & Combinations of clonidine and diuretics. & C078B02 & - Metoprolol hydrothlorohthiazide \\
\hline CO2LCOH & - Clonicine/chlorthalidone & $\mathrm{CO} 7 \mathrm{BBO} 4$ & - Acebutolol hydrocthlorolihazide \\
\hline CO2LM & Conbinations of $A C E$ inhibitors and diuretics & C07CA & Combinations of non-sielective \\
\hline CO2LMO1 & - Captoprilthydrochlorothiazide & & B-blockers and other diurellics \\
\hline COBAA & Low-celing hiazide diuretics & CO7CAOY & - Pindolollctopamido \\
\hline COBAA01 & - Bendroflumethiazide & CO7CB & Combinations of selective \\
\hline CO3AA02 & - Hydroflumethiazide & & 34-blockers and ather duretics. \\
\hline COBAAOA3 & - Hydrachlorothiazide & CO7CBO3 & Alenololchlorthaididone \\
\hline COBAAOA & - Chiorothiazide & CO7DB & Combinalions of selective \\
\hline CO3AA05 & Pollythiazide & & B-blockers, thiazides and other diuretics \\
\hline COSAAOT & - Cyclopenthiazide & CO7DBO1 & - Alenoibll hydrochllorothiazidelamiloride \\
\hline COBBA & Low-ceiling sulphonaminide diuretics & & \\
\hline $\mathrm{CO} 3 \mathrm{~B}, \mathrm{AO2}$ & - Quinethazone & & \\
\hline COSBA03 & - Clopamide & & \\
\hline CO3BAOA & - Chliorthatidone & & \\
\hline COSBA0.5 & - Meflusidide & & \\
\hline
\end{tabular}


Appendix 2 Values of the independent variables

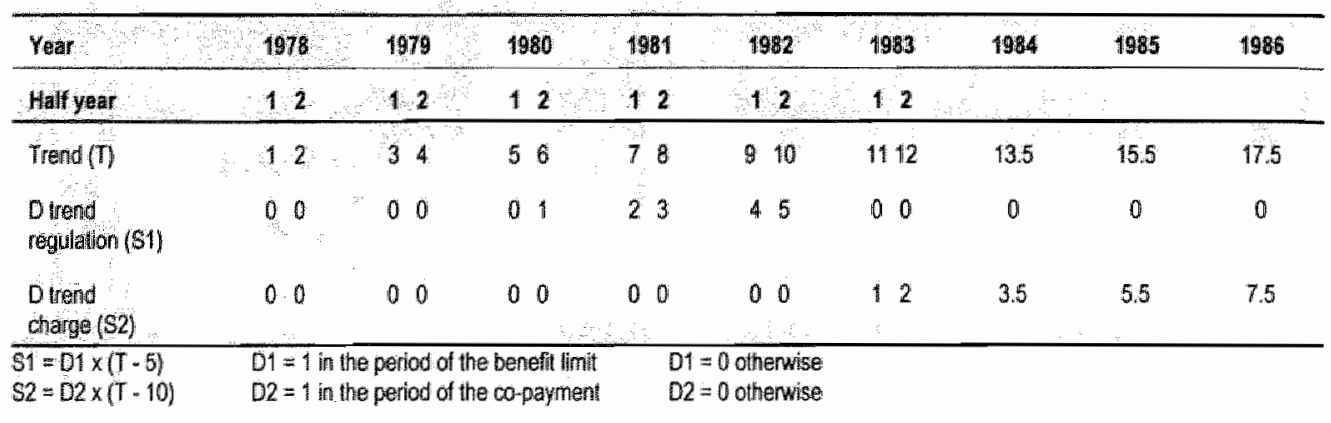


Appendix 3 Calculation of the use, turnover and price components of the increase in expenditure on antihypertensives

\begin{tabular}{|c|c|c|c|c|c|c|}
\hline $\begin{array}{l}\text { ATC-codes } \\
\text { Subgroups }\end{array}$ & A & B & c & D & E & F \\
\hline CO2AA & 0.00 & 3.55 & & 0.02 & 0.00 & 0.07 \\
\hline$C O 2 A B$ & 980.77 & 516.84 & 0.75 & 1.00 & 737.34 & 51926 \\
\hline $\mathrm{CO2AC}$ & 100.16 & 47.81 & 0.59 & 0.98 & 59.24 & 46.78 \\
\hline $\mathrm{CO2} \mathrm{CA}$ & 20.83 & 109.18 & 0.71 & 1.04 & 44.82 & 113.25 \\
\hline $\mathrm{CO} 2 \mathrm{CB}$ & 2.98 & 99.82 & 1.82 & 2.21 & 5.43 & 220.99 \\
\hline $\mathrm{CO} 2 \mathrm{CC}$ & 125.94 & 21.63 & 0.38 & 0.46 & 47.75 & 989 \\
\hline $0020 B$ & 159.66 & 266.59 & 0.31 & 0.59 & 50.05 & 136.04 \\
\hline $002 D C$ & 0.00 & 3.00 & & 2.93 & 0.00 & 881 \\
\hline CO2DE & 156.69 & 1553.44 & 1.05 & 1.41 & 164,91 & 2187.82 \\
\hline CO2DF & 133.88 & 374.14 & 0.82 & 0.72 & 110.04 & 270.91 \\
\hline$C 02 E A$ & 0.00 & 636.23 & & 2.57 & 0.00 & 1636,47 \\
\hline C02LA & 1299. 110 & 93.66 & 0.30 & 0.38 & 395.01 & 35.85 \\
\hline CO2LB & 19.83 & 6.97 & 0.58 & 0.83 & 11.53 & 5.81 \\
\hline CO2LC & 6.94 & 0.55 & 0.23 & 0.59 & 1.60 & 0.32 \\
\hline CO2LM & 0.00 & 51.09 & & 1.72 & 0.00 & $87: 76$ \\
\hline COBAA & 573.88 & 492.04 & 0.25 & 0.30 & 145.24 & 146.64 \\
\hline COBBA & 6338.31 & 2549.11 & 0.10 & 0.16 & 660.32 & 400.12 \\
\hline $\mathrm{CO} C \mathrm{CA}$ & 2186.65 & 3133.94 & 0.36 & 0.27 & 788.29 & 839.30 \\
\hline $\mathrm{CO} C \mathrm{CC}$ & 9.92 & 15.48 & 0.33 & 0.40 & 3.28 & 6.15 \\
\hline CO3DA & 156.69 & 283.22 & 2.35 & 2.10 & 367.52 & 593.92 \\
\hline C030B & 150.72 & 237.36 & 0.64 & 0.83 & 92.73 & 196.13 \\
\hline COSEA & 2784.63 & 4949.79 & 0.28 & 0.40 & 766.13 & 1999.89 \\
\hline COTAA & 1804.85 & 1509.47 & 1.12 & 1.27 & 2021.64 & 1915.33 \\
\hline C07AB & 540.46 & 1897.91 & 1.23 & 1.38 & 665.02 & 2610.93 \\
\hline COTBA & 0,00 & 70.32 & & 0.42 & 0.00 & 29.51 \\
\hline $\mathrm{CO} B \mathrm{BB}$ & 0,00 & 24.92 & & 1.00 & 0.00 & 24.85 \\
\hline COTCA & 0.00 & 195.27 & & 0.94 & 0.00 & 182.71 \\
\hline CO7CE & 0,00 & 510.47 & & $0: 70$ & 0,00 & 356.95 \\
\hline$C 07 \mathrm{DE}$ & 0.00 & 6.36 & & 0.92 & 0.00 & 5.84 \\
\hline Total & 17554.87 & $19660.16^{\mathrm{a}}$ & & & 7107.90 & $14587.31^{1 \mathrm{~B}}$ \\
\hline
\end{tabular}

$A=U s e$ (DDDs per 1,000 insurants) in 1-1978

$B=$ Use (DODs per 1,000 insurants) in 1986

$C=$ Price (costs per DOD in NLG) in 1-1978

0 = Price (cosis per DDD in NLG) in 1986

$E=$ Expenditure (per 1,000 insurants in NLG) in 1.1978

$F=$ Expendfiture (per 1,000 insurants in NLG) in 1986

$a=$ Percentage increase in total use is $11.99 \%$

$b=$ Increase in tofal expendilure (which is to be explained) is ALG 7479.41 per 1,000 insuranis 
Appendix 3 (continued)

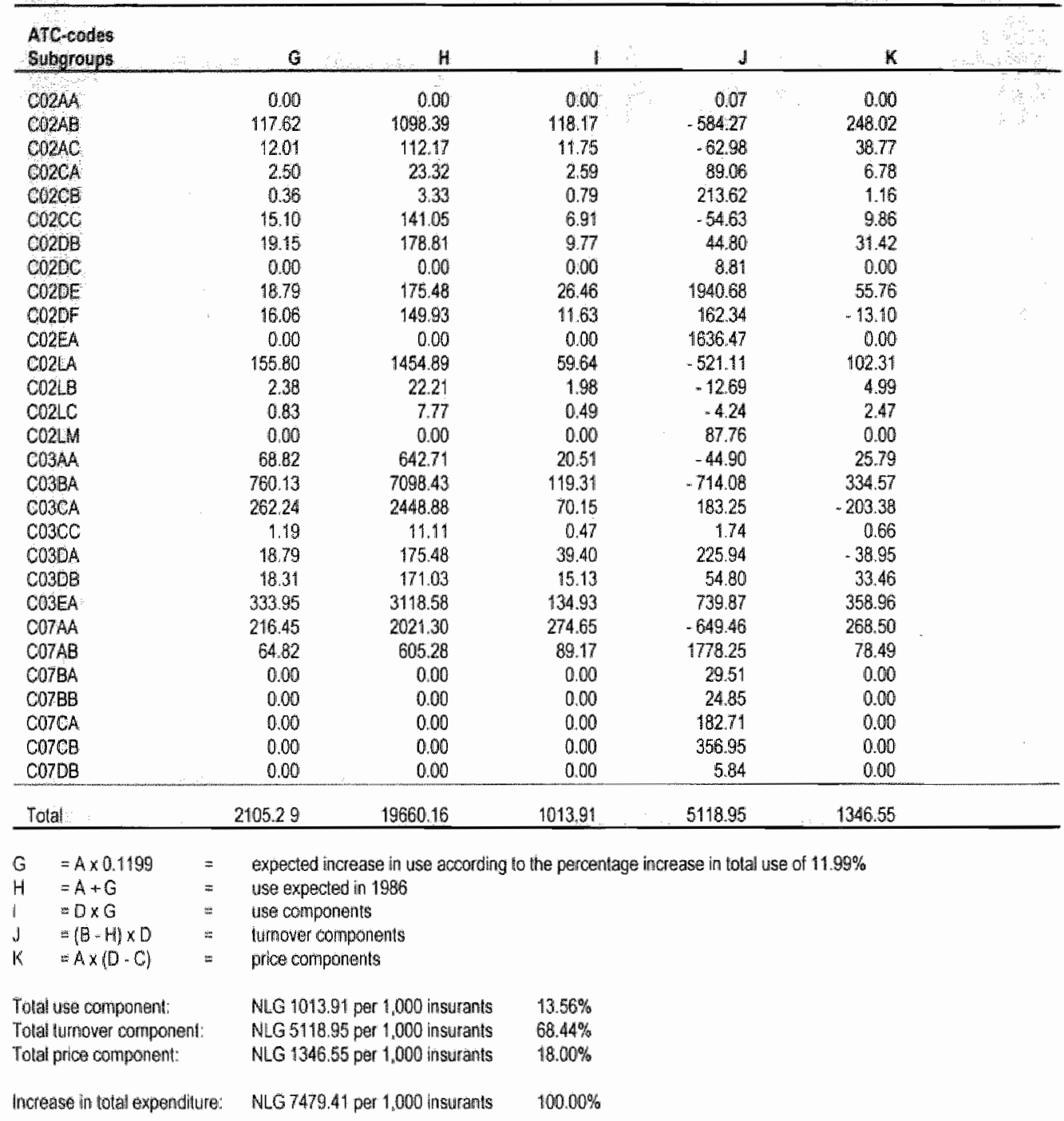


Appendix 4 Subgroups of drugs indicated for hypertension in the Dutch reference price system (1991)

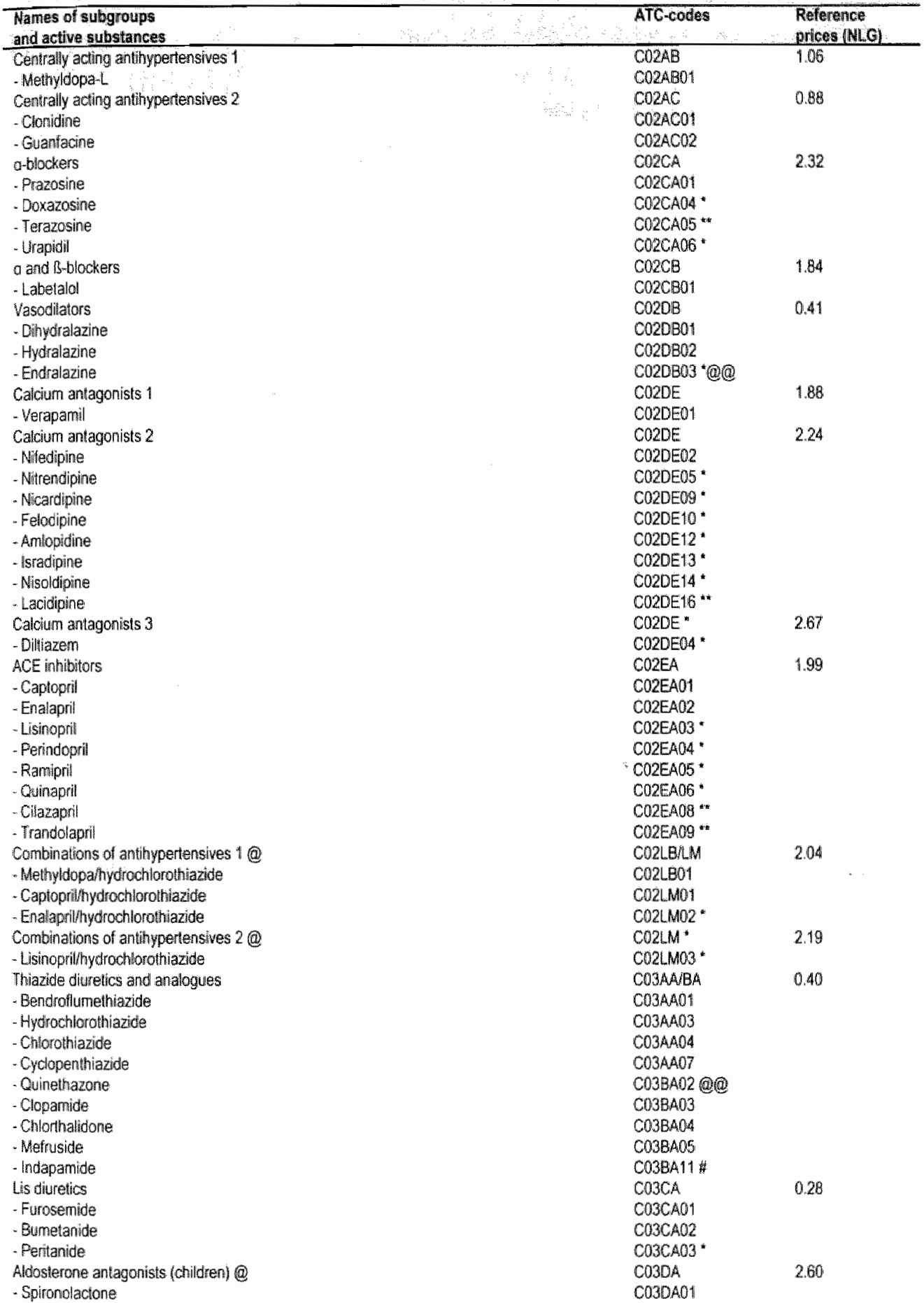




\begin{tabular}{|c|c|c|}
\hline $\begin{array}{l}\text { Names of subgroups } \\
\text { and active substances }\end{array}$ & ATC-cades & $\begin{array}{l}\text { Refierence } \\
\text { prices (NLG) }\end{array}$ \\
\hline 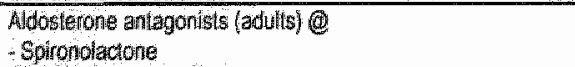 & $\begin{array}{l}\text { CO3DA } \\
\text { COSDA01 }\end{array}$ & 2.00 \\
\hline Potassium-sparing diunetics & CO30B & 0.74 \\
\hline - Amilloride & CO3DBDI & \\
\hline - Triamterene & C030B02 & \\
\hline Combinations of thiazides and potassium-sparing diuretics & COSEA & 0.57 \\
\hline - Hydrochlestothiazideftriamterene & CO3EAO1 & \\
\hline - Epilizideltriamterene & COBEAO3 & \\
\hline - Hydrocithlorothiazidelamilonide & CO3EA11 & \\
\hline Non-selective B-blockers & COTAA & 1.29 \\
\hline - Alprenoilal & COTAAO1 & \\
\hline - Oxprentiol & CO7AAO2 & \\
\hline Pindolol & COTAAD3 & \\
\hline Propraniolol & COZAA05 & \\
\hline - Timalal & CORAAOG & \\
\hline - Sotalot & COTAA07 & \\
\hline - Tertatolal & COZAA16* & \\
\hline - Penbulalal & C07AA23@@ & \\
\hline Selective B-blockers & COTAB & 1.28 \\
\hline - Metoprolol & $\mathrm{CO} A \mathrm{ABO} 2$ & \\
\hline - Alanolo! & CO7ABO3 & \\
\hline - Acebertolil & C07ABDO4 & \\
\hline - Betaxolol & C07AB05 & \\
\hline - Bevantolol & COTABO6" & \\
\hline . Bisoprolol & CO7ABO7* & \\
\hline - Celliprolol & COFABDB ** & \\
\hline Combinations of non-selective B-blockers and diwretics 1 @ & COTEANA & 1.05 \\
\hline - Propranololibendroflumethiazide & COFBAO5 & \\
\hline - Timololbendrollumethiazide & CORBADG & \\
\hline Pindololvclopamide & CO7CA03 & \\
\hline Combinations of non-selective B-blockers and diurettics 2 @. & CORDA* & 1.24 \\
\hline - Timolollhydrochlorathiazidelamiloride & COFDA07* & \\
\hline Combinations of selective B-blockers and diuretics $1 \bigcirc$ & CO7BB & 0.84 \\
\hline - Metoprolol/hycdrochlorothiazide & $\mathrm{COFBBO2}$ & \\
\hline - Acebutolol hydrochlorothiazide & CO7BBO4 & \\
\hline - Bevantolol/hydrochlorothiazide & COFBBD6* & \\
\hline Combinations of selective B-blockers and diuretics 2 (C) & $\mathrm{CO} \mathrm{CB}$ & 0.84 \\
\hline - Metoprololilchllorthalidone & $\mathrm{CO} C \mathrm{CBO} 2^{*}$ & \\
\hline - Alenololkchlorthalidone & $\mathrm{COTCBO3}$ & \\
\hline Combinalions of selective B-blockers and diuretics $3 @$ & COFDs & 1.23 \\
\hline Atenolollihydrocthlorohthiazide/amiloride & COTDBO1 & \\
\hline $\begin{array}{l}\text { Combinations of selective B-blockers and calcum antegonisis } \\
\text {-Atenolothitedigine }\end{array}$ & $\begin{array}{l}\text { COPFB } \\
\text { COPFBO3 }\end{array}$ & 1.76 \\
\hline
\end{tabular}

- Introduced in period 1987-1991

(9): Subdivision cancelled in period $1991-1994$

H: ATC oode changed in period 1987-1991 \#ntroduced in period 1991-1994

Q(e): Deletted in perios $1991-1994$

* Considered as a new subgroup im period 1991-1994 


\section{The effects of patient charges and other factors on the utilization of cross-border care: evidence of a comparative study on cross-border hospital care in the Euregio Meuse - Rhine}

(Based on: Starmans B, Leidl R, Rhodes G. A comparative study on cross-border hospital care in the Euregio Meuse - Rhine. European Journal of Public Health 1997;7:S33-S41) 


\begin{abstract}
Using data and examples from 3 academic hospitals and 1 general hospital in the Euregio Meuse Rhine in 1991 and 1992, this study illustrates the opportunities for and obstacles to cross-border inmpatient care in the European Union (EU). It defines 2 concepts of cross-border care, one related to the country of residence of the patient and the other to the country of insuranice. A number of possible determinants of cross-border in-patient hospital care in the Euregio are discussed as well as the actual evidence of this type of care in the study hospitals.

In a number of cases, the level of cross-border care measured in the study region exceeds the averagle level estimated for the EU. However, it is quite low: a share of the total hospital admissions of patients admitted from a directly neighbouring member state above $1 \%$ has been found to be extraordinarily high. On the one hand, a number of factors seem to have encouraged the crossborder in-patient care in this region: short distances between the patients' residences and foreign hospitals, lower levels of patient charges in the foreign hospitals, waiting lists in the domestic hospitals, the presence of special knowledge in the foreign hospitals, small language differences and special national regulations. On the other hand EU regulations for cross-border care for publicly insured persons in combination with generally rather low percentages of privately insured persons in this region seem to have restricted the level of cross-border care.
\end{abstract}

\title{
Introduction
}

With the increasing integration of the member states of the European Union (EU), also the interest in the possibilities for cross-border health care in the EU has been increased. Recently, within the Interregional programme (INTERREG programme) of the EU - which is directed at strengthening the cooperation across borders within the so-called Euregios - projects directed at health care issues have been set up. The project dealt with here was intended to identify the complementarities and possibilities for cooperation with respect to the supply and quality of health care in the Euregio Meuse - Rhine (1). This Euregio, covering provinces in Belgium, Germany and The Netherlands, is shown in figure 1. All the academic hospitals and also 1 general hospital in the region Meuse - Rhine, participated in the project. The project hospitals were located in Aachen (Germany), Liège (Belgium), Maastricht (The Netherlands) and Genk (Belgium), respectively. As part of the project, a study was made of the level of cross-border in-patient hospital care in this. region in 1991 and 1992 and of the factors determining this level of care.

In general, the documented volume of cross-border care in the EU for which different social health insurance systems had to be coordinated, has been found to be quite small: in 1991, the documented share of expenditure for cross-border care was no more than $0.13 \%$ of the total health care expenditure in the EU (2). However, $67 \%$ of this expenditure was accounted for by in-patient care (3). Using data and examples from the Euregio Meuse - Rhine, this study illustrates some important opportunities for and obstacles to cross-border in-patient care in the EU. 


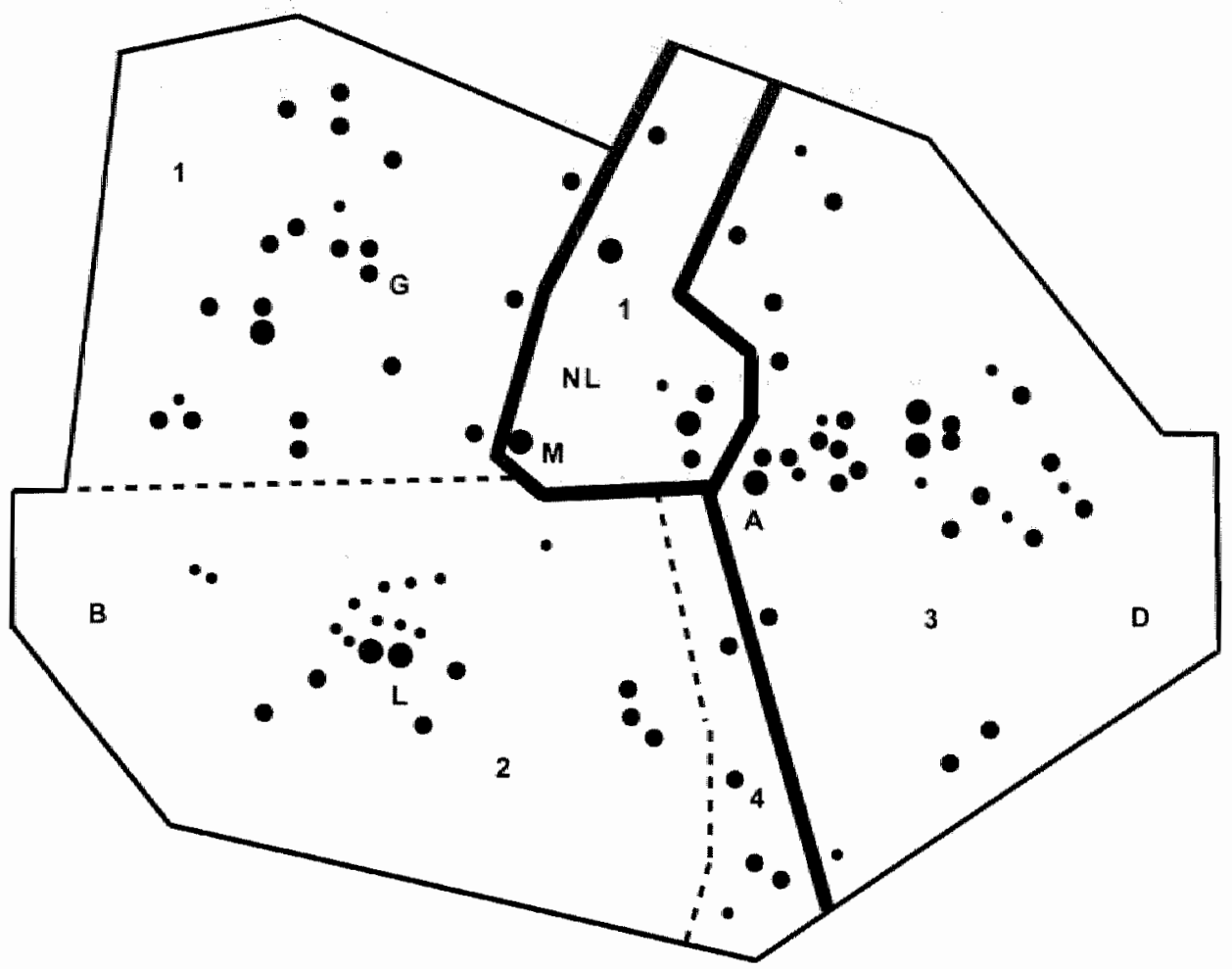

Figure 1 Hospitals and languages in the Euregio Meuse - Rhine, 1991 (23)

\section{Legend}

A. Academic hospital in Aachen; B. Beigitur, D. Germany; G: St Jans hospitat in Genk;

L. Academic hospitat in Ejege; Mcadenic hospital in Maastricht; NL: The Netherlands;

1. Dutch language; 2: French language; 3: Geman language; 4: German and French language;

- $<200$ hospital beds; $: 200$ - 500 hospital bets: $:>500$ hospital beds:

- EU member staie bordens; - Euregiomeuse - Rhine borders; - . . . language borders

The level of cross-border in-patient care in a hospital is defined as the number of foreign admissions as a percentage of the total hospital admissions. For cross-border care 2 concepts are used: (1) care delivered in one member state, while the patient is insured in a different member state and (2) care delivered in one member state, while the patient is living in a different member state (table 1). The first concept of cross-border care is the most interesting to policy makers, as it requires the financing of care across the boundaries of national health systems and, thus, the coardination of different social health insurance systems. However, as data on cross-border inpatient care on the basis of this concept were scarcely available in the project hospitals, the study adopts a broader perspective and primarily uses the second concept. First, a number of factors that can influence the utilization of cross-border in-patient hospital care - such as the presence and level of patient charges - are briefly discussed; this includes an investigation of their possible influence in the study region. Secondly, the evidence of actual cross-border care is presented and discussed, following the 2 concepts of cross-border care introduced above. 
Table 1 Concepts of cross-border care

\begin{tabular}{|c|c|c|c|c|}
\hline \multirow[t]{2}{*}{ Patient } & \multicolumn{2}{|c|}{ Live in eountry $\mathrm{A}$} & \multicolumn{2}{|c|}{ Lives in country $B$} \\
\hline & $\begin{array}{l}\text { Receives care in } \\
\text { coumthy } \mathrm{A}\end{array}$ & $\begin{array}{l}\text { Receives care in } \\
\text { country } \mathrm{B}\end{array}$ & $\begin{array}{c}\text { Receiues care in } \\
\text { country } \mathrm{A}\end{array}$ & $\begin{array}{c}\text { Recelfies care in } \\
\text { country B }\end{array}$ \\
\hline Is insured in country $A$ & & 1,2 & 2 & 1 \\
\hline Is Insured in country 8 & 1 & 2 & 1,2 & \\
\hline
\end{tabular}

1: Cross-border care with coordination of different systems.

2: Cross-border care according to country of residence

\section{Factors which can influence cross-border hospital care and their expected effects in the study region}

A first group of factors which are expected to influence the level of cross-border hospital care are those which have already been shown to be important for the utilization of hospital care within a country. A second group of factors are those which are expected to be of special relevance when hospital care is utilized across borders. Both types will be treated in the following. First, a general statement on the determinant will be presented and then the situation in the study region will be specified. All the effects hypothesized in the Euregio are summarized in table 2. A quantification of these effects is beyond the scope of this study; a formal theoretical framework for this regional analysis would be inadequately complex and data constraints would make it impossible to test any such theory. Accordingly, qualitative expectations are formulated and used in the interpretation. Many potential determinants of cross-border utilization are discussed, but the list of determinants is not claimed to be exhaustive.

The first group of determinants is discussed below and includes distance, cost sharing, hospital tariffs, the reimbursement of hospitals and physicians, the specialties and special knowledge provided, waiting lists, the referral system and population risk profiles.

Distance to hospital

An increase in the travel distance between the hospital and patient's residence is expected to lower hospital utilization $(4,5)$ and, thus, the level of cross-border hospital care. If the distance between any hospital and the patient's residence were the only variable determining hospital choice, patients from only a few locations in Belgium would be admitted to the academic hospital in Maastricht (see figure 1). In addition, patients from only a few locations in The Netherlands would be admitted to the academic hospital in Aachen. Patients from neither The Netherlands or Germany would be admitted to St Jans hospital in Genk or to the academic hospital in Liège. Finally ${ }_{*}$ patients from German locations would not be admitted to the academic hospital in Maastricht. 
Table 2 Summary of effects expected on the level of cross-border inpatient care in project hospitals

\section{Providing hosptital}

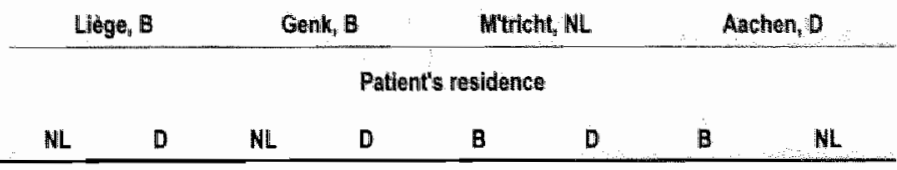

Factors of relevance in domestic care and in cross-border care

Distance to hospita:

Cosl sharing

Hospital tariff

Hospital reimbursement

Physician reimbursement

Specialties provided

Special knowiedge provided

Waiting lists

Refertal system

Risk profles (\% $\% 65 \mathrm{yrs})$

-
+
+
+
+
+
+
+

+
+
+
+
0
+
+
+

-
+
+
+
0
+
+
+

+
+
+
+
+
+
+

$\begin{array}{ccc}* & + & +1 \\ + & + & + \\ + & 0 & + \\ - & + & + \\ + & 0 & 0 \\ + & + & + \\ + & 0 & \text { na }\end{array}$

Factors of special velevance in cross-border care

EU regulation

National regulation

Percentage privately insured

Language differences

B: Belgium D: Germany NL: The Nethertands

+ positive influence $\quad x$ : negative influence 0 : indeterminate influence na: not avallable

\section{Patient charges}

Of concern to the patient is the presence of patient charges. Such charges are likely to decrease hospital utilization $(6,7)$. In 1991 and 1992 patients in Belgium were faced with a co-payment of 235 BF (5.50 in 1995 US\$) per day, if admitted to a hospital, a co-payment of 25 BF (0.60 in 1995 US\$) per day for drugs prescribed in the hospital and co-insurance of $25 \%$ of the costs of most physician services in the hospital. In Germany, publicly insured patients were faced with a copayment of 10 DM (4.80 in 1995 US $\$$ ) per day for the first 14 days admitted to the hospital. In both countries there were exemptions or reductions for some groups of insurants. In The Netherlands; publicly insured patients are not obliged to pay user charges for in-patient hospital care; privately insured patients may have to pay charges depending on their insurance contract. Current EU regulations foresee that publicly insured patients have to pay user charges according to the rules in the providing country. Accordingly, patients publicly insured in The Netherlands have to pay user charges if admitted to a hospital in Belgium or Germany, while patients publicly insured in Belgium or Germany do not have to pay user charges when receiving in-patient care in The Netherlands. This sets disincentives for Dutch patients to seek such care in Belgium or Germany, while it makes cross-border care in The Netherlands more attractive for publicly insured patients from the latter 2 countries. In addition, publicly insured patients in Belgium may, because of lower patient charges, have an incentive to seek care in Germany.

\section{Hospital tariffs}

The general level of hospital tariffs is of primary interest to the payer, who is typically in the study region, a third-party financier. While differences in the hospital financing systems make it difficult to compare the hospital tariffs in the Euregio Meuse - Rhine directly the data indicate higher levels of tariffs in The Netherlands than in Belgium or Germany. An important difference in the financing systems is that the investment costs are a part of the tariffs in The Netherlands ${ }_{\sharp}$ whereas they are paid for by the government for the most part in Belguim and Germany. Table 3 shows the costs per day (in the lowest class) for publicly insured patients in the project hospitals in April 1994. The costs 
are indicated in both the national currency and in 1995 US dollars. It is important to note that the hospitals in Aachen, Liège and Maastricht are academic hospitals, the financing of which differs somewhat from that of general hospitals because of the teaching and research activities. The academic hospital in Maastricht has the highest costs per day for publicly insured patients. This includes investment costs, the cost of drugs and specialist costs. The general hospital in Genk has the lowest costs per day but this excludes cost of specialists and the cost of drugs as well as a part of the investment costs. In sum, Dutch insurers may be interested in patients seeking hospital care in Belgium or Germany.

Table 3 Hospital tariffs for publicly insured patients in the project hospitals, April 1994

\begin{tabular}{lcccc}
\hline Prowlding hospital & Liege, B & Genk, B & M'tricht, NL & Aachen, D \\
\hline Costs per day & 10,314 EF & 7,764 BF & 837 NLG & 535 DM* \\
& 226 USs & 170 US & 336 USS & 241 US\$ \\
Speciallist cosits included & No & No & Yes & Yes \\
Cosits of drugs included & No & No & Yes & Yes \\
Inwestment costs included & $30 \%$ & $30 \%$ & Yes & No \\
\hline
\end{tabular}

B: Beigium D: Germany NL: The Netherlands ": General daily rate

\section{Hospital reimbursement systems}

Hospital budgeting is the predominant mode of financing in all 3 countries of the study (8). Budgeting however, which does not account for additional utilization, may constrain the number of admissions (9) - including that of cross-border patients. Some flexibility with respect to the number of patients treated is built into the buidget formula only in The Netherlands. Here, the budgets are determined on the basis of the population served, bed and specialist capacity and the productionrelated component which includes the number of admissions. The budget determination does not account for cross-border care in any of the 3 countries considered, although in The Netherlands the production components in the budget formula do allow a greater degree of flexibility and, consequently, might represent less of an obstacle to cross-border care.

\section{Physician reimbursement systems}

The utilization of hospital care and, then, cross-border care, can be expected to increase, if hospital physicians are paid on a fee for service basis, as compared to, for example, a salary or capitation basis $(10,11)$. In Belgium, hospital specialists are paid on a fee for service basis. In Germany, where hospital physicians are salaried employees, additional payments can only be requested for private patients. In The Netherlands, approximately $90 \%$ of the medical specialists are selfemployed, the remainder being salaried employees. The tariff lists specify reimbursement schedules, which are higher for privately insured patients. Self-employed specialists are then paid on the basis of a mix of capitation and a fee for service payment. In the academic hospital in Maastricht, the specialists are salaried employees. On the basis of this, a lower level of crossborder hospital care could be expected for both publicly and privately insured patients in Maastricht and for publicly insured persons in Aachen "as compared to the level in the Belgian hospitalls.

\section{The specialties and special knowledge provided: quality and reputation}

A higher level of the specialties provided as well as the special knowledge available in the providing hospittal are likely to increase the utilization of hospital care $(12,13)$. Due to the wide availability of most specialties in the hospitals in Belgian Limburg and Dutch South-Limburg and due to the availability of most specialties in the academic hospitals in Aachen and Liège (1), one would not expect a high level of cross-border in-patient care in the project hospitals. Similarly to these determinants, the utilization of in-patient care can be expected to increase with the reputation of the hospital physicians and the quality of the hospital services $(14,15)$. There were indications in the study that special knowledge existed, for example, in Maastricht in the field of cardiology, 
neurosurgery and paediatrics and in the field of neurosurgery in Genk. However; a general assessment of the quality and reputation in the 4 hospitals was beyond the scope of this study.

Waiting lists

Waiting lists for hospital care may decrease the additional utilization $(16,17)$ and, consequently, the level of cross-border hospital care. In 1991, in the academic hospital in Maastricht, there were frequently waiting lists of longer than 4 weeks for nearly all specialties. In all the hospitals in Dutch South-Limburg, that is in the Dutch surroundings of Maastricht, there were frequently waiting lists of up to 4 weeks for ophthalmology and plastic surgery. Waiting lists were also found for ear, nose and throat treatment, orthopaedics, theumatology, surgery and urology. In Belgian Limburg, the western part of the Euregio Meuse - Rhine in figure 1, there was only a waiting list for cardiology in 2 hospitals. The data were insufficient to determine whether the waiting lists concerned outpatient or in-patient care. On the basis of the above data, one would expect that patients living in The Netherlands would seek care in Belgium for specialties such as ear, nose and throat treatment, ophthalmology, plastic surgery, orthopaedics, rheumatology, surgery and urology. One would not expect Belgian patients to seek care in The Netherlands.

\section{The referral system}

In several but not all EU member states, publicly insured patients need a referral in order to receive hospital care (18). Referrals have been shown to be an important decision variable of the physicians in their gatekeeper function towards the utilization of hospital care (19). In the context of cross-border care, the absence of an obligatory referral system in a country is expected, other factors being equal, to ease access to cross-border hospital care. In order to receive hospital care a publicly insured patient - whether a foreigner or not - needs a referral from a physician in both Germany and The Netherlands. In Belgium, however, such a referral is not required. As a consequence, patients who are publicly insured in the former 2 countries may have an incentive to seek hospital care in Belgium. Patients publicly insured in Belgium, on the other hand, do not have an incentive to seek hospital care in Germany or The Netherlands.

\section{Population risk profiles}

The percentage of the elderly is taken as a simple indicator of the population risk profile. A higher percentage of elderly people for a given number of population is likely to increase hospital admissions (20) and, consequently, cross-border care. For pragmatic purposes, the analysis of population risk profiles had to be restricted to the percentage of the population above 65 years at the national level. in 1991, this percentage was above the EU average in Germany (14.7 and $15.3 \%$ respectively; OECD Health Data File 1995). In Belgium, this percentage was nearly equal to the EU average (14.8\%). For the last 10 years The Netherlands has had a much lower proportion (12.9\% in 1991), but faces a steeply rising trend. Just focusing on the percentage of the population over 65 years, one would expect relatively more patients living in Belgium or Germany to utilize hospital care in Maastricht, while relatively fewer patients living in The Metherlands would utilize hospital care in Belgium or Germany.

Following the discussion of factors which are also relevant in domestic hospital utilization, the next 4 factors belong to those which may specifically determine the utilization of cross-border hospital care. They comprise regulation at the EU level and at the national level, the percentage of those privately insured and language differences.

\section{Regulation on the Eu level}

The more restrictive regulations of cross-border care are, either at the EU or the national level, the more cross-border care can be expected to decrease as compared to a free choice situation (2). The current EU rules for financing cross-border care apply to publicly insured persons and are based on EU decrees $1408 / 71$ and 574/72. There are 3 main categories of access to cross-border care: (1) cross-border workers may freely chaose on which side of the border to seek care, independent of the country of insurance or residence (E106 form), (2) emergency care necessary during short stays in another member state (form E111) and (3) care pre-authorized by the 
domestic insurer (E 12). Both in the country where the patient is insured and in the country where the patient seeks care the health care service concerned should be a part of the public health insurance package. In practice, health care is also delivered if the service is not part of the public insurance package in the country where the patient is insured, but is in the country where the patient seeks care or the service is considered convenient for the patient (21). In principle, the financing of cross-border health care follows the rules of the providing country, using the same payment units and prices as for patients insured in that country. The processing of clailms is implemented through a local financier. Finally, the claims are exchanged by the national coordinating organizations of the sick funds in Brussels. As the current EU rules for publicly insured pattents allow for cross-border care only in special situations, one would generally not expect a high level of cross-border care delivered to these patients in the project hospitals. In addition, due to the procedures which have to be followed in cases of cross-border care for publicly insured persons, this care is expected to involve high transaction costs.

\section{Regulation on the national level}

Despite the EU regulations, the member states enjoy considerable discretion with respect to who is eligible to receive cross-border care (22). Some additional national legislation is pertinent here. In particular, it should be noted that in Belgium, residents within $15 \mathrm{~km}$ of the border are allowed to receive care from a provider that is located less than $25 \mathrm{~km}$ from that border. However, the costs of a normal delivery are not reimbursed if it took place in a foreign hospital.

\section{Percentage of inhabitants privately insured}

As the current EU regulations only apply to publicly insured persons, it is expected that privately insured persons will have more passibilities to opt for cross-border care. The number of privately insured persons may thus be positively correlated with cross-border care. In Belgium, however, the inhabitants are generally publicly insured for hospital care. In The Netherlands, the inhabitants are also generally publicly insured for additional in-patient hospital care after 1 year. For other in-patient hospitall care, approximately $66 \%$ of the Dutch inhabitants are publicly insured, while approximately $33 \%$ of the Dutch population rely on voluntary pivate insurance. In Germany, only approximately $10 \%$ of the population rely on voluntary private insurance for all health care risks. Belgian patients are thus expected to have the lowest share in cross-border care with respect to this determinant.

\section{Language differences}

Naturally, language differences are expected to create an obstacle to seeking or receiving care across borders. Figure 1 shows the distribution of official languages spoken in the Euregio Meuse Rhine. It can be expected that patients from many Belgian locations will have no language problems if they are admitted to the academic hospital in Maastricht nor from certain other locations in being admitted to the academic hospital in Aachen. in addition, patients living in The Netherlands. will have no difficulty if admitted to St Jans hospital in Genk. These patients may, however, face problems when admitted to the hospitals in Liege or Aachen. Finally "patients living in Germany may have language problems if they are admitted to a hospital in Genk, Liege or Maastricht. It is important to note, however, that the region has many local dialects. Generally and particularly in the Dutch/German case, the dialects have many elements in common. Therefore, the official languages as shown in figure 1 only indicate whether or not it will be difficult for a patient to receive care in a foreign hospital.

All the hypothesized effects are displayed in table 2. Clearly, no single qualitative hypothesis can be drawn by either aggregating all the effects expected per hospital in total or per hospital and catchment area. The impact of the individual determinants also varies between the 8 cross-border flows studied in the 4 hospitals, with the exception of EU regulations which apply to all in the same way by definition. As a minimum overall expectation, it can, however, be hypothesized that the existence of both negative and positive incentives for cross-border care in all cases is unlikely to lead to a particularly high volume of this type of care in the project hospitals. 


\section{Evidence of cross-border care}

Data on cross-border in-patient care have been collected from 3 academic hospitals and 1 general hospital in the study region for the years 1991 and 1992 (see the upper part of table 4 for some general information): Most data with respect to cross-border care were not immediately available in these hospitals; but had to be specially extracted from the hospital filles. In all the project hospitals, data were available with respect to the level of cross-border care on the basis of the patient's country of residence. Only in the academic hospital in Maastricht and in St Jans hospital in Genk were data available on the basis of the patient's country of insurance. The latter 2 hospitals could also provide some information with respect to the specialties visited most frequently in the case of cross-border hospital care.

Table 4 summarizes the cross-border in-patient care on the basis of the patient's country of residence for all 4 hospitals. It was not possible to receive all the data from all the countries, but the evidence so far shows considerable variation in the level of this care between the study hospitals.

Table 4 Admissions to project hospitals: the total admissions and cross-border care admissions according to country of residence

\begin{tabular}{|c|c|c|c|c|c|c|c|c|}
\hline Providing hospital & \multicolumn{2}{|c|}{ Liège, B } & \multicolumn{2}{|c|}{$\operatorname{Genk}_{x} B$} & \multicolumn{2}{|c|}{ Mtricht, NL } & \multicolumn{2}{|c|}{ Aachen, D } \\
\hline \multicolumn{9}{|l|}{ Number of heds } \\
\hline $1991 \cdot 1992$ & \multicolumn{2}{|c|}{720} & \multicolumn{2}{|c|}{470} & \multicolumn{2}{|c|}{690} & \multicolumn{2}{|c|}{1,470} \\
\hline \multicolumn{9}{|l|}{ Total admissions } \\
\hline 1991 & \multirow{2}{*}{\multicolumn{2}{|c|}{$\begin{array}{l}21,301 \\
20,829\end{array}$}} & \multirow{2}{*}{\multicolumn{2}{|c|}{$\begin{array}{l}21,947 \\
23,833\end{array}$}} & \multirow{2}{*}{\multicolumn{2}{|c|}{$\begin{array}{l}18,925 \\
20,029\end{array}$}} & \multirow{2}{*}{\multicolumn{2}{|c|}{$\begin{array}{l}38,564 \\
39,989\end{array}$}} \\
\hline 1992 & & & & & & & & \\
\hline Patient's residerice & ML. & D & NL & D & B & D & B & NL. \\
\hline \multicolumn{9}{|c|}{ Admissions by country of residence } \\
\hline 1991 & 5 & 3 & 42 & 0 & 336 & 491 & ria & па \\
\hline 1992 & 4 & 0 & 59 & 0 & 340 & na & 423 & 345 \\
\hline \multicolumn{9}{|l|}{$\begin{array}{l}\text { Percentage admissions } \\
\text { by country of residence }\end{array}$} \\
\hline 1991 & 0.02 & 0.01 & 0.19 & 0,00 & 1.78 & 0.26 & กa & ma \\
\hline 1992 & 0.02 & 0.00 & 0.25 & 0.00 & 1.70 & na & 1.06 & 0.85 \\
\hline
\end{tabular}

B: Beigium D: Germany NL: The Netherlands

The academic hospital in Aachen

In 1992, 345 admissions (0.86\% of the total admissions) to the academic hospltal in Aachen were patients living in The Netherlands. In the same year 423 admissions (1.06\% of the total admissions) were patients living in Belgium. The academic hospital in Aachen has a bed capacity approximately twice as big as the other 2 academic hospitals

The academic hospital in Liege

The numbers of admissions to the academic hospital in Liege, both for patients living in Germany and for patients living in The Netherlands, were very small in 1991 and 1992 (varying from 0.00 to $0.02 \%$ of the tolal admissions).

\section{The academic hospital in Maastricht}

In the academic hospital in Maastricht, 49 admissions (0.26\% of the total admissions) in 1991 were patients living in Germany. In the same year 336 admissions (1.78\% of the total admissions) were patients living in Belgium. In 1992 this number of admissions was $340(1.70 \%$ of the total admissions). The specialties used most frequently by patients living in Belgium, were paediatrics, 
cardiology; theurosurgery, neurology (1992 only) and urology (1992 only). Among the pattents living in Belgium, most came from the Meuse - Rhine region (318 in 1991 and 314 in 1992). They pierticularly came from Lanaken ( $82 \mathrm{in} 1991$ and 83 in 1992), a place in which many Dutch nationals live. A majority of the patients living in Belgium and admitted to the academic hospital in Maastricht were cross-border workers, that is they were employed and insured in The Netherlands. If the patient's country of insurance is used as the critertum for cross-border care, instead of the patient's country of residence, only approximately $0.71 \%$ of the total admissions in 1991 and only approximately $0.62 \%$ of the total admissions in 1992 to the academic hospital in Maastricht can be considlered as cross-border in-patient care delivered to patients who were both living and being insured in Belgium.

\section{St Jans hospital in Genk}

In St Jans hospital in Genk, there were no admissions of patients living in Germany. However, 42 admissions (0.19\% of the total admissions) in 1991 and 59 admissions ( $0.25 \%$ of the total admissions) in 1992 were patients living in The Netherlands. The specialties used most frequently by patients living in The Netherlands, were orthopaedics, neurosurgery and ophthaimology. Among these patients, most were of Dutch nationality (32 in 1991 and 54 in 1992) and came from the Dutch part of the Meuse - Rhine region (29 in 1991 and 41 in 1992). They particularly came from Maastricht (6 in 1991 and 14 in 1992). Approximately half of the Dutch patients living in The Netherlands were cross-border workers, that is they were employed and insured in Belgium, but this share dropped by half in the second study year. Again, if not the patient's country of residence but the patient's country of insurance is used as the criterium for cross-border care, only $0.07 \%$ of the total admissions in 1991 and only $0.18 \%$ of the total admissions in 1992 in the St Jans hospital can be considered as cross-border in-patient care delivered to patients who were Dutch nationals and both living and insured in The Netherlands. However, this involved little coordination between the different social health insurance systems, since almost all the cross-border patients who were insured in The Netherlands were privately and not publicly insured.

\section{Discussion}

Within the Euregio Meuse - Rhine a considerable variation in the level of cross-border care thas been found. For further discussion a three stage classification is suggested for cross-border care in this region: at a low level, cross-border care cases account for $0.00-0.09 \%$ of the total hospital admissions at an intermediate level, they account for $0.10-0.99 \%$ of the total hospital admissions and at a high level, they account for $1 \%$ or more of the total hospital admissions. These 3 classes allow a more detalled discussion of the various faclors that influence the level of cross-border care in the 4 project hospitals and their respective 8 catchment areas for this type of care.

An example of a low level of cross-border care is the academic hospital in Liège, which had between 0.00 and $0.02 \%$ of the total admissions in the study years. This low level can be related to the following factors which have been discussed as determinants of cross-border care.

(1) The larger distance between this hospital and the insurants' residences, as compared to the distance between the insurants' residences and domestic hospitals.

(2) The higher level of patient charges implemented in this hospital, as compared to the charges made in the insurants" domestic hospitals.

(3) The lack of less restrictive national regulation (as compared to EU regulation) concerning German and Dutch patients seeking cross-border care in Belgium.

(4) Large differences between the official languages of the providers in question and the insurants living across the border.

The impact of these factors could obviously not be overcome by the potentially positive influences of a lack of a referral requirement, fee for service reimbursement of physicians, special knowledge provided and shorter waiting lists. 
The cross-border care flows at the intermediate level comprise patients living in The Netherlands and admitted to the academic hospital in Aachen, patients living in The Netherlands and admitted to the St Jans hospital in Genk and patients living in Germany and admitted to the academic hospital in Maastricht. These too, could be explained on the basis of the same combination of factors mentioned above. However, for each flow and hospital in question, 1 of these factors was different, as compared to the situation in the academic hospital in Liège. These differences were as follows.

(1) For the academic hospital in Aachen, the shorter distance between this hospital and the residences of several insurants living in The Netherlands.

(2) For the academic hospital in Maastricht, the lower level of patient charges implemented in this hospital, as compared to the charges the insurants living and admitted to a hospital in Germany are required to pay.

(3) For the St Jans hospital in Genk, the lack of serious differences between the official language of the providers and insurants living in The Netherlands.

Concerning the high level of cross-border care, 2 groups can be identified which belong to this category: patients living in Belgium and admitted to the academic hospital in Aachen and patients living in Belgium and admitted to the academic hospital in Maastricht. Again the same combination of factors seems to explain the relatively high level of cross-border care. As compared to the situation for the academic hospital in Liègle "however, these factors played a different role.

(1) The frequently shorter distance between the hospital in question and the insurants' residences, as compared to the distance between the insurants' residences and the domestic hospitals.

(2) The lower level of patient charges implemented in the hospital in question, as compared to the charges made in the insurants' domestic hospitals.

(3) The presence of less restrictive national regulations for cross-border care in Belgium as compared to the EU regulations (as a consequence, both the EU regulations and the low share of privately insured persons are less important factors for the number of Belgians utilizing cross-border hospital care).

(4) The lack of serious differences between the official language of the providers in question and the insurants' residences in question.

The most important factors determining the level of cross-border in-patient care in the project hospitals seem to be distance to the hospital "cost sharing, language differences and regulations for cross-border care, both at the EU level or at the national level. Yet this does not preclude some relevance of the other factors discussed. Concerning the presence of special knowledge, patients living in Belgium have been shown to attend most frequently the units of cardiology, neurosurgery, paediatrics, neurology (1992 only) and urology (1992 only) in the academic hospital in Maastricht. The specialties in St Jans hospital visited most frequently by patients living in The Netherlands were neurosurgery, ophthalmology and orthopaedics. This also brings waiting lists into the picture, because this constraint existed in Dutch South-Limburg, but not in Belgian Limburg for the last 2 specialties. Finally, looking at the Dutch patients at St Jans hospilal by insurance type, the only hospital for which such data were availlable, the evidence here would seem to support the hypothesis that priwate insurance is a factor likely to be more positively related with cross-border care. A last aspect concerning cross-border care according to the patient's residence is the utilization of this type of care by cross-border workers. As shown in the previous section, this patient category formed the major part of the cross-border patients in Maastricht and had some varying rellevance in Genk.

Another point is cross-border care according to the country where the patient is insured. Detailed data from the hospitals in Genk and Maastricht show that in this case, the level of cross-border inpatient care was considerably lower than when referring to the country of residence. For this concept of cross-border care it is also possible to compare the figures found with an estimate of the average level of cross-border in-patient care in the EU. The latter is based upon that care for 
Which claims have been made. Approximately $67 \%$ of the expenditure clamed for cross-border care relates to in-patient care (3). It is then assumed that the share of cross-border hospital admissions equais its share in cross-border in-patient expenditures, that is the patients involved are average costly patients. Then, $67 \%$ of the $0.13 \%$ share of the cross-border care in the total EU health care expenditure (2) which is $0.09 \%$, will indicate both the EU average of cross-border inpatient care expenditure and hospital admissions. Accordingly, the levels of cross-border admissions found in Genk exceeded the estimated EU average, but only in 1992, whereas the levels found in Maastricht do so in both years and to a great extent.

\section{Conclusion}

This study investigated cross-border in-patient care in a setting of 4 hospitals in the Euregio Meuse - Rhine. The study was made possible by participation by these hospitals in a cooperation project. The study setting provided ample opportunity for investigating a wide range of factors that can contribute to cross-border health care and also allowed the collection of data on many determinants of cross-border in-patient care as well as on the level of this care rendered by the main regional providers. The level of cross-border care in a hospital was measured in the number of foreign admissions as a percentage of the total admissions.

A number of factors seem to be of primary relevance for the level of cross-border care in this region: short distance to the providing hospital, differentials in the level of patient charges, the availability of special knowledge in the providing hospital, differentials in waiting lists, special national regulations and small language differences. Most of these factors have also been shown to be important for the domestic utilization of hospittal care. In general, the levels of cross-border care exceed to some extent the estimates of the average EU levels, but they are both low in absolute terms and in terms of their share in the total admissions: a 1\% threshold is not even reached when one follows the concept based on the country of patients' insurance, whereas it is passed in some instances. when one follows the wider concept based on the country of the patients' residence. General EU regulations restrict the amount of cross-border care for publicly insured patients, but there is a potential for cross-border care in the region which can be indicated by some subgroups. Cross-border workers who have a free choice of care on both sides of the border display higher utilization rates, the publicly insured benefited from generous national regulations in the border areas and privately insured patients were also found to make use of care across the borders more frequently under certain circumstances.

The present study shows that relevant health policy issues at the mational level, such as introducing patient charges or reducing waiting lists, may also be important for medical consumption across borders: the introduction of patient charges can be expected to encourage the use of foreign health care, while the reduction of waiting lists can be expected to encourage the use of domestic health care. With the increasing integration of the member states of the European Union, the impacts of national health policy decisions on the utilization of cross-border care can be expected to further increase. This will particularly be the case, if the current EU regulation for cross-border care for publicly insured persons becomes less restrictive. 


\section{References}

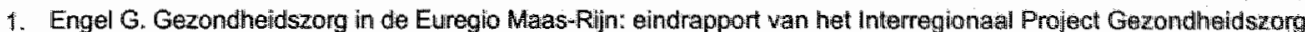
Health care in the Euregio Meuse-Rhine: final report of the Interregional Project Heath care). Maastficht: Acuademilsch Ziekenhuis Maastrioht 1994.

2. Leidl R. Auswirkungen der: EG-Integration (Impact of EC Integration). Im: Oberender P, ed. Probleme: der Transformation im Gesundheitswesen (Issues in the transformation of health care systems). Reihe Gesundheitsokkonomische Beiträge (Series Health Economics Contributions) ed. v. 20. Baden-Baden: Nomos Wertag. \$994:209-36.

3. LAssociation Internationale de la Mutualte (AM). Cross-border health care within the European Community. Brussels: Commission of the European Community, Directorate Generall V, 1991.

4. Cohen MA, Lee HL. The determinants of spatial distribution of hospital utilization in a region. Med Care $1985 ; 23-27-38$

5. Lee HL, Cohen MA. A multinominal logit model for the spatial distribution of hospital utilization. J Bus Econ Stat 4,$985 ; 3: 159-68$.

6. Frank $R$ G, Lave JR. The impact of Medicaid benefit design on length of hospital stay and patient transfers. Hosp Community Psych 1985;36:749-53.

7. Manning WG, Newhouse JP. Duan $N$, et al. Health insurance and the demand for medical care: evidence from a randomized experiment Am Econ Rev 1987;77:251-77.

8. Wiley MM, Laschober MA, Gelband H, eds. Hospital financing in seven countries Washington, D.C.: US Congress, Office of Technology Assessment, OTA-BP-H-148, US Government Printing Office, 1995.

9. Davis K, Anderson GF, Rowland D, Steimberg EP. Health care cost containment. Baltimore: John Hopkins Universitty Press, 1990.

10. Ellis RP, McGuire TG. Prowider behaviour under prospective reimbursement: cost sharing and supply. J lntealth Econ $1986 ; 5: 129-51$

11. Reinhardt $U$. The theory of physician induced demand: reflections after a decade. J Health Econ 1987;4:187-93.

12. Buczko W. Factors affecting interstate use of inpatient care by Medicare beneficiarias. Health Serv Res $1992 ; 27: 298-315$

13. Luft H, Robinson D, Garnick $S$, et al. The role of specialized clinical services in competition among hospitals. Inquiry $1986 ; 23: 83-94$.

14. Burns LR, Wholey DR. The impact of physician characteristics in conditional choice models for hospital care. J Health Econ 1992:11:43;62.

15. Luft HS, Garnick DW, Mark DH, et al. Does quality influence choice of hospital? JAMA 1990;263:2399-906.

16. Goddard JA, Malek M. Tavakoli M. An economic model of the market for hospital treatment for non-urgent conditions. Health Econ 1995;4:41-55.

17. Phelps CE, Newhouse JP. Coinsurance, the price of time and the demand for medical services. Rev Econ Stat $1974 ; 56: 334-42$

18. Schneider $M$, Denneriein RKH, Kose A, Scholtes L. Health care in the EC member states. Heatlh Folicy $1992 ; 20: 1-252$.

19. John J, Polthoff P. Cost containment in a statutory health insurance scheme by substifution of outpatient for inpatient care? The case of the Bavarian Contract. Health Policy 1987;8:153-69.

20. Leid $R$. Health economic issuas relevant to countries with ageing populations. World Health $S t a t$ Q 1992;45.95-108.

21. Roscam-Abbing HDC. Patient en gezondheidszorg in het recht wan de Europese Gemeenschap (Patients, health care, and law in the Europeam Community). Utrech: Vereniging voor Gezondheldsrecht, 1993.

22. Christelijke Mulualiteit Limburg, CZ Groep Zorgverzekeringen, Europese Unie van Christen-Democratische Werknemers. Verslag van het Europees Seminarie 'Sociale Bescherming inzake Gezandhoidszorg in enen Grensowerschrijdend Perspectief" (Proceedings of the European Seminar on Social Protection regarding Health Care in a Cross-border Perspective); 1995 May 17; Alden Blezen. Alden Blezen: CM-L, CZ-NL, EUCDW, 1995.

23. Provinciale Raad voor de Volksgezondheid Limburg. Volksgezondholdverkenningen 1: evaluatie beleid gezondheidszorg 1974-1990 (Health care explorations 1: evaluation of health care policy 1974-1990). Maastricht: Provinciale Raad woor de Volksgazondheid Limburg, 1991. 
$+3$ 
Patient charges for prescription drugs in European public health insurance schemes:

a comparison and discussion

(To be submitted) 


\section{Abstract}

This article shows that a method, previously used for synthesising empirical evidence of the impacts of patient charges in health care, can also be applied for comparing patient charge regulations in different health care systems. As an illustration, the method processes a systematic and detailed overview of prescription charge regulations in the public health insurance schemes in the member states of the European Union (EU) in 1995. Both similarities and (important) differences are indicated. In addition, the potential desirability of the existing charge regulations for reducing moral hazard is briefly elaborated.

It appears that in all EU member states there are patient charges for prescription drugs. Most frequently, there is mandatory co-insurance, without maximum expenditure, but with the possibility of reinsurance. However, the llevel of co-insurance, and the specific groups of insurants and drug categories to which a charge is applied, show a rather wide variability.

The Danish, French, Portuguese, and especially the Italian prescription charge regulation appear to correspond most with that expected to be desirable for reducing moral hazard. In Italy, there is mandatory co-insurance with a level of $50 \%$, applied to non-elderly, for non-essential drugs. Nevertheless, none of the regulations in the EU does fully correspond with the charge considered most desirable.

If the purpose of a patient charge is to reduce moral hazard, it seems to be desirable to adapt the existing patient charge regulations in the EU. Especially, in those countries were co-payment type 1 is present (in Belgium and Germany for specific kinds of drugs, and in the United Kingdom for almost all kinds of drugs), it would be desirable to replace this charge type by $50 \%$ co-insurance. In the countries were such co-insurance is already present, it may be desirable to add a moderate, income dependent maximum expenditure, and to prevent the possibility of reinsurance.

\section{Introduction}

In most public health insurance plans over the world there are patient charges. Nevertheless " the question whether or not such charges are desirable, is frequently a key issue in health policy discussions (e.g. 1-4). A patient charge comprises a specific combination of different characteristics, which finally determines the money price which an insured person has to pay outof-pocket for using a health care service that is included in a health insurance scheme. Discussion does not only concern the issue whether patient charges should be maintained, enhanced or abolished in an insurance plan, but also which kind of a patient charge should be introduced: e.g. which type of a charge, for which health care service(s), and for which group(s) of insurants.

In a previous article a method has been developed to compare the outcomes of studies of the effects of patient charges on medical utilization, expenditure, and health (5). On the basis of a synthesis of empirical evidence, this article suggested that - if the purpose of a charge is to reduce moral hazard - mandatory co-insurance with a level of about $50 \%$, with a moderate, income dependent level of a maximum expenditure (between $5 \%$ and $15 \%$ of family income per year), without the possibility of reinsurance, for non-elderly, applied to out-patient care or even all health care services, may be desirable in a public health insurance scheme. A reduction in moral hazard can be described as a reduction in medical consumption of the service(s) to which a charge is applied, without (serious) adverse health effects among the group(s) of insurants to whom this charge is applied (6). The article also suggested that co-payment type 1 , benefit limit types 4 and 5. charges applied to one (sub)provision separately, or charges applied to services for which a referral is needed, are less or even not desirable. The different terms used in these suggestions are briefly described in the next section. 
To what extent do existing patient charge regulations in public health insurance schemes differ from each other or to what extent do they correspond with each other? The primary aim of the present article is to provide a method for comparing patient charge regulations within or between different health care systems. The article shows that important parts of the method developed in the previous publication can also be used for the comparison of patient charge regulations. As an illustration, the method is applied to charge regulations for out-patient prescription drugs in the member states of the European Union (EU) in January 1995. Besides charge regulations, insurance schemes can also differ with respect to the drug categories, health carre services, or groups of insurants covered by an insurance plan. The latter aspects are not considered, however, in this article.

The secondary aim of this article is to indicate which of the prescription charge regulations presented can be expected to be desirable for reducing moral hazard. In other words: to what extent do prescription charge regulations in the EU correspond with those charges expected to be desirable for reducing moral hazard?

\section{Method}

\section{Data sources and method}

The data used in this article are coming from Abel-Smith (1), Freemantle (7), Schneider (8) and own sources (expert consultancy). Analogous to a previous article (5), the present article distinguishes different charge and insurance characteristics. On the basis of economic theory, it was expected that these characteristics would be important for the direction and magnitude of charge effects on medical utilization, expenditure, and health. Consequently, they were expected to be important for the potential desirability of a patient charge in a public health insurance scheme. As the present article focusses on out-patient prescription drugs, no distinction is made between different types of health care provisions.

\section{Identification and description of charge characteristics}

\section{Type of patient charge}

The article distinguishes the following types of patient charges: co-payment types 1 to 3, coinsurance, deductible types 1 to 3 , and benefit limit types 1 to 6 . In addition, combinations of these types or variations on these types are possible. The different types are defined and illustrated in table 1.

\section{Level of patient charge}

Examples of charge levels are also given in table 1 (e.g. a co-insurance level of $10 \%$ ). In order to improve the comparison of charge regulations in different countries, nominal charge levels (charge levels expressed as a fixed amount of money) are presented in 1995. US dollars in this overview. For this purpose, exchange rates published by the International Monetary Fund have been used (9).

\section{Presence of maximum expenditure}

Both under co-payment or co-insurance there may be a maximum to the total money price which an insurant has to pay per (sub)unit of care or which an insurant or family has to pay per unit of time. In this article such a maximum is called a "maximum expenditure". 
Table 1 Overview of different types of patient charges (examples between brackets)

\begin{tabular}{|c|c|c|c|c|}
\hline $\begin{array}{l}\text { Charge definied } \\
\text { as: }\end{array}$ & Huted amounit of money & $\begin{array}{l}\text { percentage of gross } \\
\text { price }\end{array}$ & fixed number of untts & fixed number of subunits \\
\hline pert unit of care & 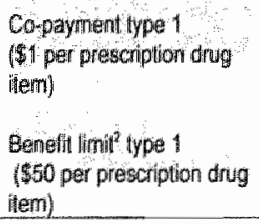 & 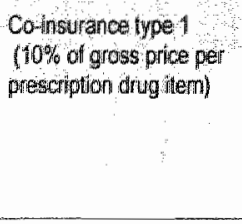 & $-\quad:$ & $\begin{array}{l}\text { Co-payment type } 3 \\
\text { first } 10 \text { tablets per } \\
\text { prescription dug lem) } \\
\text { Benefit linut type } 5 \\
\text { ( } 40 \text { labletts per } \\
\text { prescription drug item) }\end{array}$ \\
\hline $\begin{array}{l}\text { peir subunth of } \\
\text { care }\end{array}$ & $\begin{array}{l}\text { Copayment lype } 2 \\
\text { (s0.10 per preseription } \\
\text { drug lablet) } \\
\text { Benefit limil type } 2 \\
\text { (\$10 per prescriplion drug } \\
\text { lablet) }\end{array}$ & $\begin{array}{l}\text { Co-insurance type } 2 \\
\text { ("10\% of gross price per } \\
\text { prescriplion drug lathell) }\end{array}$ & $-m$ & - \\
\hline $\begin{array}{l}\text { per insurant or } \\
\text { family } \\
\text { per unit of time }\end{array}$ & 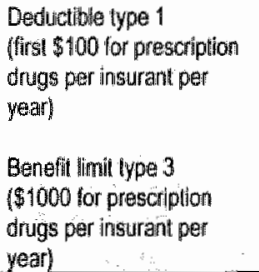 & $\begin{array}{l}\text { Co-insullanoe type } 3 \\
\text { (10\% of gross price of } \\
\text { prescription drugs per } \\
\text { insurant per year) }\end{array}$ & $\begin{array}{l}\text { Deducible type } 2 \\
\text { (first } 2 \text { presciplion drug } \\
\text { ilems per insurant per } \\
\text { month) } \\
\text { Benefil linit type } 4 \\
\text { (4 prescription drug tuterts } \\
\text { per inisurant per manth) }\end{array}$ & $\begin{array}{l}\text { Deductible fype } 3 \\
\text { (frst } 40 \text { prescriplion drug } \\
\text { fablets per insurant per } \\
\text { month) } \\
\text { Benefit timit type } 6 \\
\text { ( } 80 \text { prescripion drug } \\
\text { tablets per insurant per } \\
\text { month) }\end{array}$ \\
\hline $\begin{array}{l}\text { As in this antic } \\
\text { ypes } 1 \text { to } 3 . \\
\text { A benefit llint: }\end{array}$ & is assumred that the gross p & 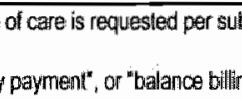 & of care, there is aclually no & ference betwaen co-insuran \\
\hline
\end{tabular}

\section{Level of maximum expenditure}

Maximum expenditures can have different levels (e.g. $\$ 500$ versus $\$ 1000$ per insurant per year). Once again, to improve the comparison of charge regulations in different countries maximum expenditure levels which were expressed in terms of a fixed amount of money are presented in 1995 US dollars in this overview.

\section{Mandatory versus voluntary patient charge}

If an insurant has the possibility to choose between a health insurance plan without patient charges for prescription drugs and a health insurance plan with patient charges for this provision (in exchange of a higher or lower insurance premium), the charges involved are voluntary. If there is only an insurance plan with patient charges, the charges involved are mandatory.

\section{Possibility of reinsurance}

If a patient charge is mandatory, insurants may have the possibility to reinsure this charge by additional (usually private) health insurance.

Number of insurants to whom the patient charge is applied

In this article the number of insurants to whom a charge for prescription drugs is applied, is considered as a charge characteristic. The features of these insurants (e.g. the average income level) are considered as insurant characteristics. The latter are described in the next paragraph. The following possibilities with respect to the number of insurants are distinguished: (a) either or not internally restricted and (b) either or not externally restricted. The number of insurants is internally restricted if certain insurants (e.g. low income persons) covered by the insurance scheme are exempted from paying the charge. The number of insurants is externally restricted if the 
insurance scheme (and, thus, the charge) covers only a certain percentage of all persons in a country.

Number of health care services to which the patient charge is applied

The number of services to which a charge is applied, is also considered as a charge characteristic. A patient charge may be applied to prescription drugs separately (one provision), or may be applied to several or even all health care services covered by a health insurance scheme. Like most health care services, prescription drugs comprise a number of different subprovisions. A patient charge may be applied to the entire provision, but may also be applied to one or more subprovisions (e.g. non-essential drugs anly).

\section{Identification and description of insurant characteristics}

\section{Level of income}

The different income categories distinguished in this article (low, middle, high, or various) are not defined in terms of a specific range of dollar amounts per insurant or family per year. They only give an impression of the income levels involved.

\section{Health status}

Once again, the different health status categories distinguished in this article, only give an impression of the health levels involved. Originally, the following categories were distinguished: low, middle, high, or various. However, it appeared to be more sufficient to distinguish the following categories: with (specific) chronic disease, without (specific) chronic disease, or various.

Age

The following age categories are distinguished: children (lower than \pm 18 years), adults (between \pm 18 and \pm 65 years), non-elderly (lower than \pm 65 years) "elderly (higher than \pm 65 years), or various (all age categories).

\section{Results}

\section{Overview of prescription charge regulations}

An overall overview of prescription charge regulations in the member states of the EU in January 1995 is given in appendix 1. The regulations are presented per charge characteristic, per insurant characteristic, and per (sub)provision, respectively (appendices 1.1 to 1.3). It appears that in all public health insurance schemes in the EU there are patient charges for prescription drugs. In some countries (e.g. in Belgium) there are different charge regulations for prescription drugs ( $\mathrm{e} . \mathrm{g}$. charges with different levels). In appendix 1 such regulations are indicated by " $a, b$, c, etc.", each character representing one specific combination of charge characteristics.

\section{Comparison of regulations per charge characteristic}

\section{Type of patient charge}

Most frequently, the type of a charge is co-insurance. In Denmark, Germany, and The Netherlands, there is (also) benefit limit type 2. More specifically, the benefit limit involved is a so-called reference price system. Such a system means that drugs are divided into different groups, according to their active substance(s). Drugs with the same active substance(s), or active substances with more or less the same properties, are classed in a single group. For each group an average drug gross price (reference price) has been calculated. This price is the maximum amount of money which is reimbursed by the insurance scheme. In The Netherlands, the reference price system is applied to almost all prescription drugs, while in Denmark and Germany, it is only 
applied to certain kinds of drugs (see "Comparison of regulations per (subjprovision"). In The Netherlands, there is actually a combination of benefit limit types 2 and 5 . In Germany, there is either a combination of different charge types - consisting of co-payment type 1 and benefit limit type 2 - or a co-payment type 1 separately. In Belgium, besides co-insurance, there is also copayment type 1, while in the United Kingdom there is only co-payment type 1. Finally, Ireland is the only country with a deductible for prescription drugs.

\section{Level of patient charge}

In appendix 1.1 the charge levels investiglated are ordered according to their heights, with the lowest height presented first. For equal patient charge types such ranking is easier (e.g. 25\% coinsurance versus $50 \%$ co-insurance) than for different charge types (e.g. $25 \%$ co-insurance versus a deductible of $\$ 1000$ per family per year). Therefore, the levels are ordered per charge type. Under co-insurance, the charge level varies from $10 \%$ to $65 \%$. In most countries having coinsurance, the level depends on the kind of prescription drug (see "Comparison of regulations per (sub)provision"). In Belgium, Portugal, and Spain the level also depends on insurance characteristics (see "Comparison of regulations per insurant characteristic"). Under co-payment type 1 , the charge level varies from $\$ 2.09$ to $\$ 8.14$ per prescription item: In Germany, the copayment level depends on the kind of prescription drug. In The Netherlands, the level of benefit limit type 5 also depends on the subprovision in question.

\section{Presence of maximum expenditure}

Most frequently, there is no maximum to the charges for prescription drugs. In Belgium and Spain, however, there are (sometimes) maximum expenditures to co-insurance, while in Germany there is a maximum expenditure to charges for both prescription drugs and other medical services in the insurance scheme.

\section{Level of maximum expenditure}

In appendix 1.1 the maximum expenditure levels are ordered according to their heights, with the lowest height presented first.

In Belgium, the level of maximum expenditure varies from $\$ 8.16$ to $\$ 20.40$ per prescription item, depending on both the kind of prescription drug and insurant characteristics. In Spain, the level is $\$ 3.29$ per prescription item (if present). In Germany, the level is $2 \%$ or $4 \%$ of family income per year.

\section{Mandatory versus voluntary patient charge}

All prescription charges are mandatory.

\section{Possibility of reinsurance}

Except for The Netherlands, in all member states there are possibilities to partly or even totally reinsure the prescription charges.

Number of insurants to whom the patient charge is applied

Most commonly, the charges are applied to a number of insurants which is only internally restricted (see also "Comparison of regulations per insurant characteristic").

Number of health care services to which the patient charge is applied

Only in 2 member states the charge is applied to the entire provision of prescription drugs. In all other countries the charge is applied to one or more specific subprovisions. In these countries there are different regullations for different kinds of drugs or certain drugs are exempted. 


\section{Comparison of regulations per insurant characteristic}

\section{Level of income}

In most member states prescription charges are applied to insurants with various income levels. In Germany, Ireland, and the United Kingdom, however, they are only applied to middle and high incomes. In Belgium, for widows, orphans, disabled, and pensioners with low income levels, the co-insurance level is lower than for all other insurants.

\section{Heaith status}

In most member states the prescription charge does generally not depend on the health status of the insurants. In Denmark, France, and the United Kingdom, however, the charge is only applied to insurants without (specific) chronic disease. In Spain, for insurants with a (specific) chronic disease, the co-insurance level is lower than for those without.

\section{Age}

Once again, in most member states prescription charges do generally not depend on the age of the insurants. However, charges are only applied to adults in the United Kingdom, adults and elderly in Germany, and to non-elderly in both Italy and Portugal.

\section{Comparison of regulations per (sub)provision}

Only in Spain and the United Kingdom, the prescription charge is applied to (almost) the entire provision of prescription drugs. In Greece, Ireland, and Luxembourg, the charge is only applied to drugs for (mainly) non-chronic disease. In Belgium and Portugal, there is co-insurance only for nonessential drugs and for essential drugs for non-chronic disease. In both countries the co-insurance level is lower for the latter than for the former subprovision. Essential drugs (e.g. antihypertension drugs) influence mortality and morbidity, while non-essential drugs (e.g. analgesics) only influence symptoms. In Belgium, there is also co-payment type 1 for drugs produced by a pharmacist. In France and Italy, there is only co-insurance for non-essential drugs. In France, the co-insurance level is higher for non-essential comfort drugs than for other non-essential drugs. In Denmark, there is a reference price system for identical drugs and co-insurance for other drugs. For the latter drugs the co-insurance level is lower for essential drugs than for non-essential drugs. In The Netherlands, there are different levels of benefit limit type 5 in combination with a reference price system. The benefit level is the lowest for drugs for chronic disease and the highest for drugs for a new indication. Finally, in Germany there are different charge regulations, depending on both the package size of the drug and whether or not the drug is included in the reference price system.

\section{Comparison of regullations with charges which are expected to be (un)clesirable}

As has been indicated in the introduction section, mandatory co-insurance with a level of about $50 \%$, with an income dependent level of a maximum expenditure, without the possibility of reinsurance, for non-elderly, applied to out-patient or even total health care, may be desirable for reducing moral hazard. It appears, however, that none of the charge regulations in the public health insurance schemes in the EU fully corresponds with the former charge (table 2). Although, most frequently, there is (at least) mandatory co-insurance, this is without maximum expenditure and with the possibility of reinsurance (Belgium, Denmark, France, Greece, ltaly, Luxembourg, Portugal ${ }_{i}$ and Spain). The level of co-insurance varies from $10 \%$ to $65 \%$, depending on the member state and (usually) the subprovision to which the charge is applied. Frequently, the charge level is higher for non-essential drugs than for essential drugs (appendix 1.3). Member states with co-insurance levels around $50 \%$ are Denmark $(25 \%-50 \%)$, France $(35 \%-65 \%)$, thaly $(50 \%)$ and Portugal $(30 \%$ $60 \%$ ). In the EU, the charges are usually applied to both elderly and non-elderly. Only in Italy, the charge is applied to non-elderly separately. This does not mean, however, that the charges are commonly applied to all insurants in the insurance plan. The number of insurants to whom the 
charge is applied, is frequently restricted (appendix 1.1). The reason for exemption, however, shows a rather wide variability (e.g. low income, having (specific) chronic disease, or low age level; see appendix 1.2 ). Further, all charge regulations are applied to prescription drugs separately. In addition, drugs for chronic disease are frequently exempted (appendix 1.3). None of charges is applied to prescription drugis in combination with other (out-patient) health care services. Nevertheless, member states cam have additional charge regulations for other services than outpatient prescription drugs (11). The latter regulations, however, are not considered in this article.

Table 2 Comparison of existing prescription charge regulations in the EU (Januay 1995)

with charge regulation which is potentially desirable for reducing moral hazard

\begin{tabular}{|c|c|}
\hline Characteriatics of change which is destrable & $\begin{array}{l}\text { EU member states having charge which corresponds with } \\
\text { characteristic. }\end{array}$ \\
\hline Coutngurance & Bel, Den, Fra, Gre, L $_{\text {ta, Lux, Por, Spa }}$ \\
\hline About $50 \%$ & $\begin{array}{l}\text { Den, Fita, 相, Por } \\
(25 \%-50 \%, 35 \%-65 \%, 50 \% \text {, and } 30 \%-60 \%)\end{array}$ \\
\hline $\begin{array}{l}\text { Hcomine dependent maximum expenditure } \\
\text { (between } 5 \% \text { and } 15 \% \text { of lamily income per yeary }\end{array}$ & $\begin{array}{l}\text { Ger } \\
\text { (between } 2 \% \text { and } 4 \% \text { of family income per year) }\end{array}$ \\
\hline Mandatory & All member states \\
\hline Whout possibility of reinsurance & Nell \\
\hline Applied lo nowelderly & lla \\
\hline Applied to oul palient or tolal health cate & - \\
\hline
\end{tabular}

As has been indicated in the introduction section, the synthesis of evidence provided by Starmans (5) also suggested that co-payment type 1 for prescription drugs would be less or even not desirable for reducing moral hazard. These charges are present in Belgium (for drugs produced by a pharmacist), Germany (for drugs not yet included in the reference price system), and the United Kingdom.

In sum, although none of the charge regulations in the member states of the EU in January 1995 fully corresponds with the charges expected to be desirable for reducing moral hazard, it seems that the regulation in Italy corresponds most with the latter charge (table 2). In Italy, there was mandatory co-insurance with a level of $50 \%$, for non-eiderly, for non-essential drugs.

\section{Conclusion}

Charge regulations for out-patient prescription drugs in public health insurance schemes in the EU show both similarities and (important) differences. Most frequently, there is mandatory co-insurance without a maximum expenditure, but with the possibility of reinsurance, applied to a restricted number of insurants as well as a restricted number of drug categories (subprovisions). However, the level of ca-insurance, as well as the specific groups of insurants and subprovisions selected, show a rather wide variability.

Of the charge regulations considered, the Danish, French, Portuguese, and especially the llalian appear to correspond most with that expected to be desirable for reducing moral hazard. in Italy, there is mandatory co-insurance with a level of $50 \%$, applied to non-elderly, for non-essential drugs. Nevertheless, this prescription regulation does neither fully correspond with the charge considered most desirable, as it can be (partly) reinsured, and as it is applied to essential drugs separately. It is expected that the possibility of reinsurance reduces the charge impacts on medical consumption, while a charge for one (sub)provision separately leaves the possibility of an adverse increase in the consumption of a different health care (sub)provision in the insurance scheme (5). 
If the purpose of a patient charge is to reduce moral hazard, it seems to be desirable to adapt the existing patient charge regulations in the EU. Especially in those countries were co-payment type 1 is present (for certain kinds of drugs in both Belgium and Germany, and for almost all drugs in the United Kingdom), it may be desirable to replace this charge lype by $50 \%$ co-insurance. In the countries were mandatory co-insurance of about $50 \%$ is already present (Denmark. France, Italy, and Portugal), it may be desirable to add a moderate, income dependent maximum expenditure, and to prevent the possibility of reinsurance. An income dependent maximum expenditure may overcome too large reductions in medical consumption, especially among low income insurants. Further, it would be desirable to replace a charge for (specific groups of prescription drugs separately, by $50 \%$ co-insurance for (out-patient) health care in general.

Especially for non-elderly, there is still insufficient quality-level evidence of patient charge effects on medical utilization, expenditure, and health (5). Therefore, one possibility may be to exempt nonelderly from patient charges. A second, more preferable, possibility would be to accompany the adaption of a prescription charge as suggested above, by an appropriate scientific evaluation. Such an evaluation may not only determine the extent to which a charge reduces imedical consumption without (serious) health effects, but may also measure the extent to which a charge results in one or more other possible desired or adverse effects (e.g. financing health care or reducing equity, respectively). Processing additional patient charge evidence will improve the possibilities of evidence based health care policy making in the field of cost sharing and health insurance.

\section{References}

1. Abel-Smith $B$, Mossialos $\mathbb{E}$, Cost containment and health care reform: a study of the European Union. Health Policy $1994 ; 28: 89-132$.

2. Hecht $\mathrm{R}_{1}$ Overholt $\mathrm{C}$, Holmberg $H$. Improwing the implementation of cost recovery for health: hessons from Zimbabwe. Health Policy 1993;25:213-42.

3. Huber JH. Ensuring access to health care with the introduction of user fees: a Kenyan example. Soc Sci Med 1993,$36 ; 485-94$.

4. Rice T, Thorpe KE. Income-felated cost sharing in health insurance Health Affair 1993, 12-1:21-39.

5. Stamans HBG. The effects of patient charges on medical utization, expenditure, and health: a synthesis of evidence from 1983 to 1995 . Forthcoming (see chapter 2 of this thesis).

6. Pauly MV. The economics of moral hazard: a comment. Am Econ Rev 1968;57:231-7.

7. Freemantte $N_{*}$ Bloor $K$. Lessions from intermational experience in controlling pharmaceutical expenditure (1): influencing patiants. Brit Med J 1996;312:1469-71.

8. Schneider $\mathrm{M}_{4}$ Blenem Dietrich $\mathrm{P}$. Gabanyi $\mathrm{M}$, al. Gesundheldssysteme im internationalen Vergleich (International comparison of health systems). Augsburg: BASYS. 1995.

9. Intemational Monetary Fund. intemational financial statistics yeabook, v. XLVIIL Washington, D.C.: Internatlonal Monetary Fund. 1995. 
Appendix 1.1 Patient charge regulations for out-patient prescription drugs in the member states of the EU (January 1995): overview per charge characteristic

\begin{tabular}{|c|c|c|c|c|c|c|c|c|c|c|c|c|}
\hline Nomber state & $B$ & 0 & $\mathrm{G}$ & $F$ & 6 & 1 & 1 & $L$ & $\mathbf{N}$ & $p$ & $\mathbf{S}$ & $\mathbf{U}$ \\
\hline 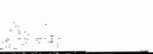 & 1 & in & $r$ & $\begin{array}{l}r \\
a\end{array}$ & $E_{0}$ & e & $\begin{array}{l}\mathrm{t} \\
\mathrm{a}\end{array}$ & $\begin{array}{l}u \\
x\end{array}$ & $\begin{array}{l}0 \\
1\end{array}$ & $\begin{array}{l}0 \\
r\end{array}$ & P & K \\
\hline
\end{tabular}

Tolal number of member slates: 12

1 Type of charge:

co-payment type 1

comintorance

ded ucitible

beinefit imit thase $2^{2}$

comblination:

$$
\begin{aligned}
& \operatorname{Cop} 1+\operatorname{Ben} 2^{2} \\
& \operatorname{Ben} 5+\operatorname{Ben} 2^{2}
\end{aligned}
$$

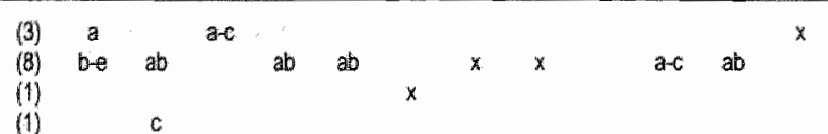

(1) df

(1) $\mathrm{ar}$

\section{Lavel of charge:}

$\$ 209$ per unit
$\$ 2.38$ per unil
$\$ 3.49$ per unit
$\$ 4.88$ per unil
$\$ 8.14$ per unil
$10 \%$
$15 \%$
$20 \%$
$25 \%$
$30 \%$
$35 \%$
$40 \%$
$45 \%$
$50 \%$
$60 \%$
$65 \%$
$\$ 144.50$ per family per quarter
Average gross price of compiarable
subprovisions

$\$ 2.09$ per unit; average gross price of comprarable sutprovisions

3.49 por unil; average gross pritoe of comparatble subprowisions

54.89 per unili, atwerage gloss price of comparable subprovistons

subumilts for 90 days average gross price of comparable subprovisions

subunits for 30 days; average gross price of comparabla subprowisions

sthunits for 15 days; average gross price of comparable subprovisions

(1) a

$\begin{array}{ll}(1): a & b \\ (1) & \text { c }\end{array}$

(1)

(1)

(1)

(1)

(3) $\mathrm{G}$ a

(1)

(1)

(1)

(3) de b

(1)

(1)

(1)

(1)

(1)

(1)

(1)

(1)

a

(1) b

(1) b

c

d

*

$$
\text { I }
$$

$b$

is a

a

$x$

a

2

b

b

$c$

3 Max expenditure:

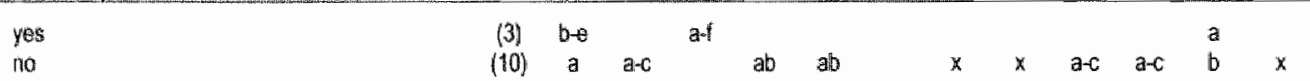

\section{Level of max expendifure:}

$\$ 3.29$ per unit

$\$ 0.16$ per unit

$\$ 12.24$ per uniti

$\$ 20,40$ per unit

$2 \%$ or $4 \%$ of tamilly income per year 


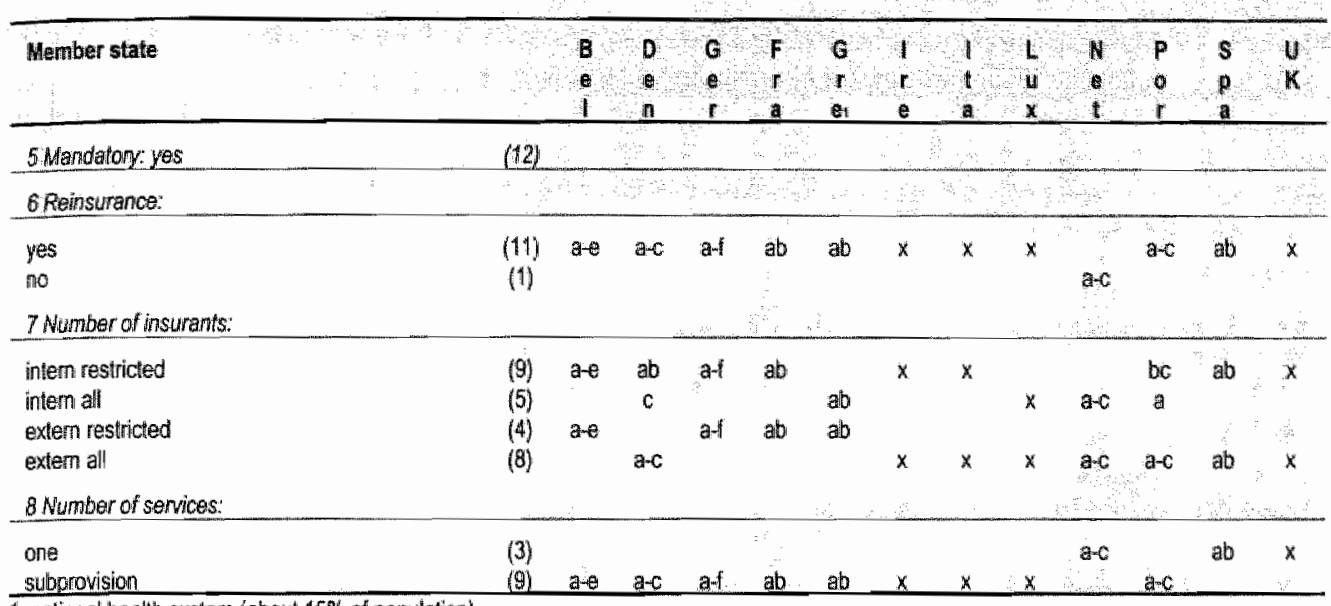

1: national health system (about $15 \%$ of population)

2. reference pirice system

3: this maximum also applies to other ciarges for medical care

Cop1: co-payment type 1

Coi: co-insurance

Ben2 (5): benefit lanit type 2 (5)

1..): number of member states per characteristic 
Appendix 1.2 Patient charge regulations for outpatient prescription drugs in the member states of the EU (January 1995): overview per insurant characteristic

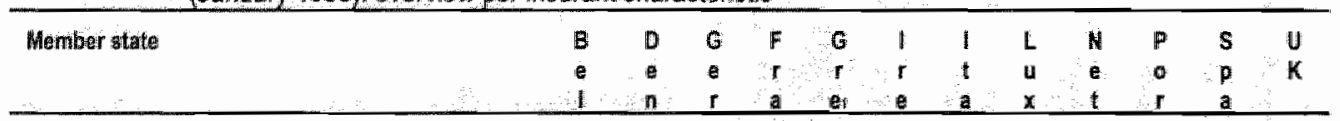

Total number of nember states: 12

1 motrome lovel:

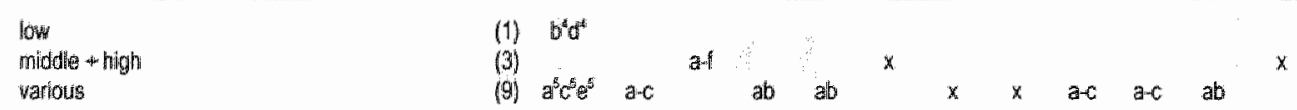

2 hedith atatus:

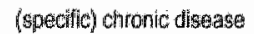

no (specific) chronic disase

various

$3 \mathrm{gge}$

adults

norimendiderly

adullis * eidderly

otderly

various

1: national health system (about $15 \%$ of poputalion)

\section{(1)}

(4) $\quad \mathrm{a}-\mathrm{c}$ ab

(B) ate atf

$a b$

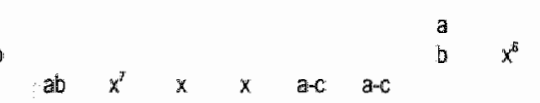

4: widows, orphans, disabled, and pensioners with low income level

5: except for widows, orphans, disabled, and pensioners with low income lewel

6: except for pregnant women

7: except for chilcren with specific chronic disease on disabilily

8: except for chituren aged $<6$

9: excepl for pensioners

(.) number of nember states per characteristic 
Appendix 1.3 Patient charge regulations for out-patient prescription drugs in the member states of the EU (January 1995): Overview per (sub) provision

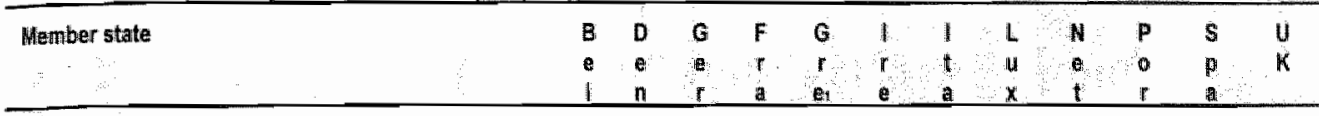

Total number of member states: 12

- (amost) entire provision of oulpat. prescription dags

- drugs for chronic disease (s)

- drugs for (mainly) non-chronic disease ${ }^{12}$ (sj

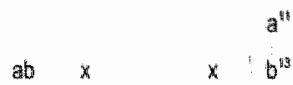

- ensential drugs (s)

$x$

$6^{12}$

- essential drugs for (mainly)

(2) bx

non-chronic disease: (s)

- non-essential drugs (s)

(4) de b

bit

- non-essential, non-comfort andgs (s)

(1)

* non-essential comilort drugs (s)

(1)

(1) $a$

* drugs for new indicalian(s)

- identical drugs (s)

(ii)

* drugis with small package size, outside neferemce price system (s)

- drugs willh medium package size, outside reference price system $(\mathrm{s})$

* drugs with large package size, ouside reference price system [s]

- drugs with small package size, inside relerence price system (s)

(1) b

(1) $\quad 0$

(1) d

* drugs with medium package size, inside (1) e reference price system (s)

- drugs with Uarge package size inside feference orice swatem (s)

1: national lhealth system (aboul $15 \%$ of population)

10: except for contraceptives

14: excepl for eg. hypnolics (subunits for 30 days), and coniraceptives (subumils for 6 monthis)

12. drugs nol for diabeles, spilepsy, cancer, tuberculosis, etc.

13: excapt for antibiotics /suburits for 15 days)

(s): subprovision

(.)): number of member states per (sulb)provision 
Patient charges in the Dutch sickness fund insurance scheme:

an overview and discussion

(To be submitted) 


\section{Abstract}

On 1 January 1997 new patient charges have been introduced in the Dutch public health insurance system. This article provides a systematic and detailed overview of the present charges in the sickness fund insurance scheme, which is one of the two public health insurance plans in The Netherlands: In addition, this article compares the current charges with that expected to be desirable for reducing moral hazard.

The most important purposes of the charges in the sickness fund insurance scheme are: (1) financing health care and (2) reducing moral hazard. However, it appears that the Dutch charges do only partly correspond with the charge which is considered most desirable for reducing moral hazard. Although, in general, there is mandatory co-insurance without the possibility of reinsurance, but with an income dependent maximum expenditure, both the co-insurance and the maximum expenditure levels are rather low. In addition, the charges are applied to specific (sub)provisions which all need prior authorization.

If the purpose of charges is (at least) reducing moral hazard, it seems to be desirable to adapt the present charges in the sickness fund insurance scheme. Firstly "both the charge level and the maximum expenditure level should be increased. Secondly, the charges should also or even mainly be applied to those services which have free access. Thirdly, it seems preferable to make the present system of cost sharing more transparent by replacing combinations of different charge types by co-insurance.

\section{Introduction}

In January 1997 new patient charges have been introduced in the Dutch sickness fund insurance scheme (1). This scheme is one of two public health insurance plans in The Netherlands. It covers approximately two-third of the population (generally low and middle income persons), mainly for socalled minor events (e.g. out-patient prescription drugs and out-patient primary physician care). The second plan, the so-called exceptional health insurance scheme, covers all inhabitants, mainly for so-called major events (e.g. continued in-patient general hospital care after one year and nursing home care). Patient charges in the first plan are generally applied to (para)medical care, while those in the second plan are frequently applied to other services, such as out-patient nursing care or house and lodging in case of in-patient medical care. A patient charge can be defined as a specific combination of different characteristics, which finally determines the money price which an insured person has to pay out-of-pocket for using a service that is included in a health insurance scheme. Patient charges can have different purposes. The most important of those in the Dutch sickness fund insurance scheme are: (1) financing health care and (2) reducing moral hazard. A reduction in moral hazard can be described as a reduction in medical consumption without (serious) adverse health effects (2).

The charges introduced in January 1997 can be considered as a result of a long lasting Dutch discussion about the desirability of patient charges in public health insurance plans. As this discussion is still continuing, it can be expected that the present charges will be adapted, or that additional charges will be introduced after 1997. The discussion does not onlly concern the issue whether patient charges should be introduced "maintained, or abolished in an insurance plan, but also which kind of a patient charge should be introduced: e.g. which type of a charge, for which health care service(s) and for which group(s) of insurants. An important question is: do charges only result in an expenditure shift (from the collective sector to the patient) or do they also result in an expenditure reduction (due to a reduction in moral hazard)?

The primary aim of this article is to provide a systematic and detailed overview of the present (January 1997) patient charges in the Dutch sickness fund insurance scheme. The method used 
for this purpose corresponds with that applied in a previous article for synthesising empirical evidence of the effects of patient charges on medical utilization, expenditure ${ }_{n}$ and health ( 3 ).

The secondary aim is to indicate to which extent the Dutch charges correspond with those expected to be desirable for reducing moral hazard: The previous synthesis of empirical evidence suggested that - if the purpose of a charge is to reduce moral hazard - mandatory co-insurance with a level of about $50 \%$, with a moderate, income dependent level of a maximum expenditure (between $5 \%$ and $15 \%$ of family income per year), without the possibility of reinsurance, for non-elderly, applied to out-patient care or even all health care services, may be desirable. The synthesis also suggested, however, that co-payment type 1 , benefit limit types 4 and 5 , charges applied to one (sub)provision separately, or charges applied to services for which a referral is needed, are less or even not desirable. The next section will explain the different terms used in these suggestions.

\section{Method}

For the description and comparison of different charge regulations this article distinguishes analogous to a previous article (3) - different charge, insurance, and service characteristics. On the basils of economic theory, it was expected that these characteristics would be important for the direction and magnitude of charge effects on medical consumption and health. Consequently, they were expected to be important for the potential desirability of a patient charge in a public health insurance scheme.

\section{Identification of charge characteristics}

\section{Type of patient charge}

The article distinguishes the following types of patient charges: co-payment types 1 to 3, coinsurance, deductible types 1 to 3 and benefit limit types 1 to 6 . In addition, combinations of these types or variations on these types are possible. The different types are defined and illustrated in table 1.

\section{Level of patient charge}

Examples of charge levels are also given in table 1 (e.g. a co-insurance level of 10\%). In order to facilitate eventual comparisons of the Dutch charges with those in other countries, charge levels which are expressed in terms of a fixed amount of money, are presented in 1997 US diollars in this overview.

\section{Presence of maximum expenditure}

Both under co-payment and co-insurance there may be a maximum to the total money price which an insurant has to pay per (sub)unit of care or which an insurant or family has to pay per unit of time. In this article such a maximum is called a "maximum expenditure".

\section{Level of maximum expenditure}

Maximum expenditures can have different levels (e.g. $\$ 500$ versus $\$ 1000$ per insurant per year). Once again, to facilitale eventual comparisons of the Dutch regulations with those in other countries, maximum expenditure levels which are expressed in terms of a fixed amount of money, are presented in 1997 US dollars in this overview. 
Table 1 Overview of different types of patient charges (examples between brackets)

\begin{tabular}{|c|c|c|c|c|}
\hline $\begin{array}{l}\text { Charge defined } \\
\text { as: }\end{array}$ & fixed amount of money & $\begin{array}{l}\text { percentage of gress } \\
\text { pricer }\end{array}$ & fixed number of units & fixed number of subunits \\
\hline per wnit of care & $\begin{array}{l}\text { Coppayment type } 1 \\
\text { (\$1 per prescription drug } \\
\text { item) } \\
\text { Benefit limint tyge 1 } \\
\text { (\$50 per prescription drug } \\
\text { ftem) }\end{array}$ & $\begin{array}{l}\text { Co-insurance type } 1 \\
\text { (10\% of gross price per } \\
\text { prescription drug flem) }\end{array}$ & 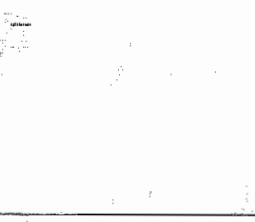 & $\begin{array}{l}\text { Co-payment type } 3 \\
\text { (first 10 tablets per } \\
\text { preseription drugg item) } \\
\text { Benefit limit type } 5 \\
\text { (40 tablets per prescription } \\
\text { drug item) }\end{array}$ \\
\hline $\begin{array}{l}\text { per subunit of } \\
\text { care }\end{array}$ & $\begin{array}{l}\text { Co-payment lype } 2 \\
\text { (\$0.10 per prescription } \\
\text { drug tablet) } \\
\text { Benefil limit type } 2 \\
\text { (\$10 per prescription drug } \\
\text { lablel) }\end{array}$ & $\begin{array}{l}\text { Co-nnsurance type } 2 \\
\text { (10\% of gross price per } \\
\text { prescription drug thablet })\end{array}$ & - & $-\infty$ \\
\hline $\begin{array}{l}\text { per insurant or } \\
\text { family, per unit } \\
\text { of time }\end{array}$ & $\begin{array}{l}\text { Deductible lype } 1 \\
\text { (lirst } \$ 100 \text { for prescription } \\
\text { drugs per insurani per } \\
\text { year) } \\
\text { Benefil limit lype } 3 \\
\text { (\$1000 for prescription } \\
\text { drugs per insurant per } \\
\text { year) }\end{array}$ & $\begin{array}{l}\text { Co-insurance type } 3 \\
\text { (10\% of gross price of } \\
\text { prescription drugs per } \\
\text { insurant per year) }\end{array}$ & $\begin{array}{l}\text { Deductible type } 2 \\
\text { (first } 2 \text { prescription drug } \\
\text { tems per insurirant per } \\
\text { month) } \\
\text { Benefil limil type } 4 \\
\text { (4 prescription drug items } \\
\text { per insuramt per month) }\end{array}$ & $\begin{array}{l}\text { Deductible type } 3 \\
\text { (first } 40 \text { prescription drug } \\
\text { tablets per insurant per } \\
\text { month) } \\
\text { Benefit limil type } 6 \\
\text { ( } 80 \text { prescription drug } \\
\text { tablets per insurant per } \\
\text { month) }\end{array}$ \\
\hline $\begin{array}{l}\text { As in th } \\
\text { types } 1 \\
\text { Albene }\end{array}$ & 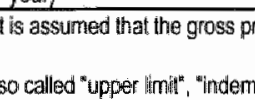 & & ( & ence between \\
\hline
\end{tabular}

\section{Mandatory versus voluntary patient charge}

If an insurant has the possibility to choose between a health insurance plan without patient charges and a health insurance plan with patient charges (in exchange of a higher or lower insurance premium), the charges involved are voluntary. If there is only an insurance plan with patient charges, the charges involved are mandatory.

\section{Possibility of reinsurance}

If a patient charge is mandatory, insurants may have the possibility to reinsure this charge by additionall (usually private) health insurance.

Number of insurants to whom the patient charge is applied

The number of insurants to whorn a charge is applied, is considered as a charge characteristic. The features of these insurants (e.g. the average income level) are considered as insurant characteristics and are discussed later. The following possibilities with respect to the number of insurants are distinguished: (a) either or not internally restricted and (b) either or not externally restricted. The number of insurants is internally restricted if certain insurants (e.g. low income persons) covered by the insurance scheme are exempted from paying the charge. The number of insurants is externally restricted if the insurance scheme (and, thus, the charge) covers only a certain percentage of all persons in the country. 
Number of health care services to which the patient charge is applied

The number of services to which a charge is applied, is also considered as a charge characteristic. The features of these services are considered as service characteristics. A patient charge may be applied to one, several, or even all health care services covered by a health insurance scheme. Most services (e.g. out-patient prescription drugs) comprise a number of different subprovisions (e.g. different drug categories). A patient charge may be applied to an entire service category, but may also be applied to one or more subprovisions.

\section{Identification of insurant characteristics}

\section{Level of income}

The different income categories distinguished (low, middle, high, or various) are not defined in terms of a specific range of guilder or dollar amounts per insurant or family per year. They only give an impression of the income levels involved.

\section{Health status}

Once again, the different health status categories distinguished in this article, onlly give an impression of the health levels involved. The following categories are distinguished: having a (specific) chronic disease, withoult a (specific) chronic disease, or various (both health categories).

Age

The following age categories are distinguished: children (lower than \pm 18 years), adults (between \pm 18 and \pm 65 years), non-elderly (lower than \pm 65 years), elderly (higher than \pm 65 years), or various (all age categories).

\section{Identification of service characteristics}

The present overview of charge regulations focusses on the (sub)provisions to which a charge is applied. Table 2 gives an overview of health care services which are considered as one provision in this article. It also indicates which of these provisions are being covered by one of the two Dutch public health insurance plans. Further, the following two service characteristics are idlentified in this article:

Free access versus prior authorization

A provision can have free access or it can need prior authorization (e.g. a prescription or referral).

Reimbursement system

A provision can have a system in which the reimbursement amount depends on the quantity of care delivered (usually fee-for-service system) or it can have a system in which this amount does not depend on the quantity of care delivered (e.g. a salary or capitation system). 
Table 2 Overview of health care services considered as one provision

(abbreviations between brackets)

Provistoms belonging to the group of in patient care

\begin{tabular}{|c|c|}
\hline$(\mathrm{HOOH})^{\mathrm{s}}$ & in-patient general losoplal care \\
\hline (thaH) & in pratlent haterity hospital care \\
\hline$(\mathrm{MeH})^{2}$ & in palient mental hospital care \\
\hline$(\mathrm{MNOC})^{2}$ & nursing home care. \\
\hline$(10 t c)$ & ofher ifl-patient care \\
\hline
\end{tabular}

Provistons belonging to the group of out-patient care

\begin{tabular}{|c|c|}
\hline (QEmC) & energency rondicate \\
\hline$(\mathrm{OPph})^{2}$ & oulopatient primary physician care : \\
\hline$(\mathrm{OSPh})^{3}$ & oul-patient apecial (no dental or mental) physician care \\
\hline$(\mathrm{ODP} H \mathrm{y})^{3}$ & $\begin{array}{l}\text { cutpatient dental physicion care } \\
\text { (outpatient dental ron-physician care, such as orthodonist care, included) }\end{array}$ \\
\hline$\left(O M D^{2}\right)^{2}$ & $\begin{array}{l}\text { out-pationt mental physician care } \\
\text { (out-patient mental non-physician care, such as psychologist care, included) }\end{array}$ \\
\hline (Omac) & Dut-palient matemily care \\
\hline$(\mathrm{OHOC})^{\sharp}$ & outpatient midwife care \\
\hline$(0 \mathrm{poc})$ & oulpalient opiomelrist care \\
\hline (OPHC) & out-palient physical therapist care \\
\hline$(O S p C)^{\prime}$ & out-pattient speech therapist care \\
\hline$(\mathrm{ONWC})^{2}$ & out-patiant nursing care \\
\hline $\mathrm{OHC}$ & 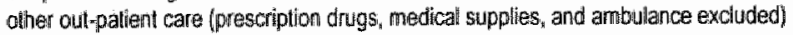 \\
\hline
\end{tabular}

\section{Other prowisions}

(OMis) $\quad$ out-patient medical supplles

$(\mathrm{OPrD})^{i} \quad$ out-pationt prescriplion drugs.

$(\mathrm{OAmb})^{\prime} \quad$ ambulance

1: commonly covered by sickness fund insurance scheme

2: commonly covered by exceptional health insurance scheme

in2: for 1 year covered by silckness iund insurance scheme; follow wo covered by exceptional health insurance scheme

\section{Results}

\section{Overview of Dutch patient charges in January 1997}

An overall overview of the patient charges in the Dutch sickness fund insurance scheme is given in appendix 1. The charges are presented per health care provision to which they are applied on the one hand and per charge, insurant, and service characteristic, respectively, on the other hand (appendices 1.1 to 1.3). For several provisions (e.g. out-patient specialist physician care) there are different kinds of patient charges (e.g. charges with different maximum expenditure levels). In appendix 1 such charges are indicated by " $a, b, c$, etc.", each character representing one specific combination of charge characteristics. Except for those charges applied to in-patient hospital maternity care (IMaH) and oult-patient matemity care (OMaC), all charges presented are (at least partly) new since 1 January 1997.

\section{Description of patient charges per charge characteristic}

\section{Type of patient charge}

Appendix 1 shows that for almost all provisions considered, there are patient charges. The only two exceptions are out-patient primary physician care (OPPh) and out-patient midwife care (OMiC). Appendix 1.1 shows that the charge type is most frequently co-insurance or a combination of coinsurance and a benefit limit. Exceptions are co-payment type 1 for in-patient general hospital care $(\mathrm{GeH})$, a combination of $\mathrm{CO}$-payment and a benefit limit for maternity care (IMaH and OMaC), and 
a combination of co-insurance and co-payment type 1, as well as a combination of co-insurance. co-payment type 1 and benefit limit type 1, for certain out-patient medical supplies (OMeS) (see also appendix 1.3). The benefit limit type 2 (in combination with co-insurance and benefit limit type 4) for out-patient prescription drugs (OPrD) is a so-called reference price system. This system means that drugs are divided into different groups, according to their active substance(s). Drugs with the same active substance(s) or active substances with more or less the same properties, are classed in a single group. For each group an average drug gross price (reference price or benefit limit) has been calculated.

\section{Level of patient charge}

In appendix 1.1 it is tried to order the charge levels according to their heights, with the lowest height presented first (under a benefit limit, the lowest hight last). In general, for equal patient charge types, such ranking is easier (e.g. $20 \%$ co-insurance wersus $40 \%$ co-insurance) than for different charge types. Therefore, the levels are ordered per charge type (co-payment type 1 "co-insurance and combinations of different charge types, respectively).

It appears that under co-insurance, the charge level is always $20 \%$. However, under a combination of different charge types (usually co-insurance with a benefit limit), there are different benefit limits types with different benefit limit levels. Although the co-insurance level is, once again, always $20 \%$. it is generally rather difficult to order the different combinations of charge types according to their levels. Appendix 1.1 shows that the benefit limit type at least depends on the health care provision in question. For out-patient medical supplies (OMeS) the benefit limit type also depends on the subprovision in question (see appendix 1.3). Further, for this provision the benefit limit level sometimes depends on the group of insurants to whom the charge is applied (see "Description of patient charges per insurant characteristic $c^{\prime \prime}$. For out-patient prescriptian drugs (OPrD) the level of benefit limit type 5 also depends on the subprovision in question (see appendix 1.3 ).

\section{Presence of maximum expenditure}

Almost all patient charges have a maximum expenditure. This maximum is applied to all these charges together. The only provisions to which a charge without maximum expenditure is applied, are in-patient maternity hospital care (IMaH) and out-patient maternity care (OMaC).

\section{Level of maximum expenditure}

In appendix 1.1 the maximum expenditure levels are ordered according to their heights, with the lowest height presented first. It appears that there are only two different levels, depending on the groups of insurants to whom the charge is applied (see also "Description of patient charges per insurant characteristic ${ }^{17}$ and appendix 1,2 ).

\section{Mandatory versus voluntary patient charge}

All patient charges in the Dutch sickness fund insurance scheme are mandatory.

Possibility of reinsurance
Reinsurance of the mandatory charges is (partly) possible only for in-patient maternity hospital care $(\mathbb{M a H})$, out-patient maternity care $(\mathrm{OMaC})$, out-patient physical therapist care (OPhC) and outpatient medical supplies (OMeS). Dutch sickness funds supply several kinds of additional, private insurance plans. These plans (partly) cover some of the mandatory patient charges as well as costs of services not included in the sickness fund insurance scheme. At least ca. $90 \%$ of all sickmess fund insurants have some form of additional insurance.

\section{Number of insurants to whom the patient charge is applied}

Most commonly, the charges are applied to a number of insurants which is both internally and externally restricted. As has already been indicated in the introduction section, the sickness fund insurance scheme with its charges, applies to only about two-third of the Dutch population. In addition, the number of insurants to whom a specific patient charge regulation is applied, is usually also internally restricted (see "Description of patient charges per insurant characteristic"). 
Number of health care senvices to which the patient charge is applied

The charges are generally applied to several provisions or to one provision separately. In case of cut-patient dental physician care (ODPh) and out-patient medical supplies (OMeS), the charges are applied to one or more specific subprovisions (see also appendix 1.3)

\section{Description of patient charges per insurant characteristic}

\section{Level of income}

As has been indicated above, most of the charges have a maximum expenditure which level depends on the group of insurants to whom the charge is applied. There are two levels: $\$ 50$ and $\$ 100$ (NLG 100 and NLG 200, respectively) per family per year (see appendix 1.1). Appendix 1.2 shows that, if an insurant has a low income level, the first maximum expenditure level is applied. If an insurant thas a middle income level, either the first or the second maximum expenditure levell is applied, depending on the age of the insurant in question (see the following paragraph). As has already been indicated in the introduction section, the sickness fund insurance scheme generally covers only low and middle income persons (in January 1997, persons with an income lower than ca. $\$ 30,000$ - or NLG 60,000 - per family per year).

\section{Health status}

Almost all charges are applied to both chronical and non-chronical ill insurants (appendix 1.2). Only for out-patient physical therapist care (OPhC), there are different charges for chronical and nonchronical ill insurants. For those having a specific chronic disease there is $20 \%$ co-insurance, while for those without such a disease there is a combination of $20 \%$ co-insurance and a benefit limit type 4 (usually 9 units of care per insurant per indication per year; see also appendix 1.1).

\section{Age}

As has been described above, most charges have a maximum expenditure. There are two levels: $\$ 50$ and $\$ 100$ per family per year. Appendix 1.2 shows that if an insurant belongs to the elderly, the first level is applled. If an insurant belongs to the non-elderly, either the first or the second level is applied , depending on the income level of the insurant in question (see also the previous paragraph). Further, for those subprovisions of medical supplies to which a combination of coinsurance and co-payment type 1 is applied, children have to pay a lower level of co-payment than adults or elderly (see also appendix 1.1). Appendix 1.3 shows that these subprovisions are orthopaedic shoes and non-allergen shoes.

\section{Description of patient charges per service characteristic}

\section{Free access versus prior authorization}

All of the (sub)provisions to which a patient charge is applied, need prior authorization. Most frequently, this means that an insurant needs a referral from an out-patient primary physician. It is interesting to note that there are no charges for the only two provisions which have free access: outpatient primary physician care (OPPh) and out-pattent midwife care (OMiC).

\section{Reimbursement system}

For almost all provisions to which a patient charge is applied, there is some kind of a fee-for-service system. For the only exception, in-patient general hospital care $(\mathrm{IGeH})$, there is a budget system which does only partly depend on the quantity of care delivered. 


\section{Identification of those charges which are expected to be (un)desirable for reducing moral hazard}

As has been indicated in the introduction section mandatory co-insurance with a level of about $50 \%$, with an income dependent level of a maximum expenditure, without the possibility of reinsurance, for non-elderly, applied to out-patient or even total health care, may be desirable for reducing moral hazard. It appears, however, that none of the charges in the Dutch sickness fund insurance scheme fully corresponds with the former charge (table 3 ). Although, most frequently, there is mandatory co-insurance without the possibility of reinsurance, but with an income dependent maximum expenditure, both the co-insurance level and the maximum expenditure level are rather low (20\% and $\$ 50$ or $\$ 100$ per family per year, respectively). In addition, none of the charges is applied to out-patient or health care in general. Instead, the charges are generally applied to specific (sub)provisions. Further, there are charges for both elderly and non-elderly, although the maximum expenditure level is generally lower for the first group of insurants.

Table 3 Comparison of existing patient charges in The Netherlands (Janulary 1997) with charge which is potentially desirable for reducing moral hazard

\begin{tabular}{|c|c|}
\hline Characteristics of charge which is desirable & Provisions havinig charge corresponding with characteristic \\
\hline Co-insurance & OEMC, OSPh, ODPh, OPhC, OSpC, OMES, OAmb \\
\hline Aboul $50 \%$ & - \\
\hline $\begin{array}{l}\text { Income dependent maximum expenditure } \\
\text { (between } 5 \% \text { and } 15 \% \text { of family income per year) }\end{array}$ & Partty for almost all prowisions \\
\hline Mandalory & All prowisions \\
\hline Mithout possibility of reinsurance & OEmC, OSPH, ODPh, OPhC, OSpC, OAmb \\
\hline Applied to non-elderly & Partly for aimost all provisions \\
\hline Applied to out-patient or total health care & - \\
\hline
\end{tabular}

As has been indicated in the introduction section, the synthesis of evidence provided by Starmans (3) also suggested that co-payment type 1 , benefit limit types 4 and 5 , charges applied to one (sub)provision separately, or charges applied to services for which a referral is needed, are less or even not desirable. Therefore, it seems to be a serious disadvantage that the present charges in the sickness fund insurance scheme are only applied to those services which need prior authorization. Benefit limit type 4 or 5 is not present separately in the insurance scheme (only within combinations of different charge types), but co-payment type 1 is present for in-patient general hospital care $(\| \mathrm{GeH})$. It is important to note, however, that the latter charge - in contrast to all other charges in the sickness fund insurance scheme - has not been introduced for (al least) reducing moral hazard, but only for financing health care (more precisely, for house and lodging).

\section{Conclusion}

Although on 1 January 1997 new patient charges have been introduced in the Dutch sickness fund insurance scheme, these charges seem to be insufficient for the purpose of reducing moral hazard. Although there is most frequently mandatory co-insurance without the possibility of reinsurance, but with an income dependent maximum expenditure, the levels of both co-insurance (20\%) and maximum expenditures ( $\$ 50$ or $\$ 100$ per family per year) are rather low. in addition, the charges, are applied to specific (sub)provisions which all need prior authorization. Consequentlly, it can be expected that these charges will not or insufficiently reduce total medical utilization and expenditure (3). 
For the purpose of reducing moral hazard, it seems to be desirable to adapt the existing patient charges in the Dutch silckness fund insurance scheme. Firstly, charges should also or even mainly be introduced for services which have free access. The most important provision in this respect is out-patient primary physician care. A different possibility would be to introduce a charge for outpatient care in general or even total health care. Seconilly, both the charge level and the maximum expenditure level should be increased. According to the previous synthesis of empirical evidence (3) the most preferable levels would be about $50 \%$ and $5 \%$ to $15 \%$ per family per year respectively. Thirdly, co-payment type 1 for in-patient general hospital care should be abolished or at least be replaced by co-insurance. It is important to note, howewer, that this charge has been introduced only to finance health care. Further, although there is insufficient evidence with respect to the effects of combinations of different charge types on medical consumption and health, it seems preferable to make the present system of cost sharing more transparent for insurants, health care providers and sickness funds by replacing combinations of different charge types by coinsurance.

\section{References}

1. Staten-Generaal. Bestuit wan 24 oktober 1996 tot wijziging wan het Verstrekkingenbesiuit ziekenfondsverzekering an het Vergoedingembesluit particulier werzekerden in vertband met invoering van een algemeen systeem van eigen bijdragen (24 October 1996 Decree on changing the Decree on services in the sickness fund insurance act and the Decree on reimbursements in the priwate health insurance sector with respect to the introduction of a general system of patient charges). Staatsblad 1996(541):1-20.

2. Pauly MW. The economics of moral hazard: a comment. Am Econ Rev 1968;57:231-7.

3. Starmans HBG. The effects of patient charges on medical utlization, expenditure, and health: a synthesis of evidence from 1983 to 1995 . Forthcoming (see chapter 2 in this thesis). 


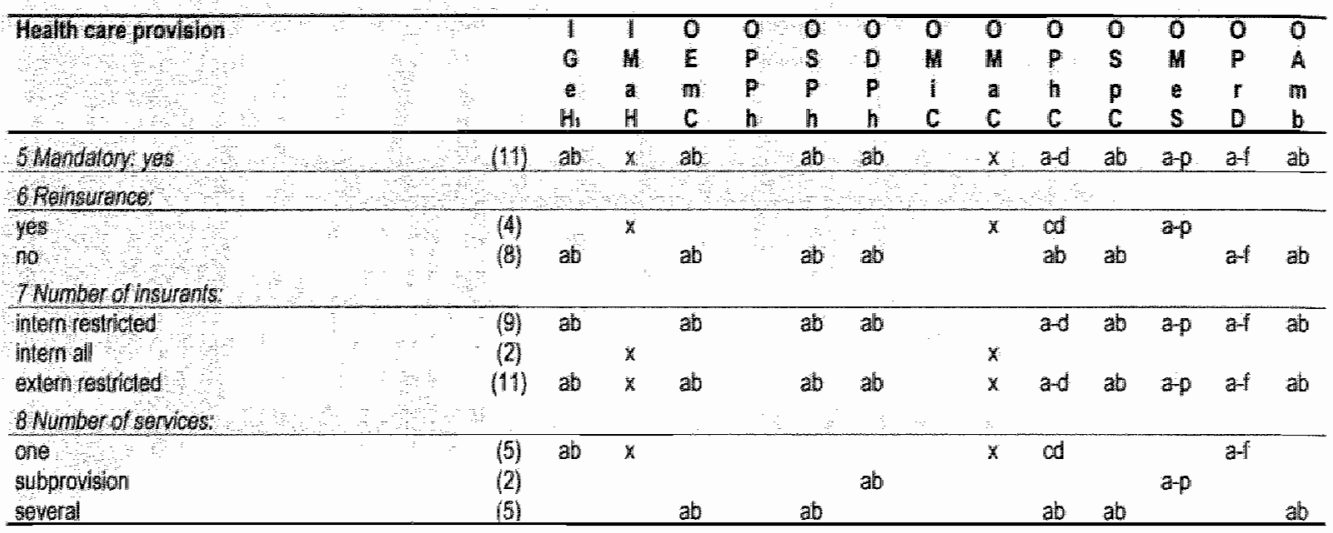

1. See table 2 for explaniation of abbreviations of subprowisions

2: there are addilional patient charges for matemity care, however, in case of hospitalizalion without medical necessity

3: there are patien charges for midwife care, however, in case of a deliwery in an out-patient hospital clinic without medical necessity

4: referenco price system

5: Whis is only ari exarnple of one specfic subprowision; conesponding charges, but having different benefit himith levells, are applied to a mumber of other subprowisions

6. If considered medical recessary, this mumber can be extended by a maximum of 9 units Cesar therapy, Memsendieck therapy or children physical therapy per insurant per indication per year

7: Hn case of co-insurance in combination with one or more different charge types, the maximum only applies to co-insurance; in addition, the meximum applies to all charges, except for those applied to lMat and $\mathrm{OMaC}$

8. single insurarits who feach thits maximum, receive $\$ 45$ back from their sickness fund

Cop 1 (or 2): comparnent lype 1 (or 2)

Coi: co-ingurance

Eem1 $(2,4$, or 5$)$ : benefil limit lype $1(2,4$, or 5$)$

Pigi gross price

Piga average gross price

(.) homber of provisions per characteristic 
Appendix 1:2 Patient charges for different health care provisions in The Wetherlands (January 1997): overview per insurant characteristic

\begin{tabular}{|c|c|c|c|c|c|c|c|c|c|c|c|c|c|c|}
\hline Heatth care provision & & $\begin{array}{l}1 \\
\mathrm{H} \\
\mathrm{H}\end{array}$ & $\begin{array}{r}1 \\
\mathbf{M} \\
\mathbf{H} \\
\end{array}$ & $\begin{array}{l}0 \\
\mathrm{c} \\
\mathrm{m}\end{array}$ & $\begin{array}{l}q \\
p \\
p \\
h\end{array}$ & $\begin{array}{l}0 \\
s \\
\mathrm{P} \\
\mathrm{h}\end{array}$ & $\begin{array}{l}0 \\
D \\
P \\
H\end{array}$ & $\begin{array}{c}0 \\
n \\
1 \\
0\end{array}$ & $\begin{array}{l}0 \\
1 \\
c \\
c\end{array}$ & $\begin{array}{l}\mathrm{a} \\
\mathrm{p} \\
\mathrm{h} \\
\mathrm{c}\end{array}$ & $\begin{array}{l}0 \\
s \\
p \\
c\end{array}$ & $\begin{array}{l}0 \\
M \\
\text { s } \\
\text { S }\end{array}$ & $\begin{array}{l}0 \\
p \\
r \\
0\end{array}$ & $\begin{array}{l}0 \\
\mathrm{~A} \\
\mathrm{~m} \\
\mathrm{~b}\end{array}$ \\
\hline Inoome level: & & & 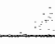 & 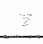 & & 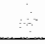 & & $\vdots$ & & & & & & \\
\hline $\begin{array}{l}\text { lown } \\
\text { middes } \\
\text { low } * \text { middle }\end{array}$ & $\begin{array}{l}191 \\
191 \\
(2)\end{array}$ & $\begin{array}{c}a \\
a b\end{array}$ & $x$ & ab & & ab & $\begin{array}{l}a \\
a b\end{array}$ & & $x$ & ac & $\begin{array}{c}a \\
a b\end{array}$ & $\begin{array}{l}a 00 \\
a-p\end{array}$ & $\begin{array}{l}a 00 \\
a-1\end{array}$ & $\mathrm{a}$ \\
\hline 2 thealth staius: & & & & & & & & & & & & & & \\
\hline $\begin{array}{l}\text { (specific) chronic disease } \\
\text { no (specific) chronic disease } \\
\text { warious } \\
3 \text { age: }\end{array}$ & $\begin{array}{l}(1) \\
(1) \\
(10)\end{array}$ & $a b^{9}$ & $x$ & $\mathrm{ab}$ & & $a b$ & $a b$ & & $x$ & $\mathrm{ab}$ & $a b$ & $a p$ & at & $\mathrm{ab}$ \\
\hline $\begin{array}{l}\text { children } \\
\text { adults } \\
\text { non-elderlly" } \\
\text { elderly } \\
\text { warious }\end{array}$ & $\begin{array}{l}(1) \\
(1) \\
(9) \\
(9) \\
(2)\end{array}$ & $\begin{array}{c}a b^{\prime} \\
a\end{array}$ & $x$ & $\begin{array}{c}a b \\
a\end{array}$ & & $\begin{array}{c}a b \\
a\end{array}$ & $\begin{array}{l}\mathrm{ab} \\
\mathrm{a}\end{array}$ & & $x$ & $\begin{array}{l}a d d \\
a c\end{array}$ & $\begin{array}{c}a b \\
a\end{array}$ & $\begin{array}{l}\text { cdmn } \\
\text { efop } \\
\text { abgh-kl } \\
\text { aeg-ok }\end{array}$ & ace & ab \\
\hline
\end{tabular}

9: excepi for pregnant women (they are exempted) 
Appendtw 13 patent charges for dfferent health care provisions in The Wethertands (January 1997): overview per serwice characteristic

\begin{tabular}{|c|c|c|c|c|c|c|c|c|c|c|c|c|c|c|}
\hline 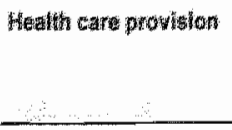 & & $\begin{array}{l}1 \\
6 \\
4 \\
\end{array}$ & $\begin{array}{l}1 \\
4 \\
a \\
H\end{array}$ & $\begin{array}{l}0 \\
E \\
0\end{array}$ & $\begin{array}{l}0 \\
p \\
p \\
0\end{array}$ & $\begin{array}{l}0 \\
s \\
p \\
4\end{array}$ & $\begin{array}{l}0 \\
0 \\
P \\
n\end{array}$ & $\begin{array}{l}0 \\
0 \\
c \\
c\end{array}$ & $\begin{array}{l}0 \\
M \\
\mathrm{C} \\
\end{array}$ & $\begin{array}{l}0 \\
p \\
h \\
6\end{array}$ & $\begin{array}{l}0 \\
5 \\
p \\
c\end{array}$ & $\begin{array}{l}0 \\
\text { Th } \\
0 \\
3\end{array}$ & $\begin{array}{l}0 \\
\mathrm{P} \\
\mathrm{T} \\
0\end{array}$ & $\begin{array}{l}0 \\
A \\
m \\
b\end{array}$ \\
\hline 1her aboses no & (1) & $a b$ & $x$ & $a b$ & & $a b$ & ab: & & $x$ & $a$ & ab & $a p$ & $a+4$ & 30 \\
\hline \multicolumn{15}{|l|}{2 fae-for sondos: } \\
\hline $\begin{array}{l}\text { yes } \\
\text { no }\end{array}$ & $\begin{array}{c}(10) \\
(5)\end{array}$ & $a b$ & $\begin{array}{l}x \\
x\end{array}$ & $\begin{array}{l}a b \\
a b\end{array}$ & & $a b^{17}$ & $a b^{11}$ & & $\begin{array}{l}x \\
x\end{array}$ & $a d$ & $a b$ & $a p$ & ant: & $\begin{array}{l}a b \\
a b\end{array}$ \\
\hline
\end{tabular}

dentall hospltat plysician care

$a b^{12}$

ght subponctisions of medical supplies, (1)

$a b$

axcept for those to which a

pombitiotion of difforen charge types

in applied (see below)

orthopaedic shoers

frearing ald ${ }^{13}$

(1)

(1)

incontinence stimp stockirg

incontinence aissorpton aids

non-allergan shoes

(1)

ab

$\infty$

(1)

$c t$
$g h$
$i j$
$k i$
$m-p$

drugs for chronic disease ${ }^{\text {it }}$

dugs fir non-chronic disease

dugs for new indication

11: excest for physicians in mainly acadernic hospilals

12: lor adulfs, only few olher subprovisions of outpaltent dental physician cate are covered by the insurance solneme; these concen mainly prewentive care (no charges) and denures (whth additional charges); for children, nearly all other subprovisions of out-patient dental physician care are covered without othages, prowided that the dentist is visited regutlarly

13: this is only an example of one specific subprovision; the same kind of patient charge is also applied to a number of difterent subprovisions

14: axcept for e.g. Hypnotics (suburitus tor 30 days), and contraceptives (suburits for 6 moniths)

15: axcept for antibiotics (subunits for 15 days) 
General discussion and health policy implications 


\section{General discussion and health policy implications}

The purpose of this thesis is to deliver a contribution to the current discussion in The Netherlands as well as in other countries about the desirability of patient charges in public health insurance schemes. More specifically, the thesis tries to answer the question which kind of a patient charge may be desirable, if the purpose of a patient charge is to reduce moral hazard (reducing medical consumption without adverse health effects). For this purpose, a number of cost sharing studies in the province of Limburg (the southern part of The Netherlands) has been carried out (chapters 3 to 7) and a synthesis of international evidence of cost sharing has been made (chapter 2).

Chapter 3 showed that an increase in the level of co-payment for orthopaedic shoes in the Dutch sickness fund insurance scheme resulted in a decrease in the number of deliveries of these shoes in the study region. On the short term this decrease was approximately $4 \%$, while on the long term this decrease was even $37 \%$. These decreases correspond with the effects of patient charges on the frequency of using a service, such as out-patient prescription drugs or out-patient primary physician care, measured in foreign studies (e.g. 1, 2). lin addition, the patient-charge-level-elasticity of the frequency of using orthopaedic shoes ( -0.01 on the short term and -0.10 on the long term) corresponds with that calculated in foreign studies for the frequency of using out-patient prescription drugs (e.g. 3, 4). It is important to note that most foreign studies, such as the famous RAND-study in the US, measured the effects of patient charges only among the non-elderly (e.g. 5, 6). The study of the increase in co-payment for orthopaedic shoes in Limburg, however, was performed among both elderly and non-elderly. It appeared that the patient charge effect, particularly on the short term, was the largest among the elderly. A possible explanation for this finding may be that the elderly are generally less mobile than the non-elderly due to a lower average health status. As a consequence, it may have been easier for the elderly to reduce the number of requests for orthopaedic shoes. This means that the measure may have been effective in reducing moral hazard. The presence of possible adverse health effects, however, was not investigated.

Chapter 4 showed that the introduction of a co-payment for out-patient specialist physician care in the Dutch sickness fund insurance scheme did not result in a decrease in the frequency of using this provision for most specialisms in the study region. It seems, therefore that the measure was generally not effective in reducing moral hazard. This outcome also corresponds with those of foreign studies: in general, effects of patient charges were found to be smaller if prior authorization was needed (e.g. 5, 7). In The Netherlands, sickness fund insurants need a referral (generally from a primary physician) in order to use out-patient specialist physician care. The co-payment for outpatient specialist care in the Dutch sickness fund insurance scheme was accompanied by a maximum expenditure with a rather low level (NLG 75 - or 37.50 in 1997 US\$ - per family per year). This may explain why for most specialisms the co-payment finally did not at all affect the frequency of using out-patient specialist care in the study region. A decrease was measured only for ophthalmology. A possible explanation for the latter finding is that the consumer had, to a certain extent, the possibility to substitute the visit to the ophthalmologist by a visit to the optician.

In chapter 5 the effects of both the introduction of a benefit limit and the introduction of a copayment for out-patient prescription drugs in the Dutch sickness fund insurance scheme on the utilization of antihypertension drugs in Limburg were investigated. Corresponding with the effect of the increase in the co-payment level on the total frequency of using orthopaedic shoes (see under chapter 3), it appeared that the introduction of the 2 different types of patient charges for prescription drugs did not immediately result in a lower (or higher) level of the frequency of using antihypertension drugs, but did result in a slightly decreasing (or increasing) trend. Four years after the introduction of the co-payment, the frequency of using antihypertension drugs was approximately $9 \%$ lower than in a period withoul patient charges. However, chapter 5 also showed that this decrease was compensated for by an increase in the number of tablets per prescription item. After the introduction of the benefit limit, the opposite occurred: the number of tablets per prescription item showed a slightly decreasing trend, but this decrease was compensated for by an increase in the frequency of using antihypertension drugs. As a consequence, neither measure did 
result in a decrease in the total number of tablets per insurant or the total number of Defined Daily Doses (DDDs) per insurant, and thus, neither measure seems to have been effective in reducing moral hazard.

As could be expected on the basis of the outcomes in chapter 5 , neither the introduction of the benefit limit nor that of the co-payment for out-patient prescription drugs in the Dutch sickness fund insurance scheme did result in a reduction in total expenditure on antihypertension drugs in Limburg (chapter 6). Instead, this expenditure showed a sharply increasing trend during the entire period investigated. It was demonstrated that this increasing trend was mainly due to a turnover in the utilization of antihypertension drugs from less expensive to more expensive drugs: It was also demonstrated that the current reference price system in The Netherlands, which comprises a combination of 2 types of benefit limits, does neither contain incentives to overcome this turnover component in the increase in total expenditure on antihypertension drugs.

Chapter 7 described a comparative study on cross-border in-patient hospital care in the Euregio Meuse - Rhine. This region covers the major part of the Dutch province of Limburg as well as provinces in Belgium and Germany. It appeared that, among other factors, the presence and level of patient charges might be important for the level of cross-border hospital care (the frequency of hospital admissions across the border). In particular, if the current regulation of cross-border care in the European Union becomes less restrictive, introducing patient charges or increasing the level of patient charges within the national borders may result in consumers searching for medical care in a foreign country. On the other hand, abolishing patient charges or reducing the lievel of patient charges may result in foreign consumers searching for medical care within the national borders. So far, no other empirical studies have investigated these effects of patient charges.

The Dutch cost sharing evidence described in chapters 3 to 7 and the synthesis of international cost sharing evidence described in chapter 2 show that at least the following aspects seem to be important for the effects of patient charges on medical utilization, expenditure and health:

- the patient charge type

- the patient charge level

- the level of a maximum expenditure

- the number and type of services to which a patient charge is applied

- the effect variable

- the group of health care users investigated.

The evidence suggests that the choice of the effect variable in a study is (partly) important for both the direction (increase or decrease) and the magnitude of a patient charge impact. Effect variables for which generally a decrease or no effect has been measured are: the probability of using care (Cii), the frequency of using care (CijFi), the total quantity of using care (CijFiQi) and expenditure on care (CijFiQiPgi). In general, somewhat larger decreases have been measured in CijFi than in Cij. Variables for which - besides a decrease or no effect - more than once an increase has been measured are: the frequency of using care (CijFi), the quantity of subunits per unit of care (Qii), expenditure per unit of care (QiPgi) and the probability of using care - covered by the insurance scheme - to which the charge was not applied (Coj). In general, no effect has been measured on the gross price of using care (Pgi) and the health status of insurants $(\mathrm{Hj})$.

The evidence also suggests that for 3 effect variables, CijFi, Qi and QiPgi, the patient charge type was important for the direction of the patient charge impact. For the variable CijFi adverse increases have been measured under benefit limit type 5, while decreases have been measured under copayment type 1 and co-insurance. Benefit limit type 5 means a reimbursement of a fixed, maximum number of subunits of care per unit of care (e.g. 30 prescription drug tablets per prescription item), co-payment type 1 means a fixed amount of money payable per unit of care (e.g. $\$ 1$ per prescription item), and co-insurance means paying a percentage of the gross price of care $(e . g$. $25 \%$ of the gross price of prescription drugs). For the variables Qi and QiPgi adverse increases or no effects have been measured under co-payment type 1 and benefit limit type 4 , while decreases 
or no effects have been measured under co-insurance and benefit limit types 5 and 6 . Benefit limit type 4 means a reimbursement of a fixed, maximum number of units of care per insurant or family per unit of time (e.g. 3 prescription items per insurant per month), and benefit limit type 6 means reimbursement of a fixed, maximum number of subunits of care per insurant or family per unit of time (e.g. 90 prescription drug tablets per insurant per month): Adverse increases in the consumption of services - covered by the insurance scheme - to which a charge was not applied, were generally found if a charge was applied to one provision separately $(\mathrm{e} . \mathrm{g}$. an increase in the probability of using nursing home care under a patient charge for out-patient prescription drugs).

As was expected, larger effect magnitudes were generally found, if the level of a patient charge or maximum expenditure was higher or if the charge effect was measured among high users of care. Also the health care (sub)provision to which a charge is applied, seems to be important for the magnitude of charge effects on medical consumption. In general, it seems that out-patient care is more sensitive to introducing or increasing patient charges than in-patient care or total health care. In particular, it seems that expenditure on both out-patient mental and out-patient dental physician care is rather sensitive to patient charges. As was expected, it seems that at least the presence or absence of free access to care is important for the magnitude of the effects on medical utilization and expenditure. For out-patient care - especially for primary physician, dental physician, and optometrist care - there is generally free access, while for in-patient care usually a referral is needed. Although also for out-patient prescription drugs prior authorization is needed, the consumption of this provision appears to be relatively sensitive to patient charges. It seems that non-essential and ineffective drugs are generally more sensitive to charges than essential drugs. Naturally, if the purpose of a charge is to reduce moral hazard, a reduction in the use of nonessential and, especially, ineffective drugs can be considered as beneficial. The evidence shows that also other characteristics ( $1 . \mathrm{g}$. . insurants" age, and the measurement of a charge effect in the short term or in the long term) can be important determinants for differences in the magnitude of charge effects (chapters $2,3,5$ and 6). However, the evidence does not show clear relationships between these characteristics and the charge effects measured.

The evidence presented in this thesis suggests that co-payment type 1 and benefit limit types 4 and 5 may be less or even not desirable for reducing moral hazard due to adverse increases in $\mathrm{CijFi}$ (the frequency of using care), Qi (the quantity of subunits per unit of care) or QiPgi (expenditure per unit of care). In addition, adverse increases in Coj (the probability of using a service in the insurance scheme to which the charge is not applied) may occur if a charge is applied to one provision separately. The evidence further suggests that especially introducing mandatory co-insurance with a level of about $50 \%$, with an income dependent level of a maximum expenditure (between $5 \%$ and $15 \%$ of farmily income per year), without the possibility of reinsurance, for out-patient care or even total health care, for non-elderly, may be desirable for reducing moral hazard. The evidence shows that such a charge can be expected to result in a reduction in medical expenditure of approximately $30 \%$ among the services and insurants in question. This reduction is due to a reduction in medical utilization rather than a reduction in the gross-price of medical care.

It is important to note, however, that not any study measured the effects of a patient charge on total health care expenditure in a country. As charges may result in "spill-over-effects" (an increase in medical consumption among those insurants to whom the charges are not applied), the original reduction in medical consumption may be (partly) compensated. Further, it is important to note that the major part of total health care expenditure is generally incurred by a rather small group of insurants (8\%10). For example, approximately $80 \%$ of total health care expenditure in The Netherlands is incurred by approximately $20 \%$ of the inhabitants, while approximately $20 \%$ of total health care expenditure is incurred by approximately $80 \%$ of the inhabitants (11). The first group of inhabitants comprises the chronically ill patients, while the second group comprises the incidentally ill patients. As the chronically ill patients will generally be elderly patients ${ }_{n}$ the most important part of total health care expenditure will remain unaffected if charges are applied to nonelderly. 
If the patient charge which can be considered as potentially most desirable for reducing moral hazard (see above), is compared with the current patient charges in the Dutch sickness fund insurance scheme or is compared with the current patient charges for prescription drugs in the public health insurance schemes in the member states of the European Union (EU), it seems that the current charges could generally be best adapted.

The patient charge which seems to be optimal on the basis of empirical evidence does rather well correspond with the current cost sharing system in the so-called Dutch IZA-insurance scheme. This scheme covers minor events for certain groups of civil servants (approximately $5 \%$ of the Dutch population). Both the co-insurance level and the maximum expenditure level in this system, however, are considerably lower than the likely optimal levels. The IZA-scheme generally has coinsurance levels between $10 \%$ and $20 \%$, depending on the type of health care provision, while the maximum expenditure level is $1 \%$ of the family income per year. In the IZA-scheme, the coinsurance is mandatory and is applied to several out-patient care provisions. It is not restricted however, to the non-elderly.

According to a Dutch management consultancy office, the so-called VB-group, it is very well possible to introduce an IZA-like system also in the Dutch public health insurance scheme (see the publications of this group for more technical details $(11,12)$ ). However in the Dutch sickness fund insurance system, out-patient primary physicians are paid by a capitation system, which means that no gross-price per (sub)unit of care has been calculated. Therefore, the VB-group advised to introduce a co-payment of NLG 5 (2.50 in 1997 US\$) per out-patient physician visit if an IZA-like system is to be introduced $(11,12)$. In addition, for out-patient mental physician care there are no tariffs which, again, means that no gross-price per (sub) unit of care has been calculated. If an IZAlike system is to be introduced, the VB-group suggested the introduction of a co-payment of NLG 20 (10 in 1997 US\$) per out-patient mental physician wisit (11). However, as has been indicated above, the introduction of co-payment type 1 (a fixed amount of money payable per unit of care) may be less or even not desirable for reducing moral hazard. Therefore, it seems preferable to introduce tariffs for both out-patient primary and mental physician care and to apply co-insurance for all (out-patient) health care services.

The apparently optimal patient charge system indicated above does also rather well correspond with that recommended by the Commissie Strategische Heroriëntatie Gezondheidszorg (13). On the basis of several assumptions, this committee recommended the introduction of co-insurance of $10 \%$ with a maximum expenditure of NLG 200 (100 in 1997 US\$) per family per year for several services. Again , both the co-insurance level and the maximum expenditure level, that seem to be optimal in the present thesis, are substantially higher

So far most empirical studies of patient charges were focussed on the effects among the nonelderly. Therefore, if the purpose of a patient charge is to reduce moral hazard, this thesis finally suggests introducing the "optimal" patient charge for both non-elderly and elderly. In addition, it advises to make an appropriate scientific evaluation of its short-term and long-term effects, in particular on medical utilization, expenditure and health among the elderly. Combining the introduction of a patient charge with an appropriate scientific study will increase the possibilities for evidence based health care policy in the field of cost sharing. If politicians hesitate, however, to introduce co-insurance of $50 \%$ with an income dependent maximum with a level between $5 \%$ and $15 \%$ for all publicly insured persons (e g. because of possible adverse income-effects), it may be useful to introduce lower co-insurance and maximum expenditure levels first and to increase these levels if appropriate scientific research shows that no or only minor adverse effects appear. 
Of course, patient charges can have (also) other purposes than reducing moral hazard (e.g. financing health care or reducing expenditure on administration). As a consequence, they can have other desired effects than reducing medical consumption and can have other adverse effects than reducing health. This means that this thesis does not provide a complete answer to the question about the desirability of patient charges. It may be clear that evidence based health policy making in the field of cost sharing requires an enormous amount of (additional) information. Continuing scientific research (e.g, analyses of charge effects on equity) seems to be important to further solve the issue of patient charges. This thesis may be regarded, therefore, as just one important part of the large cost sharing puzzle.

\section{References}

1. Cherkin DC, Grothaus L, Wagner EH. lls magnitide of co-payment effect rellated to income?" using census data for health serwices research. Soc Sci Med 1992;34:33-41.

2. Harris $B$, Stergach $1 s$, Rled $L$. The effect of drug copayments on utilization and cost of phamaceuticals in a health maintenance organizatlon. Med Care 1990:28:907-17.

3. Ryan M. Birch S. Charging for health care: evidence on the utilization of NHS prescribed drugs. Soc Soi Med 1991;33:681-7,

4. Smith $D G_{n}$ The effects of copayments and generic substitution on the use and costs of prescription drugs. Inquiry $1993 ; 30: 189-98$.

5. Manning WG, Nowhouse JP, Duan $\mathrm{N}_{\text {, }}$ et al. Health insurance and the demand for medical care: ewidence from a randomized experiment. Am Econ Rev 1987;77:2511-77.

6. Rogers WH, ORourke TW, Ware JE, et al. Effects of cost sharing in health insurance on disability days. Health Pollcy $1991: 18: 131-9$.

7. Cherkin DC, Grothaus L, Wagner EH. The effect of office visit copayments on utilization in a health maintenance organization. Med Care 1989;27:669-79.

8. Light DW. The practice and ethics of risk-rated health insurance. JAMA 1992;267:2503-8.

9. Light DW. Escaping the traps of postwar Western medicine: how to maximize health and minimize expenses. Eur J Public Health 1993;3;281-9.

10. Schrijvers AJP, ed. Een kathedraal van zorg: een inleiding over het functioneren van de zorgverlening (A cathedra of care: an introduction to the performance of health care). Utrecht: De Tijdstroom, 1994.

11. Voorzee $H$, Dekker $M_{4}$ Galesloot $F_{\text {, Juch }} H_{\text {, Lamers }} A_{\text {, van }}$ Leeuwen $H$. Betalen voor zorg: rapport haalbaarheidsonderzoek eigen bijdragen (Paying for care: report feasibility study patient charges). Nieuwegein: VB-advies Marnagement Consultants, 4993.

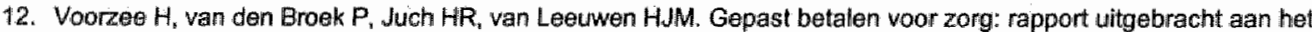
Ministerie van WWS (Properly payng for care: report for the Ministry of Health, Welfare and Sport). Nieuwegen: VE-advies Management Consultants, 1995.

13. Wan der Zwan $A$, ed. Gezondheidszorg in tel. Deel 2. Overbrugging van de zorgkloof: handreiking van een ondernemende sector (Health care in the ruming. Part 2. Bridging the care gap: a heiping handi of ari enterprising sector). Utrecht: Nederlandse Zargfederatie, 1994. 
11

\section{Summary}




\section{Summary}

This thesis tries to give an evidence based answer to the question which kind of a patient charge for medical care may be desirable if the purpose of such a charge is to reduce moral hazard (reducing medical consumption without adwerse health effects). A patient charge is defined as a specific combination of different characteristics, which finally determines the money price which an insured person has to pay out-of-pocket for using a medical service that is included in a health insurance scheme. Examples of characteristics are the charge type, the income level of the insurants to whom this charge is applied, and the gross-price of the service(s) to which this charge is applied.

Chapter 1 shows that in The Netherlands the discussion about the desirability of patient charges in the public health insurance scheme has been relevant for many years. Except for the presence of a maximum to the charges payable, there has been little consensus with respect to the issue which kind of a patient charge should be introduced $(e . g$. Which type and level of a patient charge and for which services). Also in other countries, the desirability of patient charges has frequently been a topical health policy issue.

Chapter 2 describes the development of a systematic method to synthesise empirical evidence of the effects of patient charges on medical consumption and health. To provide quality-level evidence, the method sets a minimum standard for study and outcomes inclusion. In addition, on the basis of economic literature, "it distinguishes different effect variables (e.g. the probability of using care) on the one hand, and different charge, insurant, service, and measurement characteristics (e.g. short-term versus long-term effects) on the other hand. Finally, the method is applied to empirical evidence published in the period from 1983 to 1995.

Chapters 3 to 7 describe a number of empirical cost sharing studies which have been carried out among sickness funds insurants in he Dutch province of Limburg. These studies generally comprise interrupted time-series analyses.

Chapter 3 shows the effects of an increase in the level of a co-payment for orthopaedic shoes from NLG 35 to NLG 150 per pair (16 to 67 in 1995 US\$). Immediately after this increase, the number of requests for orthopaedic shoes per insurant (the frequency of using orthopaedic shaes) showed a slightly decreasing trend. After 3 years, the total number of requests was $37 \%$ lower than in the previous period. The patient-charge-level-elasticity of the frequency of using orthopaedic shoes was -0.01 and -0.10 on the short term and the long term, respectively. The largest reduction in medical consumption was found among the elderly.

Chapter 4 elaborates the effects of the introduction of a co-payment of NLG 25 - with a maximum of NLG 75 per family per year - for out-patient specialist physician care (10 with a maximum of 31 in 1995 US\$). It appeared that among the 13 different specialisms studied this co-payment did not result in a decrease in the frequency of using this provision, except for ophthalmology. For this specialism a reduction of ca. $9 \%$ in medical consumption was measured.

Chapter 5 shows the effects of both the introduction of a so-called benefit limit and the introduction of a co-payment for out-patient prescription drugs on the utilisation of antihypertension drugs. The benefit limit implied that, for the majority of drugs, sickness funds refunded only a quantity of tablets per prescription item for no more than 30 days. The co-payment consisted of NLG 2.50 (1.10 in 1995 US\$) per prescription item, with a maximum of NLG 125 (55 in 1995 US\$) per family per year. Although both types of patient charges did not immediately result in a lower (or higher) level of antihypertension drug items (the frequency of using antihypertension drugs), they did result in a slightly decreasing (or increasing) trend. Four years after the introduction of the co-payment, the number of antihypertension drug items was ca. $9 \%$ lower than in a period without patient charges. This decrease was compensated, however, by an increase in the number of tablets per item. After the introduction of the benefit limit the opposite accurred: the number of tablets per item showed 
a slightly decreasing trend, but this decrease was compensated for by an increase in the number of antihypertension drug items. As a consequence, neither measure resulted in a decrease in the total number of tablets per insurant or the total number of Defined Daily Doses (DDDs) per insurant for these prescription drugs.

Chapter 6 describes the effects of both the introduction of the benefit limit and the introduction of the co-payment for prescription drugs on expenditure for antihypertension drugs. It appeared that neither measure resulted in a reduction in this expenditure. Instead, this expenditure showed a sharply increasing trend during the entire period investigated. Chapter 6 shows that this increasing trend was mainly due to a turnover in the utilization of antihypertension drugs from less expensive to more expensive drugs. In addition, this chapter demonstrates that the current reference price system for prescription drugs in The Netherlands, which comprises a combination of 2 types of benefit limits, does neither contain incentives to overcome this turnover component in the increase in total expenditure on antihypertension drugs.

Chapter 7 presents the results of a comparative study on cross-border in-patient hospital care in the Euregio Meuse - Rhine. This region covers the major part of the Dutch province of Limburg as well as provinces in Belgium and Germany. The study illustrates that, among other factors, the presence and level of patient charges may be important for the level of crosis-border hospitall care. Lower charge levels or the absence of charges in a foreign country can be an incentive for crossborder hospital admissions.

Chapter 8 compares and discusses the current patient charges for prescription drugs in the public health insurance schemes in the member states of the European Union (data 1995). It also compares these charges with the patient charge considered as potentially most desirable for reducing moral hazard (see chapter 10 bellow).

Chapter 9 gives an overview of the current patient charges for medical care in the Dutch sickness fund insurance scheme (data 1997). In addition, it compares these charges with the chargle that may be most desirable for reducing moral hazard (see chapter 10 below).

Chapter 10 summarizes and discusses the results and health policy implications of the previous chapters. The cost sharing evidence described in chapters 2 to 7 shows that at least the following aspects seem to be important for the effects of patient charges on medical consumption and health: patient charge type, patient charge level, the level of a maximum to the charges payable, the number and type of services to which a patient charge is applied, the effect variable and the group of health care users investigated. The evidence shows that especially introducing mandatory coinsurance (paying a percentage of the gross-price of a medical service) with a level of about $50 \%$. with an income dependent level of a maximum expenditure (between $5 \%$ and $15 \%$ of family income per year), without the possibility of reinsurance, for out-patient care or even total health care, for non-elderly, may be desirable for reducing moral hazard. Such a charge can be expected to result in a reduction in medical expenditure of $\mathrm{ca}$. $30 \%$ among the services and insurants in question. while there are no important adverse health effects. If the previous patient charge is compared with the current charges for prescription drugs in the member states of the European Union or with the current charges for medical care in the Dutch sickness fund insurance scheme, it seems that the present charges could generally be best adapted according to the first mentioned patient charge.

It is important to note that not any of the studies that have been considered in this thesis measured the effects of a patient charge on total health care expenditure in a country. This means that the presence of possible so-called spillover-effects have not been analyzed. Further, the studies have analyzed a limited range of different effect variables and patient charge regulations. Only the effects on medical consumption or health have been considered. Patient charges, however, can (also) have other purposes than reducing moral hazard. As a consequence, this thesis is not able to give a fully complete picture of the potential desirability of patient charges. 
Chapter 10 also notes that the patient charge which - on the basis of empirical evidence - seems to be most desirable for reducing moral hazard, does rather well correspond with the current cost sharing system in the so-called Dutch IZA-insurance scheme. This scheme covers minor events for certain groups of civil servants (approximately $5 \%$ of the Dutch population). Both the charge level and the maximum expenditure level in the latter system, however, are considerably lower than the levels that are considered as optimal in this thesis. 


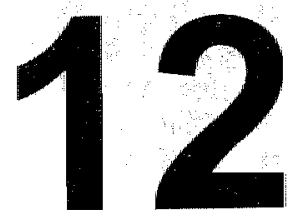

Samenvatting 


\section{Samenvatting}

Dit proefschrift probeert een antwoord te geven op de vraag welke soort eigen betaling voor medische zorg wenselijk kan zijn indien het doel van een dergelijke betaling is om te komen tot een reductie van "moral hazard" (een vermindering wan medische consumptie, zonder negatieve gezondheidseffecten). Een eigen betaling is gedefinieerd als een specifieke combinatie van kenmerken, welke uiteindelijk de geldprijs bepaalt die een verzekerde zelf moet betalen voor het gebruik van een medische voorziening die is opgenomen in een ziektekostenverzekeringspakket. Voorbeelden van kenmerken zijn het type eigen betaling, het inkomensniveau van de verzekerden en de vraagprijs van de voorziening(en) waarvoor de eigen betaling geldt.

Hoofdstuk 1 laat zien dat in Nederland de discussie over de wenselijkheid van eigen betalingen in het sociale ziektekostenverzekeringssysteem al jaren relevant is. Behalve dat eigen betalingen gebondlen zouden moeten zijn aan een maximum, is er weinig overeenstemming over de soort eigen betaling die zou moeten worden ingevoerd (bijvoorbeeld welk type eigen betaling en voor welke voorzieningen). Ook in andere landen is de wenselijkheid wan eigen betalingen regelmatig een actueel onderwerp in de gezondheidspolitiek.

Hoofdstuk 2 beschrijft de ontwikkeling van een systematische methode om empirische gegevens over de effecten van eigen betalingen op de medische consumptie en gezondheid in kaart te brengen. Ten behoeve van de kwaliteit van de resultaten, hanteert de methode een set van inclusiecriteria waaraan de studies en de bijbehorende uitkomsten minimaal moeten voldoen. Verder maakt de methode - op basis van economische literatuur - onderscheid tussen enerzijds verschillende effectvariabelen (bijvoorbeeld de kans op het gebruik van medische zorg) en anderzijds verschillende kenmerken. Deze kenmerken betreffen de eigen betaling, de verzekerden en de voorziening(en) waarvoor de eigen betaling geldt, alsmede de effectmeting (bijvoorbeeld een meting op de korte of de lange termijn). Uiteindelijk is de methode toegepast op empirische studlies gepubliceerd in de periode van 1983 tot 1995.

De hooffdstukken 3 to en met 7 geven een beschrijving van verschillende Nederlandse empirische studies naar het effect van eigen betalingen, uitgevoerd bij ziekenfondsverzekerden in de provincie Limburg. Deze studies bestaan grotendeels uit onderbroken tijdreeksanalyses.

Hoofdstuk 3 laat de effecten zien van een verhoging van een eigen bijdrage voor orthopedisch schoeisel van NLG 35 naar NLG 150 per paar. Direct na deze verhoging vertoonde het aantal aanvragen voor orthopedisch schoeisel (de frequentie van het gebruilk van deze voorziening) een dalende trend. Na 3 jaar was het totaal aantal aanvragen $37 \%$ lager dan het aantal in de periode ervoor. De grootste daling van de medische consumptie trad op bij oudere verzekerden.

Hoofdstuk 4 behandelt de effecten van de introductie van een eigen bijdrage van NLG 25 (het zogenaamde specialistengeeltje) - met een maximum van NLG 75 per verzekeringseenheid per jaar - voor poliklinische specialistenhulp. Het bleek dat deze eigen bijdrage bij de 13 verschillende bestudeerde specialismen niet resulteerde in een daling van de frequentie van het gebruik, behalve bij oogheelkunde. Bij dit specialisme daalde de medische consumptie met ca. $9 \%$. Een mogelijke werklaring voor deze daling is dat de verzekerden in zekere mate de mogelijkheid hadden om een bezoek aan de oogarts te vervangen door een bezoek aan de opticien.

Hoofdstuk 5 laat de effecten zien van zowel de introductie van een maximale vergoeding als de introductie van een eigen bijdrage voor geneesmiddelen op recept op het gebruik van antihypertensiva. Voor de meeste geneesmiddelen hield de maximale vergoeding in dat het ziekenfonds slechts een hoeveelheid tabletten per geneesmiddelvoorschrift vergoedde voor een periode van maximaal 30 dagen. De eigen bijdrage (de zogenaamde medicjnenknaak) bestond uit een bedrag van NLG 2,50 per geneesmiddelvoorschrift met een maximum van NLG 125 per verzekeringseenheid per jaar. Alhoewel geen van beide maatregelen leidde tot een onmiddellijk lager (of hoger) niveau wan het aantal geneesmiddelvoorschriften bij antihypertensiva (de frequentie 
van het gebruik van deze voorziening), resulteerden de maatregelen wel in een calende (of stijgende) trend in het aantal woorschriften. Vier jaar na de introductie van de eigen bijdrage was het aantal voorschriften van antihypertensiva ca. $9 \%$ lager dan in een periode zonder eigen betalingen. Deze daling werd echter gecompenseerd door een stijging van het aaltal tabletten per voorschrift Na de intraductie van de maximale vergoeding gebeurde het omgekeerde: het aantal tabletten per voorschrift toonde een dalende trend" maar deze daling werd gecompenseerd door een stijging van het aantal voorschriften van antihypertensiva. Het gevolg was dat geen van beide maatregelen resulteerde in een daling van het totaal aantal tabletten per verzekerde of het totaal aantal "Defined Daily Doses" (DDDs) per verzekerde bij deze geneesmiddelen.

Hoofdstuk 6 beschrijft de effecten van de introductie van de maximale vergoeding en de introductie van de eigen bijdrage voor geneesmiddelen op recept op de uitgaven voor antihypertensiva. Het bleek dat geen van beide maatregelen leidde tot een reductie van deze uitgaven. In plaats hiervan vertoonden deze uitgaven een sterk stijgende trend gedurende de gehele onderzoeksperiode. Hoofdstuk 6 laat zien dat deze stijging voornamelijk het gevolg was van een verschuiving in het gebruik van goedkopere naar duurdere antihypertensiva. Verder maakt dit hoofdstuk duidelijk dat ook het huidige GeneesmiddelenVergoedingsSysteem (GVS), dat bestaat uit 2 typen van maximale vergoedingen, géén prikkels bevat om de hiervoor genoemde verschuiving legen te gaan.

Hoofdstuk 7 presenteert de resultaten van een vergelijkende studie naar grensoverschrijdende intramurale ziekenhuiszorg in de Euregio Maas - Rijn. Deze regio omvat het grootste deel van de Nederlandse provincie Limburg, alsmede provincies in België en Duitsland. De studie laat zien dat de aanwezigheid en het niveau van eigen betalingen - naast andere factoren - belangrijk kunnen zijn voor de hoeveelheid grensoverschrijdende ziekenhuiszorg. Lagere eigen betalingen of de afwezigheid van eigen betalingen in het buitenland kunnen een prikkel vormen voor grensoverschrijdende ziekenhuisopnamen.

Hoofdstuk 8 vergelijkt en bediscussieert de huidige eigen betalingen voor geneesmiddelen op recept in de sociale ziektekostenverzekeringssystemen in de lidstaten van de Europese Unie (data 1995). De desbetreffende eigen betalingen worden tevens vergelleken met de eigen betaling die voor het reduceren van moral hazard als potentieel de meest optimale kan worden beschouwd (zie hoofdstuk 10 hieronder).

Hoofdstuk 9 geeft een overzicht van de huidige eigen betalingen voor medische zorg in de Nederlandse ziekenfondsverzekering (data 1997). Ook deze eigen betalingen worden vergeleken met de eigen betaling die voor het reduceren van moral hazard als potentieel de meest wenselijke kan worden gezien (zie hoofdstuk 10 hieronder).

Hoofdstuk 10 geeft een samenwatting van de resultaten en bediscussieert de uitkomsten en de beleidsimplicaties van voorgaande hoofdstukken. De empirische resultaten zoals beschreven in de hoofdstukken 2 tot en met 7 laten zien dat tenminste de volgende aspecten belangrijk zijn voor de effecten van eigen betalingen op de medische consumptie en gezondheid: het type en het niveau van de eigen betaling, het niveau van het aan de eigen betaling verbonden maximum, het aantal en de soort voorzieningen waarvoor de eigen betaling geldt, de gemeten effectvariabele en de groep verzekerden waarbij het effect is bestudeerd. De resultaten laten zien dat woor het reduceren van moral hazard, met name de introductie van een verplichte procentuele eigen bijdrage, met een niveau van ca. $50 \%$, met een inkomensafhankelijk maximum (tussen $5 \%$ en $15 \%$ van het gezinsinkomen per jaar), zonder de mogelijkheid tot herverzekering, voor ambulante zorg of zelfs alle medische zorg, voor mensen tot ca. 65 jaar, wenselijk kan zijn. Een dergelijke eigen betaling zal naar verwachting leiden to een reductie van ca. $30 \%$ van de uitgaven voor medische zorg bij de verzekerden en voorzieningen waarvoor deze eigen betaling van toepassing is, zonder dat dit gepaard gaat met belangrijke nadelige gezondheidseffecten. Wanneer de hiervoor genoemde eigen betaling wordt vergeleken met de bestaande eigen betalingen voor geneesmiddielen op recept in de landen van de Europese Unie of met de bestaande eigen betalingen voor medische zorg in de 
Nederlandse zlekenfondsverzekering, lijkt het in het algemeen wenselijk om de huidige eigen betalingen aan te passem in de richting van de eerder genoemde eigen betaling.

Het is belangrijk om op te merken dat geen enkele van de beschouwde studies de effecten van een eigen betaling op de totale gezondheidszorguitgaven in een land heeft gemeten. Dit betekent dat niet is gekeken naar de mogelijke aanwezigheid van zogenaamde "spillover" effecten. Verder hebben de studies slechts een beperkte reeks van effect-variabelen en eigen betalingsregelingen geanalyseerd. Er is bijvoorbeeld alleen gekeken naar de effecten op de medische consumptie of gezondheid. Eigen betalingen kunnen echter (ook) andere doelen hebben dan het reduceren van moral hazard. Als gevolg hiervan is dit proefschrift niet in staat om een volledig overzicht te geven van de potentiële wensellijkheid van verschillende soorten eigen betalingen.

Hoofdstuk 10 constateert dat de eigen betaling welke - op basis van de empirische uitkomsten het meest wenselijk lijkt te zijn voor het reduceren van moral hazard, vriij goed overeenkomt met het huidige eigen betalingssysteem in de zogenaamde Nederlandse IZA-ziektekostenregeling. welke geldt voor bepaalde groepen ambtenaren. Zowel het niveau van de eigen betalingen als het niveau van het aan deze eigen betalingen verbonden maximum, zijn in het laatste systeem echter aanzienlijk lager dan de niveaus die in dit proefschrift als optimaal worden beschouwd. 


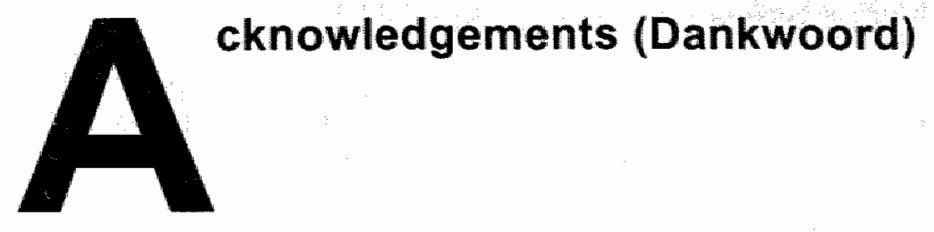




\section{Acknowledgements (Dankwoord)}

Firstly, | would the to thank my promotor Professor Hans Maarse and the members of the review committee: Professor Frans van Wijmen (chairman), Professor Richard Janssen "Professor Guus Schrijvers, Professor Cor Spreeuwenberg and Hans van Mierlo.

Beste Hans (Maarse), zeer bedankt voor jouw interesse, betrokkenheid en vertrouwen in mijn werk. Ondanks je werkzaamheden als Decaan van de Faculteit der Gezondheidswetenschappen, heb je steeds voldoende tijd gevonden om je voor de afronding van mijn proefschrift in te zetten. Beste Frans, Richard, Guus, Cor en Hans (van Mierlo), op deze wat informele wijze dank ik jullie hartelijk omdat jullie graag bereid waren om mijn proefschrift te beoordelen. Dank voor jullie inzet en natuurlijk voor de complimenten en het positieve oordeel.

In addition, I would like to thank my parents, brothers and sisters (in law), as they have always supported me during my study period or during my work as a scientific researcher at Maastricht University.

Hartelijk dank Pap en Mam in Margraten voor jullie steun en belangstelling gedurende vele jaren! Bedankt voor de goede raad, het niet aflatende vertrouwen, de eigen studeerkamer en ook voor de "puzzels" met pindakaas. Natuurlijk ook Pap en Mam in Slenaken hartelijk dank voor jullie goede zorgen, hulp en interesse. Beste François (jr.). Lisette en Richard, Sonja en Peter, Eduard en Anneke, jullie zijn allen een zeer fijne broer of zus. Mede dankzij jullie heb ik mijn energie kunnen besteden aan dit proefschrift. Dank jullie wel hiervoor!

I thank Mathis Verkooijen as he introduced the subject "patient charges" to me as an important research and health policy item. He invited me for working at the department of Health Economics at Maastricht University and gave me the opportunity to study this relevant item.

Beste Mathis, bedankt voor het initiêren van dit project, je vertrouwen in mij, je grappen en je belangrijke bijdrage aan de totstandkoming van dit proefschrift. Ik hoop dat je tevreden bent met het eindresultaat.

I acknowledge the contributions of Professor Reiner Leidl, Professor Richard Janssen, Grant Rhodes, Martin Scheepers and Marc VanderBroeck. With Mathis Verkooijen, they are all co-author of at least one of the scientific publications in this thesis. In addition. Reiner Leid $\|$ has given me many useful comments, especially on diaft versions of the most extensive journal articles. At Maastricht University, he also gave me the opportunity to delliver a contribution to a second relevant research and health policy item: cross-border health care.

Herzlichen Dank Reiner, für deine Interesse in meiner Arbeit und in besonderes für deinen professionelle Kornmentar in der Niederländische Sprache! Hartelijk dank Richard, speciaal voor je enorme inzet en warme belangstelling voor je collega's. Je bent voor mij op cruciale momenten een bellangrijke steun geweest. Thanks a lot Grant, also for your time consuming work in checking my English writing. I will not forget that you did this for even less than one peanut! Beste Martin en Marc, bedankt voor jullie wezenlijke bijdrage aan de totstandkoming van dil proefschrift en voor de fijne wijze waarop we hebben kunnen samenwerken.

In addition, I acknowledge the contributions of Jan van Emmerik, Linda Heurman, Nel Knols and Belinda Kramer to this thesis. Jan van Emmerik spended much energy in providing computer support. He also played an important role in constructing the lay-out of this thesis. Both Linda Heurman, Nel Knols and Belinda Kramer delivered important contributions to the accurate collection and analysis of data from hospitals and health sickness funds.

Beste Jan, Linda, Nel en Bellinda, hartelijk dank voor jullie enorme inzet, jullie grote accuratesse en de plezierige manier van samenwerken.

Thanks to all persons at Dutch sickness funds - especially in the provinces of Limburg and ZuidHolland - who delivered data and other useful contributions to this thesis. I acknowledge the support from the members of the INTERREG-project, as well as the (co-)financing of this project by the Commission of the European Union and the EU concerted action "Health Care Financing and the 
Single European Market" (SEM project, contract BMH1-CT92-0740, BIOMED1 Programma, General Directorate XII). I would also like to thank Professor Frans Rutten for his suggestions in an early stage of this cost sharing study, as well as my former colleagues at the department of Health Economics, and my present colleagues at the Department of Health Organization. Policy and Economics at Maastricht University. Further, I thank my "colleagues" in the cost sharing committee "Werkgroep Standpunt eigen betalingen in de gezondheidszorg" of the Dutch Society for Public Health and Science: Professor Wynand van de Ven (chairman), Professor Henk Leenen, Marijke Mootz and Petra van Dam. Our interesting discussions have given me an important incentive to further investigate the subject of patient charges.

Dank u wel voor uw hulp, Danke schön für Ihre Hilfe, Merci beaucoup pour votre laide, Thank you very much for your help!

Finally (or seventhly !), I thank my wife and angel Mirian. She has supported me with her knowledge, her skills, her time, her energy and, especially, her love.

Lieve Mirian, je bent er altijd van overtuigd geweest dat ik mijn onderzoek zou afronden met een proefschrift. Wanneer ik moeilijkheden ondervond tijdens mijn werk heb je me steeds duidelijk gemaakt dat deze samenhingen met de complexiteit van de materie en niet met mijn capaciteiten. Oak heb je me erop gewezen dat een goede begeleiding essentieel is bij het tot stand komen van een proefschrift. Voor de excellente begeleiding en ondersteuning die jij me hebt gegeven - in het bijzonder na de afronding van je eigen proefschrift - ben ik je heel dankbaar. Hoewel je sinds kort regelmatig in Londen verblijft, heb je mij tot en met het laatste moment met woord en daad geweldig bijgestaan.

Hiel veul dank Mirke, veur al dieng stroalende leefde! 


\section{urriculum Vitae}




\section{Curriculum Vitae}

Bent (Hubertus Bernardus Gerardus) Starmans

October 1961 Born in Margraten, The Netherlands

$1973-1978$ HAVO, Sophianum College Vaals, The Netherlands

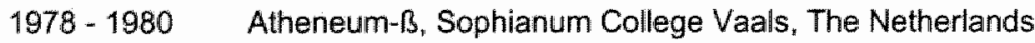

1980-1984 Health Sciences, course Health Policy and Management, Faculty of Health Sciences, Maastricht University, The Netherlands

$1983-1984$ Student-assistant at the department of Health Economics, Faculty of Health Sciences, Maastricht University, The Netherlands (Professor F.F.H. Rutten, Ph.D.)

June 1984 M.Sc. graduate, Health Scientist

1984 - 1986 Post-graduate scientific research training, Faculty of Health Sciences, Maastricht University, The Netherlands

July $1986 \quad$ Researcher graduate

$1986-1996$ Scientific researcher at the department of Health Economics, Faculty of Health Sciences, Maastricht University, The Netherlands (Professor R.M. Leidl, Ph.D.)

June 1993 Married with Mirian (Maria Josephina Francina) Kool, M.D., Ph.D.

$1997-$

Health economist / University lecturer at the department of Health Organization, Policy and Economics, Faculty of Health Sciences, Maastricht University. The Netherlands (Professor J.A.M Maarse, Ph.D. / I.M. Mur, Ph.D.) 